\author{
UNIVERSIDADE DE SÃO PAULO \\ INSTITUTO DE QUÍMICA DE SÃO CARLOS \\ DEPARTAMENTO DE QUÍMICA E FÍSICA MOLECULAR
}

Utilização de nanoestruturas de carbono e nanopartículas metálicas como modificadores para o desenvolvimento de eletrodos compósitos

Marina Baccarin 


\section{Utilização de nanoestruturas de carbono e nanopartículas metálicas como modificadores para o desenvolvimento de eletrodos compósitos}

Tese apresentada ao Instituto de Química de São Carlos da Universidade de São Paulo, como parte dos requisitos para obtenção do título de Doutor em Ciências.

Área de concentração: Química Analítica e Inorgânica.

Orientador: Prof. Dr. Éder T. G. Cavalheiro

São Carlos

2019 
Autorizo a reprodução e divulgação total ou parcial deste trabalho, por qualquer meio convencional ou eletrônico para fins de estudo e pesquisa, desde que citada a fonte.

\section{Assinatura: \\ Data:}

\section{Baccarin, Marina}

Utilização de nanoestruturas de carbono e nanopartículas metálicas como modificadores para o desenvolvimento de eletrodos compósitos / Marina Baccarin. - São Carlos, 2019.

$145 \mathrm{f}$.

Tese (Doutorado em Química Analítica e Inorgânica) - Instituto de Química de São Carlos / Universidade de São Paulo, 2019.

Edição revisada

Orientador: Prof. Dr. Éder Tadeu Gomes Cavalheiro

1. Química analítica. 2. Grafeno. 3. Eletrodo compósito de grafitepoliuretana. 4. Nanodiamantes. 5. Eletrodo impresso modificado. I. Título. 


\section{AGRADECIMENTOS}

Aos meus pais, pelo amor incondicional e o suporte financeiro de toda minha educação;

$>$ Aos meus irmãos, Bruno e Vitória pelos momentos de alegria, companheirismo e convivência;

$>$ Ao meu marido Yuri, por todo o seu amor, carinho, incentivo e alegria;

Ao Prof. Dr. Éder Tadeu Gomes Cavalheiro, pela orientação deste trabalho de doutorado, amizade e paciência;

Ao Prof. Dr. Craig Banks, por aceitar me supervisionar durante o doutorado sanduíche na Manchester Metropolitan University;

$>$ Ao Dr. Samuel Rowley-Neale, pela amizade e pelos momentos de discussão científica durante o doutorado sanduíche na Manchester Metropolitan University;

Aos meus amigos de São Carlos pela amizade e convívio;

$>$ A todos os meus familiares, avós, primos, tios que mesmo morando longe sempre me deram carinho, conselho e palavras de apoio;

$>$ Aos amigos do LATEQS, pela amizade, pelos momentos de discussão científica e também de descontração;

> Ao Programa de Pós-Graduação em Química do Instituto de Química de São Carlos e funcionários da Universidade de São Paulo;

> A Universidade de São Paulo;

Aos órgãos de fomento: CNPq, FAPESP e principalmente CAPES pela bolsa concedida durante a realização deste trabalho de doutorado;

> Finalmente, meus agradecimentos ao Banco Santander pelo auxílio financeiro durante o doutorado sanduíche na Manchester Metropolitan University. 


\section{RESUMO}

Eletrodos compósitos convencionais e impresso, à base de grafite-poliuretana (EGPU) e tinta comercial foram desenvolvidos para determinação de analitos de interesse biológico e ambiental. Os eletrodos foram modificados com nanoestruturas de carbono e nanopartículas metálicas, visando maior sensibilidade e baixos limites de detecção (LOD). Assim, o desempenho de um EGPU e dois EGPU modificados com grafeno (EGPU-GR) e nanotubos de carbono funcionalizados (EGPU-CNTs) foram comparados, em relação à resposta voltamétrica ao antidepressivo escitalopram. O EGPU-GR foi escolhido para os estudos quantitativos apresentando as melhores respostas analíticas. Utilizando voltametria de onda quadrada (SWV) e de pulso diferencial (DPV), sob condições otimizadas obteve-se a mesma faixa linear, entre 1,5 e $12 \mu \mathrm{mol} \mathrm{L}{ }^{-1}$, com LOD de 0,25 e $0,32 \mu \mathrm{mol} \mathrm{L}^{-1}$, respectivamente. $\mathrm{O}$ método proposto foi aplicado para quantificação de escitalopram em amostras sintéticas biológicas, oferecendo vantagens como simplicidade de fabricação e renovação da superfície do eletrodo, além da utilização de um material sustentável como aglutinante. Em um segundo desenvolvimento, um dispositivo eletroquímico contendo eletrodo de trabalho, auxiliar e referência, no mesmo suporte do tipo caneta (denominado PEN LAB), todos baseados em EGPU, foi construído de forma inédita em um novo design. Para a fabricação do eletrodo de trabalho, diferentes quantidades de AgNPs foram reduzidas diretamente na estrutura de grafite pelo método do poliol. Para o preparo dos eletrodos auxiliar e referência foi utilizada a razão em massa grafite:poliuretana 60:40\% e para os de trabalho foram desenvolvidos três eletrodos modificados com as razões em massa AgNPs:EGPU 2:98, 5:95 e 10:90\%. Quatro dispositivos compostos de três eletrodos - auxiliar, referência e trabalho não modificado e/ou modificado foram fabricados e denominados PEN LAB EGPU, PEN LAB AgNP $_{2 \%}$-EGPU, PEN LAB $\mathrm{AgNP}_{5 \%}$-EGPU e PEN LAB AgNP ${ }_{10 \%}$-EGPU. A resposta eletroquímica destes sensores, para determinação de bisfenol-A, foi avaliada utilizando DPV. A melhor resposta foi obtida com o sensor PEN $L A B \mathrm{AgNP}_{2}$-EGPU, então selecionado para a quantificação da molécula em amostras de rios e água de abastecimento, por apresentar maior sensibilidade $(0,016 \mu \mathrm{A}$ $\left.\mu \mathrm{mol}^{-1} \mathrm{~L}\right)$ e menor $\operatorname{LOD}\left(0,24 \mu \mathrm{mol} \mathrm{L}{ }^{-1}\right)$. Por fim, um eletrodo impresso à base de tinta comercial modificado com nanodiamantes (ND) foi proposto pela primeira vez para determinação eletroquímica concomintante de dopamina e ácido úrico. Voltamogramas cíclicos mostraram aumento de corrente de pico e diminuição dos potenciais de oxidação para as moléculas usando o eletrodo proposto, em relação ao sem modificação, com separação de pico entre os analitos de $134 \mathrm{mV}$ ( $v s$. pseudo referência de $\mathrm{Ag} / \mathrm{AgCl}$ ), permitindo a determinação concomitante. Na literatura, os efeitos eletrocatalíticos dos ND para diferentes moléculas eletroativas são atribuídos à presença de carbonos $\mathrm{sp}^{2}$ e grupos oxigenados em sua superfície. Entretanto, neste trabalho, apresentou-se uma ideia diferente em relação a esses efeitos eletrocatalíticos. Voltamogramas cíclicos obtidos com eletrodos de pasta de carbono e impressos, modificados com diferentes quantidades de ND, evidenciaram que um excesso dessas nanopartículas na superfície ocasiona uma perda de sinal voltamétrico. Levando isto em consideração, após a modificação com ND, tem-se a formação de zonas inertes (partículas de ND) e ativas por toda a superfície do eletrodo. Esses sítios ativos da superfície exposta do eletrodo impresso atuariam como um arranjo de microeletrodos com uma área de difusão cumulativa maior que a do eletrodo impresso não modificado, resultando em maiores densidades de corrente para as mais diferentes espécies eletroativas.

Palavras chave: Eletrodo compósito de grafite-poliuretana; Grafeno; Nanotubos de carbono; Nanodiamantes; Eletrodo impresso modificado. 


\begin{abstract}
Conventional and screen printed (SPE) composite electrodes based in graphite-polyurethane (EGPU) and commercial ink, respectively, were developed for the determination of biological and environmental analytes. Aiming high sensitivity and low detection limit (LOD), the modification of these proposed sensors with carbon nanostructures and metallic nanoparticles was explored. Thus, a bare EGPU and two EGPU modified with graphene (EGPU-GR) and with functionalized carbon nanotubes (EGPU-CNTs) were compared in the electrochemical response of the antidepressant escitalopram. The EGPU-GR was chosen for quantitative studies because it presented the best analytical responses. Using square wave (SWV) and differential pulse voltammetry (DPV), under optimal conditions, the same linear dynamic

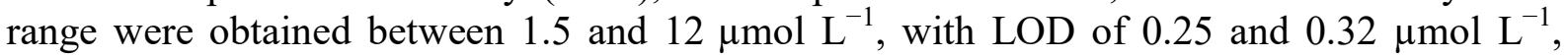
respectively. The proposed method was applied for the quantification of escitalopram in synthetic biological samples, with advantages including simplicity of manufacture and surface renewal of the electrode, and using a sustainable material as a binder. In a second development, a complete electrochemical system containing the electrodes: working (WE), auxiliary (AE) and reference (RE) in the same pen type support (called PEN LAB), all based on EGPU, were proposed for the first time. For the WE manufactured, different amounts of AgNPs were reduced directly in the graphite structure using the polyol method. For the preparation of $\mathrm{AE}$ and $\mathrm{RE}$ it was used graphite:PU at a mass ratio of 60:40\% and for WE it was developed three modified electrodes with the AgNPs-EGPU at mass ratios of 2:98, 5:95, and 10:90\%. The four devices composed of three electrodes - AE, RE and unmodified and/or modified WE - were called PEN LAB EGPU, PEN LAB AgNP ${ }_{2 \%}$-EGPU, PEN LAB AgNP $\%_{5-}$ EGPU, and PEN $L A B \mathrm{AgNP}_{10 \%}$-EGPU. Using DPV, their electrochemical responses were compared for bisphenol-A determination, and the PEN LAB AgNP ${ }_{2 \%}$-EGPU was selected for the molecule quantification in river and tap waters samples, as it showed higher sensitivity $\left(0.016 \mu \mathrm{A} \mu \mathrm{mol}^{-1} \mathrm{~L}\right)$ and lower LOD $\left(0.24 \mu \mathrm{mol} \mathrm{L}{ }^{-1}\right)$. The developed method offered advantages such as the use of a stable and robust electrode, with easiness of surface renewal and possibility of portability for field analysis. Finally, a SPE based on commercial ink modified with nanodiamonds (ND) for the first time was developed for the simultaneous electrochemical determination of dopamine and uric acid. Cyclic voltammograms showed current increase and decrease of oxidation potentials for the molecules using the proposed electrode compared to the unmodified electrode, and, with a peak separation of $134 \mathrm{mV}$ ( $v s$. pseudo reference of $\mathrm{Ag} / \mathrm{AgCl}$ ), allowing the simultaneous determination. It was reported that the electrocatalytic effects of ND for different electroactive molecules are attributed to the presence of $\mathrm{sp}^{2}$ carbons and oxygen groups on their surface. However, in this work, a different idea was presented to explain these electrocatalytic effects. Cyclic voltammograms obtained with carbon paste electrodes and SPE, modified with different amounts of ND showed that an excess of these nanoparticles in the electrodes surface leads to a voltammetric signal loss. Considering this, after modification with ND, the formation of inert zones (ND particle) and active zones (exposed surface of the SPE) along the entire surface of the electrode occurred, which act as an arrangement of microelectrodes with a cumulative diffusion area greater than that of an unmodified SPE, resulting in higher current densities for the most different electroactive species.
\end{abstract}

Keywords: Graphite-polyurethane composite electrode; Graphene; Carbon nanotubes; Nanodiamonds; Screen printed modified electrode. 


\section{ÍNDICE DE FIGURAS}

Figura 1. Representação dos planos basal e de bordas no CNTs e no grafeno. 22

Figura 2. Representação da molécula de oxalato de escitalopram. 37

Figura 3. Representação das moléculas de dopamina (A) e ácido úrico (B). 39

Figura 4. Representação da molécula de bisfenol-A. 40

Figura 5. Fotografias representando as etapas de preparação do compósito. Em (A) mistura do material condutor (grafite e/ou grafeno-grafite e CNTs-grafite) mais PU; em (B) material é colocado em um copo de metal (com orifício de extrusão de 3,0 mm de diâmetro) com o auxílio de uma espátula; em (C) o copo de metal é encaixado em uma prensa manual, na qual o material é extrudado.

Figura 6. Esquema da montagem dos eletrodos de trabalho. 48

Figura 7. Espectros Raman obtidos para os CNTs não funcionalizados e os CNTs funcionalizados. 52

Figura 8. Imagens microscópicas do ângulo de contato entre a água deionizada e os GPU (A), GPU-GR (B) e GPU-CNTs (C) em 200× de magnificação.

Figura 9. Imagens de SEM obtidas das fraturas dos compósitos de GPU (A), GPU-GR (B) e GPU-CNTs (C), com 5000× de magnificação. Imagens de SEM obtidas da superfície lixada dos compósitos de GPU (D), GPU-GR (E) e GPU-CNTs (F), com 50000× de magnificação.54 Figura 10. Voltamogramas cíclicos obtidos em solução de $\left[\mathrm{Fe}(\mathrm{CN})_{6}\right]^{3-} 1,0 \mathrm{mmol} \mathrm{L}^{-1} \mathrm{em} \mathrm{KCl}$ $0,10 \mathrm{~mol} \mathrm{~L}^{-1}$, em diferentes velocidades de varredura de potenciais $\left(v, 10\right.$ a $\left.500 \mathrm{mV} \mathrm{s}^{-1}\right)$ utilizando (A) EGPU, (B) EGPU-GR e (C) EGPU-CNTs. Inserido os respectivos gráficos de $\mathrm{I}_{\mathrm{a}}$ vs. $v^{1 / 2}$. 56

Figura 11. Voltamogramas cíclicos obtidos na ausência e na presença de escitalopram 100 $\mu \mathrm{mol} \mathrm{L} \mathrm{L}^{-1}$ em tampão Britton-Robinson $0,10 \mathrm{~mol} \mathrm{~L}^{-1}$ ( $\mathrm{pH}$ 6,3) usando o EGPU (A), EGPUGR (B) e EGPU-CNTs (C), $v=50 \mathrm{mV} \mathrm{s}^{-1}$

Figura 12. Representação da reação de oxidação eletroquímica do citalopram ${ }^{123}$..................58

Figura 13. (A) Voltamogramas de DPV obtidos na presença de escitalopram $100 \mu \mathrm{mol} \mathrm{L}{ }^{-1}$ em tampão Britton-Robinson $0,10 \mathrm{~mol} \mathrm{~L}^{-1}$ em diferentes valores de $\mathrm{pH}$ utilizando o EGPUGR. (B) Correntes de pico anódico $\left(I_{\mathrm{pa}}\right)$ e valores de potencial $(E)$ para os diferentes valores de $\mathrm{pH}$ estudados. Velocidade de varredura de potenciais $=20 \mathrm{mV} \mathrm{s}^{-1}$ e amplitude de pulso $=$ $50 \mathrm{mV}$. 
Figura 14. (A) Voltamogramas de DPV e (B) voltamogramas de SWV obtidos utilizando o EGPU; (C) Voltamogramas de DPV e (D) voltamogramas de SWV obtidos utilizando o EGPU-GR; (E) Voltamogramas de DPV e (F) voltamogramas de SWV obtidos utilizando o EGPU-CNTs, todos para análises de diferentes concentrações de escitalopram (1-5) de 1,5 a $12 \mu \mathrm{mol} \mathrm{L}{ }^{-1}$ em tampão Britton-Robinson $0,10 \mathrm{~mol} \mathrm{~L}^{-1}$ (pH 6,3). Parâmetros da DPV: velocidade de varredura de potenciais $=20 \mathrm{mV} \mathrm{s}^{-1}$ e amplitude de pulso $=50 \mathrm{mV}$ e para $\mathrm{SWV}$ : frequência $=8 \mathrm{~Hz}$, amplitude de pulso $=50 \mathrm{mV}$ e incremento de varredura $=2 \mathrm{mV} \ldots 61$

Figura 15. Curvas analíticas obtidas utilizando a DPV (A) e a SWV (B), com medidas feitas em triplicata.

Figura 16. Voltamogramas de SWV obtidos para escitalopram $6,0 \mu \mathrm{mol} \mathrm{L}{ }^{-1}$ em BrittonRobinson 0,10 $\mathrm{mol} \mathrm{L}^{-1}$ (pH 6,3) EGPU-GR para (A) para 10 medidas consecutivas no mesmo dia sem renovação de superfície entre as medidas e (B-D) 5 medidas consecutivas para cada dia $(\mathrm{n}=3)$. Parâmetros: frequência $=8 \mathrm{~Hz}$, amplitude de pulso $=50 \mathrm{mV}$ e incremento de varredura $=2 \mathrm{mV} \mathrm{s}^{-1}$.

Figura 17. Esquema da preparação das AgNPs suportadas sob o grafite pelo método poliol.72 Figura 18. Fotografias representando as etapas de preparação do compósito e do conjunto compósito/fio de cobre. Em (A) mistura do material condutor (grafite e/ou AgNPs-grafite) mais PU; em (B) material é colocado em um copo de metal (com orifício de extrusão de 1,2 mm de diâmetro) com o auxílio de uma espátula; em (C) o copo de metal é encaixado em uma prensa manual, na qual o material é extrudado; em (D) tarugos variando de comprimento entre 4 e $7 \mathrm{~cm}$; e em (E) tarugos conectados a um fio de cobre usando cola de prata, utilizando um gabarito para alinhamento.

Figura 19. Em (A) fotografia do conjunto compósito/fio de cobre e fio termocontrátil. Em (B) fotografia do conjunto compósito/fio de cobre envolvido por fio termocontrátil.

Figura 20. Fotografia: do PEN $L A B$ (A); da superfície do PEN $L A B$ (B); do PEN $L A B$ imerso em uma cela eletroquímica convencional (C); e de uma poça de solução sobre a superfície do PEN LAB (D).

Figura 21. Curvas TG e DTG do EGPU, do A-AgNP-EGPU, do B-AgNP-EGPU e do CAgNP-EGPU em atmosferas dinâmicas de $\mathrm{N}_{2}$ até $600^{\circ} \mathrm{C}$ e ar $\left(>600{ }^{\circ} \mathrm{C}\right.$ até $\left.1000{ }^{\circ} \mathrm{C}\right)$ a $50 \mathrm{~mL}$ $\min ^{-1}$, com razão de aquecimento de $10{ }^{\circ} \mathrm{C} \min ^{-1}$, massa de amostra de $10 \pm 0,1 \mathrm{mg}$ e suporte amostra de $\alpha$-alumina. 78 
Figura 22. Imagens de SEM referentes à fratura dos compósitos (A) $\mathrm{AgNP}_{2 \%}$-EGPU, (B) $\operatorname{AgNP}_{5 \%}$-EGPU e (C) AgNP $_{10 \%}$-EGPU, com magnificação de 2000×, e em (D) referentes ao EGPU, com magnificação de 500×.

Figura 23. Espectro de EDX obtido do pó de grafite com AgNPs, a partir da análise pontual da imagem da Figura 22 A.

Figura 24. Imagens de SEM-FEG do pó de $\mathrm{AgNP}_{10 \%}$-grafite com magnificação de $50000 \times$ (A) e $5000 \times(B)$.

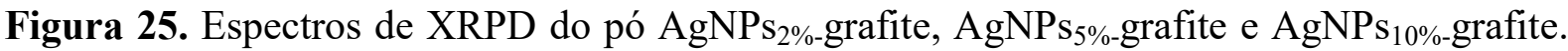

Figura 26. Voltamogramas cíclicos obtidos utilizando (A) PEN LAB AgNP ${ }_{2 \%}$-EGPU (-),

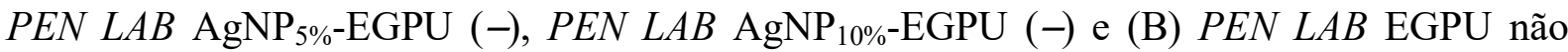
modificado em tampão fosfato $0,10 \mathrm{~mol} \mathrm{~L}^{-1}(\mathrm{pH} 7,4)$, a $v$ de $20 \mathrm{mV} \mathrm{s}^{-1}$.

Figura 27. Voltamogramas cíclicos obtidos utilizando (A) PEN LAB $\operatorname{AgNP}_{2 \%}$-EGPU, (B)

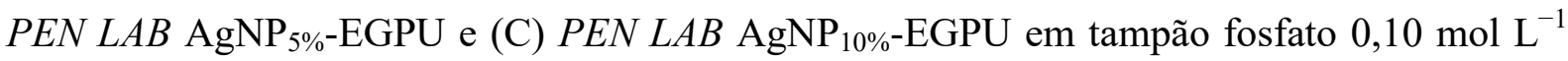
$(\mathrm{pH} 7,4), v=50 \mathrm{mV} \mathrm{s}^{-1}$. Inserido nos gráficos de $I_{\mathrm{a}}$ vs. número de ciclos. .85

Figura 28. Voltamogramas cíclicos obtidos em diferentes velocidades de varredura de potencial ( $v, 5$ to $200 \mathrm{mV} \mathrm{s}^{-1}$ ) da resposta eletroquímica dos $P E N \operatorname{LAB} \mathrm{AgNP}_{2 \%}$-EGPU (A), PEN LAB AgNP (\%)-EGPU (B) e PEN LAB AgNP $_{10 \%}$-EGPU (C) em tampão fosfato 0,10 mol $\mathrm{L}^{-1}(\mathrm{pH} 7,4)$.

Figura 29. Voltamogramas de DPV obtidos para bisfenol-A $15 \mu \mathrm{mol} \mathrm{L}{ }^{-1}$ em tampão fosfato 0,10 mol L $^{-1}$ (pH 7,4) usando PEN LAB AgNP $2 \%$-EGPU para diferentes valores de amplitude de pulso $(10,25$ e $50 \mathrm{mV})(\mathrm{A})$ e diferentes valores de velocidade de varredura de potenciais $\left(5,10\right.$ e $\left.15 \mathrm{mV} \mathrm{s}^{-1}\right)(\mathrm{B})$, com tempo de pulso de $0,5 \mathrm{~s}$ e tempo de modulação de $0,05 \mathrm{~s}$ 88

Figura 30. Voltamogramas de DPV obtidos para diferentes concentrações de bisfenol-A entre 2,5 a $15 \mu \mathrm{mol} \mathrm{L}{ }^{-1}$ em tampão fosfato $0,10 \mathrm{~mol} \mathrm{~L}^{-1}(\mathrm{pH} 7,4)$ utilizando o PEN LAB EGPU (A), PEN LAB AgNP ${ }_{2 \%}$-EGPU (B), PEN LAB AgNP ${ }_{5 \%}$-EGPU (C) e PEN LAB AgNP $10 \%$-EGPU (D); Parâmetros: amplitude $=50 \mathrm{mV}$, velocidade de varredura $=10 \mathrm{mV} \mathrm{s}^{-1}$, tempo de intervalo $=0,5 \mathrm{~s}$ e tempo de modulação $=0,05 \mathrm{~s}$. (E) Gráfico de $I v s . \mathrm{C}_{\text {bisfenol-A }}(\mathrm{n}=3)$.

Figura 31. Esquema proposto para processo da oxidação do bisfenol-A, na presença do eletrodo contendo AgNPs. 
Figura 32. Voltamogramas de DPV obtidos para uma concentração de bisfenol-A 9,0 $\mu \mathrm{mol}$ $\mathrm{L}^{-1}$ em tampão fosfato $0,10 \mathrm{~mol} \mathrm{~L}^{-1}(\mathrm{pH} 7,4)$ usando PEN LAB AgNP $2 \%$-EGPU para (A) para 10 medidas consecutivas no mesmo dia sem renovação de superfície entre as medidas e (B-D) 5 medidas consecutivas para cada dia, com renovação de superfície entre cada dia. Parâmetros: velocidade de varredura $=10 \mathrm{mV} \mathrm{s}^{-1}$, amplitude $=50 \mathrm{mV}$, tempo de intervalo de $0,5 \mathrm{~s}$ e tempo de modulação de $0,05 \mathrm{~s}$. 95

Figura 33. Voltamogramas de DPV obtidos para uma concentração de bisfenol-A 9,0 $\times 10^{-6}$ mol L ${ }^{-1}$ em tampão fosfato $0,10 \mathrm{~mol} \mathrm{~L}^{-1}(\mathrm{pH} 7,4)$ usando PEN LAB $\operatorname{AgNP}_{2 \%}$-EGPU para 5 medidas consecutivas no mesmo dia. Parâmetros: velocidade de varredura $=10 \mathrm{mV} \mathrm{s}{ }^{-1}$, amplitude $=50 \mathrm{mV}$, tempo de intervalo de $0,5 \mathrm{~s}$ e tempo de modulação de $0,05 \mathrm{~s}$.

Figura 34. Esquema da fabricação dos SPE (A); componentes do SPE (B) preparo do ND/SPE (C) 104

Figura 35. Imagens de TEM obtidas dos ND comerciais (A) e (B). Em amarelo estão destacados os contornos distintos das nanopartículas do ND individualmente. (C) Imagens de SEM obtidas dos ND. (D) Espectro de XRPD dos ND. 107

Figura 36. Mapas de topografia superficial de perfilometria de luz branca de (A) EPPG, (B) GCE e (C) SPE. 108

Figura 37. Voltamogramas cíclicos obtidos na presença de DA 50,0 $\mu \mathrm{mol} \mathrm{L}^{-1}$ (A) e UA 60,0 $\mu \mathrm{mol} \mathrm{L} \mathrm{L}^{-1}$ (B) em tampão fosfato $0,10 \mathrm{~mol} \mathrm{~L}^{-1}$ (pH 7,4), a $50 \mathrm{mV} \mathrm{s}^{-1}$, utilizando o SPE e o ND/SPE. 109

Figura 38. Voltamogramas cíclicos obtidos utilizando SPE (A) e ND/SPE (B) para concentrações de DA de 50,0 a 400,0 $\mu \mathrm{mol} \mathrm{L}^{-1}$ em solução de tampão fosfato $0,10 \mathrm{~mol} \mathrm{~L}^{-1}$ (pH 7,4), velocidade de varredura: $50 \mathrm{mV} \mathrm{s}^{-1}$. Inserida as respectivas curvas analíticas, com cada medida em triplicata.

Figura 39. Voltamogramas de voltametria cíclica obtidos utilizando SPE (A) e ND/SPE (B) para concentrações de UA de 60,0 a $500,0 \mu \mathrm{mol} \mathrm{L} \mathrm{L}^{-1}$ em solução de tampão fosfato $0,10 \mathrm{~mol}$ $\mathrm{L}^{-1}(\mathrm{pH} 7,4)$, a $50 \mathrm{mV} \mathrm{s}^{-1}$. Inserida as respectivas curvas analíticas, com cada medida em triplicata.

Figura 40. Voltamogramas de DPV obtidos na presença de DA $50 \mu \mathrm{mol} \mathrm{L}{ }^{-1}$ e UA $60 \mu \mathrm{mol}$ $\mathrm{L}^{-1}$ em tampão fosfato $0,10 \mathrm{~mol} \mathrm{~L}^{-1}$ em diferentes valores de $\mathrm{pH}: 4,4(-), 5,5(-), 6,5(-), 7,4$ (-) e 8,4 (-), com velocidade de $10 \mathrm{mV} \mathrm{s}^{-1}$ e amplitude $25 \mathrm{mV}$, utilizando ND/SPE 112 
Figura 41. Voltamogramas de DPV obtidos na presença de DA $50 \mu \mathrm{mol} \mathrm{L}{ }^{-1}$ e UA $60 \mu \mathrm{mol}$ $\mathrm{L}^{-1}$ em $0,10 \mathrm{~mol} \mathrm{~L}^{-1}$ de tampão fosfato $\mathrm{pH}$ 6,5, meio de fosfato $\mathrm{pH}$ 5,5 e tampão acetato $\mathrm{pH}$ 5,5 utilizando ND/SPE, com velocidade de $10 \mathrm{mV} \mathrm{s}^{-1}$ e amplitude $25 \mathrm{mV}$,

Figura 42. Voltamogramas de DPV obtidos utilizando ND/SPE para concentrações de: (A) DA de 2,0 a 100,0 $\mu \mathrm{mol} \mathrm{L}^{-1}$ na presença de 20,0 $\mu \mathrm{mol} \mathrm{L}^{-1}$ de UA e (B) UA de 2,0 a 97,0 $\mu \mathrm{mol} \mathrm{L} \mathrm{L}^{-1}$ na presença de $20,0 \mu \mathrm{mol} \mathrm{L}{ }^{-1}$ de DA em solução de tampão acetato $0,10 \mathrm{~mol} \mathrm{~L}^{-1}$ $(\mathrm{pH}$ 5,5). Inserida as respectivas curvas analíticas, $\mathrm{n}=3$. Parâmetros de DPV: amplitude de 50 $\mathrm{mV}$ e velocidade de varredura de potenciais de $10 \mathrm{mV} \mathrm{s}^{-1}$

Figura 43. Voltamogramas cíclicos obtidos em diferentes velocidades de varredura potencial ( 5 e $500 \mathrm{mV} \mathrm{s}^{-1}$ ) utilizando SPE (A) e ND/SPE (B) na presença de $\mathrm{K}_{3}\left[\mathrm{Fe}(\mathrm{CN})_{6}\right] 1,0 \mathrm{mmol} \mathrm{L}^{-1}$ em solução de $\mathrm{KCl} 0,10 \mathrm{~mol} \mathrm{~L}^{-1}$. (C) Gráfico de $I_{\mathrm{p}} v s . v^{1 / 2}$. (D) Gráfico de $\log I_{\mathrm{pa}} v s . \log v .118$ Figura 44. Voltamogramas cíclicos obtidos em diferentes velocidades de varredura potencial (5 e $500 \mathrm{mV} \mathrm{s}^{-1}$ ) utilizando SPE (A) e ND/SPE (B) na presença de $\mathrm{K}_{2}\left[\operatorname{IrCl}_{6}\right] 1,0 \mathrm{mmol} \mathrm{L}{ }^{-1} \mathrm{em}$ solução de $\mathrm{KCl} 0,10 \mathrm{~mol} \mathrm{~L}{ }^{-1}$. (C) Gráfico de $I_{\mathrm{p}} v s . v^{1 / 2}$. (D) Gráfico de $\log I_{\mathrm{pa}} v s . \log v \ldots \ldots . .119$

Figura 45. Voltamogramas cíclicos obtidos em diferentes velocidades de varredura potencial (5 e $500 \mathrm{mV} \mathrm{s}^{-1}$ ) utilizando SPE (A) e ND/SPE (B) na presença de $\left[\mathrm{Ru}\left(\mathrm{NH}_{3}\right)_{6}\right] \mathrm{Cl}_{3}$ 1,0 mmol $\mathrm{L}^{-1}$ em solução de $\mathrm{KCl} 0,10 \mathrm{~mol} \mathrm{~L}^{-1}$. (C) Gráfico de $I_{\mathrm{p}} v s . v^{1 / 2}$. (D) Gráfico de log $I_{\mathrm{pa}} v s . \log v$.

Figura 46. Voltamogramas cíclicos obtidos utilizando eletrodos de pasta de carbono nas seguintes proporções: negro de fumo:Nujol 60:40 (\% $\left.\mathrm{m} \mathrm{m}^{-1}\right)$, ND:Nujol 60:40 (\% $\left.\mathrm{m} \mathrm{m}^{-1}\right)$ e negro de fumo: ND:Nujol 55:5:40 $\left(\% \mathrm{~m} \mathrm{~m}^{-1}\right)$ na presença de $\left[\mathrm{Ru}\left(\mathrm{NH}_{3}\right)_{6}\right] \mathrm{Cl}_{3} 1,0 \mathrm{mmol} \mathrm{L}{ }^{-1} \mathrm{em}$ solução de $\mathrm{KCl} 0,10 \mathrm{~mol} \mathrm{~L}^{-1}$, em $v=50 \mathrm{mV} \mathrm{s}^{-1}$. 123

Figura 47. Voltamogramas cíclicos obtidos na presença de $\mathrm{Fe}(\mathrm{CN})_{6}{ }^{3-}(\mathrm{A}), \mathrm{IrCl}_{6}{ }^{2-}$ (B) e $\mathrm{Ru}\left(\mathrm{NH}_{3}\right)_{6}{ }^{3+} 1,0 \mathrm{mmol} \mathrm{L}{ }^{-1}$ em solução de $\mathrm{KCl} 0,10 \mathrm{~mol} \mathrm{~L}^{-1}$ para as diferentes dispersões de $\mathrm{ND}$ em água: 0,$1 ; 0,5 ; 0,8 ; 1,0 ; 1,5$ e $2,0 \mathrm{mg} \mathrm{mL}^{-1}$, das quais $8 \mu \mathrm{L}$ foram gotejados sob a superfície do SPE, em $v=50 \mathrm{mV} \mathrm{s}^{-1}$...... 124

Figura 48. Voltamogramas cíclicos obtidos em $\mathrm{KCl} 0,10 \mathrm{~mol} \mathrm{~L}^{-1}$ contendo $1 \mathrm{mmol} \mathrm{L}^{-1}$ de $\left[\mathrm{Ru}\left(\mathrm{NH}_{3}\right)_{6}\right]^{3+}$ com SPE não modificado $(\mathrm{A})$, com SPE modificado com $8 \mu \mathrm{L}$ da dispersão NDágua com diferentes concentrações $\left(0,1\right.$ a 2,0 $\left.\mathrm{mg} \mathrm{mL}^{-1}\right)$ (B) e SPE modificado com $8 \mu \mathrm{L}$ da dispersão ND-água $10 \mathrm{mg} \mathrm{mL}^{-1}(\mathrm{C}), v=50 \mathrm{mV} \mathrm{s}^{-1}$. Uma visão representativa da camada difusional para cada caso do SPE não modificado, parcialmente modificado com ND, e completamente coberto com ND na superfície é apresentada. Fonte: Adaptado de Baccarin et al., $2019^{68}$. 126 


\section{ÍNDICE DE TABELAS}

Tabela 1. Área eletroativa dos eletrodos propostos

Tabela 2. Comparação dos três eletrodos desenvolvidos para a determinação de escitalopram utilizando DPV .

Tabela 3. Comparação dos três eletrodos desenvolvidos para a determinação de escitalopram utilizando SWV

Tabela 4. Resultados obtidos utilizando a DPV e a SWV para a determinação de escitalopram em amostras de urina e fluido cérebro-espinal sintética.

Tabela 5. Resultados obtidos a partir das curvas TG/DTG, com intervalos de temperatura e perda de massa...

Tabela 6. Área eletroativa dos eletrodos preparados 82

Tabela 7. Valores de carga e concentração de espécies ativas de AgNPs para cada eletrodo de trabalho desenvolvido

Tabela 8. Comparação dos três $P E N L A B$ desenvolvidos para a determinação de bisfenol-A90

Tabela 9. Possíveis interferentes na determinação de bisfenol-A

Tabela 10. Resultados obtidos das análises de água de rio e de abastecimento público 98

Tabela 11. Comparação entre o trabalho presente e outros eletrodos compósitos reportados para a determinação de bisfenol-A

Tabela 12. Comparação entre o desempenho do SPE e do ND/SPE para a determinação de DA

Tabela 13. Comparação entre o desempenho do SPE e do ND/SPE para a determinação de UA

Tabela 14. Comparação entre o trabalho presente e alguns sensores reportados na literatura para a determinação concomitante de DA e UA 115

Tabela 15. Diferentes eletrodos modificados com ND para a determinação de diferentes analitos 116

Tabela 16. Valores de $\Delta E$ para $\mathrm{K}_{3}\left[\mathrm{Fe}(\mathrm{CN})_{6}\right], \mathrm{K}_{2}\left[\mathrm{IrCl}_{6}\right]$ e $\left[\mathrm{Ru}\left(\mathrm{NH}_{3}\right)_{6}\right] \mathrm{Cl}_{3}$ utilizando o SPE e o ND/SPE para diferentes valores de velocidade de varredura de potenciais. 122

Tabela 17. Valores de $\Delta E, I_{\mathrm{pa}}$ e $I_{\mathrm{pc}}$ para $\mathrm{K}_{3}\left[\mathrm{Fe}(\mathrm{CN})_{6}\right], \mathrm{K}_{2}\left[\mathrm{IrCl}_{6}\right]$ e $\left[\mathrm{Ru}\left(\mathrm{NH}_{3}\right)_{6}\right] \mathrm{Cl}_{3}$ utilizando SPE modificado com diferentes dispersões de ND em água..... 124 


\section{LISTA DE ABREVIATURAS}

AA ácido ascórbico

CNTs nanotubos de carbono (do inglês "carbon nanotubes")

CPE eletrodo de pasta de carbono (do inglês "carbon paste electrode")

DA dopamina

DPV voltametria de pulso diferencial (do inglês "differential pulse voltammetry")

$\boldsymbol{E} \quad$ potencial

EDX

espectroscopia de dispersão de energia por raio-X (do inglês “energy-dispersive $X$-ray spectroscopy")

EGPU eletrodo de grafite-poliuretana (do inglês "graphite-polyurethane electrode")

EPPG grafite pirolítico de plano de borda (do inglês "edge plane pyrolytic graphite")

GCE eletrodo de carbono vítreo (do inglês "glassy carbon electrode")

I corrente

$\boldsymbol{I}_{\mathrm{a}} \quad$ corrente de pico anódica

$I_{\mathbf{c}} \quad$ corrente de pico catódica

IL líquido iônico ( do inglês "ionic liquid")

LOD limite de detecção (do inglês "limit of detection")

MNPs nanopartículas metálicas (do inglês "metallic nanoparticles")

MWCNTs

nanotubos de carbono de paredes múltiplas (do inglês "multi-walled carbon nanotubes")

ND nanodiamantes (do inglês "nanodiamonds")

r coeficiente de correlação

SCE eletrodo saturado de calomelano (do inglês "saturated calomel electrode")

SEM microscopia eletrônica de varredura (do inglês "Scanning Electron Microscopy")

SPE eletrodo impresso (do inglês "screen printed electrode") 


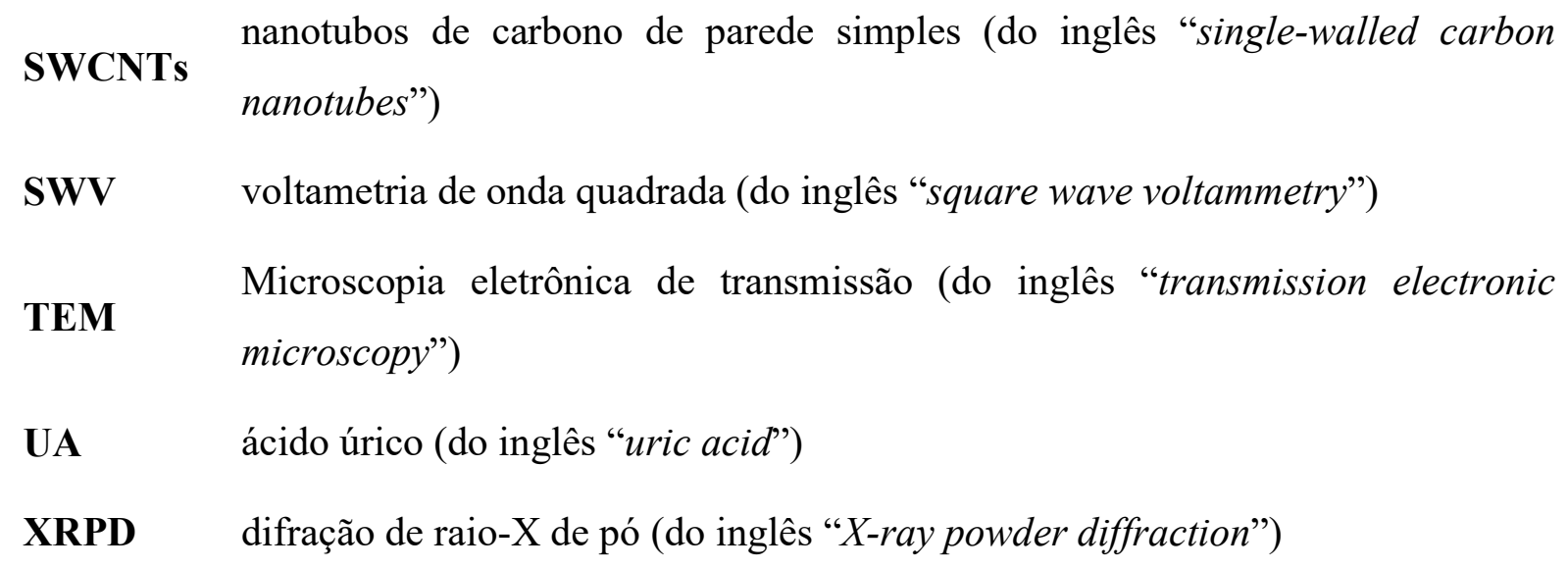




\section{SUMÁRIO}

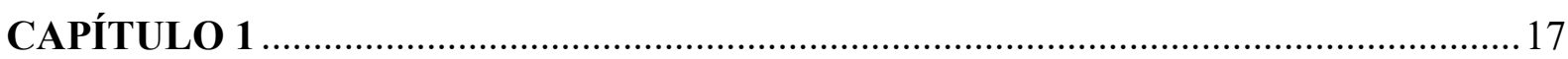

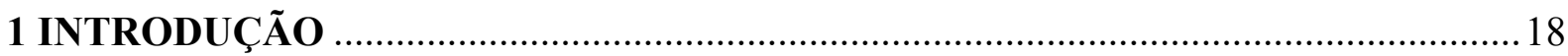

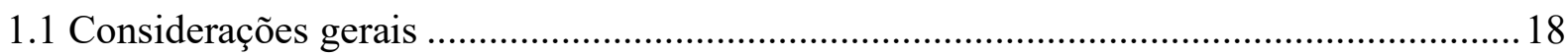

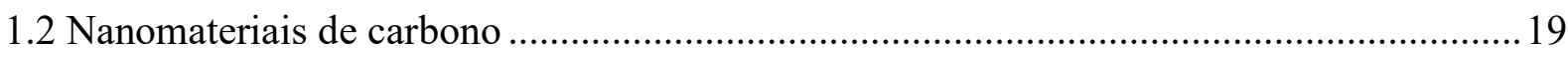

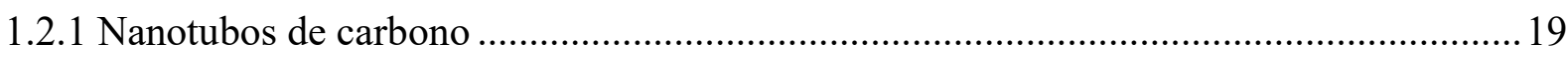

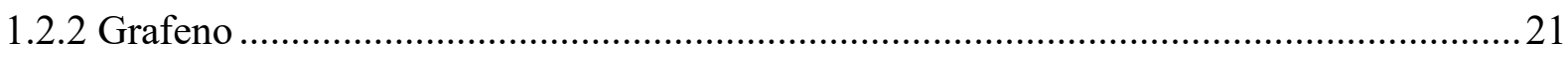

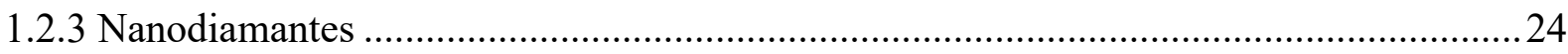

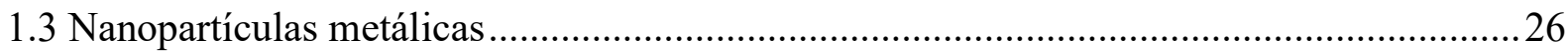

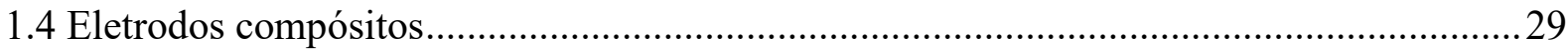

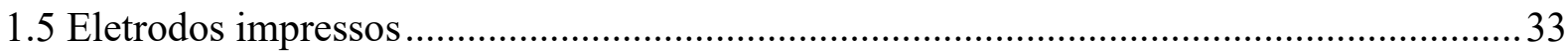

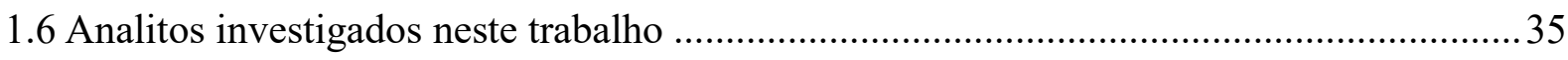

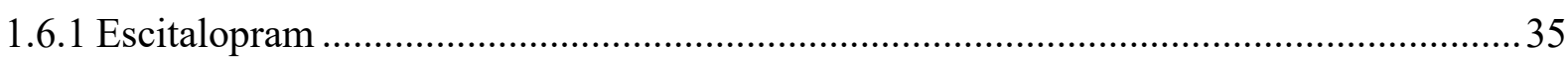

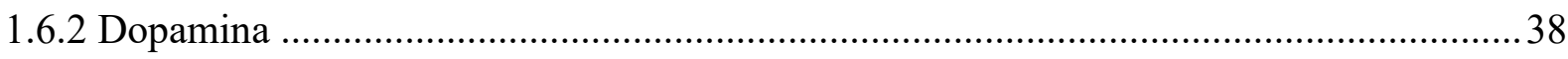

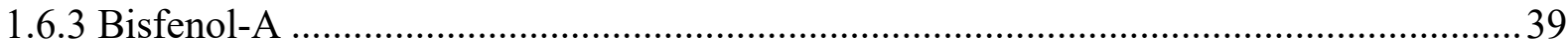

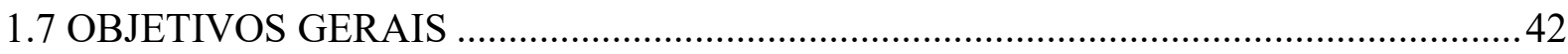

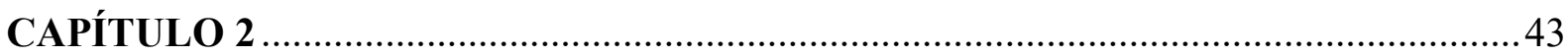

ESTUDO COMPARATIVO DO DESEMPENHO DOS ELETRODOS GPU, GPU-GR E GPU-CNTS NA DETERMINAÇÃO DE ESCITALOPRAM EM AMOSTRAS

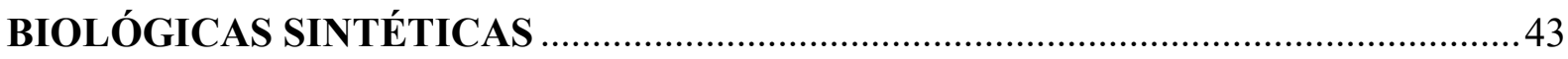

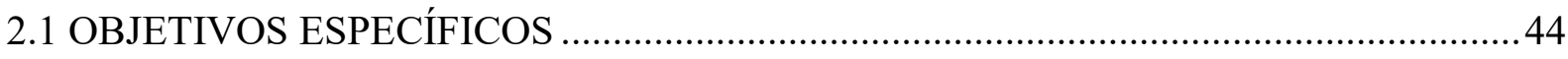

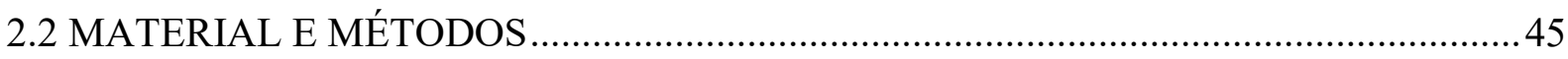

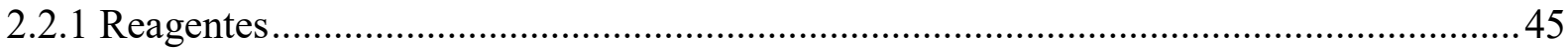

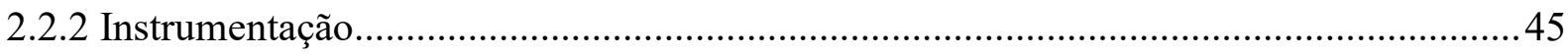

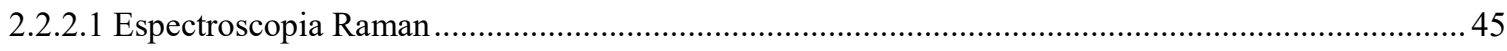

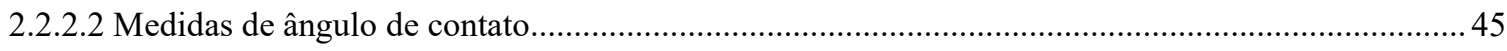

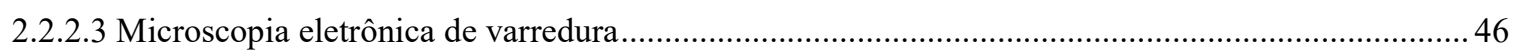

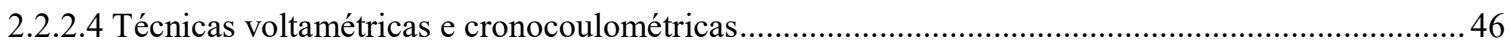

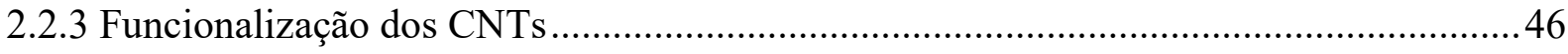

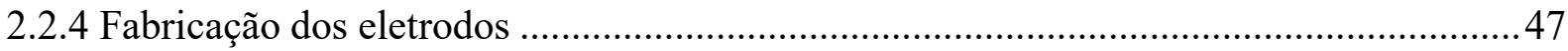

2.2.5 Preparo das amostras de urina e fluido cérebro-espinal sintéticos .................................48

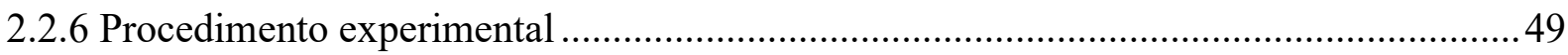

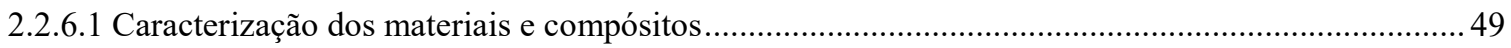


2.2.6.2 Cálculo da área eletroativa dos eletrodos desenvolvidos

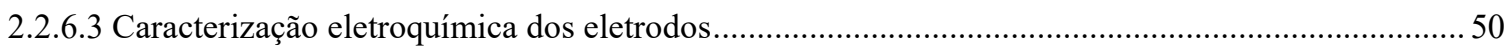

2.2.6.4 Procedimento eletroanalítico para a determinação de escitalopram .............................................50

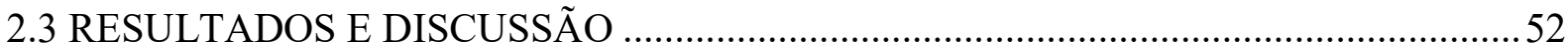

2.3.1 Caracterização dos materiais e compósitos …………………………………………...52

2.3.2 Caracterização eletroquímica dos três eletrodos ............................................................54

2.3.3 Comportamento eletroquímico do escitalopram ............................................................56

2.3.4 Aplicação do método desenvolvido em amostras biológicas sintéticas ............................. 64

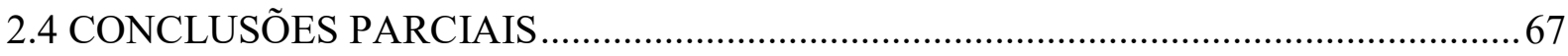

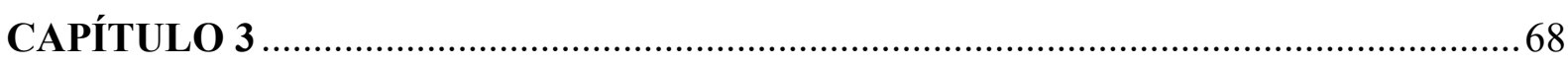

DESENVOLVIMENTO DE UM ELETRODO TIPO PEN LAB BASEADO EM UM COMPÓSITO GRAFITE-POLIURETANA E NANOPARTÍCULAS DE PRATA PARA DETECÇÃO DE BISFENOL-A EM AMOSTRAs DE ÁGUA DE RIO E DE

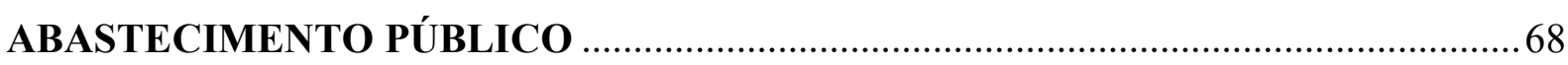

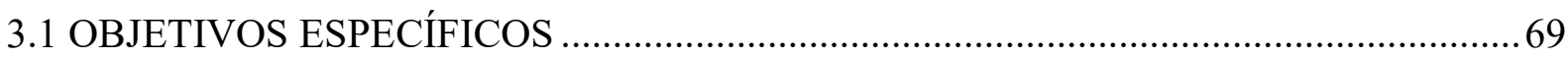

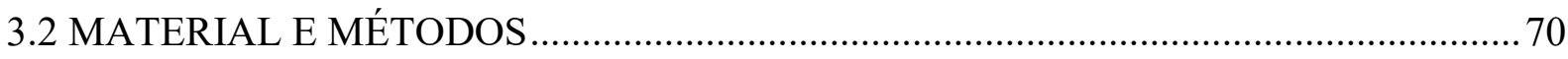

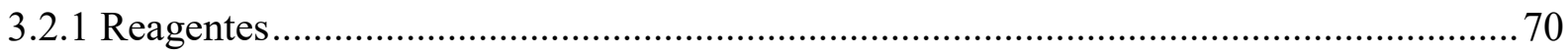

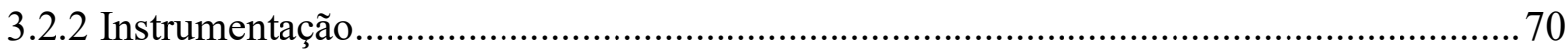

3.2.2.1 Equipamento e condições utilizadas nas análises de termogravimetria …………………….............. 70

3.2.2.2 Microscopia eletrônica de varredura e espectroscopia de dispersão de energia por raios X............... 70

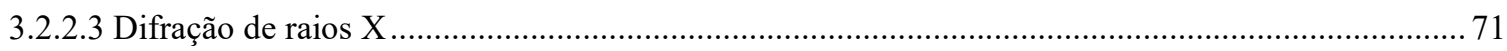

3.2.2.4 Técnicas voltamétricas e cronocoulométricas................................................................................ 71

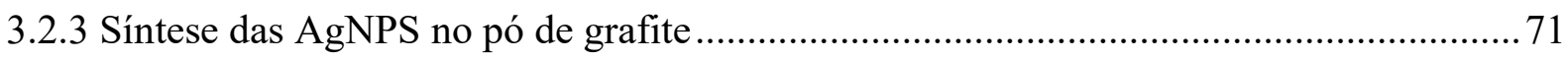

3.2.4 Preparo do compósito AgNPs-grafite-poliuretana e dos PEN LABs ............................. 72

3.2.5 Coleta das amostras de águas de rio e de abastecimento público...................................75

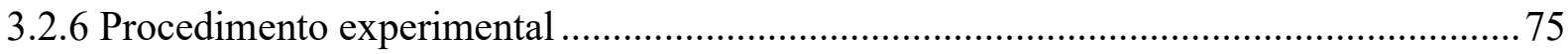

3.2.6.1 Caracterização e quantificação das AgNPs formadas no grafite.......................................................... 75

3.2.6.2 Cálculo da área eletroativa dos eletrodos desenvolvidos ................................................................. 75

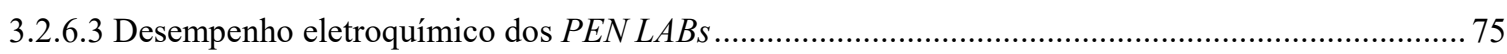

3.2.6.4 Procedimento eletroanalítico para a determinação de bisfenol-A........................................................ 76

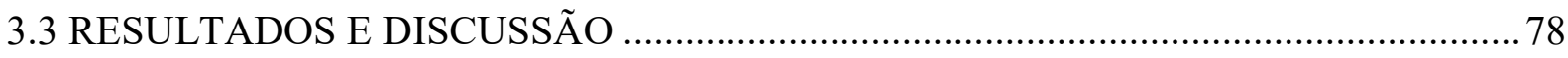

3.3.1 Quantificação das AgNPs no compósito grafite-poliuretana por termogravimetria .......78

3.3.2 Caracterização das AgNPs no grafite e no compósito grafite-poliuretana ......................80

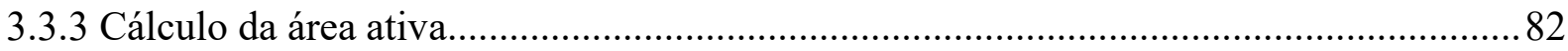

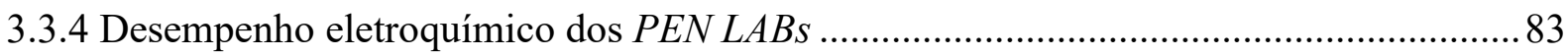


3.3.5 Desempenho analítico dos PEN LAB para determinação de bisfenol-A .........................87

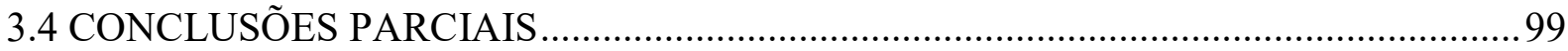

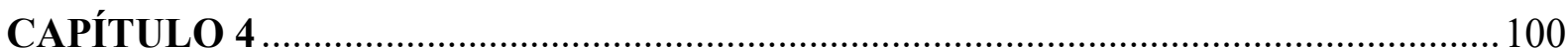

EFEITO DA PRESENÇA DOS NANODIAMANTES EM SUPERFÍCIES DE

ELETRODOS COMPÓSITOS IMPRESSOS: SONDAS INORGÂNICAS E DISCRIMINAÇÃO DO SINAL VOLTAMÉTRICO DA DOPAMINA E ÁCIDO ÚRICO 100

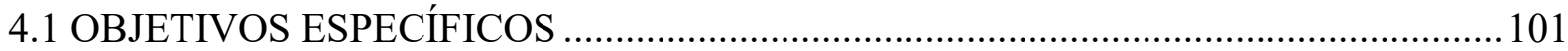

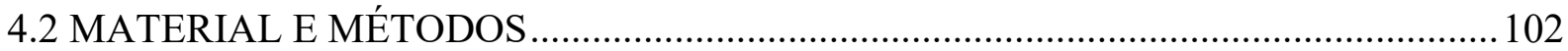

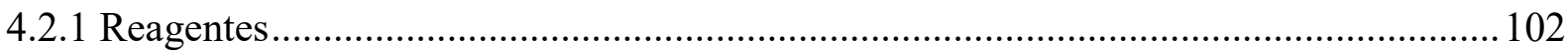

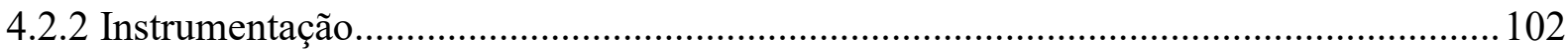

4.2.2.1 Microscopia eletrônica de transmissão..................................................................... 102

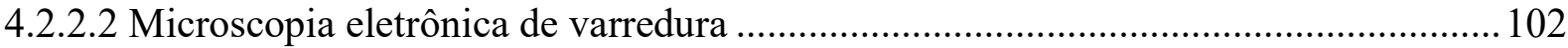

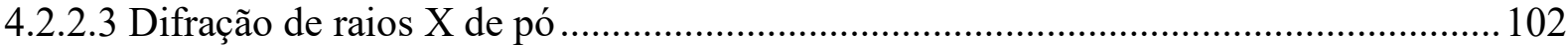

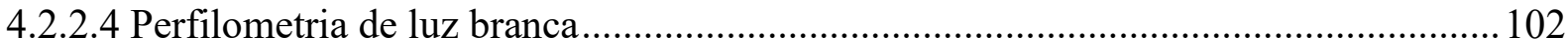

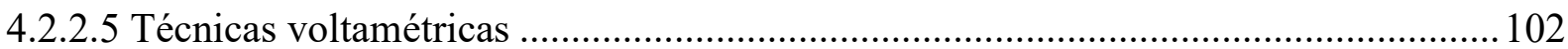

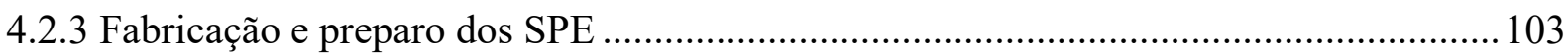

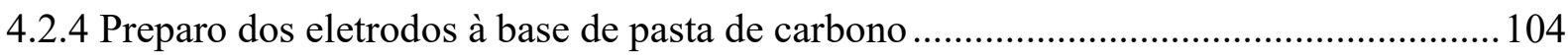

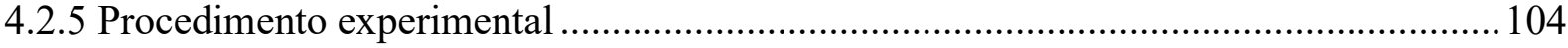

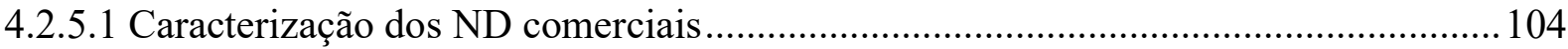

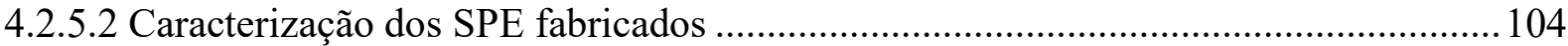

4.2.5.3 Comportamento eletroquímico da DA e UA sob o SPE e o ND/SPE ........................ 105

4.2.5.4 Avaliando e investigando o desempenho catalítico do ND/SPE ................................ 105

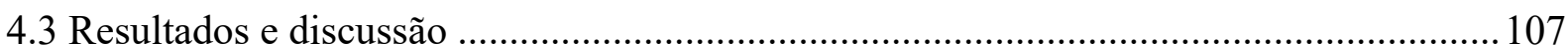

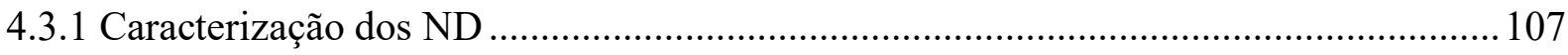

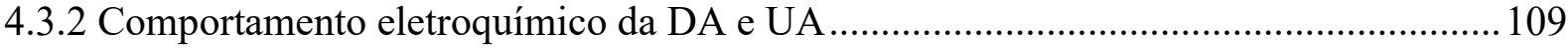

4.3.3 Entendendo a melhora do desempenho eletroanalítico utilizando ND.........................115

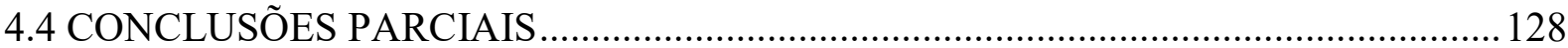

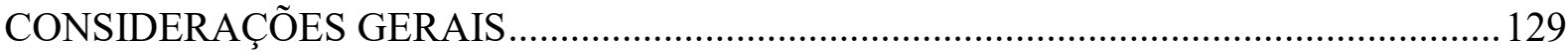

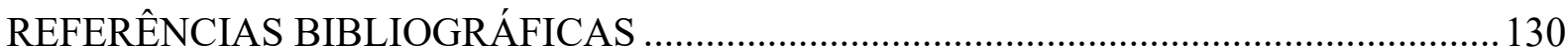

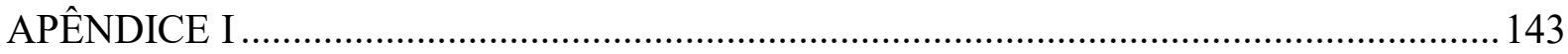

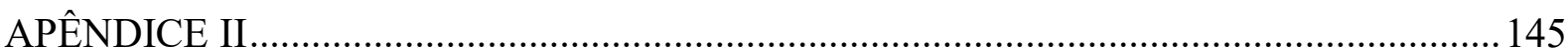


CAPÍTULO 1

Introdução 


\section{Introdução}

\subsection{Considerações gerais}

Os últimos anos ${ }^{1,2}$ foram marcados pela consolidação e crescimento vertiginoso do desenvolvimento de sensores eletroquímicos, abrindo novos horizontes com a diversidade de possíveis aplicações a cada dia. A expansão global desses dispositivos, vinculada ao avanço da tecnologia, permite o seu uso para monitoramento de biomarcadores de doenças, diagnósticos de contaminação ambiental e de alimentos, monitoramento e degradação de fármacos, avaliação da qualidade de combustíveis, entre outros. O que se observa é uma demanda cada vez maior por métodos rápidos, confiáveis, dispositivos com materiais de baixo custo, sem a utilização de equipamentos sofisticados e pessoal treinado para operá-los. Como exemplo de evolução científica e tecnológica tem-se o surgimento dos sensores vestíveis e/ou implantáveis $^{3,4}$ que apresentam diversas aplicabilidades, desde o monitoramento do suor de atletas até a identificação de biomarcadores de doenças. Outros exemplos são as possibilidades de análises em campo de possíveis contaminantes ambientais de solo e rio (eg. pesticidas e polifenóis), utilizando-se dispositivos portáteis e miniaturizados.

É importante ressaltar que, muitas vezes, o desenvolvimento desses dispositivos traz como desafio a dificuldade de se estabelecer métodos reprodutíveis, nos quais se tenham medidas com repetibilidade, materiais de baixo custo com menor ou sem toxicidade. Nesse contexto, evidencia-se a importância do investimento em mais pesquisas e no vasto leque de possibilidades a explorar.

Atrelado a este avanço tecnológico e científico está à busca por novos materiais para o desenvolvimento de sensores eletroquímicos. Nesse contexto, a nanotecnologia tem-se destacado, uma vez que novas propriedades eletrônicas, magnéticas e catalíticas têm sido descobertas devido ao tamanho nanométrico dos materiais, quando comparado a sua forma de sólido estendido (do inglês "bulk"). Devido a essas propriedades, muitos trabalhos na área de sensores têm sido propostos utilizando nanomateriais como modificadores incorporados à superfície e/ou ao corpo do eletrodo. Como consequência da sua presença, de maneira geral, observa-se um aumento da área ativa, formando sítios ativos na região eletródica do eletrodo, que levam a uma maior interação com espécies de interesse. De fato, uma facilitação da taxa de transferência de elétrons na interface eletrodo/solução é observada, o que leva a melhores desempenhos analíticos dos eletrodos modificados em relação aos eletrodos base, permitindo métodos analíticos com maiores valores de sensibilidade e menores de limite de detecção 
(LOD, do inglês "limit of detection"). Como exemplos dessas nanoestruturas têm-se os materiais de carbono tais como: grafeno, nanotubos de carbono (CNTs, do inglês "carbon nanotubes"), nanodiamantes (ND, do inglês "nanodiamonds") e negro de fumo; e as nanopartículas metálicas (MNPs, do inglês “metallic nanoparticles”): AgNPs (nanopartículas de prata), AuNPs (nanopartículas de ouro), PdNPs (nanopartículas de paládio), PtNPs (nanopartículas de platina), e entre outras, as quais serão mais detalhadas a seguir.

\subsection{Nanomateriais de carbono}

\subsubsection{Nanotubos de carbono}

Os CNTs, apresentados pela primeira vez em 1991 por Iijima $^{5}$, são materiais carbonáceos com estruturas cilíndricas (tubulares) de diâmetro de alguns nanômetros e comprimentos de micrômetros. Trata-se de uma folha de grafeno enrolada em torno de um eixo central, sendo sua estrutura formada por carbonos $\mathrm{sp}^{2}$ hibridizados. São classificados em duas categorias: de parede simples (SWCNTs, do inglês "single-walled-carbon nanotubes"), com apenas uma folha de grafeno enrolada e de paredes múltiplas (MWCNTs, do inglês “multi-walled carbon nanotubes"), com várias folhas de grafeno, formando múltiplos cilindros concêntricos, com espaçamento entre 0,3 e $0,4 \mathrm{~nm}$ entre eles.

Algumas características que atraem o uso desse material para o desenvolvimento de sensores eletroquímicos são, de maneira geral, as de condutores de eletricidade, facilitação da transferência de elétrons, alta razão área superficial/volume e possibilidade de ser utilizado como matriz para incorporação/ancoramento de muitas espécies químicas e biológicas (eg. MNPs e enzimas).

Os CNTs apresentam duas regiões em sua estrutura, chamadas de plano basal e plano de bordas, referente ao plano da folha e as extremidades dos CNTs, respectivamente. Além disso, essas pontas podem ser abertas ou fechadas em uma forma hemisférica. Alguns trabalhos reportam a possibilidade de funcionalização desses materiais utilizando ácidos oxidantes concentrados $\left(\mathrm{H}_{2} \mathrm{SO}_{4}, \mathrm{HCl}\right.$ ou $\left.\mathrm{HNO}_{3}\right)$ ou uma mistura desses ácidos ${ }^{6}$, visando abrir as extremidades e expor as pontas do material. Isso é de extrema importância uma vez que já foi observado que a condutividade dos CNTs é atribuída majoritariamente ao plano de bordas, elucidando o comportamento eletroquímico do material ${ }^{7}$. Somado a isso, essas funcionalizações promovem uma limpeza dos CNTs, eliminando impurezas metálicas provenientes das diferentes sínteses ${ }^{8}$, promovem defeitos na parede da estrutura, além da possibilidade de incorporação de diferentes grupos funcionais (eg. carboxilas, quinonas, 
hidroxilas, aminas, nitros e sulfônicos) nas bordas. Como consequência, um aumento da reatividade desses materiais é observado, o que é muito atraente para o desenvolvimento de sensores eletroquímicos.

Em muitos trabalhos foram reportados que a presença dos CNTs nas superfícies dos diferentes eletrodos pode permitir, em alguns casos, eletrocatálise, o que possibilita a detecção de diferentes analitos em potenciais menores de trabalho, eliminando a possibilidade de possíveis espécies interferentes. Ainda, a presença dos CNTs pode proporcionar aumento de sinal analítico, o que permite métodos mais sensíveis com menores valores de LOD e quantificação. Para exemplificar, alguns serão descritos a seguir.

O primeiro trabalho a reportar a aplicação dos CNTs para o desenvolvimento de um sensor eletroquímico foi proposto por Britto et al. ${ }^{9}$. Um eletrodo de pasta de carbono (CPE, do inglês "carbon paste electrode") à base de MWCNTs e bromofórmio foi utilizado para estudar a oxidação do neurotransmissor dopamina (DA). Com a voltametria cíclica, utilizando o eletrodo proposto, foi observado um comportamento quasi-reversível, com pico de oxidação em $0,22 \mathrm{~V}(v s$. SCE) e um de redução em $0,19 \mathrm{~V}$, diferente do comportamento irreversível observado para outros eletrodos de grafite. Os autores atribuíram esse pequeno valor de diferença de potencial de pico $(\Delta E=0,30 \mathrm{~V})$ a rápida transferência de elétrons promovida pelos CNTs na interface eletrodo/solução.

Outro neurotransmissor estudado foi a epinefrina utilizando um CPE à base grafiteparafina modificado com CNTs e o líquido iônico (IL, do inglês "ionic liquid") brometo de 1metil-3-butilimidazólio (o sensor proposto foi chamado IL/CNTPE) ${ }^{10}$. Utilizando a voltametria cíclica, em uma velocidade de varredura de potenciais de $50 \mathrm{mV} \mathrm{s}^{-1}$, as respostas eletroquímicas dos sensores CPE, CNTPE, IL/CPE e IL/CNTPE foram avaliadas para epinefrina. Correntes de pico de oxidação de $16,7 \mu \mathrm{A}$ (no potencial de $375 \mathrm{mV} v s . \mathrm{Ag} / \mathrm{AgCl}$ $\left(\mathrm{KCl} 3,0 \mathrm{~mol} \mathrm{~L}^{-1}\right)$ ) e 20,7 $\mu \mathrm{A}$ (no potencial de $355 \mathrm{mV}$ ) utilizando o CPE e o CNTPE foram obtidos, respectivamente. Essa diminuição no potencial de oxidação e aumento de corrente de pico anódica foram atribuídos à atividade catalítica dos CNTs. Já para as medidas utilizando IL/CPE e IL/CNTPE foram obtidos, respectivamente, correntes de pico de oxidação de 28,3 $\mu \mathrm{A}$ (no potencial de $315 \mathrm{mV} v s$. $\mathrm{Ag} / \mathrm{AgCl}\left(\mathrm{KCl} 3,0 \mathrm{~mol} \mathrm{~L}^{-1}\right)$ ) e $33,8 \mu \mathrm{A}$ (no potencial de 310 $\mathrm{mV})$. A combinação dos CNTs junto com o IL como modificador do CPE apresentou maior sinal analítico (quase duas vezes) e menor potencial de oxidação (65 $\mathrm{mV}$ de diferença) comparado ao CPE, justificando o uso do modificador. 
Em outro trabalho, Vicentini et al. ${ }^{11}$ reportaram um procedimento voltamétrico para a determinação do princípio ativo ciprofibrato utilizando um eletrodo de carbono vítreo (GCE, do inglês "glassy carbon electrode") modificado com MWCNTs e IL de 1-butil-3metilimidazólio. Para isso, a dispersão do modificador em três diferentes matrizes poliméricas - dihexadecilfosfato, Nafion e quitosana - foram avaliadas e os GCE modificados com os três filmes tiveram suas estabilidades e respostas voltamétricas avaliadas para a sonda $\left[\mathrm{Fe}(\mathrm{CN})_{6}\right]^{4-/ 3-}$. O IL-MWCNTs-dihexadecilfosfato/GCE foi o que apresentou menor valor de $\Delta E(55,5 \mathrm{mV})$ comparado ao IL-MWCNTs-nafion/GCE $(\Delta E=105 \mathrm{mV})$ e IL-MWCNTsquitosana/GCE $(\Delta E=79,3 \mathrm{mV})$, evidenciando a transferência rápida de elétrons na superfície do eletrodo. Em seguida, a resposta eletroquímica dos sensores IL-MWCNTsdihexadecilfosfato/GCE， MWCNTs-dihexadecilfosfato/GCE， IL-MWCNTs-nafion/GCE, MWCNTs-nafion/GCE, IL-MWCNTs-quitosana/GCE e MWCNTs-quitosana/GCE foram avaliadas com relação à detecção de ciprofibrato. A partir dos resultados foi possível observar que os maiores valores de corrente foram obtidos com a combinação de MWCNTs e IL para os diferentes filmes poliméricos. A interação entre a carga negativa dos grupos funcionais dos MWCNTs e cátions imidazólios do IL fizeram com que houvesse maior desdobramento dos MWCNTs, expondo mais as pontas eletroativas desse material. Considerando estabilidade e maiores valores de corrente, o IL-MWCNTs-dihexadecilfosfato/GCE foi selecionado para a determinação de ciprofibrato em amostras farmacêuticas.

\subsubsection{Grafeno}

O grafeno foi isolado pela primeira vez em 2004 pelos pesquisadores Konstantin Novoselov e Andre Geim, da Manchester University, na Inglaterra, por meio da esfoliação mecânica do grafite utilizando uma fita adesiva (método conhecido como "scotch tape") ${ }^{12}$. Inicialmente, um pedaço de fita adesiva foi cortado, colado sob a superfície de um pedaço sólido de grafite e em seguida removido. A partir dessa etapa, eles usaram produtos químicos para dissolver a fita adesiva e caracterizaram o material obtido. Devido à simplicidade do método proposto para a obtenção de uma única folha do grafite, o grafeno, os pesquisadores ganharam o prêmio Nobel em Física em 2010.

Trata-se de um material com átomos de carbono $\mathrm{sp}^{2}$ hibridizados, dispostos em hexágonos (moléculas de benzeno) interligados em uma camada única (também chamada de folha). Apresenta uma estrutura bidimensional com espessura atômica. Nesta rede regular em que os átomos de carbono $\mathrm{sp}^{2}$ estão arranjados, a movimentação dos elétrons é possível por 
toda a folha, de forma aleatória e em todas as direções. Além disso, na estrutura de grafeno, assim como nos CNTs, temos o plano basal (do inglês "basal-plane") e o plano de borda (do inglês "edge-plane"), como apresentado na Figura 1. A alta condutividade elétrica deste material está relacionada principalmente à região do plano de bordas com uma pequena contribuição do plano basal, devido à presença de alguns defeitos na estrutura da folha.

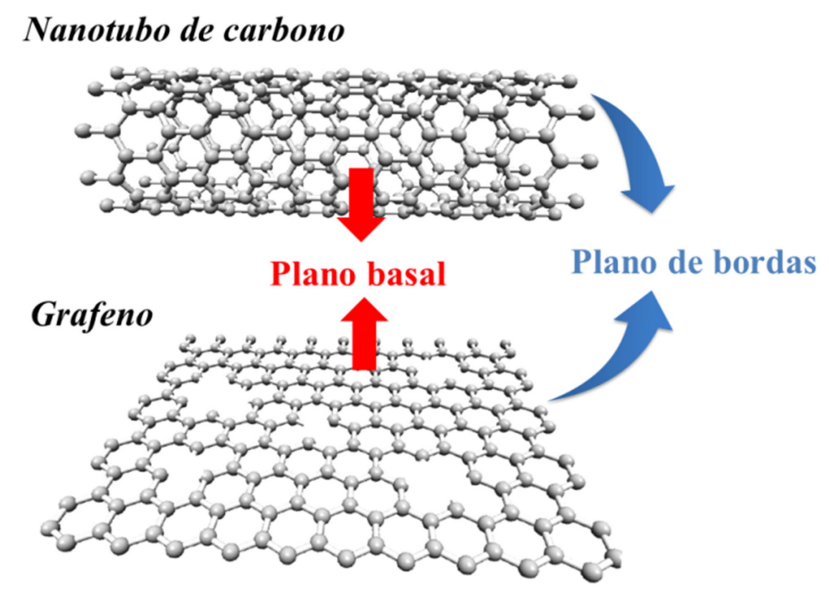

Figura 1. Representação dos planos basal e de bordas no CNTs e no grafeno.

Outras propriedades físico-químicas ${ }^{13}$ observadas do grafeno são resistência mecânica (quase 200 vezes maior que aço), elevada área superficial $\left(2630 \mathrm{~m}^{2} \mathrm{~g}^{-1}\right)$, transmitância óptica, flexibilidade e condutividade térmica, o que o torna atraente para as mais diferentes aplicações tais como em dispositivos eletrônicos, armazenamento e conversão de energia (supercapacitores, baterias e células a combustível), biotecnologia e desenvolvimento de sensores eletroquímicos ${ }^{14}$.

Nesse contexto, diferentes tratamentos químicos e mecânicos do grafite têm sido propostos e, como consequência, diferentes tipos de grafeno podem ser obtidos. Esses derivados do grafeno podem diferir em solubilidade e estabilização em meio aquoso ou orgânico, purificação, métodos simples ou sofisticados para sua síntese. Muitas revisões na literatura descrevem esses diferentes métodos de preparar o grafeno e seus derivados. Pumera et $a l .{ }^{13}$ destacam três métodos de síntese para serem utilizados para desenvolvimento de sensores:

a) Deposição química do vapor, a qual resulta em estruturas de multicamadas, também chamadas de palhetas empilhadas de grafeno (do inglês "stacked graphene platelets"); 
b) Intercalação de pequenas moléculas entre as camadas da estrutura de grafite e a esfoliação desse material por choque térmico ou ultrassom; e

c) "Abrir" os tubos das estruturas dos CNTs (folha de grafeno enrolada no formato de tubo), através de rotas diferentes. Como exemplos, tem-se a possibilidade de utilizar permanganato como reagente oxidante ou esfoliação por plasma.

As principais vantagens desses métodos são a produção de grandes quantidades de grafeno.

Para o desenvolvimento de sensores eletroquímicos, tem se reportado que muitos eletrodos modificados com o grafeno apresentaram aumento de área superficial e facilidade de transferência de elétrons comparados ao eletrodo base, o que, como consequência, possibilitou a determinação de diferentes analitos em menores potenciais de trabalho com maiores valores de corrente de pico.

Em 2008, Shang et al. ${ }^{15}$ foram os primeiros a reportar a aplicação de grafeno no desenvolvimento de sensores eletroquímicos. Para isso, foi proposto um método de deposição química do vapor assistido por plasma de micro-ondas, na ausência de catalisadores metálicos ou qualquer pré-tratamento superficial, visando o crescimento de multicamadas de nanofolhas de grafeno sobre um substrato de silício. Um crescimento uniforme das folhas com orientação vertical em relação ao substrato e espessuras inferiores a $10 \mathrm{~nm}$ foi observado. A utilização desse material propiciou a separação de picos de oxidação da DA, ácido ascórbico (AA) e ácido úrico (UA, do inglês "uric acid"), permitindo a determinação simultânea das três moléculas, diferente do GCE (sensor utilizado para comparação), que apresentou sobreposição dos picos. Essa distinção dos picos foi atribuída à facilitação da transferência de elétrons na interface eletrodo/solução devido às pontas das folhas de grafeno verticalmente expostas.

Em 2009, em outra abordagem, Alwarappan et al. ${ }^{16}$ propuseram filmes de grafeno e SWCNTs modificando o GCE, e suas performances voltamétricas foram comparadas para a determinação de DA, AA e serotonina. Os autores demonstraram haver maior densidade de carga negativa na estrutura do grafeno e uma condutividade de quase 60 vezes maior em relação aos SWCNTs. Assim, em todas as medidas, o grafeno exibiu melhor estabilidade, maiores valores de corrente de pico e menor razão sinal-ruído do que os SWCNTs. Além disso, foi possível a distinção dos três picos de oxidação para DA, AA e serotonina utilizando o GCE modificado com grafeno, enquanto, para o GCE modificado com SWCNTs foi observado uma sobreposição dos picos. 
Em 2010, Kang et al. ${ }^{17}$ propuseram o desenvolvimento de um sensor eletroquímico baseado em um GCE modificado com grafeno funcionalizado para determinação de paracetamol em amostras farmacêuticas. A partir de medidas de voltametria cíclica, a uma velocidade de varredura de $50 \mathrm{mV} \mathrm{s}^{-1}$, foi observado um pico de oxidação em $0,37 \mathrm{~V}$ (vs.

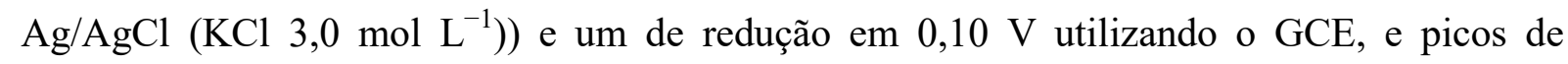
oxidação e redução em $0,27 \mathrm{~V}$ e $0,23 \mathrm{~V}$, respectivamente, utilizando o GCE modificado. Essa diminuição de $\Delta E$ de $270 \mathrm{mV}$ para $40 \mathrm{mV}$ foi correlacionada ao efeito eletrocatalítico que o grafeno funcionalizado promoveu na superfície do GCE, além da interação e adsorção da molécula de interesse nos grupos funcionais do material de carbono.

Inspirados nos resultados alcançados com o grafeno e seus derivados, seu potencial de eletrocatálise para diferentes analitos, capacidade adsortiva, diferentes rotas de funcionalização, possibilidade de ancorar biomoléculas em sua estrutura o tornaram alvo de pesquisa para ser combinado com outros materiais. Sobre trabalhos mais recentes, tem sido proposta a combinação dele com outros materiais de carbono (eg. $\mathrm{CNTs}^{18}$, negro de fumo ${ }^{19}$, fulereno $\left.{ }^{20}\right), \mathrm{MNPs}^{21}$, biomoléculas ${ }^{22}, \mathrm{IL}^{23}$, entre outros. A ideia é que a combinação do grafeno com os mais diferentes materiais possa permitir o desenvolvimento de métodos mais sensíveis, em alguns casos mais seletivos, com menores LOD para as mais diferentes espécies de interesse.

\subsubsection{Nanodiamantes}

Os ND, sintetizados pela primeira vez na década de 60, na antiga União Soviética, foram obtidos a partir da irradiação do grafite por ondas de choque, geradas pela detonação dos explosivos TNT (2-metil-1,3,5-trinitrobenzeno, fórmula molecular $\left(\mathrm{C}_{6} \mathrm{H}_{2}\left(\mathrm{NO}_{2}\right)_{3} \mathrm{CH}_{3}\right)$ e RDX (1,3,5-trinitroperidro-1,3,5-triazina, fórmula molecular $\mathrm{C}_{3} \mathrm{H}_{6} \mathrm{~N}_{6} \mathrm{O}_{6}$ ), em uma câmara metálica fechada com atmosfera de nitrogênio, gás carbônico e água líquida e/ou gasosa ${ }^{24,25}$. Após a detonação controlada, a fuligem obtida foi purificada por meio de oxidação e/ou tratamento com ácidos minerais, e como resultado obtiveram-se nanopartículas de carbono com diâmetro inferior a $10 \mathrm{~nm}$, os ND. Entretanto, foi na década de 80 que este material passou a atrair interesse científico e industrial, sendo hoje produzido por diferentes métodos tais como ablação a laser, plasma assistido por deposição química do vapor, síntese em autoclave a partir de fluídos supercríticos e cavitação com ultrassom ${ }^{25}$.

$\mathrm{Na}$ literatura são descritos como nanoesferas, constituídas em sua maioria de carbonos $\mathrm{sp}^{3}$, com a presença de alguns carbonos $\mathrm{sp}^{2}$ e grupos oxigenados na superfície de sua camada 
externa $^{26,27}$. Mochalin et al. $^{25}$ publicaram um artigo de revisão na conceituada Nature Nanotechnology sobre a síntese, estrutura e propriedades desse material. Em particular uma ênfase sobre como a presença de grupos funcionais na superfície podem alterar características química, eletrônicas e ópticas.

Além disso, devido às suas propriedades como estabilidade química, dureza, baixa toxicidade e capacidade de produzir dispersões estáveis em meio aquoso têm sido utilizados para uma infinidade de aplicações, como a fabricação de micro abrasivo, a produção de cosméticos, veículo para princípio ativo de fármacos e medicamento contra diferentes tipos de câncer no organismo humano. Ainda, a presença dos grupos funcionais e carbonos $\mathrm{sp}^{2} \mathrm{em}$ sua superfície começaram a despertar o interesse da utilização deste material para o desenvolvimento de sensores eletroquímicos.

Holt et $a{ }^{28}{ }^{28}$ propuseram que a transferência de elétrons pode ocorrer na superfície dos ND não dopados devido à presença de um arranjo complexo de carbono $\mathrm{sp}^{2} \mathrm{e} \mathrm{sp}^{3}$, o que facilita a transferência de elétrons entre os ND e o analito de interesse. Em estudos de voltametria cíclica, foi observado um aumento na corrente faradaíca para as sondas redox $\mathrm{Fe}(\mathrm{CN})_{6}{ }^{3-}$ e $\mathrm{Ru}\left(\mathrm{NH}_{3}\right)_{6}{ }^{3+}$ utilizando um eletrodo de ouro modificado com ND, pelo método da deposição, em comparação ao eletrodo sem modificação. Em outro trabalho, Varley et al. ${ }^{29}$ utilizaram um eletrodo de diamante dopado com boro modificado com ND de diâmetro de $1000,250,100,10$ e $5 \mathrm{~nm}$ e observaram um aumento da corrente de pico de oxidação do ferroceno metanol dependente do tamanho dos ND, sendo que, quanto menor a nano esfera, maior foi a corrente de pico. Este efeito foi atribuído a dois processos catalíticos: a transferência de elétrons entre as espécies redox da solução e grupos redox-ativos da superfície ND; e outro a transferência de elétrons sendo medida pelo ferroceno metanol ${ }^{+}$ adsorvido na superfície do ND.

A seguir são apresentados alguns exemplos de trabalhos que têm sido reportados para o desenvolvimento de novos sensores e determinação de diferentes espécies eletroativas utilizando essas nanopartículas de carbono.

Simioni et al. ${ }^{30}$ modificaram a superfície de um GCE com uma dispersão aquosa de ND e utilizaram o sensor proposto para a determinação do antibiótico pirazinamida em amostras biológicas. Por meio de medidas de voltametria cíclica, utilizando a sonda redox $\left[\mathrm{Fe}(\mathrm{CN})_{6}\right]^{3-}$ e a equação de Nicholson, foram calculados os valores da constante heterogênea de transferência de elétrons $\left(k^{\circ}\right)$ de $3,8 \times 10^{-3}$ e $6,0 \times 10^{-4} \mathrm{~cm} \mathrm{~s}^{-1}$ para o ND/GCE e GCE, respectivamente. Os autores correlacionaram o maior valor de $k^{\circ}$ para o eletrodo modificado 
devido a um aumento na taxa de transferência de elétrons na interface eletrodo/solução, devido à presença dos ND na superfície. Além disso, foi observado um aumento da área eletroativa de 3,5 vezes maior comparada ao GCE, proporcionado maior sensibilidade para a determinação da pirazinamida.

Em outro trabalho, uma dispersão de ND em uma matriz de dihexadecil hidrogenofosfato foi utilizada para modificar um GCE e o novo sensor proposto foi aplicado na determinação eletroquímica de codeína em amostras farmacêuticas e biológicas ${ }^{31}$. Utilizando voltametria cíclica, foi observado um aumento na intensidade do pico de oxidação da codeína de quase duas vezes maior comparado ao GCE sem modificação.

Dai et $a l .{ }^{32}$ reportaram um eletrodo de diamante dopado com boro modificado com nanofolhas de níquel e ND para a determinação de glicose em amostras de soro humano. Para isso, os ND foram depositados na superfície do eletrodo de diamante dopado com boro e atuaram como locais de nucleação para a posterior eletrodeposição de níquel, e com isso a estrutura de rede do Ni-ND aumentou significativamente a área de contato entre o material ativo e o eletrólito. Sobre condições otimizadas, a resposta à glicose foi linear na faixa de 0,2 a $1055,4 \mu \mathrm{mol} \mathrm{L}-1$, com um LOD de $0,05 \mu \mathrm{mol} \mathrm{L}{ }^{-1}$.

Na literatura também se tem reportado a utilização desse material de carbono para o desenvolvimento de biossensores eletroquímicos para a quantificação dos mais diferentes analitos tais como glicose ${ }^{33}$, citocromo $\mathrm{c}^{34}$, peróxido de hidrogênio ${ }^{35}$, hemoglobina ${ }^{35}$, e catecol $^{36}$. Em linhas gerais, tem-se teorizado que os ND apresentam propriedades eletroquímicas úteis devido à presença de carbono $\mathrm{sp}^{2}$ e grupos oxigenados sobre sua estrutura externa. Como consequência, a maioria dos eletrodos modificados com ND apresenta um efeito de catálise no sinal desses analitos de interesse, atribuído ao deslocamento para valores menores de potencial e incremento de corrente de pico observado. Estas propriedades eletrocatalíticas/eletrônicas relatadas sugerem que os ND são potencialmente atraentes para a base de plataformas eletroquímicas de detecção.

\subsection{Nanopartículas metálicas}

MNPs são estruturas constituídas de átomos, cuja dimensão nanométrica, medida intermediária entre o tamanho do átomo e o sólido na forma estendida, confere-lhe propriedades eletrônicas, ópticas e químicas atraentes para as mais diversas aplicações industriais e científicas. Tais características seriam facilitação de transferência de elétrons, promoção de eletrocatálise, aumento de área superficial em relação ao material na escala 
macroscópica, condutividade elétrica e compatibilidade com materiais biológicos ${ }^{37}$. Já os setores em que elas têm sido amplamente aplicadas são: eletrônica, sensor, óptica, magnética, catalítica e até mesmo para fins biológicos (eg. administração controlada de medicamentos). Em termos tecnológicos, algumas motivações para a redução da escala macro para nano são o desenvolvimento de dispositivos com maior possibilidade de armazenamento de informações, miniaturização e/ou compactação com possibilidade de portabilidade para diferentes lugares e a utilização de menos materiais para a fabricação dos mesmos. Já em termos de estudos clínicos e saúde, possibilidade de inovação em novos veículos para princípio ativo de fármacos e tratamentos contra diferentes doenças, detecção de biomarcadores com métodos mais sensíveis, segurança alimentar e ambiental com maior controle e monitoramento de potenciais substâncias toxicológicas.

Como exemplos de MNPs têm-se as de prata (AgNPs), ouro (AuNPs), paládio (PdNPs), platina (PtNPs), níquel (NiNPs), rutênio (RuNPs), e entre outras. De modo geral, a síntese e/ou preparo pode ser categorizada de duas formas ${ }^{38}$ : o método físico (do inglês conhecido como top down), no qual há uma fragmentação das partículas da escala macroscópica até a nanométrica; e o método químico (do inglês conhecido como botton up), no qual se utiliza como precursores reagentes moleculares e atômicos e, a partir de reações químicas se obtêm produtos na escala desejada. Dentro dessas categorias, há muitos protocolos e técnicas de produção para a fabricação dessas nanopartículas utilizando uma gama de materiais e possibilitando a obtenção dos mais variados tamanhos e formas geométricas.

Como exemplo, um dos métodos mais empregados na literatura, para a obtenção de diversas NPs (eg. ouro, prata, platina, ródio) é o do citrato proposto por Turkevich et al. ${ }^{39}$, no qual, em condições controladas e meio aquoso, ocorre uma reação de óxido-redução entre o agente redutor citrato e o sal solúvel do cátion metálico de interesse. Neste método, o citrato funciona também como estabilizante, não sendo necessária adição de polímeros estabilizantes para maior controle do tamanho das partículas, o que torna um método simples com utilização de poucos reagentes.

Outro método também muito utilizado para a obtenção de diversas NPs (eg. ouro, platina, prata, paládio, rutênio e irídio), nesse caso, para ser realizado em meio orgânico, é do poliol, proposto por Fievet et al. ${ }^{40}$. O preparo das MNPs ocorre em três etapas: (I) dissolução do reagente precursor no meio orgânico, que pode ser etilenoglicol ou outro poliálcool; (II) em seguida, a redução do metal de interesse no meio orgânico; e por fim (III) ocorre a 
nucleação e crescimento das NPs. Como vantagens desse método, destacam-se: ausência de estabilizantes poliméricos, uma vez que o poliálcool atua como agente estabilizante, evitando aglomeração e crescimento descontrolado das NPs; os sais inorgânicos dos metais de interesse tem alta solubilidade nos poliálcoois, devido ao caráter polar dessas moléculas; e utilização de poucos reagentes, pois o poliálcool atua como agente redutor, solvente do meio reacional e passivante. Além disso, é importante destacar que este método é realizado em altas temperaturas, no caso do etilenoglicol, a $150^{\circ} \mathrm{C}$, pois é nesta temperatura que ele se oxida a glicoladeído e atua como agente redutor. Por se trabalhar em altas temperaturas, é maior a possibilidade de se obter produtos com maior cristalinidade.

No campo da eletroanalítica e eletroquímica inúmeros sensores têm sido propostos baseados em eletrodos convencionais modificados com MNPs para a determinação dos mais diferentes analitos ${ }^{41-45}$. Essas modificações podem ser feitas por eletrodeposição, pelo método do gotejamento (na qual um filme com NPs é formado sobre a superfície do eletrodo), ou até mesmo no caso de eletrodos compósitos NPs podem ser incorporadas no corpo desses. A seguir, alguns trabalhos serão descritos para exemplificar.

Goulart et $a l .{ }^{46}$ reportaram a determinação simultânea de hidroquinona, catecol, bisfenol-A e fenol em amostras de água de distribuição utilizando um GCE modificado com MWCNTs e AgNPs. Para isso, os MWCNTs foram depositados na superfície do GCE, e então, as AgNPs, eletrodepositadas sob o MWCNTs/GCE pela aplicação de 10 ciclos de varredura, a uma velocidade de varredura de potencial de $100 \mathrm{mV} \mathrm{s}^{-1}$, utilizando uma solução de AgNPs. Utilizando voltametria cíclica, picos de oxidação em $0,15 \mathrm{~V} ; 0,25 \mathrm{~V} ; 0,59 \mathrm{~V}$ e 0,67 $\mathrm{V}\left(v s . \mathrm{Ag} / \mathrm{AgCl}\left(\mathrm{KCl} \mathrm{3,0} \mathrm{mol} \mathrm{L}^{-1}\right)\right)$ foram obtidos para hidroquinona, catecol, bisfenol-A e fenol, respectivamente, o que possibilitou a determinação simultânea das moléculas. Utilizando o AgNPs/MWCNTs/GCE, observou-se um aumento de corrente de pico de oxidação para os diferentes analitos em relação ao MWCNTs/GCE, o que os autores atribuíram a rápida transferência de elétron promovida pela presença das AgNPs.

Raymundo-Pereira et al. ${ }^{44}$ utilizaram o método poliol para reduzir $\mathrm{Ag}^{+}$e formar AgNPs diretamente na superfície de nanoesferas do Printex L6 (um tipo de negro de fumo). Em seguida, 1,0 mg do material preparado, Printex L6-AgNPs, foi disperso em 1,0 mL de dimetilformamida e, $6 \mu \mathrm{L}$ dessa dispersão foram gotejados sob a superfície de um GCE $(\phi=$ $3.0 \mathrm{~mm}$ ). O sensor Printex L6-AgNPs/GCE foi utilizado para quantificar ácido gálico em amostras de vinho. Utilizando voltametria de pulso diferencial (DPV, do inglês "differential 
pulse voltammetry"), a faixa linear entre 0,50 e $8,5 \mu \mathrm{mol} \mathrm{L}{ }^{-1}$ foi encontrada, com um LOD de $66 \mathrm{nmol} \mathrm{L}{ }^{-1}$.

Kalambate et $a l^{47}$ propuseram um CPE modificado com nanofibras de carbono e AgNPs para determinação de maleato de metilergometrina (fármaco amplamente utilizado para interromper o sangramento do útero após o nascimento da criança) em amostras de formulações farmacêuticas, urina e soro sanguíneo. As AgNPs foram formadas diretamente nas nanofibras de carbono utilizando como agente redutor AA. O material AgNPs-nanofibras de carbono foi misturado com grafite e óleo mineral para a formação do CPE, e assim, a modificação proposta foi feita no corpo inteiro do eletrodo e não somente na superfície. Um

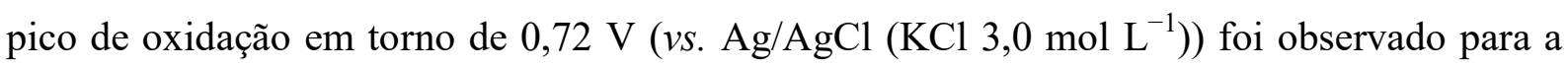
molécula do fármaco, sendo o maior valor de corrente obtido utilizando o AgNPs-nanofibras de carbono/CPE em comparação ao CPE sem modificação e ao CPE modificado com nanofibras de carbono. Utilizando DPV, a faixa linear entre 0,040 e $20 \mu \mathrm{mol} \mathrm{L^{-1 }}$ foi encontrada, com um LOD de 7,1 nmol L ${ }^{-1}$.

Como pode ser observado, alguns trabalhos têm sido reportados utilizando as AgNPs, devido as propriedades como biocompatibilidade, estabilidade em solventes orgânicos e aquosos, atividade catalítica, baixa toxicidade e condutividade ${ }^{48}$. Além disso, a síntese de AgNPs apresenta baixo custo de reagentes quando comparada a de outras nanopartículas metálicas (eg. AuNPs), sendo, extremamente interessante para ser explorada para o desenvolvimento de novos sensores eletroquímicos.

\subsection{Eletrodos compósitos}

Eletrodos compósitos foram definidos por Tallman and Petersen ${ }^{49}$ como "um material constituído de pelo menos uma fase condutora misturada a uma fase isolante". Esta fase isolante teria como função transformar a mistura em uma pasta compacta e consistente, sendo, portanto, hoje conhecida como aglutinante.

Algumas vantagens são observadas no uso desses eletrodos tais como estabilidade (principalmente em solventes não aquosos e aplicações em fluxo), resistência mecânica, melhoria da relação sinal/ruído (com consequente ganho nos LOD), relativa simplicidade e baixo custo de preparação.

Ainda, podem-se confeccionar eletrodos de diferentes tamanhos e formatos, incorporando uma variedade de modificadores no corpo do eletrodo e não somente na superfície, o que evita necessidade de novos modificadores a cada renovação de superfície. 
Dessa forma, para a renovação da superfície, é necessário apenas um simples polimento, e novamente tem-se a superfície eletródica com o modificador exposta.

$\mathrm{Na}$ literatura, muitos eletrodos compósitos têm sido reportados utilizando como material condutor o grafite, combinado com diferentes materiais aglutinantes como epóxi ${ }^{50}$,

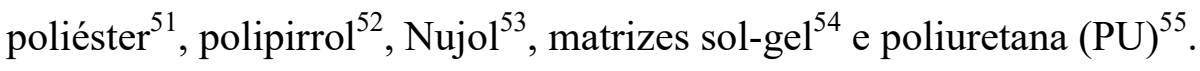

Nesse contexto, destaca-se o emprego da PU como aglutinante. A PU é um polímero formado a partir da polimerização de unidades de uretana (contendo o grupo funcional carbamato em sua estrutura $)^{56}$. Muito utilizado na área industrial para a fabricação de espumas flexíveis, rodas elastoméricas duráveis e pneus (como montanhas-russas, escadas rolantes, carrinhos de compras, elevadores e rodas de skate); revestimentos e selantes de superfície; peças de plástico duro (por exemplo, para instrumentos eletrônicos) e mangueiras ${ }^{57}$. Dentre algumas vantagens da PU usada neste trabalho, destacam-se:

- Ser um material sustentável, uma vez que é obtido do óleo de mamona;

- Cura à temperatura ambiente;

- Alta hidrofobicidade, o que a torna mais atrativa comparada a outras resinas para análise em meio aquoso. Como por exemplo, tem-se a resina epóxi, que devido ao seu caráter hidrofílico, em meio aquoso, pode ter efeito de inchaço, o que pode levar ao aumento da área geométrica do eletrodo e, consequentemente, em mudança na resposta eletroquímica do mesmo;

- Independência tecnológica, por ser produzida no Brasil;

- Material de baixo custo;

- Facilidade na renovação de superfície;

- Resistência em solventes orgânicos; e

- Facilidade na preparação, manuseio e moldagem.

Em 2002, Mendes et al. ${ }^{58}$ investigaram pela primeira vez o uso de resina PU à base de óleo vegetal para o preparo de um composto de grafite e possíveis aplicações voltamétricas deste eletrodo compósito. Para isso, diferentes quantidades de grafite foram misturadas com a resina PU, a fim de se obter 30, 40, 50, 60 e 70\% em massa do material condutor no compósito. Medidas de voltametria cíclica, a uma velocidade de varredura de potenciais de $100 \mathrm{mV} \mathrm{s}^{-1}$, para a sonda ferricianeto de potássio em solução de $\mathrm{KCl}$, evidenciaram que as respostas eletroquímicas dos eletrodos começaram a partir de 50:50\% (grafite:PU, $\mathrm{m} \mathrm{m}^{-1}$ ). As composições 50 a 70\% (grafite:PU, $\mathrm{m} \mathrm{m}^{-1}$ ) foram comparados nos critérios: valores de 
corrente de pico obtidos para o ferricianeto de potássio e correntes mais repetitivas entre renovações sucessivas da superfície, sendo o eletrodo 60:40\% (grafite:PU, $\mathrm{m} \mathrm{m}^{-1}$ ) com os melhores valores. Inspirado nos resultados obtidos utilizando-se a composição 60:40\% (grafite:PU, $\mathrm{m} \mathrm{m}^{-1}$ ) e a voltametria cíclica, o eletrodo foi utilizado para detecção de catecol em $\mathrm{H}_{2} \mathrm{SO}_{4} \quad 0,10 \mathrm{~mol} \mathrm{~L}^{-1}$ e hidroquinona em tampão acetato $0,10 \mathrm{~mol} \mathrm{~L}^{-1}$ (pH 4,0), comparando-se os dados obtidos com o GCE sob mesmas condições. Foram reportadas menores correntes capacitivas com maiores valores de corrente de pico para os analitos estudados em relação ao GCE.

A partir desses estudos, muitos trabalhos foram propostos utilizando eletrodos à base de grafite:PU (GPU), na condição otimizada $\left(60: 40 \%, \mathrm{~m} \mathrm{~m}^{-1}\right)$, para aplicações eletroquímicas e eletroanalíticas, sendo alguns descritos a seguir.

Em 2006, Mendes et al. ${ }^{59}$ avaliaram a resposta voltamétrica do eletrodo compósito GPU em DPV na determinação de hidroquinona em reveladores fotográficos. O LOD de 66 nmol L ${ }^{-1}$ foi observado para hidroquinona dentro da faixa linear de 66 a $530 \mathrm{nmol} \mathrm{L}^{-1}$. A determinação da hidroquinona em amostras de reveladores fotográficos mostrou uma concordância com os valores rotulados.

Em 2008, Cervini et al. ${ }^{60}$ utilizaram o eletrodo compósito GPU como detector amperométrico para análise em fluxo para a determinação de paracetamol em formulações farmacêuticas. Uma curva analítica foi obtida no intervalo de 0,050 a $50 \mathrm{mmol} \mathrm{L}^{-1}$ com um LOD de $0,019 \mathrm{mmol} \mathrm{L}^{-1}$. Os resultados obtidos estão de acordo com os alcançados empregando-se o método de cromatografia líquida de alta eficiência, dentro de um nível de confiança de $95 \%$.

Em 2012, Calixto et al. ${ }^{61}$ avaliaram o eletrodo compósito GPU na determinação do antibiótico tetraciclina em amostras de água natural, em DPV, obtendo um LOD de 2,8 $\mu \mathrm{mol}$ $\mathrm{L}^{-1}$, sem necessidade de renovação da superfície. Foram obtidas recuperações entre $92,6 \%$ e $100 \%$, após as etapas de pré-concentração.

A partir de 2009, os eletrodos à base do compósito GPU começaram a ser desenvolvidos com diferentes modificadores (eg. polímeros molecularmente impressos, nanoestruturas de carbono, óxidos de grafite, MNPs), com o intuito de se buscar melhores parâmetros analíticos (eg. baixos LOD, maiores sensibilidades e seletividade). Em adição, a possibilidade de incluir modificadores não somente na superfície, mas também no corpo do eletrodo, viabilizou a fabricação de novos sensores eletroquímicos. 
Em 2009, a preparação de um polímero metracrilato moleculamente impresso com paracetamol foi proposto por Cervini et $a l^{62}$. Diferentes quantidades do polímero foram incorporadas a um eletrodo compósito GPU, variando-se de 2,5 a $10 \%$ da massa total do eletrodo. O sensor desenvolvido e DPV foram utilizados para a determinação de paracetamol em formulações farmacêuticas, obtendo-se um LOD de $0,67 \mathrm{nmol} \mathrm{L}^{-1}$.

Em 2016, Santos et al. ${ }^{63}$ reportaram o desenvolvimento de um eletrodo compósito à base de MWCNTs:PU para a determinação de hidroquinona em amostras de cosméticos. Para isso, diferentes proporções do eletrodo compósito à base de MWCNTs:grafite:PU (60:0:40\%, $45: 15: 40 \%, 30: 30: 40 \%, 15: 45: 40 \%$ e $0: 60: 40 \% ; \mathrm{m} \mathrm{m}^{-1}$ ) foram avaliados por voltametria cíclica para a resposta eletroquímica de hidroquinona em tampão acetato $0,10 \mathrm{~mol} \mathrm{~L}^{-1}(\mathrm{pH}$ 4,0), a uma velocidade de varredura de potencial de $50 \mathrm{mV} \mathrm{s}^{-1}$. Com o aumento de massa de MWCNTs no compósito houve um incremento na corrente de pico e uma diminuição na separação dos potenciais de pico, sendo os melhores resultados alcançados com o eletrodo compósito à base de MWCNTs:PU (60:40\%, $\mathrm{m} \mathrm{m}^{-1}$ ). A hidroquinona foi determinada utilizando a DPV e o eletrodo otimizado, obtendo-se uma faixa linear de 0,050 a $1,1 \mathrm{mmol}$ $\mathrm{L}^{-1}$ e um LOD de $12 \mu \mathrm{mol} \mathrm{L}{ }^{-1}$.

Em 2019, Wong et al. ${ }^{64}$ desenvolveram um eletrodo à base de óxido de grafite-PU modificado com $\beta$-ciclodextrina para a determinação simultânea de três fármacos: terbutalina, nimesulida e metocarbamol, como possíveis contaminantes em amostras de rio. Em condições otimizadas, usando a voltametria de onda quadrada (SWV, do inglês "square wave voltammetry", as faixas lineares obtidas (e o LOD) para terbutalina, nimesulida e metocarbamol foram de 2,5 a $30(0,55), 0,62$ a 7,3 (0,083) e 0,62 a 7,3 $(0,077) \mu \mathrm{mol} \mathrm{L} \mathrm{L}^{-1}$, respectivamente. O método desenvolvido foi aplicado na determinação simultânea dos analitos em amostras de rio, com resultados similares àqueles obtidos pelo método espectrofotométrico de referência (com nível de confiança de 95 \%).

No mesmo ano, Matiolli et al. ${ }^{43}$ eletrodepositaram AuNPs sobre a superfície de um eletrodo compósito GPU e compararam a sua resposta voltamétrica com um eletrodo GPU sem modificação para a determinação de triptofano. Medidas de espectroscopia de impedância eletroquímica mostraram que a modificação com as AuNPs reduz a resistência à transferência de elétrons. Estes dados corroboram os resultados obtidos de voltametria cíclica, na qual é possível observar maior incremento de corrente de pico anódico e menores valores de potencial para oxidação do triptofano utilizando o eletrodo modificado. O eletrodo 
proposto foi utilizado para a determinação do triptofano em amostra de urina sintética e suplemento comercial de poli-aminoácidos.

\subsection{Eletrodos impressos}

A impressão serigráfica, também conhecida como a tecnologia "screen-printing" ou "silk-screen" 65 tem sido amplamente utilizada para a fabricação de eletrodo impresso (SPE, do inglês "screen printed electrode"), possibilitando o desenvolvimento de uma infinidade de sensores. A simplicidade dessa técnica possibilita uma produção em larga escala desses eletrodos, a qual pode ser executada em qualquer laboratório, utilizando materiais de baixo custo. Um dos principais aspectos dos SPE é a possibilidade de um sistema integrado contendo os eletrodos de trabalho, auxiliar e referência, todos impressos em único suporte. Somado a isso, eles podem ser descartáveis, o que elimina a necessidade de regeneração da superfície eletródica com etapas de limpeza e polimento, minimizando tempo de preparo do eletrodo e possibilitando a condução de vários estudos em único dia.

Outra característica desses dispositivos que chama a atenção é a possibilidade de portabilidade, o que viabiliza a sua aplicação nas mais diversas áreas, podendo ser utilizado para análises clínicas (eg. monitoramento de biomarcadores para alguma doença específica), monitoramento de substâncias tóxicas em amostras ambientais e até aplicações industriais (eg. monitoramento de efluentes e controle de qualidade de bebidas). Ainda, com o avanço da tecnologia foi possível a automação de fabricação desses dispositivos, podendo hoje já se encontrar formas comerciais disponíveis de diferentes fabricantes.

Kadara et $a l .{ }^{66}$ avaliaram eletroquimicamente e caracterizaram a superfície de seis diferentes SPE comerciais, com suas tintas à base de carbono, das marcas Zensor ${ }^{\circledR}$ (Taiwan), Dropsens ${ }^{\circledR}$ (Espanha) e Kanichi ${ }^{\circledR}$ (Inglaterra), disponíveis para aplicações na área acadêmica e industrial. Uma relação entre a rugosidade do eletrodo e a facilitação de transferência de elétrons foi observada, sugerindo que uma superfície áspera pode expor mais planos de bordas e defeitos desses materiais de carbono, o que leva a uma transferência de elétrons mais rápida na interface eletrodo/solução (evidenciado pelo cálculo de $k^{\circ}$ ). Em resumo, os autores observaram diferentes respostas eletroquímicas para a sonda eletroquímica ferrocianeto de potássio utilizando as diferentes plataformas.

Apesar da possibilidade de comprar comercialmente esses SPE, muitas vezes eles apresentam um alto custo e, em geral, é difícil obter informações exatas a respeito da formulação das tintas, uma vez que maioria é patenteada. Assim, muitos trabalhos têm sido 
reportados utilizando eletrodos de fabricação própria (também conhecidos como "home made"). Além disso, para minimizar ainda mais os custos de fabricação desses sensores, diferentes materiais estão sendo utilizados como suporte inerte para aplicação da tinta de carbono condutora, tais como $\mathrm{PVC}^{67}$, poliéster ${ }^{68}$, papel $^{69}$ e polietileno tereftalato (PET) de garrafas de bebidas ${ }^{70}$. Todos são elegantes em sua abordagem e evidenciam a potencialidade de se desenvolver SPE com materiais de baixo custo comparado aos comerciais, cuja maioria utiliza cerâmica. Considere-se, ainda, o benefício de alguns utilizarem, como suporte da tinta, materiais recicláveis.

Aliado a este fato, tem-se a possibilidade de incorporação de modificadores na superfície do SPE e/ou também na composição da tinta de fabricação, o que promove uma variedade de novos sensores eletroquímicos a serem propostos.

Nesse contexto, nanomateriais de carbono, como grafeno, CNTs, negro de fumo, entre outros, são muito explorados para o desenvolvimento de SPE. Muitas vezes a presença desses materiais na superfície eletródica leva a uma facilitação de transferência de elétrons e, como consequência, pode proporcionar maiores sinais analíticos ou até mesmo a determinação de analitos em potenciais de trabalhos menores comparados àqueles utilizando outros eletrodos. Para exemplificar, tem-se alguns trabalhos reportados na literatura que evidenciam essas melhoras analíticas para os mais diferentes analitos utilizando SPE modificados com nanomateriais carbonáceos, sendo alguns descritos a seguir.

Jahani et $a l{ }^{71}$ propuseram um SPE modificado com folhas de grafeno e nanopartículas de óxido de níquel para determinação de DA na presença de UA em amostras farmacêuticas. Inicialmente, utilizando a voltametria cíclica, foi observado um pico de oxidação para a DA em $250 \mathrm{mV}$ (vs. pseudo referência de $\mathrm{Ag} / \mathrm{AgCl}$ ) utilizando o SPE, enquanto para grafeno/SPE esse pico foi observado em $90 \mathrm{mV}$ (vs. pseudo referência de $\mathrm{Ag} / \mathrm{AgCl}$ ). Essa diminuição significativa de $160 \mathrm{mV}$ no potencial de oxidação indica, que a transferência de elétrons foi facilitada pela presença das folhas de grafeno. Já para o caso do grafeno/NiO/SPE foi observado um pico em $90 \mathrm{mV}$ (vs. pseudo referência de $\mathrm{Ag} / \mathrm{AgCl}$ ), porém quando se compara as correntes de pico anódicas obtidas utilizando os três eletrodos foi encontrada a seguinte ordem crescente: $\mathrm{SPE}<$ grafeno/SPE $<$ grafeno/NiO/SPE, indicando que a combinação de grafeno e $\mathrm{NiO}$ melhorou significativamente o desempenho do eletrodo em relação à oxidação da DA. Além disso, uma separação de pico de $150 \mathrm{mV}$ (vs. pseudo referência de $\mathrm{Ag} / \mathrm{AgCl}$ ) entre DA e UA foi observada utilizando-se o grafeno/NiO/SPE, o que viabilizou a determinação simultânea das duas moléculas. 
Li et al. ${ }^{72}$ descreveram um SPE descartável modificado com MWCNTs e AuNPs, para a determinação simultânea de hidroquinona, catecol e resorcinol. Os comportamentos eletroquímicos das moléculas de interesse nos sensores: SPE, AuNPs/SPE, MWCNTs/SPE e AuNPs/MWCNTs/SPE foram estudadas utilizando a voltametria cíclica. No SPE e AuNPs/SPE foi observado um pico de oxidação em 0,40 V (vs. $\mathrm{Ag} / \mathrm{AgCl}\left(\mathrm{KCl} \mathrm{3,0} \mathrm{mol} \mathrm{L}^{-1}\right)$ ) correspondente à sobreposição dos sinais analíticos da hidroquinona e do catecol, e em $0,60 \mathrm{~V}$ correspondente ao resorcinol. Já no MWCNTs/SPE, três picos de oxidação bem definidos são observados nos potenciais de 0,$050 ; 0,15$ e $0,54 \mathrm{~V}$, correspondentes à oxidação da hidroquinona, catecol e resorcinol, respectivamente. A presença dos MWCNTs permitiu a separação dos sinais analíticos dos analitos de interesse, bem como sua determinação simultânea. Para o AuNPs/MWCNTs/SPE, foram observados os mesmos potenciais de oxidação, porém com um incremento de corrente para as diferentes moléculas, o que pode ser justificado pela presença das AuNPs, as quais promovem sítios ativos na superfície do eletrodo e facilitam a transferência de elétrons.

Em outro trabalho, um SPE modificado com negro de fumo para a determinação amperométrica de cloreto em águas de piscina foi proposto por Tomei et al. ${ }^{73}$ A modificação foi feita a partir do método de deposição (do inglês "drop casting"), o qual permitiu um preparo em massa de SPE modificados. Com o sensor proposto foi possível detectar uma faixa linear entre 0,050 e 200 ppm de cloreto, com um LOD de 0,010 ppm, o que está abaixo do recomendado pela Organização Mundial da Saúde (WHO, do inglês "World Health Organization"), entre 3 e 5 ppm em águas de piscina. Neste trabalho obteve-se um SPE modificado com um material de carbono de baixo custo, rentável, possível de produzir em bateladas, com a possibilidade de ser usado fora do laboratório juntamente com um potenciostato portátil para o monitoramento de cloreto em águas de piscina.

Até o presente momento nenhum SPE modificado com ND foi explorado para aplicações eletroquímicas.

\subsection{Analitos investigados neste trabalho}

\subsubsection{Escitalopram}

O uso de antidepressivos está crescendo constantemente em todo o mundo, impulsionado principalmente pelo aumento de pessoas com transtornos depressivos e de ansiedade, estimado ter ultrapassado 320 milhões de pessoas (equivalente a $4,4 \%$ da população mundial) em 2015, segundo um relatório divulgado pela $\mathrm{WHO}^{74}$. No Brasil, 
segundo dados publicados pela WHO em 2015, 11.548 .577 de pessoas (equivalente a 5,8\% da população), foram diagnosticadas com transtornos depressivos e 18.657 .94 com transtornos de ansiedade (equivalente a $9,3 \%$ da população) ${ }^{74}$. Também corrobora um levantamento feito pela companhia de seguro SulAmérica, no qual se constatou um aumento de $74 \%$ do número de antidepressivos adquiridos entre 2010 e 2016, indo de 35.453 a 61.859 unidades.

Os antidepressivos são uma classe de compostos farmacêuticos utilizados para o alívio de sintomas característicos do transtorno de humor. Em outras palavras, são drogas que aumentam o tônus psíquico melhorando o humor e, consequentemente, o conforto emocional e o desempenho de maneira global do paciente. Dentre as classes de antidepressivos, a de inibidores seletivos da recaptura de serotonina ${ }^{75}$, tem sido bastante utilizada no Brasil.

A serotonina é um neurotransmissor envolvido na comunicação dos neurônios, associada à regulação do humor, das emoções, do sono e do apetite. Os inibidores seletivos de recaptura de serotonina agem impedindo a retirada da serotonina da fenda sináptica, local onde este neurotransmissor exerce suas ações, consequentemente há um aumento da concentração extracelular do neurotransmissor disponível para se ligar ao receptor póssináptico $^{76}$.

Um exemplo de substância dessa classe é o escitalopram (cuja fórmula estrutural do sal de oxalato é apresentada na Figura 2). Este enantiômero $S(+)$ do citalopram (um racemato $R, S$ ), é mais eficaz que o citalopram, sendo usado no tratamento de depressão e transtornos de ansiedade ${ }^{77,78}$. Este composto é extremamente seletivo em relação às proteínas de transporte serotonérgicas, quando comparado com outros antidepressivos, como fluoxetina, paroxetina, fluvoxamina ou sertralina ${ }^{79}$. Em muitos estudos foi observado que os fármacos antidepressivos também apresentam atividade analgésica ${ }^{80}$. No entanto, o escitalopram e o citalopram podem causar reações efeitos colaterais como diarreia, sonolência, dor de cabeça, insônia e náuseas ${ }^{81}$. Assim em função desses efeitos, o desenvolvimento de métodos específicos para sua determinação é extremamente importante na pesquisa farmacêutica. 


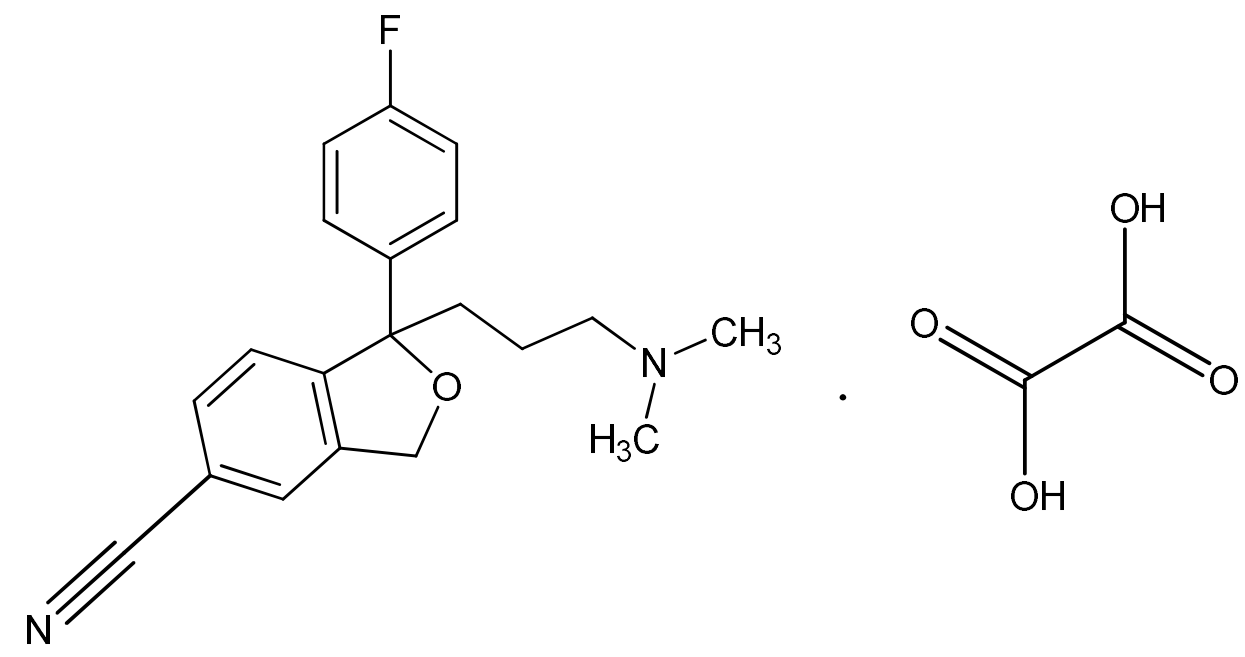

Figura 2. Representação da molécula de oxalato de escitalopram.

Alguns métodos têm sido descritos para a determinação de escitalopram em amostras farmacêuticas e biológicas. A maioria deles utiliza a cromatografia líquida de alta eficiência ${ }^{82-}$ ${ }^{84}$, espectrometria ${ }^{85-87}$, ou eletroforese capilar ${ }^{88,77}$. Na literatura, poucos trabalhos reportaram a utilização de técnicas eletroanalíticas. Alarjaf et al. ${ }^{89}$ descreveram um método capaz de realizar 200 e 164 quantificações de escitalopram por hora, utilizando a injeção em fluxo, com um detector de quimiluminescência ou quimiluminescência eletrogerada, respectivamente.

Em 2013, Al-Amri et al. ${ }^{90}$ reportaram um método potenciométrico utilizando três diferentes classes de eletrodo de trabalho: de membrana polimérica, de fio de alumínio e de fio de grafite, para a determinação de escitalopram em amostras farmacêuticas e fluidos biológicos. As regiões lineares de concentração encontradas foram de 1,0 a $10000 \mu \mathrm{mol} \mathrm{L}^{-1}$, de 1,0 a $10000 \mu \mathrm{mol} \mathrm{L}{ }^{-1}$ e de 0,10 a $10000 \mu \mathrm{mol} \mathrm{L}{ }^{-1}$, para os três sensores, respectivamente.

No mesmo ano, Jain et al. ${ }^{91}$ desenvolveram um sensor baseado na modificação de um GCE com nanopartículas de óxido de bismuto (III) para a quantificação de escitalopram em formulações farmacêutica. Utilizando a SWV, uma faixa linear entre 150 e $400 \mathrm{mg} \mathrm{mL}^{-1}$ foi obtida para a determinação de escitalopram em tampão fosfato $\mathrm{pH}$ 2,0, com um LOD de 53,57 $\mu \mathrm{g} \mathrm{mL} \mathrm{L}^{-1}$.

Em 2017, Attia et al. ${ }^{92}$ propuseram um CPE modificado com NiNPs, por eletrodeposição, para determinação de escitalopram em formulações farmacêuticas e urina. Utilizando a DPV e tampão Britton-Robinson ( $\mathrm{pH} 7,0)$, uma faixa linear de concentração entre 1,0 e $70 \mu \mathrm{mol} \mathrm{L}^{-1}$ (equivalente a 0,41 a $29 \mu \mathrm{g} \mathrm{mL}^{-1}$ ) foi obtida, com um LOD de 0,20 $\mu \mathrm{mol} \mathrm{L}{ }^{-1}$. 
$\mathrm{Na}$ literatura também foram reportados sensores para a quantificação de citalopram (a mistura racêmica $R, S$ ). Gholivand et al. ${ }^{93}$ descreveram um GCE modificado com MWCNTs em um filme de poli (ácido $p$-aminobenzeno sulfônico) $/ \beta$-ciclodextrina para a determinação de citalopram em amostras farmacêuticas e fluidos biológicos. Utilizando a DPV sob condições otimizadas, obtiveram-se as faixas lineares entre 0,090 e $1,0 \mu \mathrm{mol} \mathrm{L}{ }^{-1}, 1,0$ e 11 $\mu \mathrm{mol} \mathrm{L}{ }^{-1}$ e 11 e $100 \mu \mathrm{mol} \mathrm{L}{ }^{-1}$, com um LOD de $44 \mathrm{nmol} \mathrm{L}{ }^{-1}$. Em outro trabalho, Ghaedi et al. ${ }^{94}$ reportaram um CPE modificado com NPs de óxido de zinco e MWCNTs para a determinação eletroquímica de citalopram em amostra de soro humano, urina e formulação farmacêutica. Utilizando a SWV adsortiva, foi obtida uma faixa linear de 0,012 a 1,5 $\mu \mathrm{mol}$ $\mathrm{L}^{-1}$, com um LOD de 5,0 $\mathrm{nmol} \mathrm{L}{ }^{-1}$.

\subsubsection{Dopamina}

A DA é uma das dezenas de neurotransmissores, sintetizada em algumas regiões do cérebro humano, responsável por transportar sinais de uma célula nervosa para outra. É popularmente conhecida como o neurotransmissor do "bem-estar", uma vez que está associada às respostas de prazer e busca por realizações, sejam elas profissionais, físicas, motivacionais, entre outras. No corpo humano, ela desempenha diversas funções, são alguns exemplos: armazenamento de memória e aprendizagem; controle da coordenação motora; alívio de dor física e/ou emocional; desejos e prazeres alimentares, níveis de sono e atenção ${ }^{95,96}$. Foi demonstrado que níveis anormais de DA são indicadores-chave associados a certas doenças neurológicas, como Parkinson, depressão e Alzheimer. Como resultado disso, algumas pesquisas têm se concentrado em desenvolver métodos mais rápidos, precisos e com baixos LOD para a quantificação de DA. Muitos estudos reportam a detecção eletroquímica de DA em amostras biológicas, como pode ser encontrado nesta revisão descrita por Mansha et al. ${ }^{97}$.

Técnicas de detecção eletroquímica trazem como vantagem a possibilidade do desenvolvimento de sensores de baixo custo, portáteis e sensibilidade analítica para uma variedade de analitos-alvo. Existe, no entanto, um problema inerente ao uso de técnicas eletroanalíticas para a determinação de DA em amostras biológicas, que seria a presença de UA, uma vez que os sinais eletroquímicos destas moléculas podem sobrepor-se, e, consequentemente, levar a uma interpretação errada dos dados. Assim, os pesquisadores estão constantemente explorando diferentes técnicas e materiais capazes de separar esses sinais analíticos. Na Figura 3 estão representadas as fórmulas estruturais da DA e do UA. 
(A)

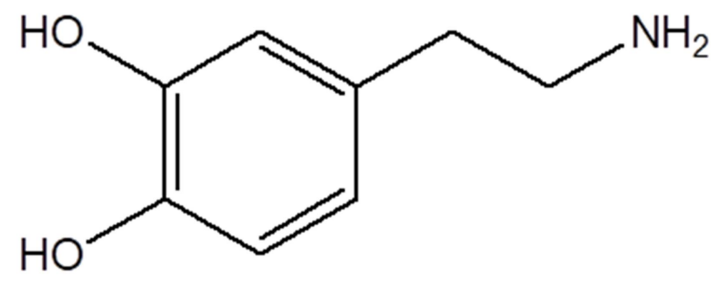

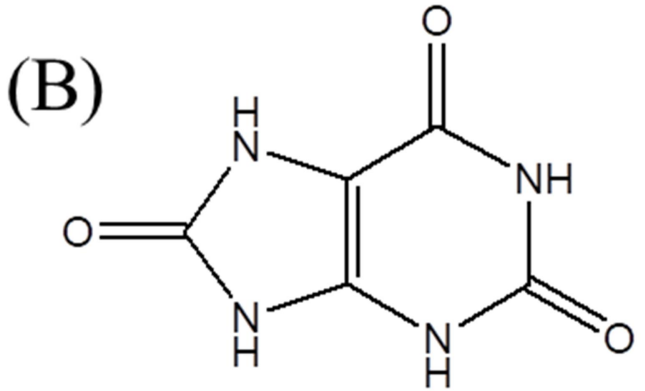

Figura 3. Representação das moléculas de dopamina (A) e ácido úrico (B).

Muitos trabalhos utilizando eletrodos modificados com materiais de carbono para a determinação de DA na presença de UA foram reportados ${ }^{98-100,71,101}$. Um exemplo foi o GCE modificado com uma dispersão de quitosana e grafeno proposto por Han et al. ${ }^{99}$ para a determinação simultânea de AA, DA e UA. Utilizando a DPV, as curvas analíticas obtidas (e os valores de LOD) foram lineares nas faixas de concentração de 50 a $1200 \mu \mathrm{mol} \mathrm{L}^{-1}$ para AA $\left(50 \mu \mathrm{mol} \mathrm{L}{ }^{-1}\right), 1,0$ a $24 \mu \mathrm{mol} \mathrm{L}-1\left(1,0 \mu \mathrm{mol} \mathrm{L}{ }^{-1}\right)$ para DA e 2,0 a $45 \mu \mathrm{mol} \mathrm{L}-1(2,0 \mu \mathrm{mol} \mathrm{L}-1)$ para UA. Em outro, Jahani et al. $^{71}$ reportaram um SPE modificado com grafeno e NPs de óxido de níquel para a determinação de DA e UA. O sensor desenvolvido proporcionou separação de pico de $150 \mathrm{mV}$ entre os sinais analíticos das moléculas estudadas. Dessa forma, a determinação de DA na presença de UA foi realizada e a faixa de concentração linear obtida para DA foi entre 1,0 e $500,0 \mu \mathrm{mol} \mathrm{L}-1$ com LOD de $0,31 \mu \mathrm{mol} \mathrm{L}-1$.

Com as novas estruturas de carbono emergentes, como o ND, seria uma alternativa interessante a ser explorada a utilização desses materiais na fabricação de novos sensores eletroquímicos que tenham por finalidade a distinção do sinal eletroquímico da DA na presença de UA e, consequentemente, para o desenvolvimento de um método analítico sensível para a quantificação deste importante neurotransmissor.

\subsubsection{Bisfenol-A}

O descarte de inúmeros compostos no meio ambiente tem despertado muitos estudos, dentre eles os desreguladores endócrinos, dentre os quais se destaca o bisfenol-A. Sua estrutura molecular contém dois grupos fenóis (Figura 4) e é um produto químico amplamente utilizado em escala industrial na produção de resinas epóxi, poliéster, plásticos de policarbonato, revestimento de embalagens metálicas, fabricação de utensílios domésticos, brinquedos e até mesmo mamadeiras ${ }^{102}$. Estudos evidenciaram que resíduos da molécula 
podem ser liberados desses produtos citados, principalmente se forem aquecidos. Dessa forma, devido à facilidade de encontrar esta substância química em diferentes produtos de consumo do dia-a-dia e a possibilidade de ingestão da mesma, o bisfenol-A tem sido alvo de muitas discussões e pesquisas sobre os seus efeitos à saúde das pessoas.

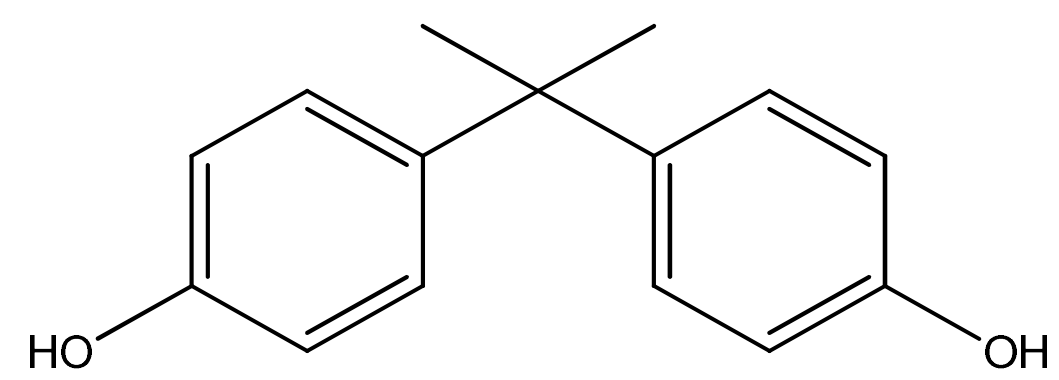

Figura 4. Representação da molécula de bisfenol-A.

Em 2008, Lang et al. ${ }^{103}$ correlacionaram concentrações mais altas de bisfenol-A em amostras de urina de adultos a problemas cardíacos, diabetes e complicações hepáticas. Em outros estudos científicos, a presença do composto foi relacionada a danos ao fígado ${ }^{104}$, bloqueio de receptores do hormônio da tireoide ${ }^{105}$, disruptor endócrino ${ }^{106}$ e de células pancreáticas $^{107}$, riscos de obesidade ${ }^{108}$, além de alguns tipos de câncer. Nesse contexto, temse, também, uma preocupação com mulheres gestantes, uma vez que em alguns estudos foi possível constatar o aumento de chances de aborto, restrição ao crescimento intrauterino e nascimento prematuro devido à exposição ao composto ${ }^{106}$.

Soma-se, ainda, a possibilidade de contaminação ambiental decorrente de dejetos industriais, além de despejo do composto por meio de lixo doméstico e/ou tratamento de esgoto e degradação natural de materiais plásticos ${ }^{106,109}$. Devido à sua produção industrial em larga escala, altos níveis de concentração do bisfenol-A são constantemente encontrados no meio ambiente, a partir das diferentes fontes de contaminação citadas. A maior concentração de bisfenol-A está em águas residuárias e naturais, devido a sua solubilidade de $300 \mathrm{mg} \mathrm{L}^{-1}$ $\left(25^{\circ} \mathrm{C}\right)$ em meio aquoso ${ }^{109}$. Sendo assim, devido a abrangente presença deste composto nos mais diferentes processos industriais e sua potencial toxicidade ao meio ambiente, aos animais e a saúde humana, é essencial o monitoramento contínuo do composto em produtos comerciais, bem como também em amostras ambientais. Alguns trabalhos utilizando métodos eletroquímicos exemplificam a determinação do composto nas mais diferentes amostras.

Um sensor eletroquímico baseado em um GCE modificado com grafeno e AuNPs foi desenvolvido para a determinação de bisfenol-A em amostras de mamadeiras infantis ${ }^{110}$. 
Utilizando a voltametria de varredura linear, foi obtida uma faixa linear de 0,080 a $250 \mu \mathrm{mol}$

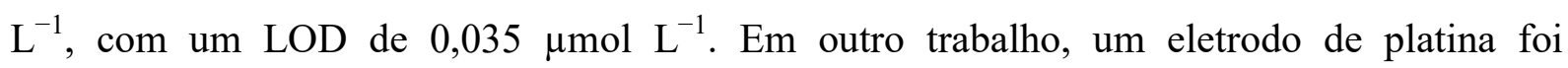
modificado com um nanocompósito de grafeno-CNTs para a determinação de bisfenol-A em papel de impressão térmica ${ }^{111}$. Sob condições otimizadas, utilizando a DPV, obteve-se uma faixa linear de 0,060 a $10 \mu \mathrm{mol} \mathrm{L}{ }^{-1}$ com um LOD de $0,042 \mu \mathrm{mol} \mathrm{L}^{-1}$. Yin et al. ${ }^{112}$ propuseram um GCE modificado com nanopartículas magnéticas de $\mathrm{Fe}_{3} \mathrm{O}_{4}$ em uma matriz de poli(amidoamina) para a quantificação do composto em amostras de leite. Utilizando amperometria foi possível obter uma faixa linear de 0,010 a $3,1 \mu \mathrm{mol} \mathrm{L} \mathrm{L}^{-1}$ com um LOD de

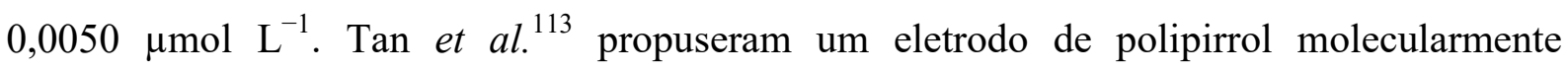
impresso modificado com quantum dots de grafeno para a determinação de bisfenol-A em água de mar e água potável engarrafada em plástico. Por meio da DPV, foi possível obter uma faixa linear de 0,10 a $50 \mu \mathrm{mol} \mathrm{L}{ }^{-1}$ com um LOD de $0,040 \mu \mathrm{mol} \mathrm{L} \mathrm{L}^{-1}$. 


\subsection{OBJETIVOS GERAIS}

O objetivo deste trabalho de tese é desenvolver novos eletrodos compósitos dos tipo convencional e impresso, modificados com nanoestruturas de carbono e MNPs, e em um segundo momento, explorar possíveis aplicações eletroanalíticas para os mesmos. 


\section{CAPÍTULO 2}

Estudo comparativo do desempenho dos eletrodos GPU, GPU-GR e GPU-CNTS na determinação de escitalopram em amostras biológicas sintéticas 


\subsection{OBJETIVOS ESPECÍFICOS}

Preparar três eletrodos compósitos à base de GPU: um sem modificação, um modificado com CNTs e um outro modificado com grafeno.

Caracterizar os compósitos preparados e avaliar a resposta eletroquímica de cada um dos eletrodos propostos para o antidepressivo escitalopram.

Desenvolver um método eletroquímico para a determinação de escitalopram em amostras biológicas sintéticas (urina e fluido cérebro-espinal). 


\subsection{MATERIAL E MÉTODOS}

\subsubsection{Reagentes}

Todas as soluções foram preparadas com água purificada em um sistema Barnstead ${ }^{\circledR}$ (resistividade $\geq 18,0 \mathrm{M} \Omega \mathrm{cm}$ ). Para as medidas eletroquímicas utilizou-se tampão BrittonRobinson ( $\mathrm{pH}=6,3$ ) como eletrólito suporte, preparado com ácido acético, $\mathrm{H}_{3} \mathrm{PO}_{4} \mathrm{e}_{3} \mathrm{BO}_{3}$, e força iônica ajustada com $\mathrm{KCl}$ (Sigma-Aldrich), para $0,10 \mathrm{~mol} \mathrm{~L}^{-1}$.

Escitalopram, DA, AA, UA, creatinina e $\mathrm{K}_{3}\left[\mathrm{Fe}(\mathrm{CN})_{6}\right]$ (Sigma-Aldrich) foram utilizados como recebidos. Pó de grafite $(<20 \mu \mathrm{m})$ e MWCNTs $(90 \%$ de pureza, $110-170 \mathrm{~nm}$ de diâmetro e 5-9 $\mu \mathrm{m}$ de comprimento), foram obtidos da Sigma Aldrich. O pó de grafeno (sintetizado pelo método de deposição química a vapor, 100-300 nm) foi adquirido da Star BioScience, sem tratamento prévio. A resina poliuretana de origem vegetal foi obtida da Poliquil (Araraquara-SP-Brasil). Os reagentes precursores utilizados para obtenção da resina poliuretana foram o pré-polímero (A-249) e o poliol (B-471). Todos os demais reagentes foram de grau analítico e usados tais como recebidos.

Diariamente, antes das medidas eletroquímicas, uma solução estoque de escitalopram $1,0 \times 10^{-2} \mathrm{~mol} \mathrm{~L}^{-1}$ foi preparada pela dissolução de uma massa dessa substância em tampão Britton-Robinson $0,10 \mathrm{~mol} \mathrm{~L}^{-1}(\mathrm{pH}=6,3)$. Quando necessário, eram realizadas diluições a partir dessa solução estoque.

\subsubsection{Instrumentação}

\subsubsection{Espectroscopia Raman}

As medidas de Espectroscopia Raman foram feitas em um sistema Renishaw 2000 com laser azul $(\lambda=488 \mathrm{~nm})$, para verificar as mudanças na estrutura dos CNTs após a funcionalização.

\subsubsection{Medidas de ângulo de contato}

Medidas de ângulo de contato foram obtidas utilizando um sistema HTM Reetz (modelo DSAHT-12) com o software DSA 3 Image. Para isso, $10 \mu \mathrm{L}$ de água deionizada foram gotejadas sobre a superfície dos compósitos de GPU, GPU-GR e GPU-CNTs. As medidas foram feitas em triplicatas para cada compósito. 


\subsubsection{Microscopia eletrônica de varredura}

Imagens de microscopia eletrônica de varredura (SEM, do inglês Scanning Electron Microscopy) da superfície polida e fraturada dos compósitos GPU, GPU-GR e GPU-CNTs foram obtidas utilizando o equipamento Zeiss LEO 440 (modelo 7060), operando com feixe de elétrons de $20 \mathrm{kV}$.

\subsubsection{Técnicas voltamétricas e cronocoulométricas}

As medidas eletroquímicas foram realizadas em um potenciostato/galvanostato Autolab PGSTAT30 (Eco Chemie), acoplado a um microcomputador controlado pelo software NOVA 2.1.3. Para os voltamogramas de SWV e DPV obtidos foram feitas correções da linha base pelo método do "moving average" (com "peak width": 0,003).

A célula eletroquímica utilizada foi um sistema convencional com compartimento único e tampa de teflon com orifícios para encaixe de três eletrodos. Uma alíquota de $10,0 \mathrm{~mL}$ de eletrólito suporte tampão Britton-Robinson $0,10 \mathrm{~mol} \mathrm{~L}^{-1}, \mathrm{pH}=6,3$, foi utilizada para a realização das medidas eletroquímicas. Todos os experimentos foram conduzidos à temperatura controlada de $25 \pm 1{ }^{\circ} \mathrm{C}$. O contra eletrodo empregado foi um fio de platina $(\phi=$ $0,5 \mathrm{~mm}$ e $1 \mathrm{~cm}$ de comprimento) soldado a um fio de cobre para contato elétrico e fixado dentro de um tubo de vidro oco $(\phi=6 \mathrm{~mm})$ com resina epóxi. O eletrodo de referência utilizado foi o de calomelano saturado ( $\left.\mathrm{SCE}, \mathrm{Hg} / \mathrm{Hg}_{2} \mathrm{Cl}_{2}\right)(\mathrm{KCl}$ saturado). E os eletrodos de trabalho utilizados foram os propostos neste trabalho, todos com área geométrica de 0,070 $\mathrm{cm}^{2}(\phi=3 \mathrm{~mm})$. Além disso, antes das medidas eletroquímicas, os eletrodos fabricados eram lixados em uma politriz motorizada da Arotec (modelo APL-02), sendo a lixa utilizada com granulometria de 600 (composição $\mathrm{SiC}$ ).

\subsubsection{Funcionalização dos CNTs}

Os CNTs foram funcionalizados para a adição de grupos funcionais oxigenados em sua estrutura. Para isto, o material foi submetido ao tratamento térmico/químico reportado por He et al. ${ }^{114}$. Descrevendo brevemente, os CNTs foram aquecidos a $550{ }^{\circ} \mathrm{C}$ durante 30 minutos em uma mufla e suspensos em $100 \mathrm{~mL}$ de uma solução concentrada de $\mathrm{HNO}_{3}$ : $\mathrm{HClO}_{4}(70: 30$ $\left.\%, v v^{-1}\right)$. A suspensão foi submetida a ultrassom por 30 minutos, em seguida, deixada sob refluxo por 2 horas a $100{ }^{\circ} \mathrm{C}$ e na sequência filtrada. Os CNTs foram lavados com água deionizada até o $\mathrm{pH}$ do lavado torna-se próximo de 7. Por fim, foram deixados secar por 2 horas a $70{ }^{\circ} \mathrm{C}^{63}$. 


\subsubsection{Fabricação dos eletrodos}

Muitos analitos já foram quantificados utilizando eletrodos à base de grafite$\mathrm{PU}^{61,60,43,64}$. Neste trabalho foi proposta a modificação desses EGPU com os nanomateriais grafeno e CNTs funcionalizados. Como ponto de partida, foi mantida a proporção material condutor:PU $\left(60: 40 \%, \mathrm{~m} \mathrm{~m}^{-1}\right)$ e fabricaram-se três eletrodos com as seguintes proporções: grafite:PU (60:40\%, $\left.\mathrm{m} \mathrm{m}^{-1}\right)$, grafeno:grafite:PU $\left(30: 30: 40 \%, \mathrm{~m} \mathrm{~m}^{-1}\right)$ e CNTs:grafite:PU $\left(30: 30: 40 \%, \mathrm{~m} \mathrm{~m}^{-1}\right)$.

Assim, para a confecção do EGPU, inicialmente foram pesados $1,20 \mathrm{~g}$ de pó de grafite e $0,80 \mathrm{~g}$ da resina poliuretana (produto obtido pela mistura de $0,44 \mathrm{~g}$ de pré-polímero e $0,36 \mathrm{~g}$ de poliol, de acordo com as instruções do fabricante), que foram misturados em um almofariz de vidro (Figura 5A). Em seguida, a mistura do compósito foi colocada em um copo de metal (com orifício de extrusão de 3,0 mm de diâmetro), com o auxílio de uma espátula (Figura 5B). Posteriormente, o material foi prensado, e em seguida extrudado com o auxílio de uma prensa manual (Figura 5C), resultando em tarugos com comprimento 3,0 cm. É importante destacar que todo o processo deve ser feito em menos de 10 minutos, porque acima deste tempo a resina começa a curar.
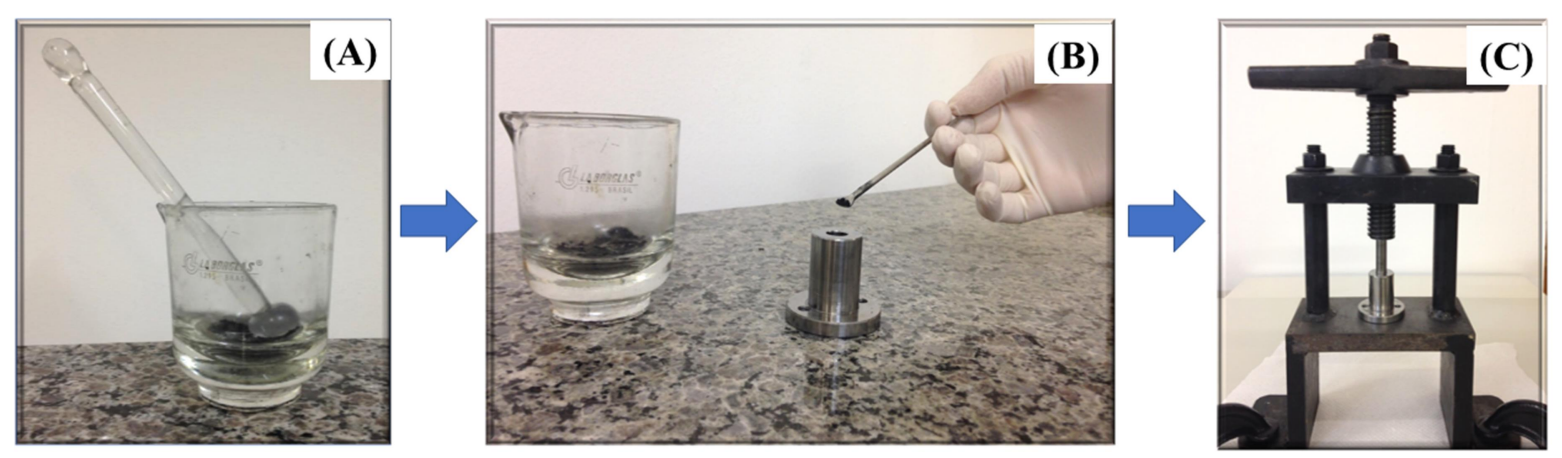

Figura 5. Fotografias representando as etapas de preparação do compósito. Em (A) mistura do material condutor (grafite e/ou grafeno-grafite e CNTs-grafite) mais PU; em (B) material é colocado em um copo de metal (com orifício de extrusão de 3,0 mm de diâmetro) com o auxílio de uma espátula; em (C) o copo de metal é encaixado em uma prensa manual, na qual o material é extrudado.

Após a cura, que se completa à temperatura ambiente $(24 \mathrm{~h})$, cortou-se os tarugos em pedaços com $1 \mathrm{~cm}$ de comprimento. Este tarugo foi chamado de compósito GPU. O compósito é então conectado a um fio de cobre $(9,0 \mathrm{~cm}$ de comprimento e $1,0 \mathrm{~mm}$ de diâmetro), usando cola de prata (cat. no. 12,642-14, Conductive Silver Epoxy Kit, Electron Microscopy Sciences), para garantir o contato elétrico e deixado para curar a $25{ }^{\circ} \mathrm{C}$ por mais 
24 h. Para auxiliar nesta etapa foi utilizado um gabarito para alinhamento do fio de cobre com o compósito. Depois de mais 24 h, o conjunto compósito/fio de cobre foi inserido num tubo de vidro (6 mm de diâmetro interno de e $9 \mathrm{~cm}$ de comprimento), preenchido com resina epóxi (Silaex 6400 Brasil) e deixado curar a $25{ }^{\circ} \mathrm{C}$ por mais 24 horas. O mesmo procedimento foi realizado para fabricar o EGPU-GR e EGPU-CNTs, a única diferença foi o processo de mistura dos componentes. Para o EGPU-GR pesou-se $0,60 \mathrm{~g}$ de pó de grafite, $0,60 \mathrm{~g}$ de GR e $0,80 \mathrm{~g}$ de resina de PU. E para o EGPU-CNTs pesou-se 0,60 g de pó de grafite, 0,60 g de CNTs funcionalizados e $0,80 \mathrm{~g}$ de resina de PU. Um esquema dessa montagem dos eletrodos de trabalho é apresentado na Figura 6.

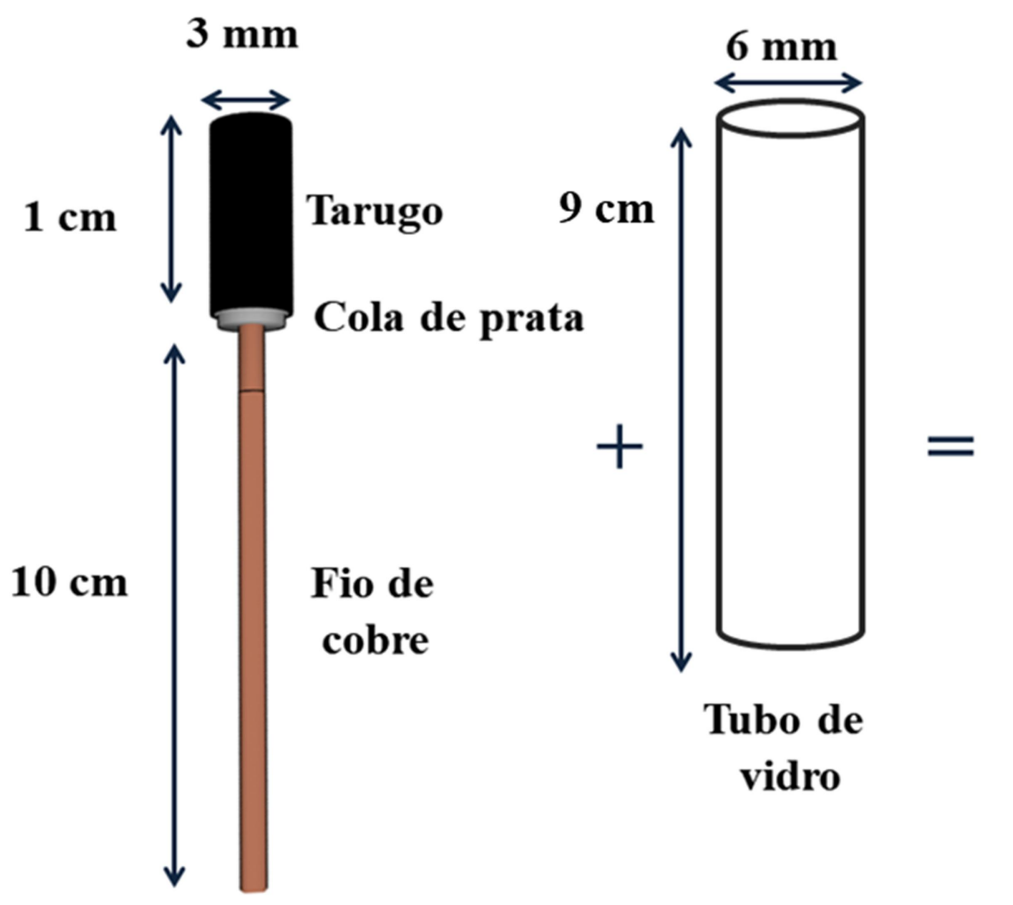

Eletrodo compósito

Figura 6. Esquema da montagem dos eletrodos de trabalho.

\subsubsection{Preparo das amostras de urina e fluido cérebro-espinal sintéticos}

Para preparar as amostras de urina sintética foram utilizados alguns componentes presentes neste fluido biológico, tais como $\mathrm{CaCl}_{2} \cdot 2 \mathrm{H}_{2} \mathrm{O}(0,28 \mathrm{~g}), \mathrm{NaCl}(0,73 \mathrm{~g}), \mathrm{Na}_{2} \mathrm{SO}_{4}(0,56$ $\mathrm{g}), \mathrm{KH}_{2} \mathrm{PO}_{4}(0,35 \mathrm{~g}), \mathrm{KCl}(0,40 \mathrm{~g}), \mathrm{NH}_{4} \mathrm{Cl}(0,25 \mathrm{~g})$ e ureia $(6,25 \mathrm{~g})^{115,116}$. Todos os reagentes foram dissolvidos em $250,0 \mathrm{~mL}$ de água.

Do mesmo modo, para o preparo das amostras de fluido cérebro-espinal utilizaram-se alguns componentes presentes neste fluido biológico: $\mathrm{NaCl}(2,10 \mathrm{~g}), \mathrm{KCl}(0,070 \mathrm{~g}), \mathrm{CaCl}_{2}$ $(0,080 \mathrm{~g})$, glucose $(0,20 \mathrm{~g}), \mathrm{NaHCO}_{3}(0,40 \mathrm{~g})$ e ureia $(0,0020 \mathrm{~g})^{117}$. A mistura das substâncias foi dissolvida em 250,0 mL de água. É importante destacar que ambas as soluções foram 
utilizadas imediatamente após o preparo para evitar possíveis alterações como a hidrólise da ureia.

\subsubsection{Procedimento experimental}

\subsubsection{Caracterização dos materiais e compósitos}

A espectroscopia Raman foi utilizada para confirmar a modificação estrutural dos CNTs após funcionalização e algumas técnicas foram utilizadas para caracterizar os compósitos preparados. Com a microscopia de ângulo de contato e SEM, foi possível obter informações sobre a superfície dos eletrodos compósitos.

\subsubsection{Cálculo da área eletroativa dos eletrodos desenvolvidos}

Medidas cronocoulométricas foram feitas para o cálculo das áreas eletroativas dos eletrodos propostos. Para isso, experimentos foram conduzidos com a sonda redox $\left[\mathrm{Fe}(\mathrm{CN})_{6}\right]^{3-} 1,0 \mathrm{mmol} \mathrm{L}{ }^{-1}$ em solução de $\mathrm{KCl} 0,10 \mathrm{~mol} \mathrm{~L}^{-1}$. O primeiro potencial aplicado foi de $0,75 \mathrm{~V}$ (vs. SCE) durante $1 \mathrm{~s}$ em um eletrodo polarizado em $0,0 \mathrm{~V}$, e o segundo potencial foi aplicado em $-0,25 \mathrm{~V}$ por mais $1 \mathrm{~s}$. A carga total $(Q) v s$. o tempo $(t)$ foi registrada durante esses $2 \mathrm{~s}$. Este experimento foi repetido três vezes e uma média da área ativa foi calculada para cada eletrodo, com os respectivos desvios padrão.

A partir dos resultados obtidos com as medidas cronocoulométricas, construiu-se o gráfico $Q v s$. raiz quadrada do $t$ corrigido e obteve-se uma regressão linear para cada eletrodo de trabalho (EGPU, EGPU-GR e EGPU-CNTs). O $t$ corrigido significa considerar o valor de $t$ igual à zero no momento em que o pulso é aplicado. Os coeficientes angulares obtidos a partir de cada regressão linear foram substituídos na forma integrada da Equação de Cottrell ${ }^{118}$ (Equação 1) e as áreas ativas foram calculadas para cada eletrodo.

$$
Q=\frac{2 n F A D^{1 / 2} C t^{1 / 2}}{\pi^{1 / 2}}
$$

Na qual $Q$ é a carga $(\mathrm{C}), n$ é o número de elétrons envolvidos na reação redox $(\mathrm{n}=1)$, $F$ é a constante de Faraday $\left(96487 \mathrm{C} \mathrm{mol}^{-1}\right), A$ é a área eletroativa $\left(\mathrm{cm}^{2}\right), D$ é o coeficiente de difusão (neste caso $\left.7,6 \times 10^{-6} \mathrm{~cm}^{2} \mathrm{~s}^{-1}\right)^{118}$ a $25^{\circ} \mathrm{C}, C$ é a concentração da espécie ativa $(1 \mu \mathrm{mol}$ $\left.\mathrm{cm}^{-3}\right)$, e $t$ é tempo (s). 


\subsubsection{Caracterização eletroquímica dos eletrodos}

Medidas de voltametria cíclica foram conduzidas utilizando o EGPU, EGPU-GR e EGPU-CNTs para a sonda redox $\left[\mathrm{Fe}(\mathrm{CN})_{6}\right]^{3-} 1,0 \mathrm{mmol} \mathrm{L}{ }^{-1}$ em solução de $\mathrm{KCl} 0,10 \mathrm{~mol} \mathrm{~L}^{-1}$, em diferentes velocidades de varredura de potenciais $\left(v, 10\right.$ a $\left.500 \mathrm{mV} \mathrm{s}^{-1}\right)$, para investigar os mecanismo de transporte de massa.

Ainda, empregando a voltametria cíclica, o comportamento eletroquímico do escitalopram (100 $\mu \mathrm{mol} \mathrm{L}^{-1}$ ) em tampão Britton-Robinson $0,10 \mathrm{~mol} \mathrm{~L}^{-1}$ (pH 6,3) foi avaliado utilizando os sensores EGPU, EGPU-GR e EGPU-CNTs, em um intervalo de varredura de potenciais entre 0,40 a $1,1 \mathrm{~V}(v s$. SCE), a fim de identificar os processos redox envolvidos. Considerando valores de maior corrente, o EGPU-GR foi escolhido para avaliar as etapas de escolha de parâmetros para o desenvolvimento do método eletroanalítico.

\subsubsection{Procedimento eletroanalítico para a determinação de escitalopram}

Um novo método foi desenvolvido utilizando o EGPU-GR para a determinação de escitalopram em amostras sintéticas de urina e fluido de cérebro-espinal. Assim, utilizando a DPV, investigou-se o efeito da concentração hidrogeniônica sobre a resposta voltamétrica do analito.

Posteriormente, os parâmetros da DPV e SWV foram otimizados para obterem-se as melhores condições para quantificar o antidepressivo. Utilizando ambas as técnicas, várias adições de escitalopram foram feitas à célula eletroquímica, em tampão Britton-Robinson 0,10 $\mathrm{mol} \mathrm{L}^{-1}$ ( $\mathrm{pH} \mathrm{6,3)} \mathrm{usando} \mathrm{EGPU-GR.} \mathrm{Para} \mathrm{efeito} \mathrm{de} \mathrm{comparação} \mathrm{também} \mathrm{foram} \mathrm{feitas}$ medidas utilizando EGPU e EGPU-CNTs. A partir dos resultados obtidos, gráficos das correntes de pico de oxidação vs. concentrações de escitalopram foram construídos para cada eletrodo. Além disso, valores de LOD foram calculados pela relação: $3 \times$ desvio padrão do branco $(n=10)$ e o resultado dividido pelo coeficiente angular da curva ${ }^{119}$.

Considerando a maior sensibilidade (coeficiente angular da curva analítica) e menor LOD, o EGPU-GR e a SWV, foram selecionados para as próximas etapas do desenvolvimento do método proposto.

Em seguida, estudos de repetibilidade sobre a resposta do eletrodo para uma concentração de escitalopram $6,0 \mu \mathrm{mol} \mathrm{L}{ }^{-1}$ foram realizadas.

Alguns compostos presentes em amostras de urina e fluido de cérebro-espinal também foram determinados na amostra utilizando técnicas voltamétricas, uma vez que podem ser 
possíveis interferentes na quantificação de escitalopram. Para isso, foi utilizada a SWV e tampão Britton-Robinson 0,10 $\mathrm{mol} \mathrm{L}^{-1}$ ( $\mathrm{pH} \mathrm{6,3)} \mathrm{como} \mathrm{eletrólito} \mathrm{suporte.} \mathrm{DA,} \mathrm{AA,} \mathrm{UA,} \mathrm{e}$ creatinina foram adicionados à solução padrão inicial nas razões de concentrações 1:0,5; $1: 1 \mathrm{e}$ 1:2 analito: interferente.

Finalmente, para verificar a seletividade do método proposto, foram realizadas medidas de recuperação utilizando o EGPU-GR. As amostras biológicas sintéticas foram fortificadas com escitalopram e analisadas individualmente. Assim, três adições consecutivas de $40 \mu \mathrm{L}$ de uma das amostras foram adicionadas a célula eletroquímica e três concentrações $\left(3,98 ; 7,94\right.$ e $\left.11,8 \mu \mathrm{mol} \mathrm{L}^{-1}\right)$ de escitalopram foram avaliadas, em triplicata. A partir dos resultados obtidos, a média e o desvio padrão foram calculados. Também calculou-se o valor de recuperação com base na concentração encontrada dividida pela concentração adicionada. Para comparação, o mesmo procedimento foi realizado utilizando a DPV nas análises de ambas as amostras. 


\subsection{RESULTADOS E DISCUSSÃO}

\subsubsection{Caracterização dos materiais e compósitos}

Os resultados aqui apresentados já foram publicados em uma revista de circulação internacional, a Talanta, por Baccarin et al., volume 178 (2018) página 1024-1032, com o seguinte título "Comparative performances of a bare graphite-polyurethane composite electrode unmodified and modified with graphene and carbon nanotubes in the electrochemical determination of escitalopram".

Inicialmente, foi utilizada a espectroscopia Raman para analisar os CNTs antes e após a sua funcionalização, a fim de confirmar sua modificação estrutural com inserção de grupos funcionais oxigenados em sua estrutura como resulta ao tratamento ácido. Na Figura 7 são apresentados os espectros de Raman obtidos para os CNTs não funcionalizados e funcionalizados. É possível observar a presença da banda $\mathrm{G}$ em $1582 \mathrm{~cm}^{-1}$ relacionada às vibrações das duplas ligações carbono-carbono $\left(\mathrm{sp}^{2}\right)$ e a banda $\mathrm{D}$ em torno de $1359 \mathrm{~cm}^{-1}$ atribuída à presença de desordem e defeitos na estrutura dos $\mathrm{CNTs}^{120}$. Uma das formas de se evidenciar as diferenças entre as amostras de CNTs funcionalizadas e não funcionalizadas, é a comparação entre a área dessas bandas $\mathrm{D}$ e $\mathrm{G}$, isto é, a razão $\mathrm{A}_{\mathrm{D}} / \mathrm{A}_{\mathrm{G}}$. Esta mudança do valor da razão da área pode indicar a quebra de simetria hexagonal ordenada que formam a parede dos CNTs, consequência de alterações de ligações carbono $\mathrm{sp}^{2}$ para $\mathrm{sp}^{3}$ e adição dos grupos funcionais oxigenados. A razão $A_{D} / A_{G}$ para os CNTs não funcionalizados foi de 0,16 e para os CNTs funcionalizados foi de 0,42 o que indicou que o processo de funcionalização promoveu a incorporação de defeitos na estrutura dos CNTs.

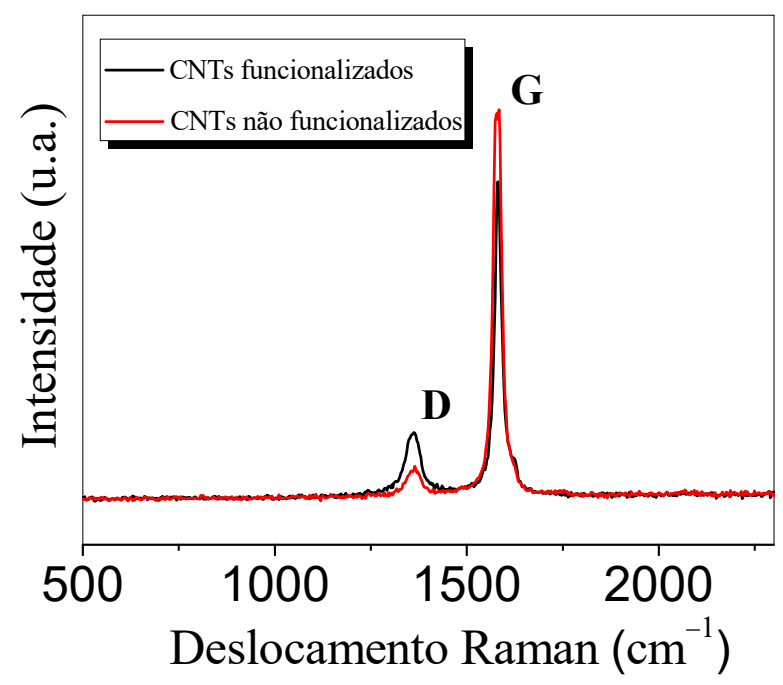

Figura 7. Espectros Raman obtidos para os CNTs não funcionalizados e os CNTs funcionalizados. 
Para mais informações sobre os eletrodos desenvolvidos, após o preparo dos compósitos GPU, GPU-GR e GPU-CNTs foram realizadas análises de ângulo de contato para avaliar o caráter hidrofílico e hidrofóbico dos mesmos. Nas Figuras 8A, 8B e 8C podem ser vistas as imagens obtidas. A média dos valores dos ângulos para os compósitos GPU, GPUGR e GPU-CNTs foram $88^{\circ}, 63^{\circ}$ e $44^{\circ}$, indicando o caráter hidrofílico deles na ordem crescente: GPU < GPU-GR < GPU-CNTs. Estes resultados confirmaram que os três compósitos propostos apresentam grupos oxigenados em suas estruturas, sendo o GPU-CNTs com a maior concentração entre eles.
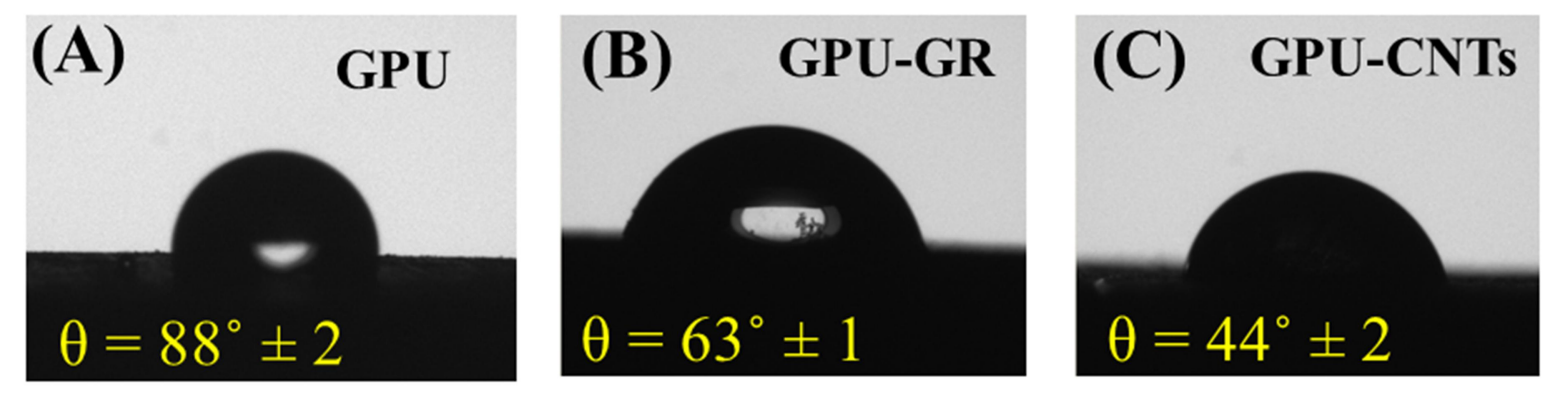

Figura 8. Imagens microscópicas do ângulo de contato entre a água deionizada e os GPU (A), GPUGR (B) e GPU-CNTs (C) em 200× de magnificação.

Em seguida, utilizou-se a SEM para investigar a morfologia dos compósitos. Imagens da fratura (Figuras 9A, 9B e 9C) e da superfície lixada (Figuras 9D, 9E e 9F) dos GPU, GPUGR e GPU-CNTs, respectivamente, foram obtidas em diferentes magnificações.

Nas imagens das superfícies fraturadas foi possível observar que o compósito GPU sem modificação apresenta uma superfície rugosa (Figura 9A), contendo as folhas de GR individuais no compósito GPU-GR (Figura 9B), e pelas estruturas tubulares dos CNTs incorporados no compósito GPU-CNTs (Figura 9C). Já no caso das imagens das superfícies lixadas também, observou-se uma superfície rugosa do compósito GPU (Figura 9D), as folhas de grafeno expostas na superfície do GPU-GR (Figura 9E) e a presença dos CNTs, (com morfologia tubular característica) no compósito GPU-CNTs (Figura 9F). A exposição dos nanomateriais modificadores pode levar a um aumento de área eletroativa do eletrodo, servindo como pontos ativos de facilitação de transferência de elétrons entre a superfície eletródica e o escitalopram. Como consequência pode-se melhorar o desempenho analítico do eletrodo. 

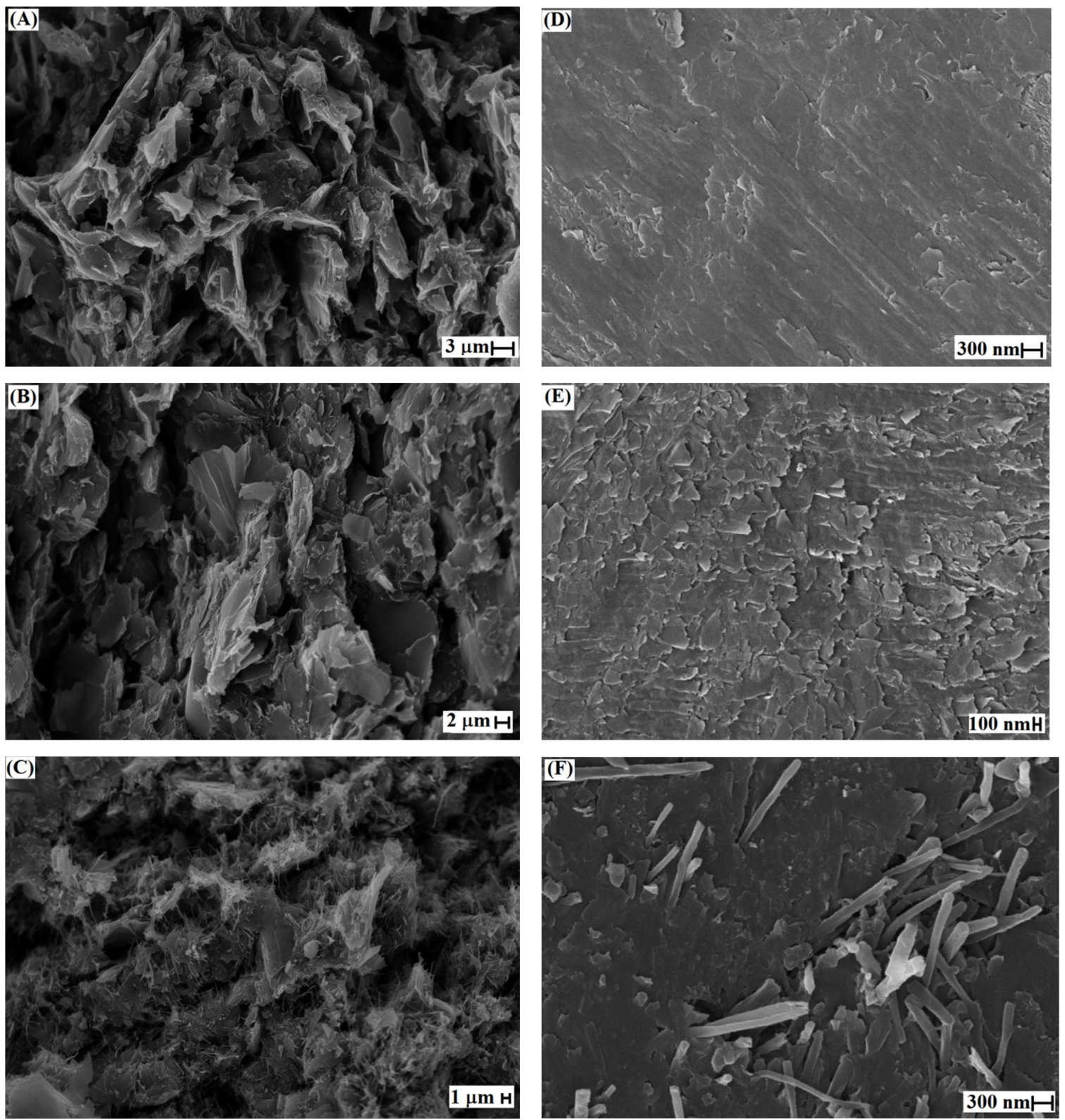

Figura 9. Imagens de SEM obtidas das fraturas dos compósitos de GPU (A), GPU-GR (B) e GPUCNTs (C), com 5000× de magnificação. Imagens de SEM obtidas da superfície lixada dos compósitos de GPU (D), GPU-GR (E) e GPU-CNTs (F), com 50000× de magnificação.

\subsubsection{Caracterização eletroquímica dos três eletrodos}

Após a caracterização física dos compósitos, utilizou-se a sonda eletroquímica $\left[\mathrm{Fe}(\mathrm{CN})_{6}\right]^{3-}$ para investigar o comportamento eletroquímico dos eletrodos propostos. Com os resultados obtidos, foi possível estimar o valor da área eletroativa, bem como entender qual o processo que controla o transporte de massa das espécies em suas superfícies.

Assim, inicialmente foi importante calcular as áreas eletroativas do EGPU, EGPU-GR e EGPU-CNTs desenvolvidos, uma vez que as massas desses eletrodos compósitos são 
constituídas de $40 \%\left(\mathrm{~m} \mathrm{~m}^{-1}\right)$ PU, um material não condutor. Para isso, medidas cronocoulométricas foram conduzidas utilizando-se solução de $\left[\mathrm{Fe}(\mathrm{CN})_{6}\right]^{3-} 1,0 \mathrm{mmol} \mathrm{L}{ }^{-1} \mathrm{e}$ como eletrólito suporte solução de $\mathrm{KCl} 0,10 \mathrm{~mol} \mathrm{~L}^{-1}$. Os coeficientes angulares obtidos de $1,82 \times 10^{-5}, 2,42 \times 10^{-5}$ e $2,79 \times 10^{-5}$ para EGPU, EGPU-GR, EGPU-CNTs, respectivamente, foram substituídos na forma integrada da Equação de Cottrell (Equação 1), e as áreas ativas foram calculadas (Tabela 1).

Tabela 1. Área eletroativa dos eletrodos propostos

\begin{tabular}{cc}
\hline Eletrodo & Área eletroativa $\left(\mathrm{cm}^{2}\right)$ \\
\hline EGPU & $0,065 \pm 0,004$ \\
EGPU-GR & $0,080 \pm 0,004$ \\
EGPU-CNTs & $0,092 \pm 0,003$ \\
\hline
\end{tabular}

Área geométrica $=0,070 \mathrm{~cm}^{2} ; \mathrm{n}=3$

Os eletrodos modificados com grafeno e CNTs apresentaram uma área eletroativa maior que a geométrica, o que pode ser explicado pelo aumento na área superficial desses materiais ${ }^{121,13}$ com os modificadores (Figura 9). Além disso, mesmo com 40\% da massa do EGPU não modificado sendo constituída de material não condutor, o valor da área geométrica é próximo o da área ativa, o que pode ser justificado pela rugosidade da superfície destes materiais, mesmo depois do polimento, como observado nas imagens de SEM.

Em seguida, medidas de voltametria cíclica foram realizadas utilizando o EGPU, o EGPU-GR e o EGPU-CNTs, utilizando solução de $\left[\mathrm{Fe}(\mathrm{CN})_{6}\right]^{3-} 1,0 \mathrm{mmol} \mathrm{L}^{-1}$ e como eletrólito suporte solução de $\mathrm{KCl} 0,10 \mathrm{~mol} \mathrm{~L}^{-1}$, em diferentes velocidades de varredura de potenciais (10 a $500 \mathrm{mV} \mathrm{s}^{-1}$ ), para investigar o mecanismo de transporte de massa. Nas Figuras 10A, 10B e 10C são apresentados os voltamogramas obtidos para os três dispositivos, nos quais é possível observar aumento, tanto das correntes de pico anódico, quanto catódico, conforme se aumenta a velocidade de varredura de potenciais. Para interpretação dos resultados, gráficos de corrente de pico anódica $\left(I_{\mathrm{a}}\right)$ vs. raiz quadrada da velocidade de varredura de potencial $\left(v^{1 / 2}\right)$ foram construídos para cada eletrodo, os quais estão inseridos nas Figuras 10A, 10B e 10C. As regressões lineares obtidas evidenciaram o transporte de massa controlado por difusão.

Além disso, regressões lineares a partir dos gráficos de $\log I_{\mathrm{a}} v s$. $\log v$ (não apresentados), foram obtidas para todos os eletrodos, resultando em coeficientes angulares de 
0,48 (EGPU), 0,51 (EGPU-GR) e 0,49 (EGPU-CNTs). Estes valores estão próximo do teórico de 0,5 , indicando que o processo de transporte de massa na superfície dos eletrodos propostos é controlado apenas por difusão ${ }^{122}$.

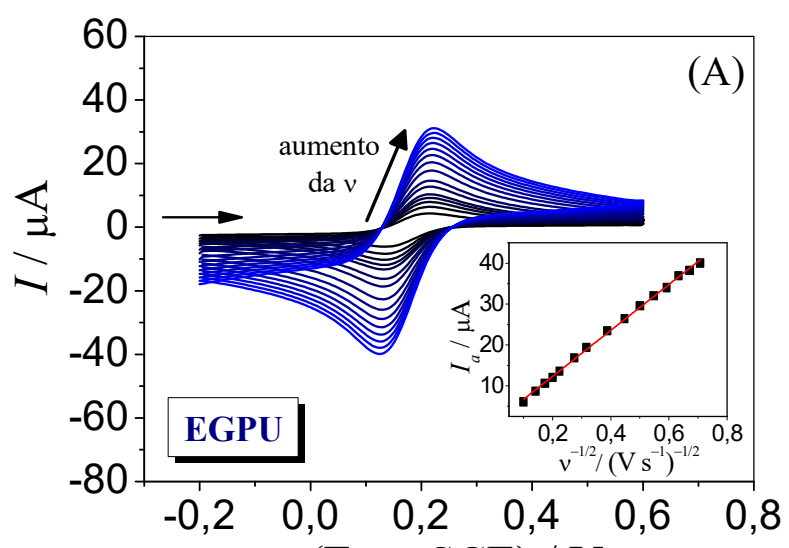

(Evs. SCE) / V

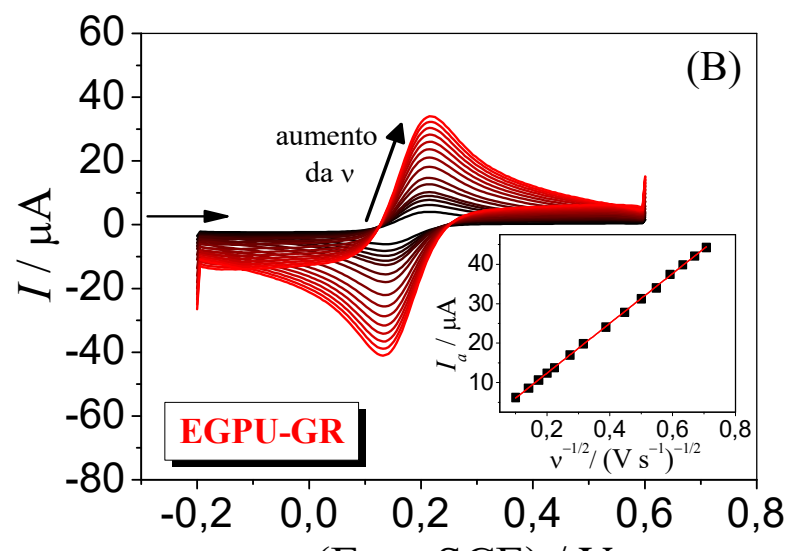

(E vs. SCE) / V

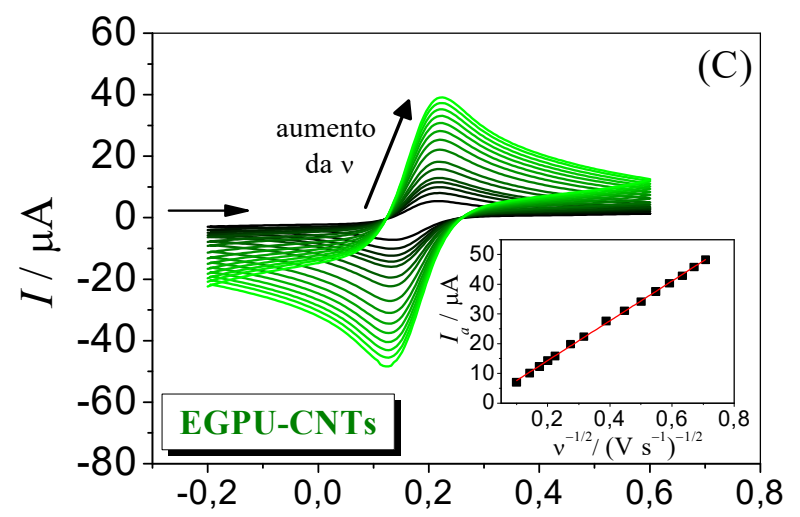

(E vs. SCE) / V

Figura 10. Voltamogramas cíclicos obtidos em solução de $\left[\mathrm{Fe}(\mathrm{CN})_{6}\right]^{3-} 1,0 \mathrm{mmol} \mathrm{L}^{-1} \mathrm{em} \mathrm{KCl} 0,10$ mol L $\mathrm{L}^{-1}$, em diferentes velocidades de varredura de potenciais $\left(v, 10\right.$ a $\left.500 \mathrm{mV} \mathrm{s}^{-1}\right)$ utilizando (A) EGPU, (B) EGPU-GR e (C) EGPU-CNTs. Inserido os respectivos gráficos de $I_{\mathrm{a}} v s . v^{1 / 2}$.

\subsubsection{Comportamento eletroquímico do escitalopram}

O comportamento eletroquímico do escitalopram foi estudado por voltametria cíclica, $v=50 \mathrm{mV} \mathrm{s}^{-1}$, utilizando os três eletrodos desenvolvidos. Nas Figuras 11A, 11B e 11C são apresentados os voltamogramas obtidos na ausência e na presença de escitalopram $100 \mu \mathrm{mol}$ $\mathrm{L}^{-1}$ em tampão Britton-Robinson 0,10 $\mathrm{mol} \mathrm{L}^{-1}$ ( $\mathrm{pH}$ 6,3), utilizando o EGPU, o EGPU-GR e o EGPU-CNTs, respectivamente. 

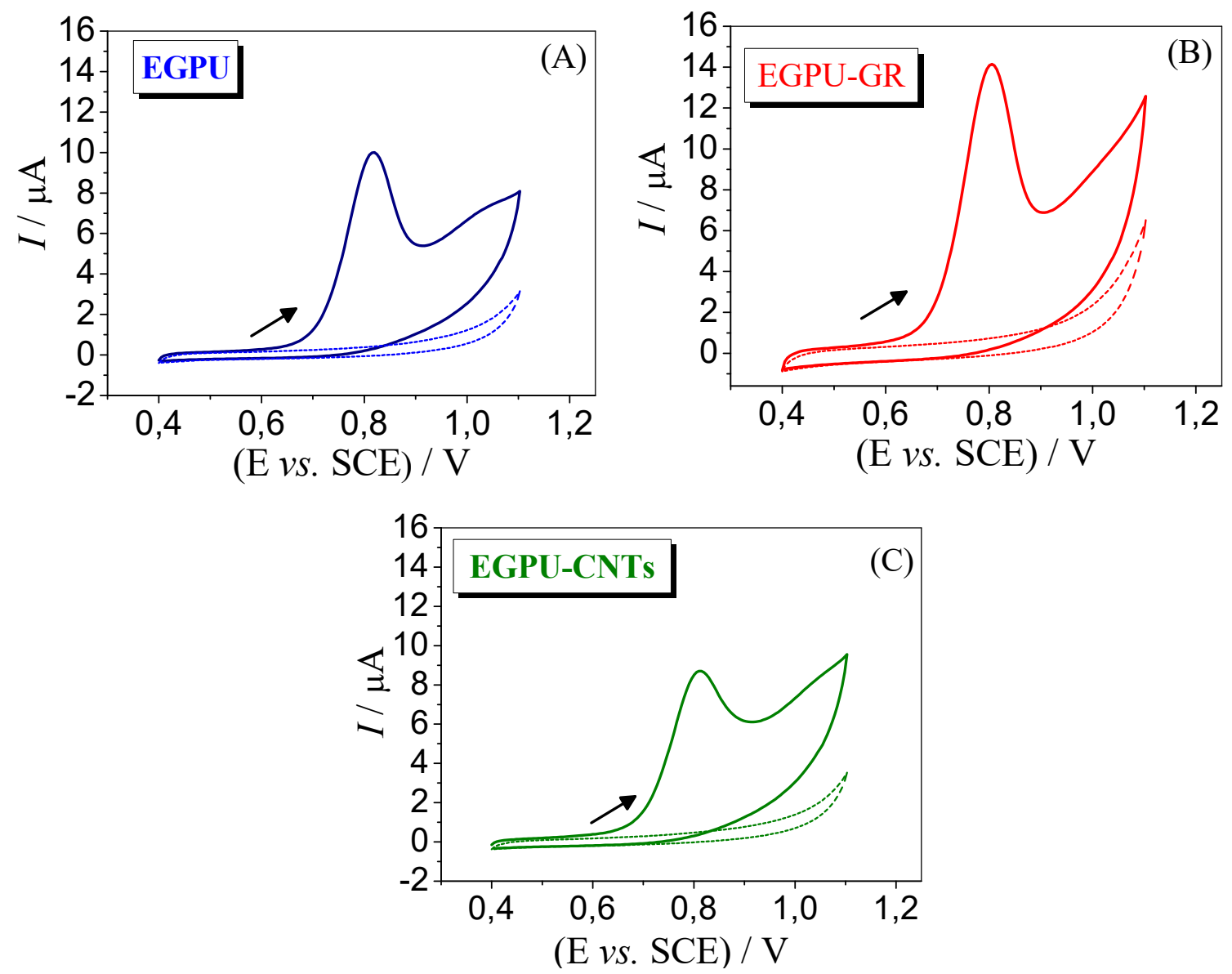

Figura 11. Voltamogramas cíclicos obtidos na ausência e na presença de escitalopram $100 \mu \mathrm{mol} \mathrm{L}{ }^{-1}$ em tampão Britton-Robinson 0,10 mol L ${ }^{-1}$ (pH 6,3) usando o EGPU (A), EGPU-GR (B) e EGPU-CNTs (C), $v=50 \mathrm{mV} \mathrm{s}^{-1}$.

$\mathrm{Na}$ varredura de potenciais no sentido positivo foi observado um pico de oxidação, por volta de $0,80 \mathrm{~V}$ ( $v s$. SCE), para os três eletrodos. Já no sentido inverso da varredura de potencial, não foi observado nenhum processo de redução, o que indica o comportamento irreversível do analito sob a superfície dos eletrodos propostos. Na literatura, Jain et al. ${ }^{91}$ reportaram um comportamento irreversível do escitalopram em tampão fosfato $0,10 \mathrm{~mol} \mathrm{\textrm {L } ^ { - 1 }}$ pH 2,0 sobre a superfície de um GCE modificado com NPs de óxido de bismuto. Foi observado um pico de oxidação em torno de $0,75 \mathrm{~V}$ (vs. $\left.\mathrm{Ag} / \mathrm{AgCl}\left(\mathrm{KCl} 3,0 \mathrm{~mol} \mathrm{~L}^{-1}\right)\right)$.

Já Nouws et al. ${ }^{123}$ utilizaram a voltametria cíclica e a SWV para estudar o comportamento voltamétrico do racemato de citalopram (cuja estrutura molecular tem os mesmo grupos funcionais que o escitalopram) em tampão fosfato $0,10 \mathrm{~mol} \mathrm{~L}^{-1}$ (pH 8,2), sobre a superfície de um GCE. Um pico anódico foi observado em 0,85 V (vs. $\mathrm{Ag} / \mathrm{AgCl}$ (3,0 mol $\left.\mathrm{L}^{-1}\right)$ ) e nenhum pico de redução foi obtido. Um mecanismo detalhado sobre a oxidação do 
citalopram foi descrito, atribuindo o único pico observado à oxidação do grupo amina terciário, envolvendo dois elétrons e dois prótons. Para verificar esta oxidação, foi feita a comparação da resposta voltamétrica do citalopram com a molécula didesmetilcitalopram, um metabólito do citalopram com estrutura semelhante com exceção da presença de um grupo amina primária em sua estrutura ao invés de um grupo amina terciária. A ausência de um pico de oxidação para a molécula de didesmetilcitalopram confirmou que a oxidação deve ocorrer no grupo amina terciária. Na Figura 12 é apresentada a representação da reação de oxidação eletroquímica do citalopram proposta por Nouws et al. ${ }^{123}$.

Em outro trabalho, Gholivand et al. ${ }^{93}$ utilizaram um GCE modificado com CNTs em um filme de poli (ácido $p$-aminobenzeno sulfônico) $/ \beta$-ciclodextrina, e também reportaram um único pico de oxidação para o racemato citalopram em $0,90 \mathrm{~V}\left(v s . \mathrm{Ag} / \mathrm{AgCl}\left(3,0 \mathrm{~mol} \mathrm{~L}{ }^{-1}\right)\right) \mathrm{em}$ tampão fosfato $0,10 \mathrm{~mol} \mathrm{~L}^{-1}(\mathrm{pH} 7,4)$, referenciando à oxidação do grupo amina terciária na molécula corroborando o mecanismo proposto por Nouws et al. ${ }^{123}$.

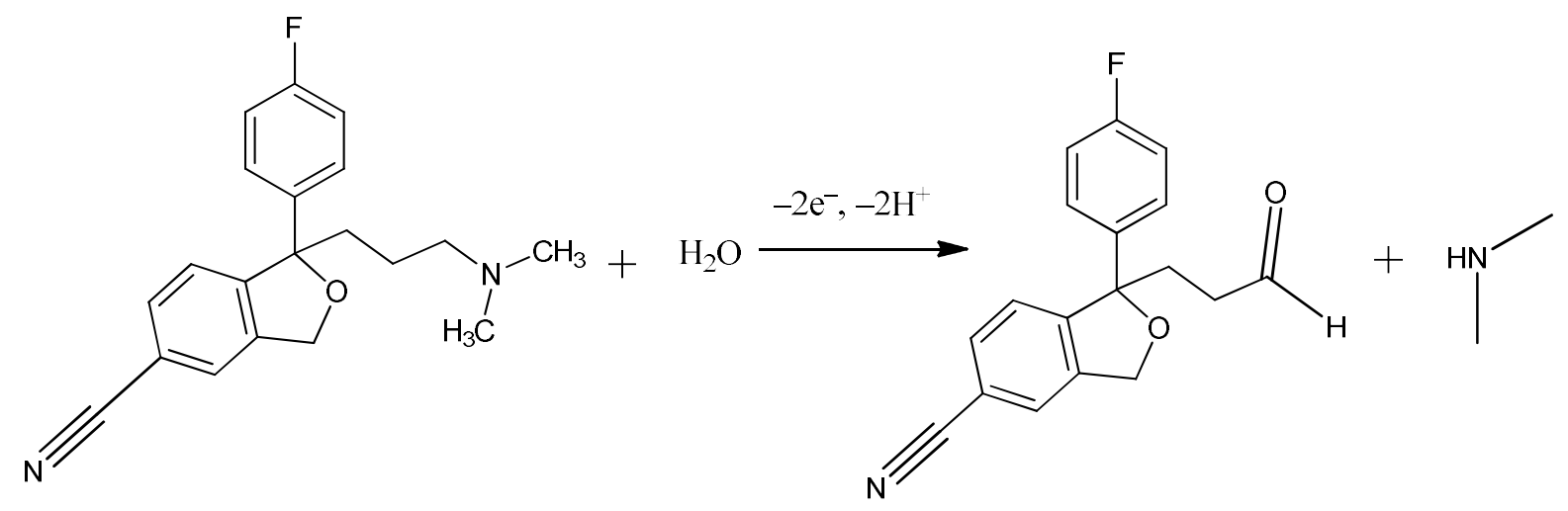

Figura 12. Representação da reação de oxidação eletroquímica do citalopram ${ }^{123}$.

Ainda, com os resultados obtidos (Figura 11A, 11B e 11C), era esperado que a presença dos nanomateriais de carbono (CNTs e grafeno) leva-se a maiores magnitudes de corrente para o analito de interesse, frente ao eletrodo controle EGPU. Porém, isso não foi observado para o EGPU-CNTs, mas sim valores de corrente de oxidação muito próximos do EGPU. Talvez o método de preparo do eletrodo, após a mistura do compósito permitiu que, poucas pontas dos CNTs ficassem expostas na superfície do EGPU-CNTs (ver imagens de SEM na Figura 9), o que pode ter levado a menores magnitudes de corrente de pico anódico do escitalopram comparado ao EGPU-GR. Ainda, no eletrodo modificado com grafeno, observa-se pelas imagens de SEM (Figura 9), maior homogeneização da distribuição deste nanomaterial de carbono sobre a superfície do eletrodo, com sua região de maior transferência de elétrons (o plano de bordas) mais expostas comparado ao EGPU-CNTs. Sendo assim, 
devido aos maiores valores de corrente de pico anódico do escitalopram serem obtidos com o EGPU-GR, este foi selecionado para as próxima etapas de otimização do método analítico.

Na sequência, foi investigado a influência da concentração hidrogeniônica do meio na resposta analítica do escitalopram. Para isto, avaliou-se o efeito de diferentes valores de $\mathrm{pH}$ $\left(4,3,6,3,8,4\right.$ e 10,3) do tampão Britton-Robinson $0,10 \mathrm{~mol} \mathrm{~L}^{-1}$ utilizando uma concentração de escitalopram de $100 \mu \mathrm{mol} \mathrm{L}^{-1} \mathrm{em} \mathrm{DPV} \mathrm{(velocidade} \mathrm{de} \mathrm{varredura} \mathrm{de} \mathrm{potenciais}=20 \mathrm{mV} \mathrm{s}^{-1}$ e amplitude de pulso $=50 \mathrm{mV}$ ). Os voltamogramas obtidos foram apresentados na Figura 13A e a partir deles foram colocados em gráficos os valores de corrente de pico anódica $\left(I_{p a}\right)$ e potencial (E) vs. pH (Figura 13B). Conforme se aumenta o valor de $\mathrm{pH}$, observa-se um deslocamento de potencial para valores menos positivos, até não ocorrer mais deslocamentos significativos em torno do $p K a$ da molécula $(9,8)^{124}$ (ver voltamogramas do $\mathrm{pH} 8,4$ e 10,3). Em meio ácido, a molécula de escitalopram está protonada, e conforme se aumenta o $\mathrm{pH}$ ela tem sua desprotonação favorecida. Para valores de $\mathrm{pH}$ acima de 9,8, o escitalopram se encontra preferencialmente na forma neutra, e por isso já não se observa deslocamento do potencial de pico nos voltamogramas, uma vez que a concentração hidrogeniônica já não influencia significativamente a reação. Assim, escolheu-se o pH 6,3 para trabalhar nas próximas etapas, levando em consideração ser mais próximo do $\mathrm{pH}$ fisiológico, apresentar melhor definição de pico comparado aos valores de 8,4 e 10,3 e potencial mais próximo da origem comparado ao $\mathrm{pH} 4,3$.

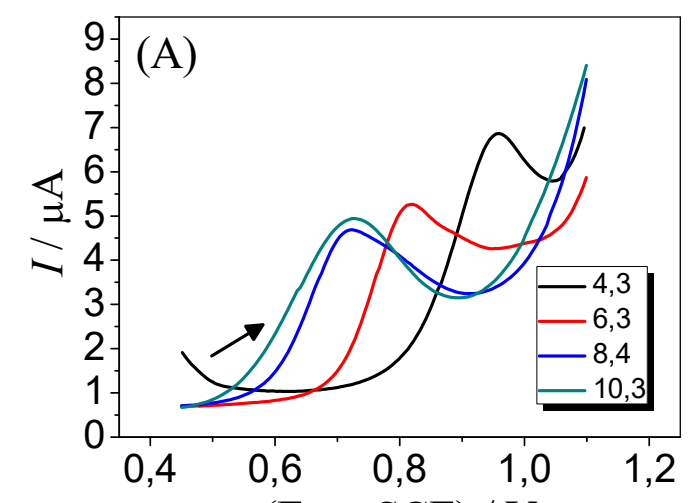

(Evs. SCE) / V

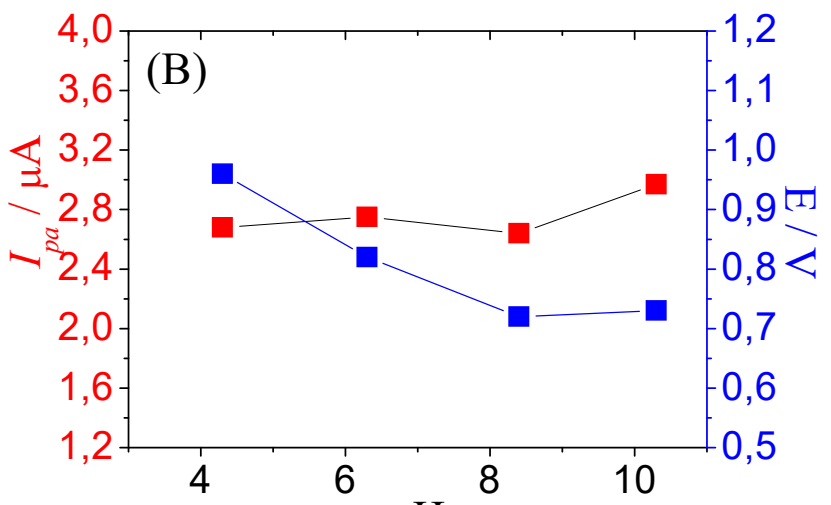

$\mathrm{pH}$

Figura 13. (A) Voltamogramas de DPV obtidos na presença de escitalopram $100 \mu \mathrm{mol} \mathrm{L} \mathrm{L}^{-1} \mathrm{em}$ tampão Britton-Robinson $0,10 \mathrm{~mol} \mathrm{~L}^{-1}$ em diferentes valores de $\mathrm{pH}$ utilizando o EGPU-GR. (B) Correntes de pico anódico $\left(I_{\mathrm{pa}}\right)$ e valores de potencial $(E)$ para os diferentes valores de $\mathrm{pH}$ estudados. Velocidade de varredura de potenciais $=20 \mathrm{mV} \mathrm{s}^{-1}$ e amplitude de pulso $=50$ $\mathrm{mV}$. 
Para o desenvolvimento do método proposto, os parâmetros em DPV e SWV foram otimizados, visto que estes podem influenciar na resposta voltamétrica do analito. Para a DPV avaliou-se velocidade de varredura de potenciais $\left(5,10\right.$ e $\left.20 \mathrm{mV} \mathrm{s}^{-1}\right)$ e amplitude de pulso $(10,25$ e $50 \mathrm{mV})$. Já para a SWV: frequência $(8,10,15$ e $20 \mathrm{~Hz})$, amplitude de pulso $(10,25$ e $50 \mathrm{mV}$ ) e incremento de varredura $(2,3$ e $5 \mathrm{mV}$ ). Levando-se em consideração melhor definição de pico e maior corrente de pico de oxidação, os seguintes valores foram escolhidos para a DPV: velocidade de varredura de potencial de $20 \mathrm{mV} \mathrm{s}^{-1}$ e amplitude de pulso de 50 $\mathrm{mV}$ e para a SWV: frequência de $8 \mathrm{~Hz}$, amplitude de pulso de $50 \mathrm{mV}$ e incremento de varredura de $2 \mathrm{mV}$.

Após a otimização dos parâmetros instrumentais, investigou-se a aplicação dos eletrodos propostos para a determinação de escitalopram. Assim, adições do analito em diferentes concentrações foram feitas na célula eletroquímica em tampão Britton-Robinson $0,10 \mathrm{~mol} \mathrm{~L}^{-1}$ (pH 6,3), estudando-se a faixa de concentração de 1,5 a $12 \mu \mathrm{mol} \mathrm{L}{ }^{-1}$, em um intervalo de varredura de potenciais entre 0,60 e 1,0 V (vs. SCE). Nas Figuras 14A-C são apresentados os voltamogramas de DPV obtidos utilizando o EGPU, o EGPU-GR e o EGPUCNTs, respectivamente. Já nas Figuras 14D-F são apresentados os voltamogramas de SWV obtidos utilizando o EGPU, o EGPU-GR e EGPU-CNTs, respectivamente. 


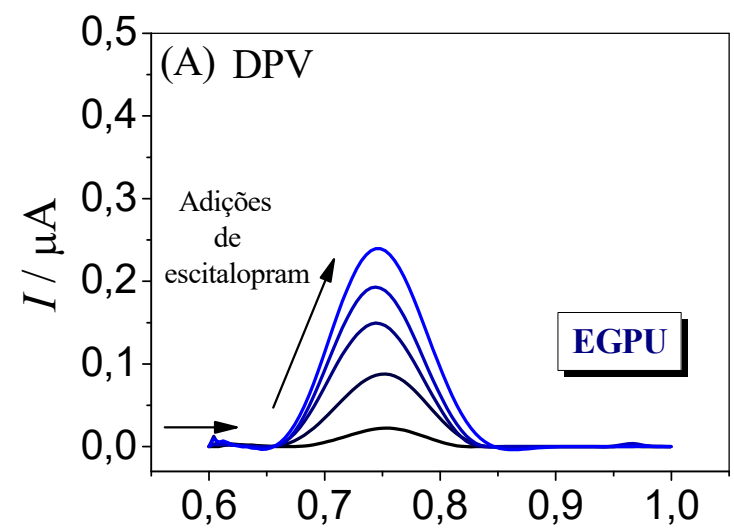

(Evs. SCE) / V

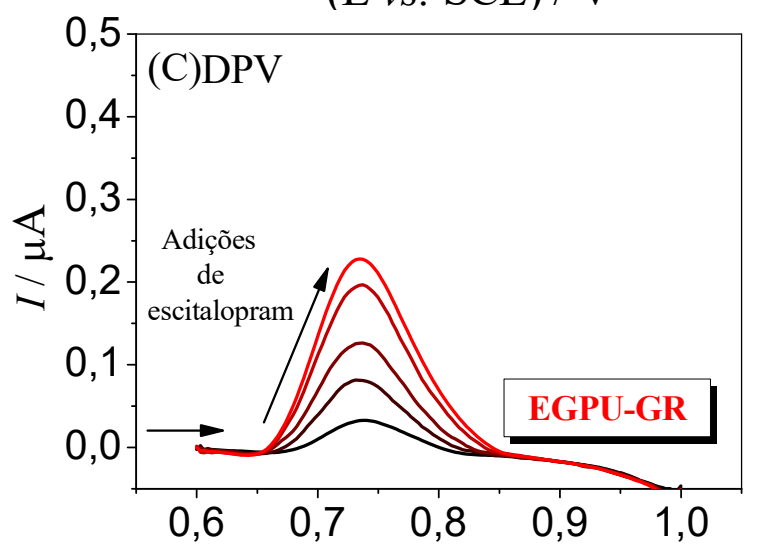

(E vs. SCE) / V

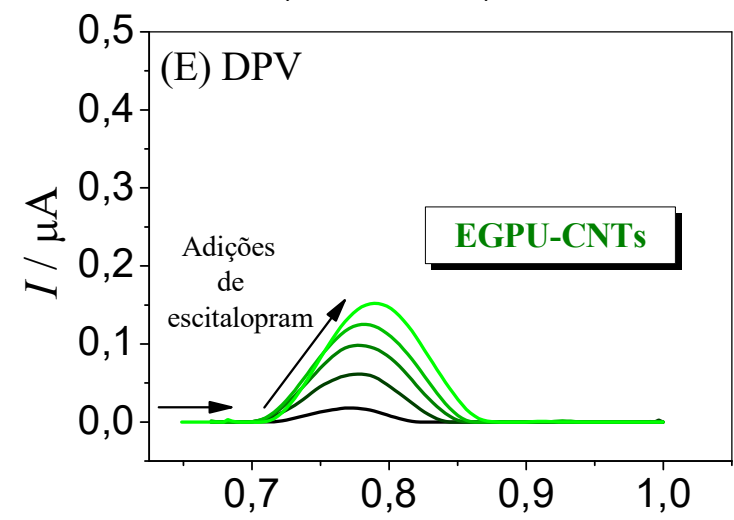

(E vs. SCE) / V

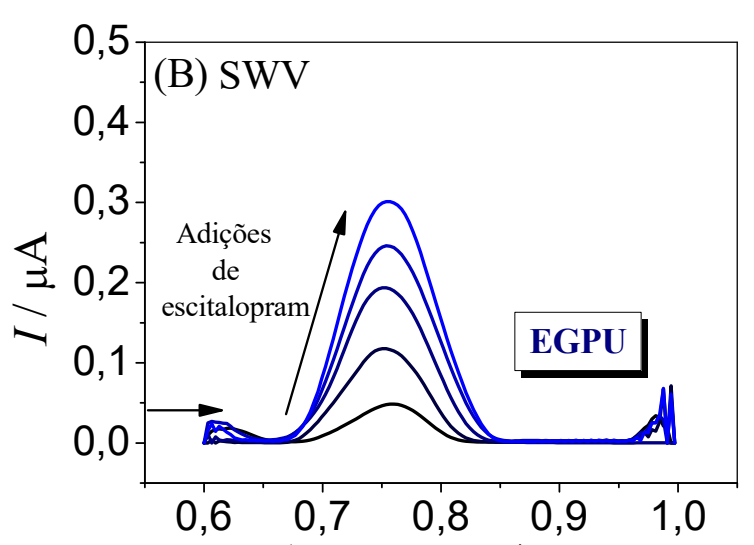

(E vs. SCE) / V

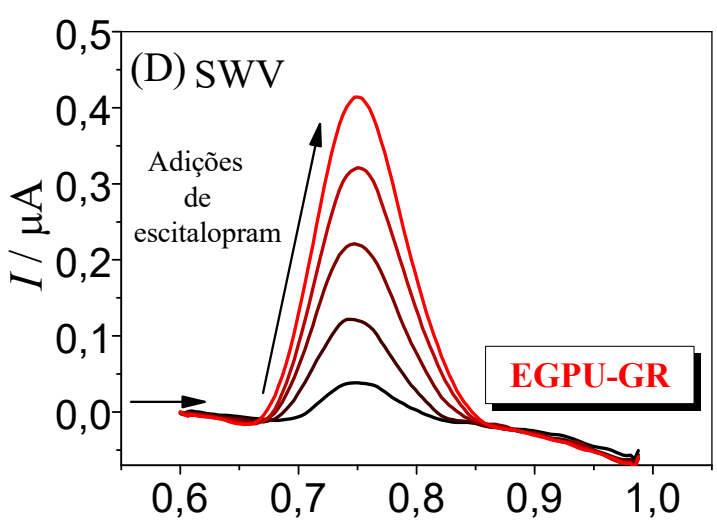

(E vs. SCE) / V

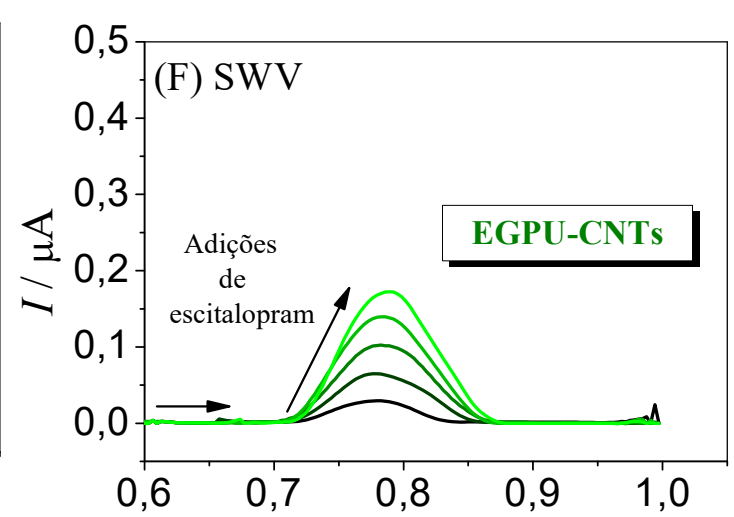

(Evs. SCE) / V

Figura 14. (A) Voltamogramas de DPV e (B) voltamogramas de SWV obtidos utilizando o EGPU; (C) Voltamogramas de DPV e (D) voltamogramas de SWV obtidos utilizando o EGPUGR; (E) Voltamogramas de DPV e (F) voltamogramas de SWV obtidos utilizando o EGPU-CNTs, todos para análises de diferentes concentrações de escitalopram (1-5) de 1,5 a $12 \mu \mathrm{mol} \mathrm{L} \mathrm{L}^{-1}$ em tampão Britton-Robinson $0,10 \mathrm{~mol} \mathrm{~L}^{-1}(\mathrm{pH} \mathrm{6,3).} \mathrm{Parâmetros} \mathrm{da} \mathrm{DPV:}$ velocidade de varredura de potenciais $=20 \mathrm{mV} \mathrm{s}^{-1}$ e amplitude de pulso $=50 \mathrm{mV}$ e para SWV: frequência $=8 \mathrm{~Hz}$, amplitude de pulso $=50 \mathrm{mV}$ e incremento de varredura $=2 \mathrm{mV}$.

A partir dos voltamogramas obtidos para os três eletrodos, gráficos de corrente de pico anódico $\left(I_{\mathrm{pa}}\right)$ vs. concentração de escitalopram foram construídos para cada técnica, apresentados nas Figuras 15A e 15B, referente à DPV e SWV, respectivamente. 

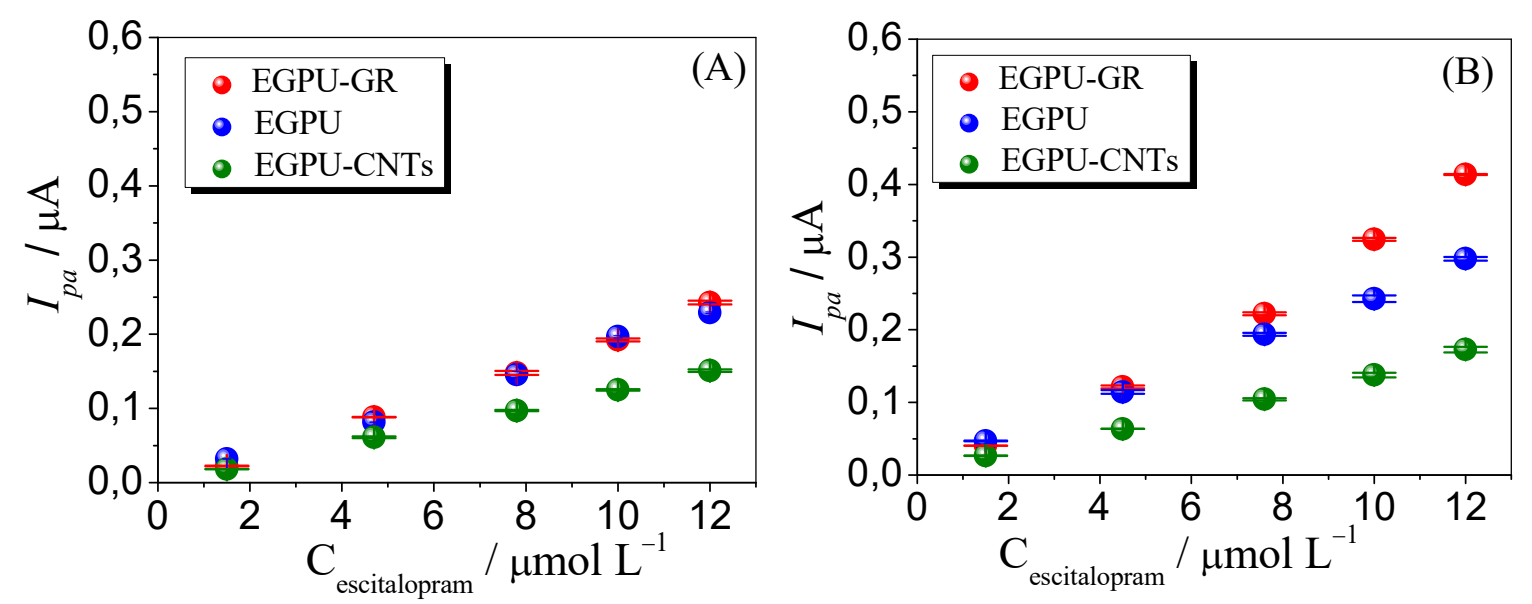

Figura 15. Curvas analíticas obtidas utilizando a DPV (A) e a SWV (B), com medidas feitas em triplicata.

Para facilitar a comparação dos parâmetros analíticos obtidos, a equação linear, os LOD calculados, a faixa linear estudada e a sensibilidade obtida para cada eletrodo utilizado foram introduzidas nas Tabelas 2 e 3 para DPV e SWV, respectivamente. Considerando maior sensibilidade, o EGPU-GR confirmou ser o melhor eletrodo dos três desenvolvidos, para a determinação de escitalopram. Além disso, a SWV foi selecionada para ser usada nos próximos estudos, uma vez que apresentou menor LOD e maior sensibilidade comparada a DPV.

Tabela 2. Comparação dos três eletrodos desenvolvidos para a determinação de escitalopram utilizando DPV

DPV

\begin{tabular}{cccc}
\hline Parâmetros & EGPU & EGPU-GR & EGPU-CNTs \\
\hline Equação da reta/ & $-0,0083+0,020 \mathrm{C}_{\mathrm{EST}}{ }^{*}$ & $0,0036+0,020 \mathrm{C}_{\mathrm{EST}} *^{*}$ & $-0,00082+0,013 \mathrm{C}_{\mathrm{EST}}{ }^{*}$ \\
$I \mu \mathrm{A}$ & 0,999 & 0,999 & 0,999 \\
$\mathrm{r}^{2}$ & 0,35 & 0,32 & 0,55 \\
$\mathrm{LOD} / \mu$ mol L & $1,5 \mathrm{a} 12$ & $1,5 \mathrm{a} 12$ \\
$\begin{array}{c}\text { Faixa linear/ } \\
\mu \text { mol L }\end{array}$ & $1,5 \mathrm{a} 12$ & 0,020 & 0,013 \\
$\begin{array}{c}\text { Sensibilidade/ } \\
\mu \mathrm{A} \mu \mathrm{mol}^{-1} \mathrm{~L}\end{array}$ & 0,020 & 0 & \\
\hline
\end{tabular}

*Concentração de escitalopram $\left(\mu \mathrm{mol} \mathrm{L}{ }^{-1}\right)$.

$\mathrm{r}^{2}=$ coeficiente de correlação 
Tabela 3. Comparação dos três eletrodos desenvolvidos para a determinação de escitalopram utilizando SWV

\begin{tabular}{|c|c|c|c|}
\hline & & SWV & \\
\hline Parâmetros & EGPU & EGPU-GR & EGPU-CNTs \\
\hline $\begin{array}{c}\text { Equação da reta/ } \\
I \mu \mathrm{A}\end{array}$ & $0,011+0,024 \mathrm{C}_{\mathrm{EST}} *$ & $-0,014+0,036 \mathrm{C}_{\mathrm{EST}} *$ & $-0,00011+0,014 \mathrm{C}_{\mathrm{EST}}{ }^{*}$ \\
\hline$r^{2}$ & 0,998 & 0,997 & 0,999 \\
\hline $\mathrm{LOD} / \mu \mathrm{mol} \mathrm{L}-1$ & 0,32 & 0,25 & 0,45 \\
\hline $\begin{array}{l}\text { Faixa linear/ } \\
\mu \mathrm{mol} \mathrm{L}-1\end{array}$ & 1,5 a 12 & 1,5 a 12 & 1,5 a 12 \\
\hline $\begin{array}{l}\text { Sensibilidade/ } \\
\mu \mathrm{A} \mu \mathrm{mol}^{-1} \mathrm{~L}\end{array}$ & 0,024 & 0,036 & 0,014 \\
\hline
\end{tabular}

Em seguida, avaliou-se a repetibilidade da resposta do EGPU-GR para o método proposto. Assim, medidas sucessivas da corrente de pico de oxidação do escitalopram $(6,0$ $\mu$ mol $\mathrm{L}^{-1}$ ) foram realizadas no mesmo dia, sem a renovação de superfície entre elas. $\mathrm{Na}$ Figura 16A são apresentados os voltamogramas de SWV obtidos para 10 medidas consecutivas, sendo o desvio padrão relativo calculado de 3,0 \%. Também foram feitas cinco medidas consecutivas para mesma concentração, em três dias diferentes, renovando-se a superfície para cada dia. Os resultados alcançados estão reportados nas Figuras 16B-D, a partir das quais foram calculadas as médias de corrente de pico de oxidação para cada dia, o desvio padrão relativo para cada dia de 4,4; 4,8 e 5,8 \%, respectivamente, e o desvio padrão relativo calculado para as três médias foi de 5,0\%. Estes resultados confirmaram a repetibilidade da resposta do eletrodo proposto para o método de determinação do escitalopram, mesmo após a renovação de superfície. 

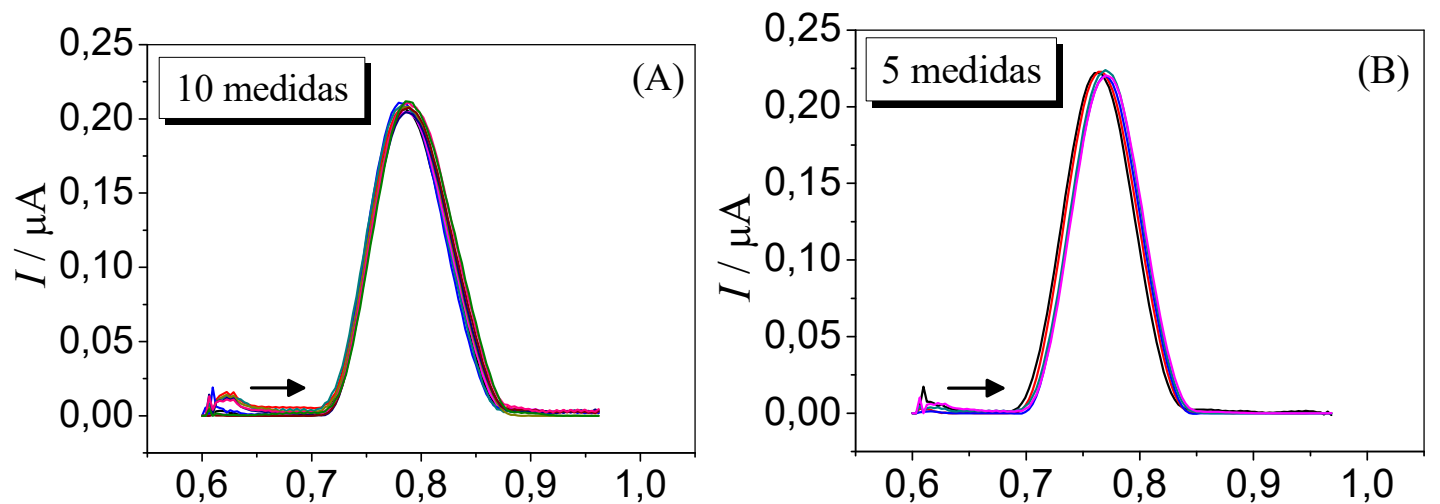

(E vs. SCE) / V

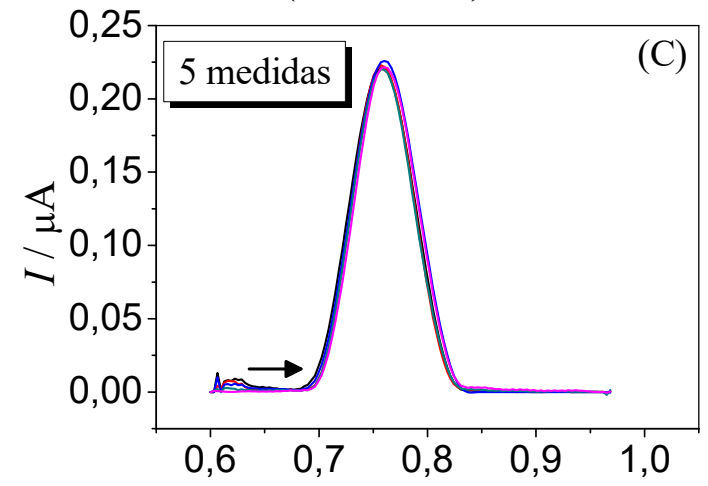

(Evs. SCE)/ V

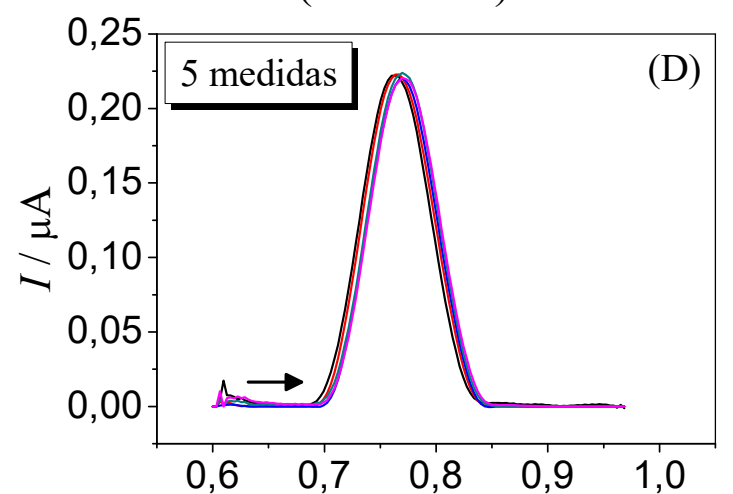

(Evs. SCE) / V

Figura 16. Voltamogramas de SWV obtidos para escitalopram $6,0 \mu \mathrm{mol} \mathrm{\textrm {L } ^ { - 1 }}$ em Britton-Robinson $0,10 \mathrm{~mol} \mathrm{~L}^{-1}$ (pH 6,3) EGPU-GR para (A) para 10 medidas consecutivas no mesmo dia sem renovação de superfície entre as medidas e (B-D) 5 medidas consecutivas para cada dia $(\mathrm{n}=3)$. Parâmetros: frequência $=8 \mathrm{~Hz}$, amplitude de pulso $=50 \mathrm{mV}$ e incremento de varredura $=2 \mathrm{mV} \mathrm{s}^{-1}$.

Também se investigou a ação de possíveis interferentes presentes em amostras de urina e fluido de cérebro-espinal, no método proposto. As substâncias analisadas foram DA, AA, UA e creatinina, que apresentaram interferência menor que 5,0 \% no sinal analítico do escitalopram, indicando uma interferência insignificante na determinação do antidepressivo. É importante ressaltar que, para este estudo, foi utilizada a janela de potenciais de $0,60 \mathrm{~V}$ a 1,0 $\mathrm{V}$ (vs. SCE), otimizada durante o desenvolvimento do procedimento. Neste intervalo de potenciais, nenhum processo de oxidação desses interferentes foi observado.

\subsubsection{Aplicação do método desenvolvido em amostras biológicas sintéticas}

Finalmente, o EGPU-GR foi utilizado para a determinação de escitalopram em amostras de urina e fluido cérebro-espinal sintéticas e os resultados obtidos juntamente com os valores de recuperação calculados são apresentados nas Tabelas 4 e 5, respectivamente. Este estudo também foi realizado em DPV para comparar os resultados obtidos. Os valores 
experimentais e adicionados estão de acordo com o test $t$-Student, com $95 \%$ de confiança. As recuperações em ambas as amostras sintéticas variaram na faixa de $97 \%$ a $102 \%$ para a SWV e de 97 \% a 106 \% para a DPV, indicando que não há interferência significativa da matriz das amostras analisadas na determinação de escitalopram, confirmando a seletividade de ambos os métodos propostos, usando o EGPU-GR.

Tabela 4. Resultados obtidos utilizando a DPV e a SWV para a determinação de escitalopram em amostras de urina e fluido cérebro-espinal sintética

urina sintética

\begin{tabular}{|c|c|c|c|c|c|c|}
\hline \multirow{3}{*}{ Amostras } & & & & & & \\
\hline & \multicolumn{3}{|c|}{ DPV } & \multicolumn{3}{|c|}{ SWV } \\
\hline & $\begin{array}{c}\text { Adic. }^{\mathrm{a}} \\
\left(\mu \mathrm{mol} \mathrm{L}{ }^{-1}\right)\end{array}$ & $\begin{array}{l}\text { Encont. }^{\mathrm{b}} \\
\left(\mu \mathrm{mol} \mathrm{L}{ }^{-1}\right)\end{array}$ & $\begin{array}{l}\text { Rec. }^{\mathrm{c}} \\
(\%)\end{array}$ & $\begin{array}{c}\text { Adic. }^{\mathrm{a}} \\
\left(\mu \mathrm{mol} \mathrm{L}{ }^{-1}\right)\end{array}$ & $\begin{array}{l}\text { Encont. }^{\mathrm{b}} \\
\left(\mu \mathrm{mol} \mathrm{L}{ }^{-1}\right)\end{array}$ & $\begin{array}{l}\text { Rec. }^{\mathrm{c}} \\
(\%)\end{array}$ \\
\hline A & 3,98 & $4,17 \pm 0,07$ & 105 & 3,98 & $4,03 \pm 0,06$ & 101 \\
\hline B & 7,94 & $8,04 \pm 0,04$ & 101 & 7,94 & $8,07 \pm 0,05$ & 102 \\
\hline $\mathrm{C}$ & 11,8 & $11,9 \pm 0,0_{3}$ & 101 & 11,8 & $11,9 \pm 0,0_{1}$ & 101 \\
\hline
\end{tabular}

fluido cérebro-espinal sintético

\begin{tabular}{|c|c|c|c|c|c|}
\hline \multicolumn{3}{|c|}{ DPV } & \multicolumn{3}{|c|}{ SWV } \\
\hline $\begin{array}{c}\text { Adic. }^{\mathrm{a}} \\
\left(\mu \mathrm{mol} \mathrm{L}{ }^{-1}\right)\end{array}$ & $\begin{array}{c}\text { Encont. }^{\mathrm{b}} \\
\left(\mu \mathrm{mol} \mathrm{L}{ }^{-1}\right)\end{array}$ & $\begin{array}{l}\text { Rec. }^{\mathrm{c}} \\
(\%)\end{array}$ & $\begin{array}{c}\text { Adic. }^{\mathrm{a}} \\
\left(\mu \mathrm{mol} \mathrm{L}{ }^{-1}\right)\end{array}$ & $\begin{array}{c}\text { Encont. }^{\mathrm{b}} \\
\left(\mu \mathrm{mol} \mathrm{L}{ }^{-1}\right)\end{array}$ & $\begin{array}{l}\text { Rec. }^{c} \\
(\%)\end{array}$ \\
\hline 3,98 & $4,20 \pm 0,08$ & 106 & 3,98 & $4,01 \pm 0,06$ & 101 \\
\hline 7,94 & $7,96 \pm 0,02$ & 101 & 7,94 & $8,05 \pm 0,03$ & 101 \\
\hline 11,8 & $11,4 \pm 0,0_{3}$ & 97,0 & 11,8 & $11,5 \pm 0,02$ & 97,0 \\
\hline
\end{tabular}

${ }^{\mathrm{a}}$ Adic. $=$ Adicionado

${ }^{\mathrm{b}}$ Encont. $=$ Encontrado

${ }^{\mathrm{c}}$ Rec. $=$ Recuperado

$\mathrm{Na}$ literatura, até o presente momento, apenas dois sensores eletroquímicos foram reportados para a determinação de escitalopram: Jain et al. ${ }^{91}$ propuseram a modificação de um GCE com filme de nanopartículas de óxido de bismuto e o sensor eletroquímico foi utilizado para a determinação de escitalopram em formulações farmacêuticas. Já Attia et al. ${ }^{92}$. descreveram um CPE modificado com NiNPs, por eletrodeposição, para determinação de escitalopram em formulações farmacêuticas e urina. As faixas lineares obtidas e os LODs calculados foram similares aos reportados neste trabalho. Entretanto, ambos os trabalhos 
propõem a modificação da superfície do eletrodo para ser realizada diariamente antes das medidas (método do gotejamento e eletrodeposição), o que consome tempo de preparo todas as vezes que for utilizar estes eletrodos. Este trabalho apresentou vantagem uma vez que modificação é feita no corpo do eletrodo, sendo necessário apenas um simples polimento para renovação da superfície. 


\subsection{CONCLUSÕES PARCIAIS}

Neste trabalho, três eletrodos compósitos diferentes foram fabricados, denominados EGPU, EGPU-GR e EGPU-CNTs, e seus desempenhos foram comparados utilizando técnicas voltamétricas em torno do sinal analítico do antidepressivo escitalopram.

Com os voltamogramas cíclicos obtidos para o escitalopram observou-se um comportamento irreversível sob a superfície dos eletrodos. O EGPU-GR foi selecionado para a quantificação do escitalopram em amostras de urina sintética e fluido cérebro-espinal sintético, por apresentar a maior sensibilidade, comparado aos demais eletrodos desenvolvidos. Neste trabalho a quantificação do escitalopram utilizando a SWV, apresentou vantagens como rapidez, simplicidade, repetibilidade, com um eletrodo mecanicamente robusto e estável. Além disso, todo o corpo do eletrodo, e não apenas na superfície, era constituído pelo compósito grafite-PU modificado com GR, o que permitiu renovação superficial com um simples polimento. 


\section{CAPÍTULO 3}

Desenvolvimento de um eletrodo tipo PEN LAB baseado em um compósito grafite-poliuretana e nanopartículas de prata para detecção de bisfenol-A em amostras de água de rio e de abastecimento público 


\subsection{OBJETIVOS ESPECÍFICOS}

Avaliar a utilização do poliol para preparar AgNPs diretamente na estrutura do grafite.

Desenvolver uma nova configuração de sensor eletroquímico integrando o eletrodo de trabalho, o de referência e o contra-eletrodo em um único dispositivo à base do compósito grafite-poliuretana.

Avaliar as potencialidades analíticas do novo sensor, na determinação de bisfenol-A em amostras de água de rio e de abastecimento público. 


\subsection{MATERIAL E MÉTODOS}

\subsubsection{Reagentes}

Todos os reagentes: bisfenol-A, $\mathrm{AgNO}_{3}$, grafite $(<20 \mu \mathrm{m})$, tetraciclina, ibuprofeno, furosemida, catecol e $\beta$-estradiol de grau analítico, PA, foram adquiridos da Sigma-Aldrich e usados como recebidos. Para a confecção dos eletrodos compósitos utilizou-se resina PU derivada de óleo vegetal composta por um pré-polímero (A-249) e um poliol (B-471) (Poliquil, Brasil). Todas as soluções foram preparadas com água purificada em um sistema Barnested $^{\circledR}$ (resistividade $\geq 18,0 \mathrm{M} \Omega \mathrm{cm}$ ). A solução de tampão fosfato $0,10 \mathrm{~mol} \mathrm{~L}^{-1}(\mathrm{pH}$ 7,4), utilizada como eletrólito suporte para as medidas eletroquímicas, foi preparada com $\mathrm{Na}_{2} \mathrm{HPO}_{4}$ e $\mathrm{NaH}_{2} \mathrm{PO}_{4}$. As soluções de bisfenol-A foram preparadas em etanol diariamente.

\subsubsection{Instrumentação}

\subsubsection{Equipamento e condições utilizadas nas análises de termogravimetria}

As curvas termogravimétricas (TGA/DTG) foram obtidas em um módulo Q-600 (TA Instruments), utilizando cerca de 10,0 $\pm 0,1 \mathrm{mg}$ de amostra, em atmosfera dinâmica de $\mathrm{N}_{2}$ até $600{ }^{\circ} \mathrm{C}$ e de ar seco de $600-1000{ }^{\circ} \mathrm{C}$ e vazão de $50 \mathrm{~mL} \mathrm{~min}^{-1}$ com razão de aquecimento de 10 ${ }^{\circ} \mathrm{C} \min ^{-1}$ em suporte de amostra de $\alpha$-alumina.

\subsubsection{Microscopia eletrônica de varredura e espectroscopia de dispersão de energia por raios $X$}

A análise por SEM e espectroscopia de dispersão de energia por raios X (EDX, do inglês "energy-dispersive X-ray spectroscopy") das AgNPs em pó de grafite foi registrada usando um microscópio LEO 440 (Zeiss-Leica, modelo 7060) operado a $20 \mathrm{kV}$. As amostras foram analisadas sem metalização. Para observar a morfologia e o tamanho do AgNPs em pó de grafite foi utilizado o microscópio SEM-FEG ZEISS (modelo SIGMA). 


\subsubsection{Difração de raios $X$}

Para confirmar a cristalinidade das AgNPs, um difratômetro Rigaku Rotaflex (modelo RU200B) a $50 \mathrm{kV}$ e $100 \mathrm{~mA}$, com radiação $\mathrm{CuK} \alpha(\lambda=1,542 \AA)$, foi usado para análise de difração de raios X de pó (XRPD, do inglês “ $X$-ray powder diffraction”).

\subsubsection{Técnicas voltamétricas e cronocoulométricas}

As medidas eletroquímicas foram realizadas em um potenciostato/galvanostato Autolab PGSTAT30 (Eco Chemie) acoplado a um microcomputador controlado pelo software NOVA 2.1.3. A célula eletroquímica utilizada foi um sistema convencional com compartimento único e tampa de teflon com orifícios para encaixe de três eletrodos. Todos os experimentos foram conduzidos à temperatura controlada de $25 \pm 1{ }^{\circ} \mathrm{C}$. Além disso, antes das medidas eletroquímicas, os eletrodos fabricados eram lixados em uma politriz motorizada da Arotec (modelo APL-02), sendo utilizada lixa com granulometria de 600 GRIT (composição $\mathrm{SiC})$.

\subsubsection{Síntese das AgNPS no pó de grafite}

As AgNPs foram sintetizadas diretamente sobre pó de grafite em meio reacional de etilenoglicol (EG) utilizando o método poliol ${ }^{125}$. Para isso, diferentes proporções de grafite e $\mathrm{AgNO}_{3}$ foram pesadas e colocadas em um balão de vidro de fundo redondo protegido com papel alumínio e suspenso em 30,0 mL de EG.

Três preparações de grafite contendo AgNPs foram feitas com quantidades crescentes de $\mathrm{AgNO}_{3}(100,200$ e 300) e retirando-se quantidades equivalentes de grafite, de forma a obter uma massa total de $900 \mathrm{mg}$ :

$1^{\circ}$ ) Preparação A: $800 \mathrm{mg}$ de pó de grafite mais $100 \mathrm{mg}$ de $\mathrm{AgNO}_{3}$;

$2^{\circ}$ ) Preparação B: 700 mg de pó de grafite mais 200 mg de $\mathrm{AgNO}_{3}$;

$3^{\circ}$ ) Preparação C: $600 \mathrm{mg}$ de pó de grafite mais $300 \mathrm{mg}$ de $\mathrm{AgNO}_{3}$.

$\mathrm{O}$ balão de vidro contendo a mistura grafite $/ \mathrm{AgNO}_{3} / \mathrm{EG}$ foi imerso em um banho de glicerina a $150{ }^{\circ} \mathrm{C}$, e conectado a um condensador, e o sistema foi mantido sob agitação por 1h. Foi reportado na literatura ${ }^{125}$ que a esta temperatura o EG funciona como agente redutor e controlador do tamanho das AgNPs formadas. Ao final desse período, a suspensão obtida foi filtrada em papel qualitativo sob vácuo e lavada com água. O produto obtido foi seco em estufa a $80{ }^{\circ} \mathrm{C}$ por 12 horas e estocado em frasco âmbar. O esquema da preparação é apresentado na Figura 17. 


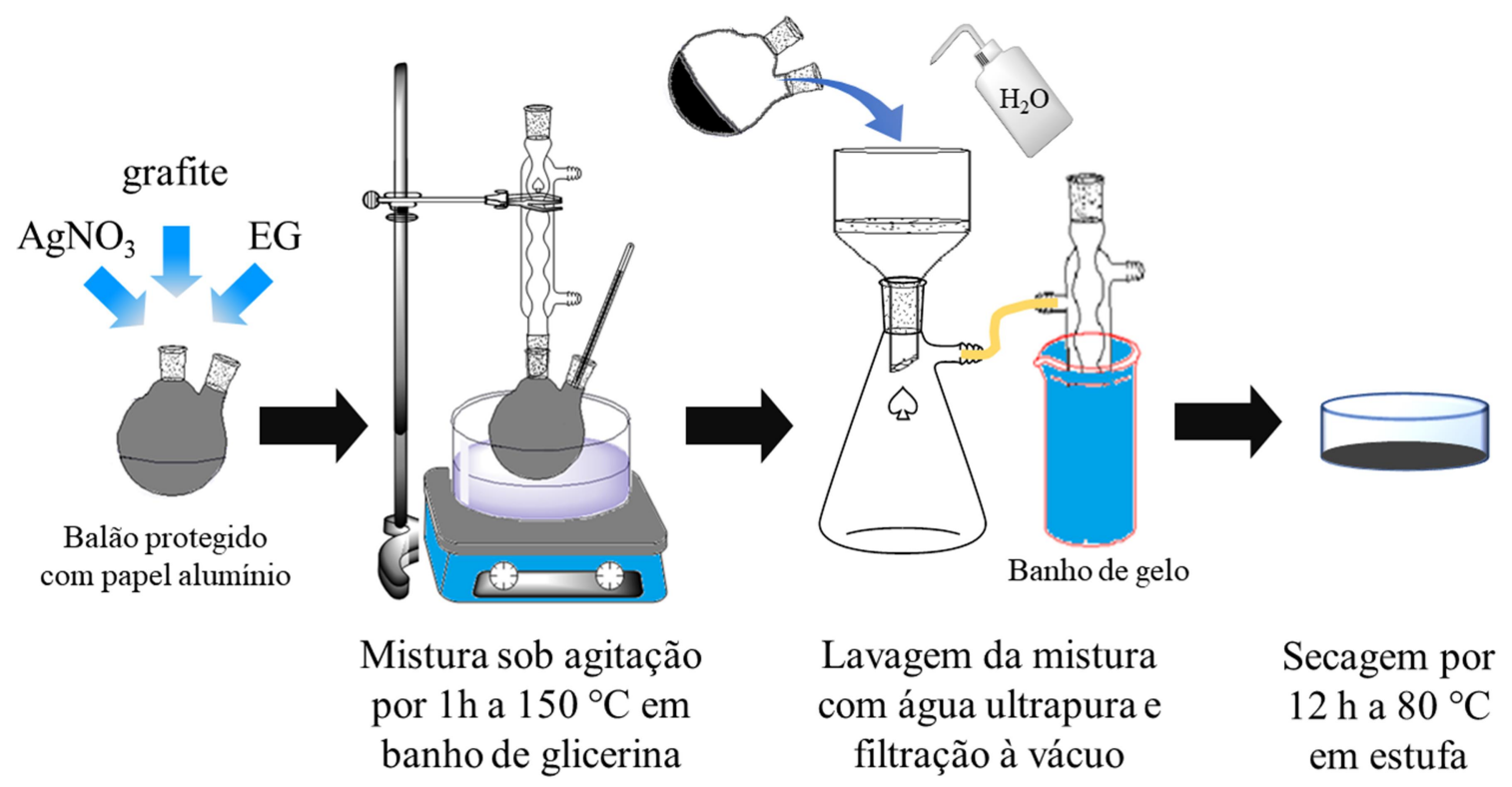

Figura 17. Esquema da preparação das AgNPs suportadas sob o grafite pelo método poliol.

\subsubsection{Preparo do compósito AgNPs- grafite-poliuretana e dos PEN LABs}

Neste trabalho foi proposto a incorporação das AgNPs suportadas no pó de grafite para a confecção de eletrodos compósitos à base de AgNPs-GPU. Como ponto de partida, foi mantida a proporção (AgNPs/grafite):PU $\left(60: 40 \%, \mathrm{~m} \mathrm{~m}^{-1}\right)$ e fabricaram-se eletrodos à base de grafite-PU e AgNPs-grafite-PU (respectivos as três preparações realizadas com diferentes quantidades de AgNPs no pó de grafite).

O grafite com as AgNPs suportadas em sua estrutura e a PU foram misturados em um almofariz de vidro (Figura 18A), colocados em um copo de metal (com orifício de extrusão de 1,2 mm de diâmetro) com o auxílio de uma espátula (Figura 18B). Posteriormente, o material foi extrudado com o auxílio de uma prensa manual (Figura 18C), resultando em tarugos com comprimento entre 4 e $7 \mathrm{~cm}$ (Figura 18D). É importante destacar que todo o processo deve ser feito em menos de 10 minutos, já que acima deste tempo, a resina começa a curar. Após a cura, que se completa à temperatura ambiente $(24 \mathrm{~h})$, cortou-se os tarugos em pedaços com 1 $\mathrm{cm}$ de comprimento. O tarugo à base de grafite-PU foi chamado EGPU e os demais modificados com AgNPs, foram chamados de acordo com as quantidades de $\mathrm{AgNO}_{3}$ utilizados em sua síntese: A-AgNP-EGPU, B-AgNP-EGPU e C-AgNP-EGPU.

Estes compósitos à base de AgNPs-EGPU e o compósito EGPU sem modificação foram conectados a fios de cobre ( $9 \mathrm{~cm}$ de comprimento e $1 \mathrm{~mm}$ de diâmetro), usando cola de prata (cat. no. 12,642-14, Conductive Silver Epoxy Kit, Electron Microscopy Sciences) para 
garantir o contato elétrico e deixados para curar a $25^{\circ} \mathrm{C}$ por mais $24 \mathrm{~h}$ (Figura 18E). Para auxiliar nesta etapa foi utilizado um gabarito para alinhamento dos fios de cobre com os compósitos.
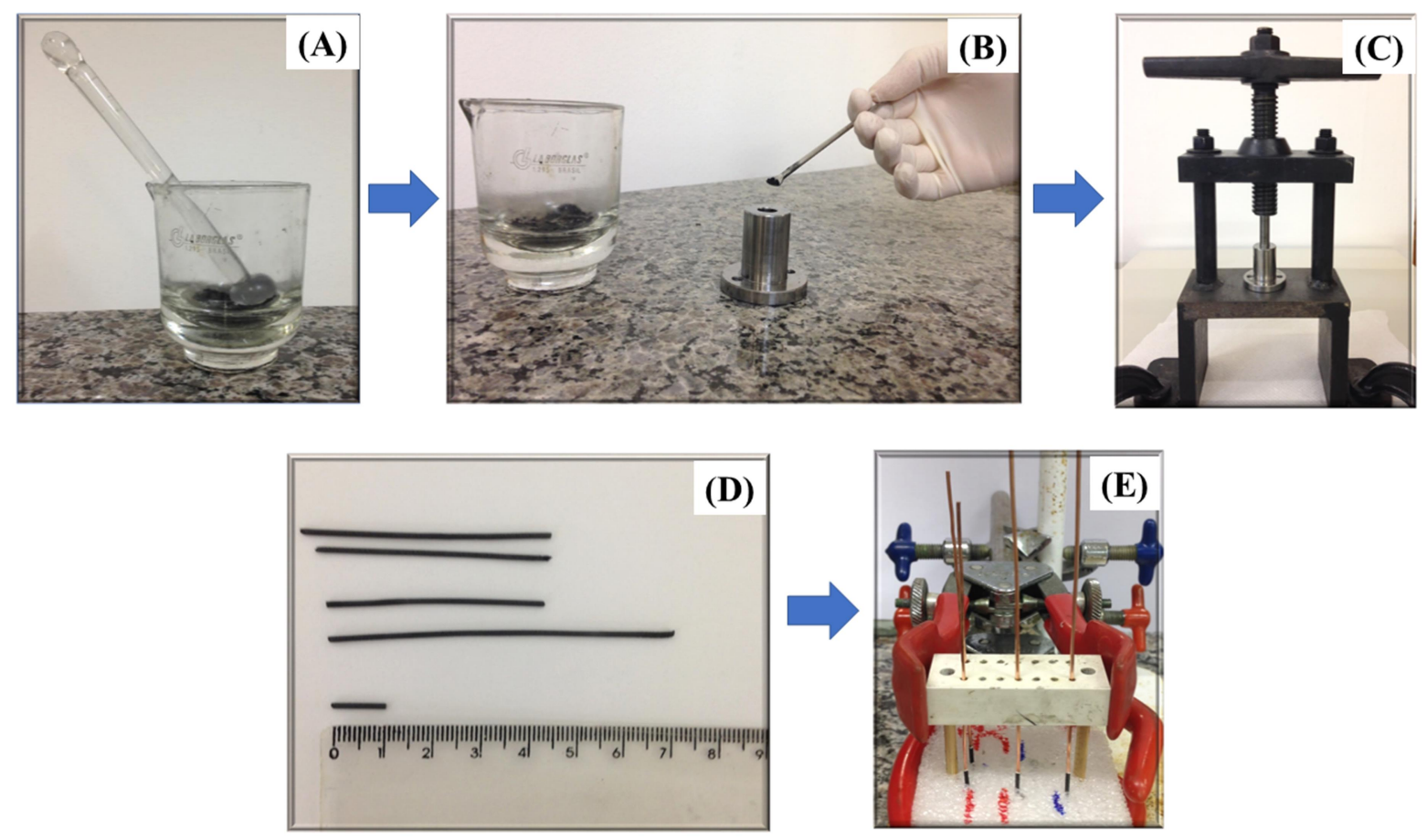

Figura 18. Fotografias representando as etapas de preparação do compósito e do conjunto compósito/fio de cobre. Em (A) mistura do material condutor (grafite e/ou AgNPsgrafite) mais PU; em (B) material é colocado em um copo de metal (com orifício de extrusão de 1,2 mm de diâmetro) com o auxílio de uma espátula; em (C) o copo de metal é encaixado em uma prensa manual, na qual o material é extrudado; em (D) tarugos variando de comprimento entre 4 e $7 \mathrm{~cm}$; e em (E) tarugos conectados a um fio de cobre usando cola de prata, utilizando um gabarito para alinhamento.

Os conjuntos compósitos/fio de cobre foram envolvidos por fios termocontráteis (Figura 19A) e fixados com um auxílio de secador de cabelo, ficando expostos apenas os compósitos e as extremidades dos fios de cobre (Figura 19B).
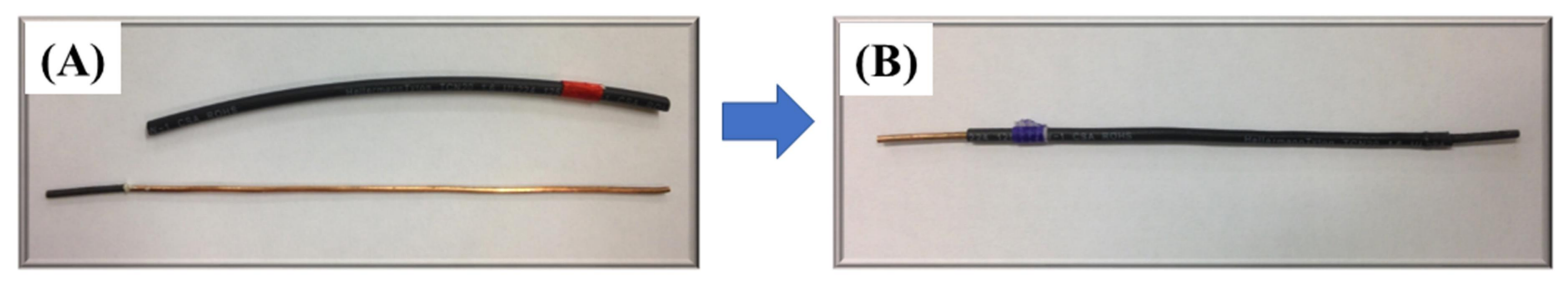

Figura 19. Em (A) fotografia do conjunto compósito/fio de cobre e fio termocontrátil. Em (B) fotografia do conjunto compósito/fio de cobre envolvido por fio termocontrátil. 
Em seguida, quatro dispositivos foram fabricados com três eletrodos cada um, com as seguintes composições:

I) Três EGPUs como eletrodo de trabalho, de pseudo-referência e de auxiliar;

II) Um A-AgNP-EGPU como eletrodo de trabalho, e dois EGPU como eletrodo de pseudo-referência e auxiliar;

III) Um B-AgNP-EGPU como eletrodo de trabalho, e dois EGPU como eletrodo de pseudo-referência e auxiliar;

IV) Um C-AgNP-EGPU como eletrodo de trabalho, e dois EGPU como eletrodo de pseudo-referência e auxiliar;

Cada conjunto de três compósitos/fio de cobre foi colocado em um tubo de vidro (6 $\mathrm{mm}$ de diâmetro interno e $9 \mathrm{~cm}$ de comprimento), preenchido com resina epóxi (Silaex 6400 Brasil) (Figura 20A). Os quatro dispositivos resultantes foram deixados curar a $25{ }^{\circ} \mathrm{C}$ durante mais 24 h. Os novos designs de dispositivos foram chamados de PEN LAB EGPU (dispositivo I), PEN LAB A-AgNP-EGPU (II), PEN LAB B-AgNP-EGPU (III) e PEN LAB C-AgNPEGPU (IV). Na Figura 20B é apresentada uma fotografia da superfície desses PEN LAB e nas Figuras 20C e D as fotografias representando duas formas de realizar medidas voltamétricas com esses dispositivos, imersos em uma cela eletroquímica convencional e usando poça de solução $(20 \mu \mathrm{L})$ sobre a superfície do PEN LAB.
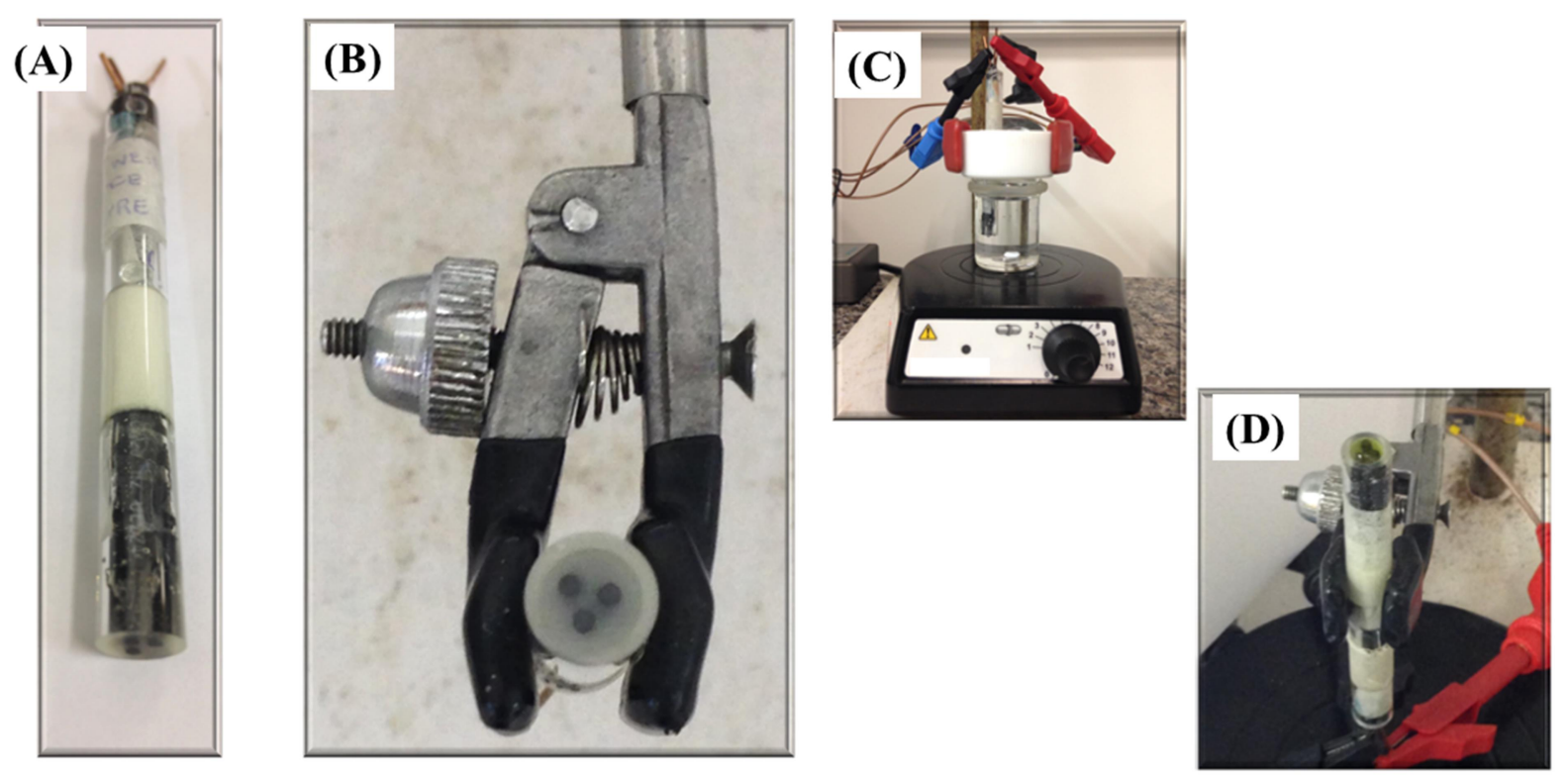

Figura 20. Fotografia: do PEN $L A B$ (A); da superfície do PEN LAB (B); do PEN LAB imerso em uma cela eletroquímica convencional $(\mathrm{C})$; e de uma poça de solução sobre a superfície do $P E N$ $L A B$ (D). 


\subsubsection{Coleta das amostras de águas de rio e de abastecimento público}

Amostras de água de rio foram coletadas no Rio Monjolinho da cidade de São Carlos

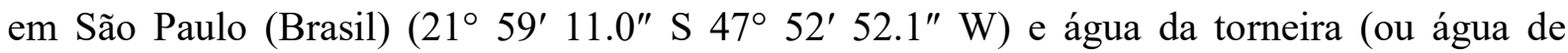
distribuição) foi coletada na mesma cidade. As amostras do rio foram filtradas em um papel filtro (marca Nalgon) com porosidade de $3 \mu \mathrm{m}$ para retirada de pequenas folhas e suspensões e a de abastecimento público foi utilizada sem qualquer tratamento prévio.

Para as análises, as amostras foram fortificadas com 7,0 e $10 \mu \mathrm{mol} \mathrm{L}^{-1}$ bisfenol-A, e foram realizadas as medidas de cada concentração. As recuperações para cada concentração e amostras foram calculadas.

\subsubsection{Procedimento experimental}

\subsubsection{Caracterização e quantificação das AgNPs formadas no grafite}

As técnicas SEM, SEM-FEG e XRPD foram utilizadas para confirmar a presença e caracterizar a morfologia e tamanho das nanopartículas obtidas no compósito AgNP-grafite. Enquanto que a termogravimetria foi utilizada para quantificar a quantidade de AgNPs presentes nos eletrodos compósitos propostos. A partir dos resultados de termogravimetria, os eletrodos PEN LAB A-AgNP-EGPU, PEN LAB B-AgNP-EGPU e PEN LAB C-AgNP-EGPU passaram a chamar PEN LAB $\operatorname{AgNP}_{2 \%}$-EGPU, PEN LAB $\operatorname{AgNP}_{5 \%}$-EGPU e PEN LAB $\operatorname{AgNP}_{10 \%}$-EGPU, respectivamente, baseado na quantidade de AgNPs no compósito.

\subsubsection{Cálculo da área eletroativa dos eletrodos desenvolvidos}

Medidas cronocoulométricas foram feitas como descrito na seção experimental do capítulo anterior.

\subsubsection{Desempenho eletroquímico dos PEN LABs}

Empregando a voltametria cíclica, as respostas eletroquímicas dos sensores PEN LAB

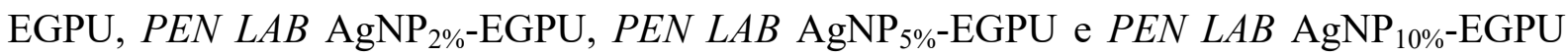
foram avaliados em tampão fosfato $0,10 \mathrm{~mol} \mathrm{~L}^{-1}$ ( $\left.\mathrm{pH} 7,4\right)$, a $v$ de $20 \mathrm{mV} \mathrm{s}^{-1}$, em um intervalo de varredura de potenciais entre - 0,2 a 0,6 V ( $v s$. EGPU), a fim de identificar os processos redox envolvidos.

A estabilidade das respostas eletroquímicas do PEN LAB AgNP ${ }_{2 \%}$-EGPU, PEN LAB $\operatorname{AgNP}_{5 \%}$-EGPU e PEN LAB AgNP $_{10 \%}$-EGPU também foram investigadas por meio de 25 
varreduras de voltametria cíclica a $50 \mathrm{mV} \mathrm{s}^{-1}$ em tampão fosfato $0,10 \mathrm{~mol} \mathrm{~L}^{-1}(\mathrm{pH} \mathrm{7,4)}$. Assim, os voltamogramas foram registrados e gráficos de corrente de pico anódica $\left(I_{\mathrm{a}}\right) v s$. número de varredura de potenciais (número de ciclos) foram construídos para avaliar a estabilidade dos eletrodos.

Voltamogramas cíclicos foram obtidos utilizando o PEN LAB AgNP ${ }_{2 \%}-\mathrm{EGPU}$, o PEN $L A B \operatorname{AgNP}_{5 \%}$-EGPU e o PEN LAB AgNP $10 \%$-EGPU em tampão fosfato $0,10 \mathrm{~mol} \mathrm{~L}^{-1}(\mathrm{pH}$ $7,4)$, em diferentes velocidades de varredura de potenciais $\left(v, 5\right.$ a $\left.200 \mathrm{mV} \mathrm{s}^{-1}\right)$. Ainda, a partir dos resultados obtidos com velocidade de $0,005 \mathrm{~V} \mathrm{~s}^{-1}$ foi possível calcular a concentração de espécies ativas de AgNPs na superfície de cada eletrodo através da Equação do recobrimento $(\Gamma)^{44}$ :

$$
\Gamma=Q / n \cdot F \cdot A
$$

(Equação 2)

Na qual $Q(\mathrm{C})$ é a carga elétrica calculada a partir da integral da área do pico de oxidação da Ag para cada eletrodo; $n$ é o número de elétrons envolvido no processo; $F$ é a constante de Faraday $\left(96485 \mathrm{C} \mathrm{mol}^{-1}\right)$ e $A$ é a área geométrica $\left(0,011 \mathrm{~cm}^{2}\right)$ dos três eletrodos propostos.

\subsubsection{Procedimento eletroanalítico para a determinação de bisfenol-A}

A DPV foi selecionada para o desenvolvimento do método eletroanalítico para a determinação de bisfenol-A em amostras de água de rio e de abastecimento público. Para isso, parâmetros como amplitude de potencial e velocidade de varredura de potenciais foram otimizados para obter as melhores condições analíticas, considerando maiores intensidades de corrente e definições de pico.

Em seguida, várias adições sucessivas de bisfenol-A foram feitas à célula eletroquímica, em tampão fosfato $0,10 \mathrm{~mol} \mathrm{~L}^{-1}$ (pH 7,4) usando PEN LAB EGPU, PEN LAB AgNP $_{2 \%}$-EGPU, PEN LAB AgNP ${ }_{5 \%}$-EGPU e PEN LAB AgNP $10 \%$-EGPU. A partir dos resultados obtidos, gráficos das correntes de pico de oxidação vs. concentrações de bisfenolA foram construídos para cada eletrodo. Além disso, valores de LOD, foram calculados como descrito na seção experimental do capítulo anterior ${ }^{119}$.

Considerando a maior sensibilidade (coeficiente angular da curva analítica) e menor LOD, o PEN LAB AgNP ${ }_{2 \%}$-EGPU foi selecionado para as próximas etapas do desenvolvimento do método proposto. Assim, estudos de repetibilidade sobre a resposta do eletrodo para uma concentração de bisfenol-A $9,0 \mu \mathrm{mol} \mathrm{L} \mathrm{L}^{-1}$ foram avaliadas. Para isso, 
medidas sucessivas da corrente de pico de oxidação do bisfenol-A foram realizadas no mesmo dia, sem a renovação de superfície entre elas. Também foram feitas 5 medidas consecutivas para mesma concentração, em três dias diferentes, renovando-se a superfície entre cada dia.

A determinação de bisfenol-A na presença de compostos de diferentes classes: tetraciclina (antibiótico), catecol (polifenol), ibuprofeno (anti-inflamatório), furosemida (diurético) e $\beta$-estradiol (hormônio) foi realizada, uma vez que esses poderiam ser possíveis interferentes na quantificação do mesmo. Para isso, foi utilizada a DPV (mesmos parâmetros dos estudos anteriores) e tampão fosfato $0,10 \mathrm{~mol} \mathrm{~L}^{-1}(\mathrm{pH} \mathrm{7,4)} \mathrm{como} \mathrm{eletrólito} \mathrm{suporte.}$ Tetraciclina, catecol, ibuprofeno, furosemida e $\beta$-estradiol foram adicionados à solução padrão inicial nas razões de concentrações 1:0,5; 1:1 e 1:2 ( $\mathrm{mol} \mathrm{mol}^{-1}$, analito: interferente). 


\subsection{RESULTADOS E DISCUSSÃO}

\subsubsection{Quantificação das AgNPs no compósito grafite-poliuretana por termogravimetria}

Com o intuito de quantificar as AgNPs presentes nos compósitos A-AgNP-EGPU, BAgNP-EGPU e C-AgNP-EGPU foram realizadas análises termogravimétricas (TG). A termogravimetria mede a variação de massa em relação à temperatura e é utilizada para a verificação da estabilidade térmica da amostra, determinação de perdas de massa e quantificação dos resíduos, dentre outras aplicações ${ }^{126}$. Na Figura 21 são apresentadas as comparações das curvas TG e sua derivada (DTG) para o compósito GPU sem modificação e os compósitos GPU modificados com as diferentes quantidades de AgNPs (A-AgNP-EGPU, B-AgNP-EGPU e C-AgNP-EGPU). Os valores dos intervalos de temperatura, assim como as perdas de massa e resíduos para as quatro amostras estão sumarizados na Tabela 5.

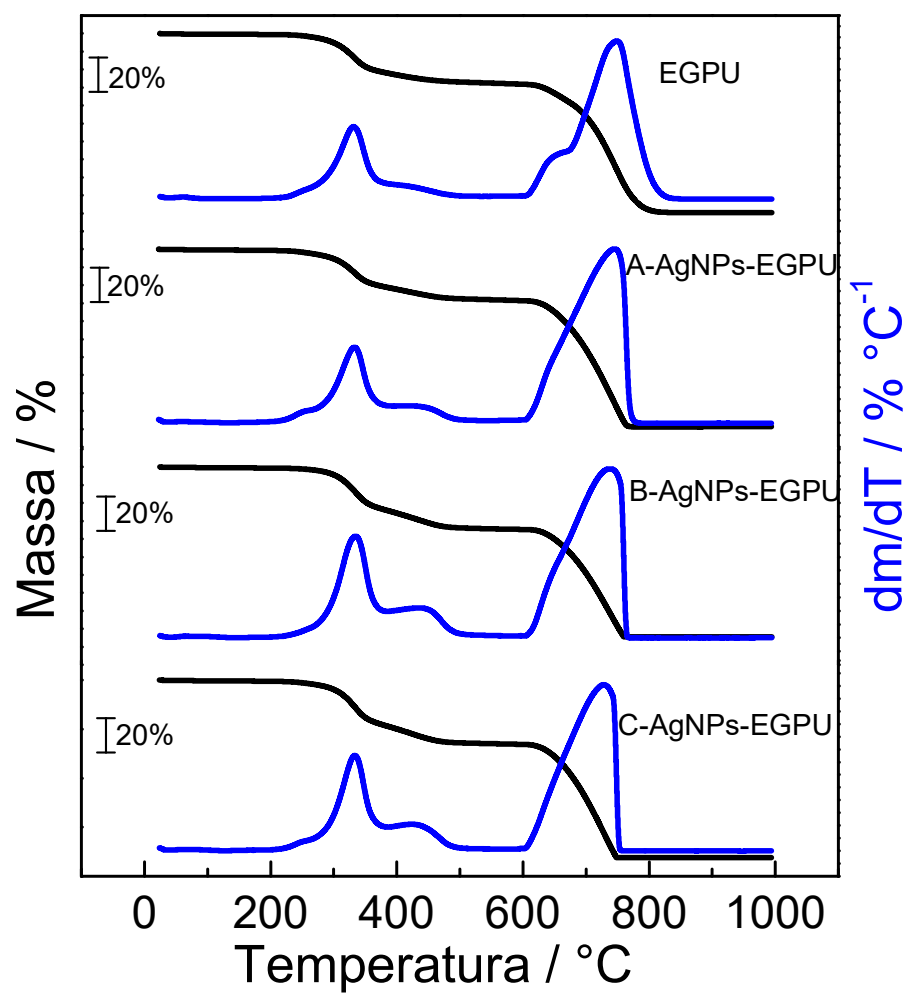

Figura 21. Curvas TG e DTG do EGPU, do A-AgNP-EGPU, do B-AgNP-EGPU e do C-AgNPEGPU em atmosferas dinâmicas de $\mathrm{N}_{2}$ até $600{ }^{\circ} \mathrm{C}$ e ar $\left(>600{ }^{\circ} \mathrm{C}\right.$ até $\left.1000{ }^{\circ} \mathrm{C}\right)$ a $50 \mathrm{~mL}$ $\min ^{-1}$, com razão de aquecimento de $10^{\circ} \mathrm{C} \min ^{-1}$, massa de amostra de $10 \pm 0,1 \mathrm{mg}$ e suporte amostra de $\alpha$-alumina. 
Tabela 5. Resultados obtidos a partir das curvas TG/DTG, com intervalos de temperatura e perda de massa

\begin{tabular}{ccc}
\hline Amostra & Intervalo de temperatura $/{ }^{\circ} \mathrm{C}$ & Perdas de massa $/ \%$ \\
\hline EGPU & $25,0-202,1$ & 0,558 \\
& $202,1-600,3$ & 27,7 \\
& $600,3-863,7$ & 71,4 \\
A-AgNP-EGPU & Resíduo a $1000{ }^{\circ} \mathrm{C}$ & 0,475 \\
& $25,0-197,0$ & 0,655 \\
& $197,0-386,7$ & 20,4 \\
& $386,7-600,1$ & 7,38 \\
B-AgNP-EGPU & $600,1-786,4$ & 70,19 \\
& Resíduo a $1000{ }^{\circ} \mathrm{C}$ & $\mathbf{1 , 5 5}$ \\
& $25,0-199,1$ & 0,501 \\
& $199,1-380,9$ & 23,1 \\
& $380,9-604,7$ & 11,0 \\
& $604,7-773,1$ & 59,7 \\
C-AgNP-EGPU & Resíduo a $1000{ }^{\circ} \mathrm{C}$ & $\mathbf{5 , 6 0}$ \\
& $25,0-200,1$ & 0,544 \\
& $200,1-379,9$ & 22,5 \\
& $379,9-599,0$ & 9,71 \\
& $599,0-760,6$ & 57,8 \\
& Resíduo a $1000{ }^{\circ} \mathrm{C}$ & $\mathbf{9 , 5 3}$ \\
\hline
\end{tabular}

Observa-se, a partir desses resultados, que as amostras apresentaram perdas de massa com intervalos de temperaturas semelhantes, indicando que as NPs presentes no meio praticamente não alteraram a estabilidade térmica do compósito.

A primeira perda de massa em ambos os casos ocorreu entre $\mathrm{T}_{\text {ambiente }}-200{ }^{\circ} \mathrm{C}$ e pode ser atribuída provavelmente à água adsorvida ou solventes residuais. A segunda e terceira etapas de perda de massa, que variaram entre $200-600{ }^{\circ} \mathrm{C}$ foram atribuídas à decomposição da PU, como já observado em trabalhos anteriores ${ }^{127}$, e a quarta perda de massa, que variou entre $600-780{ }^{\circ} \mathrm{C}$, foi relacionado com à combustão do grafite, após troca de atmosfera do forno de $\mathrm{N}_{2}$ para ar seco.

Os resíduos calculados ao fim da análise foram de 0,475 para o EGPU e 1,55; 5,60 e 9,53 para os compósitos de A-AgNP-EGPU, B-AgNP-EGPU e C-AgNP-EGPU, respectivamente. Assim, foi confirmado a composição em massa dos eletrodos modificados com AgNPs como sendo: $\operatorname{AgNP}_{2 \%}$ :G:PU (2:58:40\%, $\left.m m^{-1}\right), \operatorname{AgNP}_{5 \%}: \mathrm{G}: \mathrm{PU}(5: 55: 40 \%, m$ $\left.m^{-1}\right)$ e $\operatorname{AgNP}_{10 \%}: \mathrm{G}: \mathrm{PU}\left(10: 50: 40 \%, \mathrm{~m} \mathrm{~m}^{-1}\right)$, sendo então os eletrodos de trabalho denominados $\mathrm{AgNP}_{2 \%}$-EGPU, $\mathrm{AgNP}_{5 \%}$-EGPU e $\mathrm{AgNP}_{10 \%}$-EGPU.

De acordo com a temperatura e as perdas de massa observadas nas curvas, supõe-se que a $1000{ }^{\circ} \mathrm{C}$ já não haja mais matéria orgânica presente, portanto, o resíduo é composto 
unicamente por prata metálica, já que o óxido de prata é instável. Sendo assim, verifica-se que os valores dos resíduos determinados a partir das curvas TG refletem a quantidade de prata presente em cada um dos eletrodos propostos.

\subsubsection{Caracterização das AgNPs no grafite e no compósito grafite- poliuretana}

Para avaliar a distribuição das AgNPs suportadas na estrutura do grafite, s imagens de SEM dos compósitos à base de AgNPs-EGPU foram obtida. A partir das Figuras $22 \mathrm{~A}-\mathrm{C}$, referentes à fratura dos compósitos $\mathrm{AgNP}_{2} \%$-EGPU, $\mathrm{AgNP}_{5 \%}$-EGPU e $\mathrm{AgNP}_{10 \%}$-EGPU, respectivamente, nota-se certa homogeneidade nas formas e na distribuição das AgNPs em todo o compósito grafite-PU. Também foi perceptível a presença de alguns aglomerados destas NPs, provavelmente originadas da forma como o compósito é preparado. Já na Figura 22D, é mostrado uma imagem da fratura do compósito EGPU, em uma magnificação maior do que nas Figuras 22A-|C, para evidenciar a rugosidade da matriz de todos os compósitos.
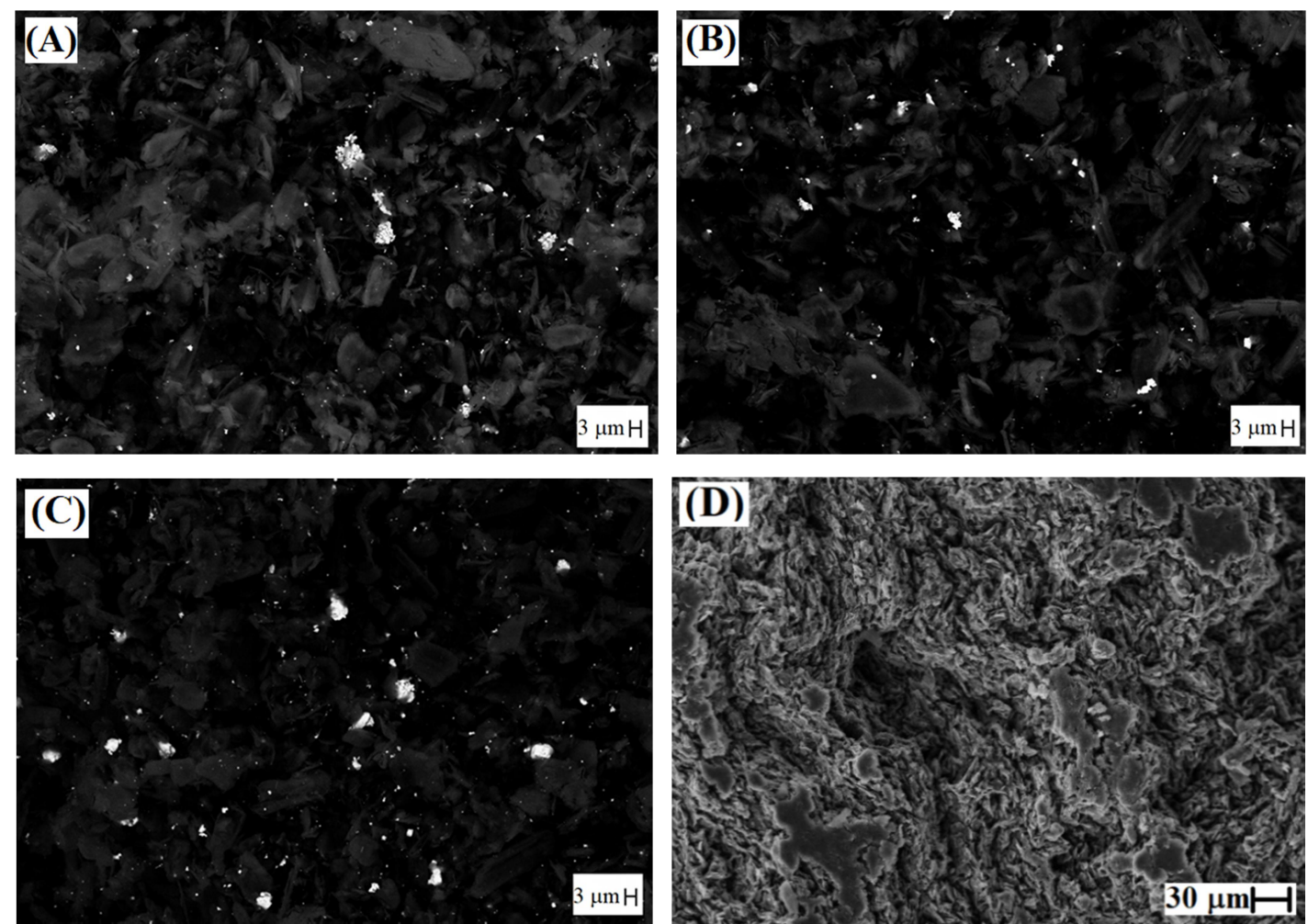

Figura 22. Imagens de SEM referentes à fratura dos compósitos (A) $\mathrm{AgNP}_{2 \%}-\mathrm{EGPU}$, (B) $\mathrm{AgNP}_{5 \%-}$ EGPU e (C) $\mathrm{AgNP}_{10 \%}$-EGPU, com magnificação de $2000 \times$, e em (D) referentes ao EGPU, com magnificação de $500 \times$. 
Em sequência, análises pontuais de EDX das partículas (AgNPs) das imagens de SEM para os compósitos $\mathrm{AgNP}_{2 \%}$-EGPU, $\mathrm{AgNP}_{5 \%}$-EGPU e $\mathrm{AgNP}_{10 \%}$-EGPU foram feitas, as quais indicaram uma composição de aproximadamente $80 \%$ prata e $20 \%$ carbono. Na Figura 23 é apresentado o espectro de EDX obtido a partir da análise do compósito $\mathrm{AgNP}_{2 \%}$-EGPU, como exemplo representativo.

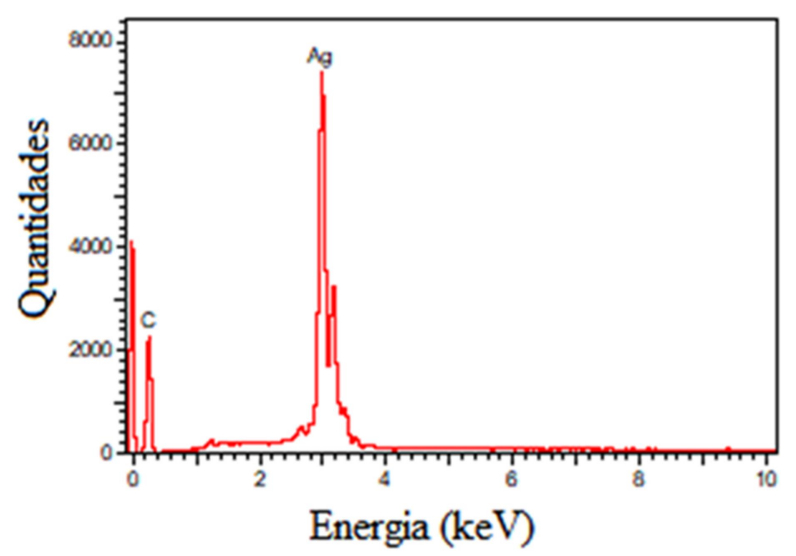

Figura 23. Espectro de EDX obtido do pó de grafite com AgNPs, a partir da análise pontual da imagem da Figura 22 A.

Nas Figuras 24A e 24B são mostradas as imagens de SEM-FEG com magnificação de 5000 e $50000 \times$ da amostra $\mathrm{AgNP}_{10 \%}$-grafite em forma de pó. Com base nessas imagens, foi possível confirmar a escala nanométrica das AgNPs, com tamanho entre 150 e $200 \mathrm{~nm}$, principalmente na Figura 24A, demonstrando a eficiência do método do poliol empregada neste trabalho. As amostras $\mathrm{AgNP}_{2 \%}$-grafite e $\mathrm{AgNP}_{5 \%}$-grafite apresentaram imagens similares (não apresentadas).
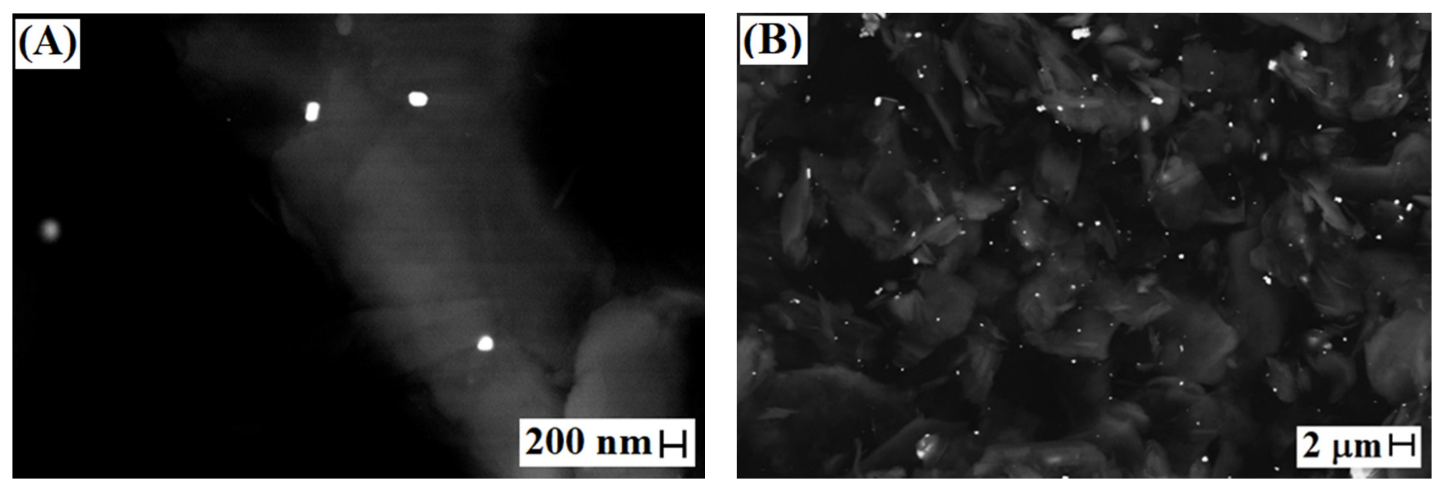

Figura 24. Imagens de SEM-FEG do pó de $\mathrm{AgNP}_{10 \%}$-grafite com magnificação de $50000 \times(\mathrm{A})$ e $5000 \times(B)$. 
Nas análises de XRPD confirmou-se a cristalinidade da prata metálica nas amostras contendo 2, 5 e 10\%. Na Figura 25 são apresentados os espectros de XRPD para os três produtos obtidos $\left(\operatorname{AgNPs}_{2 \%}\right.$-grafite, $\operatorname{AgNPs}_{5 \%}$-grafite e $\operatorname{AgNPs}_{10 \%}$-grafite), na qual se observam os picos de difração em $2 \theta=26,27^{\circ}, 54,52^{\circ}$ e $77,29^{\circ}$ correspondentes às difrações de grafite e em $38,04^{\circ}, 44,31^{\circ}$ e $64,50^{\circ}$ correspondentes às difrações (111), (200) e (220) da estrutura de cúbica de face centrada da prata metálica ${ }^{44}$. Além disso, as intensidades de picos bem definida indicam cristalinidade das AgNPs.

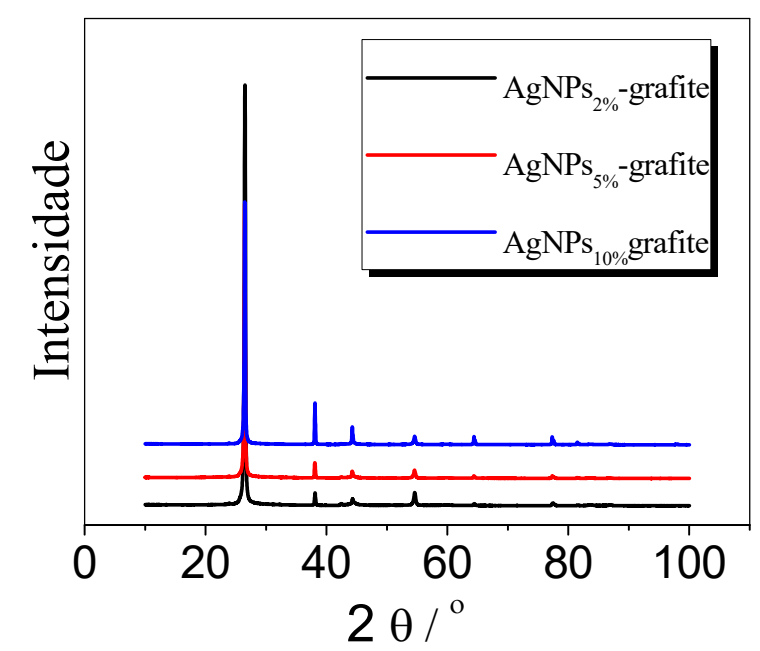

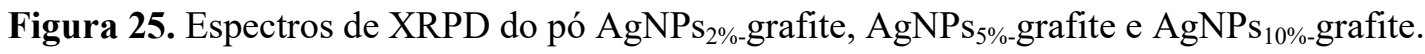

\subsubsection{Cálculo da área ativa}

$\mathrm{A}$ área eletroativa dos EGPU, AgNP $2 \%$-EGPU, $\mathrm{AgNP}_{5 \%}$-EGPU e $\mathrm{AgNP}_{10 \%}$-EGPU desenvolvidos foram determinadas, utilizando o procedimento descrito na seção experimental do capítulo anterior. Os coeficientes angulares obtidos foram de $3,51 \times 10^{-6} ; 7,23 \times 10^{-6} ; 9,56$ $\times 10^{-6}$ e $1,03 \times 10^{-5}$ para EGPU, AgNP $2 \%$-EGPU, $\operatorname{AgNP}_{5 \%}$-EGPU e $\mathrm{AgNP}_{10 \%}$-EGPU, respectivamente, e as áreas ativas foram calculadas (Tabela 6).

Tabela 6. Área eletroativa dos eletrodos preparados

\begin{tabular}{cc}
\hline Eletrodo & Área eletroativa $\left(\mathrm{cm}^{2}\right)$ \\
\hline EGPU & $0,012 \pm 0,002$ \\
$\mathrm{AgNP}_{2 \%}$-EGPU & $0,024 \pm 0,001$ \\
$\mathrm{AgNP}_{5 \%}$-EGPU & $0,030 \pm 0,001$ \\
$\mathrm{AgNP}_{10 \%}$-EGPU & $0,033 \pm 0,002$ \\
\hline
\end{tabular}

Área geométrica $=0,011 \mathrm{~cm}^{2} ; \mathrm{n}=3$ 
Foi observado que, quanto maior a quantidade de AgNPs no compóstio grafite-PU, maior a área ativa do eletrodo. Isto corrobora a ideia de que, muitas vezes, a presença das nanopartículas promovem sítios ativos que levam um aumento de área eletroativa, como visto em outros trabalhos da literatura ${ }^{41,128,43,129}$. Além disso, mesmo com $40 \%$ da massa dos eletrodos compósitos sendo constituídas de material não condutor, o valor da área geométrica é próximo do da área ativa para o EGPU, o que pode ser justificado pela rugosidade do eletrodo compósito, também observado nas imagens de SEM da Figura 22D.

\subsubsection{Desempenho eletroquímico dos PEN LABs}

A resposta eletroquímica dos três sensores PEN LAB AgNP $_{2 \%}$-EGPU, PEN LAB $\mathrm{AgNP}_{5 \%}$-EGPU e PEN LAB AgNP $10 \%$-EGPU foram avaliados em tampão fosfato $0,10 \mathrm{~mol}$ $\mathrm{L}^{-1}$ ( $\left.\mathrm{pH} 7,4\right)$, por voltametria cíclica, para observar o perfil voltamétrico dos eletrodos de trabalho modificados com AgNPs, em comparação com o eletrodo não modificado. Os voltamogramas obtidos, a $v$ de $20 \mathrm{mV} \mathrm{s}^{-1}$, em um intervalo de varredura de potenciais entre 0,2 e 0,6 V (vs. EGPU), utilizando os três sensores são apresentados na Figura 26A e o voltamograma obtido para o PEN LAB EGPU na Figura 26B.
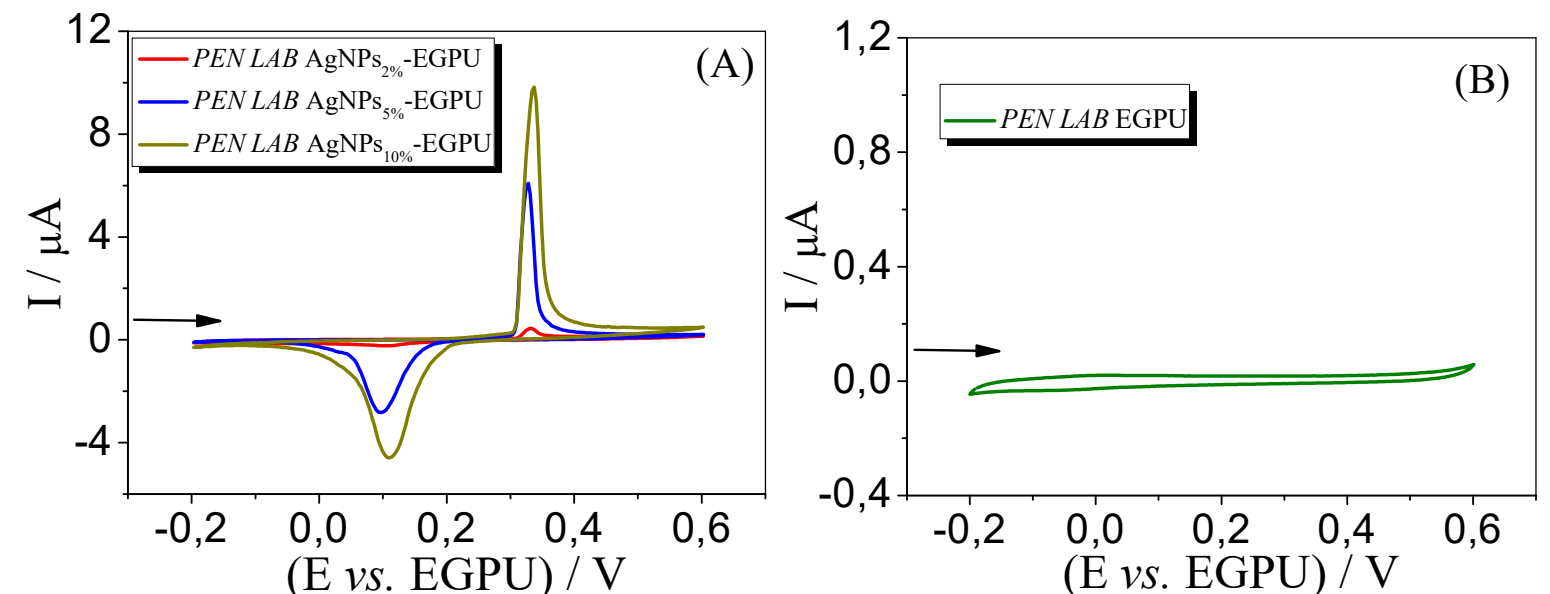

Figura 26. Voltamogramas cíclicos obtidos utilizando (A) PEN LAB AgNP ${ }_{2 \%}$-EGPU (-), PEN LAB $\operatorname{AgNP}_{5 \%}$-EGPU (-), PEN LAB AgNP ${ }_{10 \%}$-EGPU (-) e (B) PEN LAB EGPU não modificado em tampão fosfato $0,10 \mathrm{~mol} \mathrm{~L}^{-1}\left(\mathrm{pH} \mathrm{7,4)}\right.$, a $v$ de $20 \mathrm{mV} \mathrm{s}^{-1}$.

Na Figura 26A foram observados picos de oxidação em aproximadamente 0,33 V (vs. EGPU) atribuídos à oxidação de $\mathrm{Ag}^{0} \mathrm{a} \mathrm{Ag}^{+}$e picos de redução em torno de $0,10 \mathrm{~V}$ (vs. EGPU) indicando a redução de $\mathrm{Ag}^{+}$para $\mathrm{Ag}^{0}$. Picos confirmam presença de AgNPs na superfície do grafite corroborando com os dados observados nas análises espectroscópicas, microscópicas e termoanalíticas. Também é possível verificar que o aumento das quantidades 
de AgNPs nos diferentes eletrodos compósitos leva ao aumento das correntes de pico de oxidação-redução referente ao par redox $\mathrm{Ag}^{0} / \mathrm{Ag}^{+}$.

Os resultados obtidos corroboram outros estudos relatados usando eletrodos modificados com AgNPs e são descritos a seguir. Li et al. ${ }^{128}$ propuseram o desenvolvimento de um sensor eletroquímico baseado em GCE modificado com óxido de grafeno e AgNPs, para a determinação de triptofano em amostras farmacêuticas e soro humano. A partir de medidas de voltametria cíclica, a uma velocidade de varredura de potenciais de $100 \mathrm{mV} \mathrm{s}{ }^{-1}$, em $0,10 \mathrm{~mol} \mathrm{~L}^{-1}$ de tampão acetato, foram comparados os voltamogramas obtidos utilizando o GCE, o óxido de grafeno/GCE e o AgNPs/óxido de grafeno/GCE. Não foi observado processo redox para os dois primeiros eletrodos, por outro lado, um pico de oxidação em um potencial de $0,38 \mathrm{~V}$ (vs. SCE) e um pico de redução em $0,28 \mathrm{~V}$ foi observado para o AgNPs/óxido de grafeno/GCE, os quais foram atribuídos ao par redox $\mathrm{Ag}^{0} / \mathrm{Ag}^{+}$.

Em outros trabalhos, o mesmo processo de oxidação-redução atribuído às AgNPs foi observado, porém com menor definição de pico comparado aos resultados aqui apresentados. Em um GCE modificado com $\mathrm{AgNPs} / \mathrm{SiO}_{2} /$ óxido de grafeno, Cincotto et al. ${ }^{130}$ apresentaram o voltamograma cíclico obtido, a velocidade de varredura de potenciais de $20 \mathrm{mV} \mathrm{s}^{-1}$, em tampão fosfato $0,10 \mathrm{~mol} \mathrm{~L}^{-1}$ (pH 7,0), no qual é possível observar os picos em $E_{\text {oxidação }}=0,45$ $\mathrm{V}$ (vs. $\left.\mathrm{Ag} / \mathrm{AgCl}\left(\mathrm{KCl} 3,0 \mathrm{~mol} \mathrm{~L}^{-1}\right)\right)$ e $E_{\text {redução }}=0,20 \mathrm{~V}$ relacionados ao processo redox do $\mathrm{Ag}^{0} / \mathrm{Ag}^{+} \mathrm{e}^{+} \mathrm{gg}^{+} / \mathrm{Ag}^{0}$, respectivamente, com um $\Delta E$ de $250 \mathrm{mV}$. Este valor de $\Delta E$ está próximo ao encontrado neste trabalho $(230 \mathrm{mV})$, evidenciando o comportamento típico de sistemas quasi-reversíveis atribuído à transferência de um elétron entre o par redox $\mathrm{Ag}^{0} / \mathrm{Ag}^{+}$. $\mathrm{Já}$ Canevari et $a l .{ }^{41}$ apresentaram um GCE modificado com AgNPs/SiO $/ \mathrm{MWCNTs}$, e sob a mesmas condições experimentais, foi mostrado um voltamograma cíclico obtido utilizando o

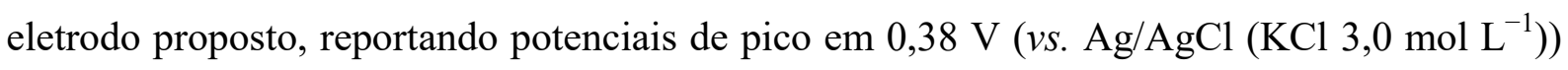
e $0,26 \mathrm{~V}(\Delta E=120 \mathrm{mV})$ relacionado a oxidação e redução das AgNPs. Essa maior facilidade de transferência de elétrons, evidenciado por um menor valor de $\Delta E$ comparado ao reportado neste trabalho, provavelmente se deve à presença dos MWCNTs.

Sequencialmente, a estabilidade da resposta eletroquímica do PEN $L A B \operatorname{AgNP}_{2 \%}$ EGPU, PEN $L A B \quad \mathrm{AgNP}_{5 \%}$-EGPU e $P E N \quad L A B$ AgNP $10 \%$-EGPU foram investigadas realizando-se varreduras de voltametria cíclica a $50 \mathrm{mV} \mathrm{s}^{-1}$ em tampão fosfato $0,10 \mathrm{~mol} \mathrm{~L}^{-1}$ (pH 7,4). Assim, 25 voltamogramas foram registrados com cada eletrodo modificado e os resultados são apresentados na Figura 27A-C. Com os dados obtidos foram construídos 
gráficos de corrente de pico anódica $\left(I_{\mathrm{a}}\right)$ vs. número de varredura de potenciais (número de ciclos), os quais foram inseridos nas Figuras 27A-C, para cada eletrodo proposto.

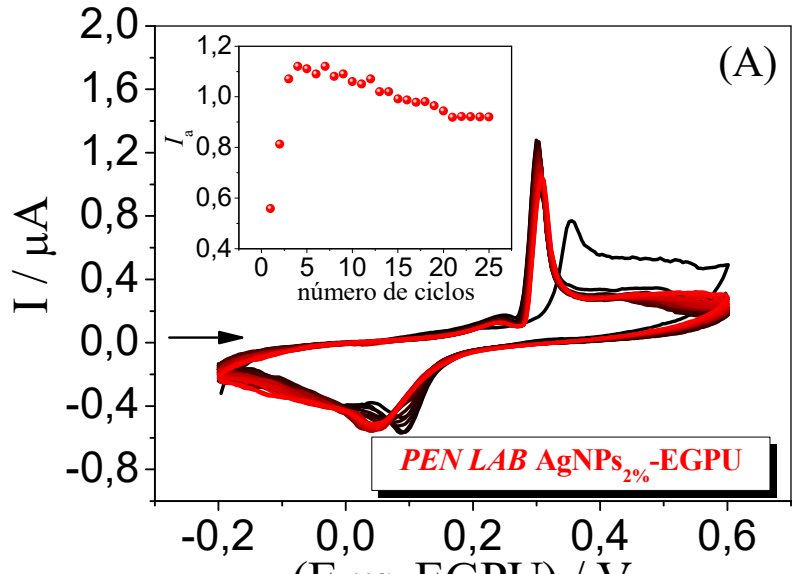

(E vs. EGPU) / V

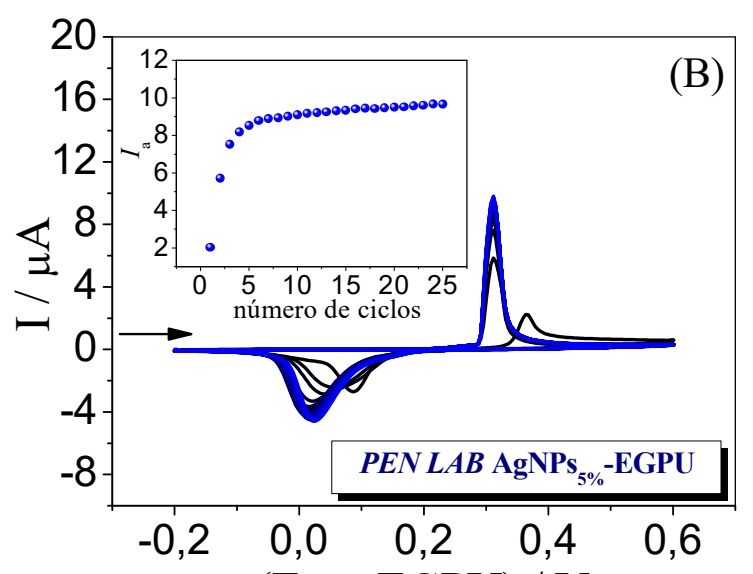

(E vs. EGPU) / V

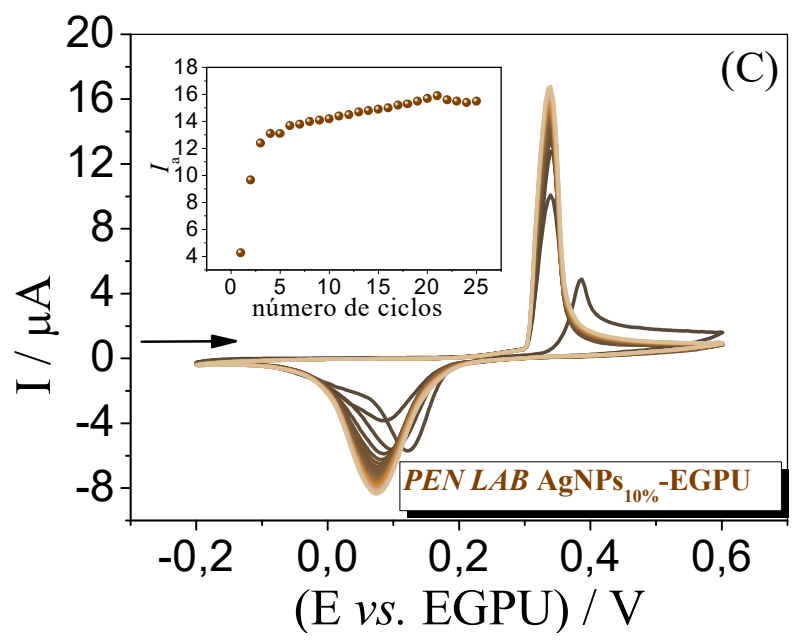

Figura 27. Voltamogramas cíclicos obtidos utilizando (A) PEN LAB AgNP ${ }_{2 \%}$-EGPU, (B) PEN LAB $\mathrm{AgNP}_{5 \%}$-EGPU e (C) PEN LAB AgNP ${ }_{10 \%}$-EGPU em tampão fosfato $0,10 \mathrm{~mol} \mathrm{~L}^{-1}(\mathrm{pH} 7,4)$, $v=50 \mathrm{mV} \mathrm{s}^{-1}$. Inserido nos gráficos de $I_{\mathrm{a}} v s$. número de ciclos.

Esse número de ciclos foi selecionado para ser realizado antes das medidas voltamétricas, uma vez que demonstrou ser suficiente para oferecer a estabilidade das correntes de pico anódico referentes à oxidação da $\mathrm{Ag}^{0}$ a $\mathrm{Ag}^{+}$para todos os eletrodos propostos, observado a partir dos gráficos inseridos nas Figuras 27A-C.

Voltamogramas cíclicos foram obtidos utilizando o PEN LAB $\operatorname{AgNP}_{2 \%}$-EGPU, o PEN $L A B \mathrm{AgNP}_{5 \%}$-EGPU e o PEN LAB AgNP $10 \%$-EGPU, em diferentes velocidades de varredura de potenciais ( $v, 5$ a $200 \mathrm{mV} \mathrm{s}^{-1}$ ), em tampão fosfato $0,10 \mathrm{~mol} \mathrm{~L}^{-1}(\mathrm{pH} \mathrm{7,4).} \mathrm{Na} \mathrm{Figura} \mathrm{28A-C}$ estão apresentados os voltamogramas obtidos para os três sensores, nos quais é possível observar aumento tanto das correntes de pico anódico, quanto catódico conforme se aumenta 
a velocidade de varredura de potenciais. Uma vez que se observa um deslocamento de potencial dos picos de redução para valores mais negativos, sugerindo menor velocidade de transferência de carga, neste caso, conforme a velocidade de varredura é aumentada, escolheu-se trabalhar somente com os picos de oxidação dos eletrodos compósitos.
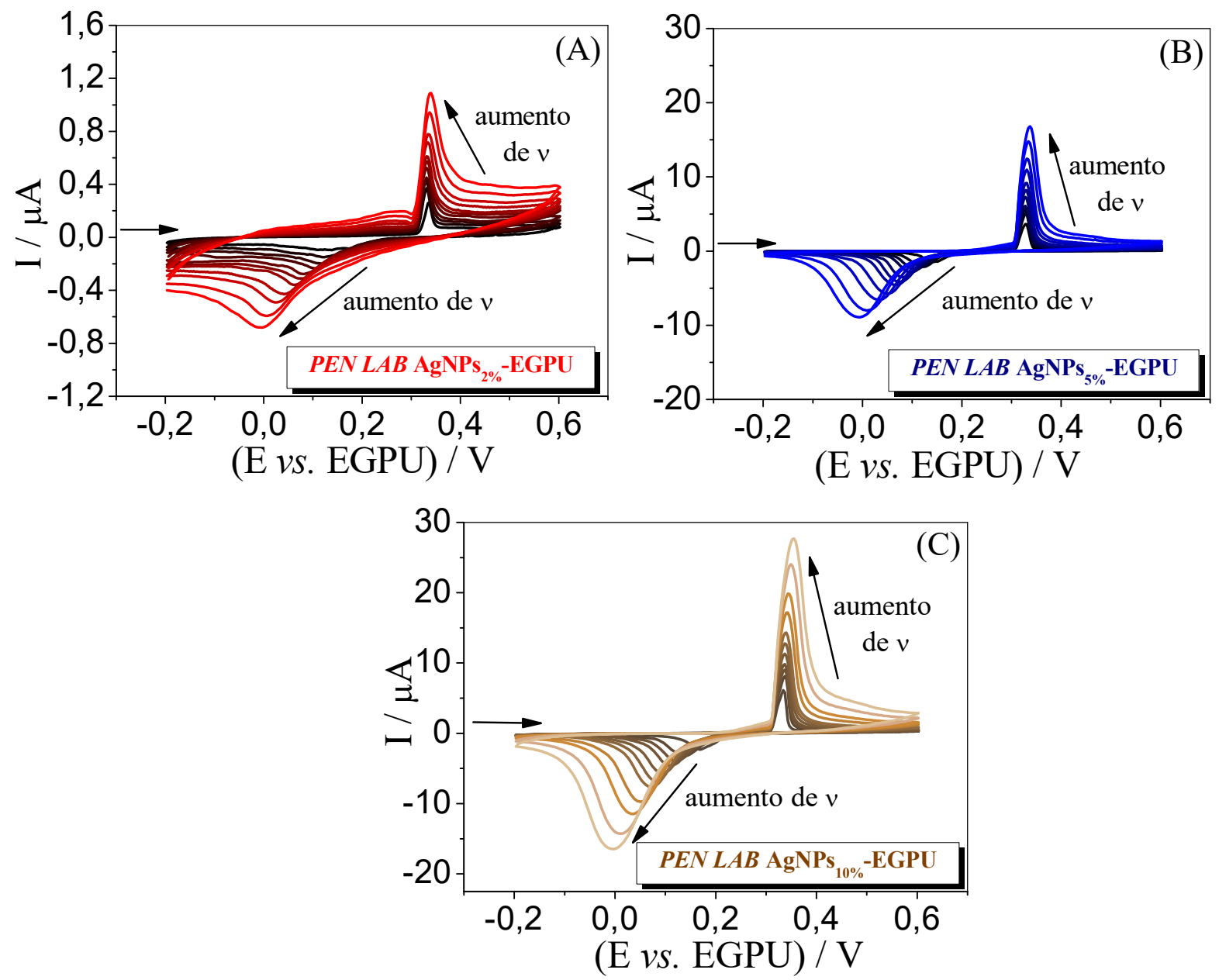

Figura 28. Voltamogramas cíclicos obtidos em diferentes velocidades de varredura de potencial $(v, 5$ to $200 \mathrm{mV} \mathrm{s}^{-1}$ ) da resposta eletroquímica dos PEN LAB AgNP $2 \%$-EGPU (A), PEN LAB $\operatorname{AgNP}_{5 \%}$-EGPU (B) e PEN LAB AgNP $10 \%$-EGPU (C) em tampão fosfato $0,10 \mathrm{~mol} \mathrm{~L}^{-1}(\mathrm{pH}$ $7,4)$.

Ainda, utilizando os resultados obtidos com a velocidade de $0,0050 \mathrm{~V} \mathrm{~s}^{-1}$ foi possível calcular a concentração de espécies ativas de AgNPs na superfície de cada eletrodo através da Equação do recobrimento $(\Gamma)^{44}$ (Equação 2), descrita na seção experimental. Os valores de Q e $\Gamma$ calculados foram apresentados na Tabela 7 . 
Tabela 7. Valores de carga e concentração de espécies ativas de AgNPs para cada eletrodo de trabalho desenvolvido

\begin{tabular}{ccc}
\hline Eletrodo & $\mathrm{Q}(\mu \mathrm{C})$ & $\Gamma\left(\mathrm{nmol} \mathrm{cm}^{-2}\right)$ \\
\hline AgNP $_{2 \%}$-EGPU & 1,28 & 1,21 \\
AgNP $_{5 \%}$-EGPU & 16,6 & 15,6 \\
AgNP $_{10 \%}$-EGPU & 28,5 & 26,8 \\
\hline
\end{tabular}

Comparando-se os valores de $\Gamma$, observou-se um aumento das quantidades de AgNPs na ordem crescente $\mathrm{AgNP}_{2 \%}$-EGPU $<\mathrm{AgNP}_{5 \%}$-EGPU $<\mathrm{AgNP}_{10 \%}$-EGPU nas superfícies dos eletrodos. Isso já era esperado uma vez que foi utilizado mais reagente de partida $\left(\mathrm{AgNO}_{3}\right)$ na seguinte ordem crescente de preparação: A, B e C, referentes aos eletrodos de trabalho $\mathrm{AgNP}_{2 \%}$-EGPU, $\mathrm{AgNP}_{5 \%}$-EGPU e $\mathrm{AgNP}_{10 \%}$-EGPU, respectivamente e que foi confirmado por termogravimetria. O aumento do número de AgNPs na superfície do eletrodo produz um aumento no pico de oxidação de $\mathrm{Ag}^{0}$ para $\mathrm{Ag}^{+}$, corroborando os resultados voltamétricos apresentados na Figura 27.

\subsubsection{Desempenho analítico dos $P E N L A B$ para determinação de bisfenol-A}

Para o desenvolvimento do método proposto, foi utilizada a DPV, por ser uma técnica mais sensível que a voltametria cíclica, capaz de discriminar significativamente os sinais de corrente residual daqueles referentes aos processos faradaicos. Assim, alguns parâmetros foram estudados e otimizados visto que estes podem influenciar na resposta voltamétrica do analito de interesse.

Para avaliar a influência da amplitude de pulso e velocidade de varredura de potencial na resposta do PEN LAB $\mathrm{AgNP}_{2 \%}$-EGPU, realizaram-se voltamogramas de DPV em solução

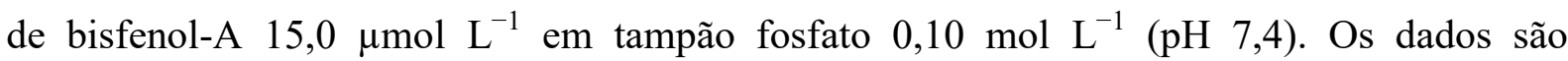
apresentados na Figura 29A, para amplitudes de pulso de 10, 25 e $50 \mathrm{mV}$ e na Figura 29B, para velocidades de varredura de 5, 10 e $15 \mathrm{mV} \mathrm{s}^{-1}$. Os valores dos parâmetros de tempo de pulso e tempo de modulação foram fixados em $0,5 \mathrm{~s}$ e $0,05 \mathrm{~s}$, respectivamente. $\mathrm{O}$ pico de oxidação da molécula de bisfenol-A foi observado em 0,42 V (vs. EGPU), após a oxidação da $\mathrm{Ag}^{0}$ à $\mathrm{Ag}^{+}$em aproximadamente $0,30 \mathrm{~V}$ (vs. EGPU), a partir dos voltamogramas apresentados na Figura 29A e B.

Levando-se em consideração o maior valor de corrente de pico de oxidação obtido para o bisfenol-A, os seguintes valores foram escolhidos para a DPV: amplitude $=50 \mathrm{mV}$ e velocidade de varredura $=10 \mathrm{mV} \mathrm{s}^{-1}$. É importante ressaltar, que os picos obtidos entre $-0,20$ 
e $0,10 \mathrm{~V}$ (vs. EGPU) já foram observados em trabalhos anteriores ${ }^{127,58}$. Estes picos correspondem à oxidação de alguns grupos presentes na PU, e estão em uma faixa de potencial na qual não interferem no sinal do bisfenol-A.

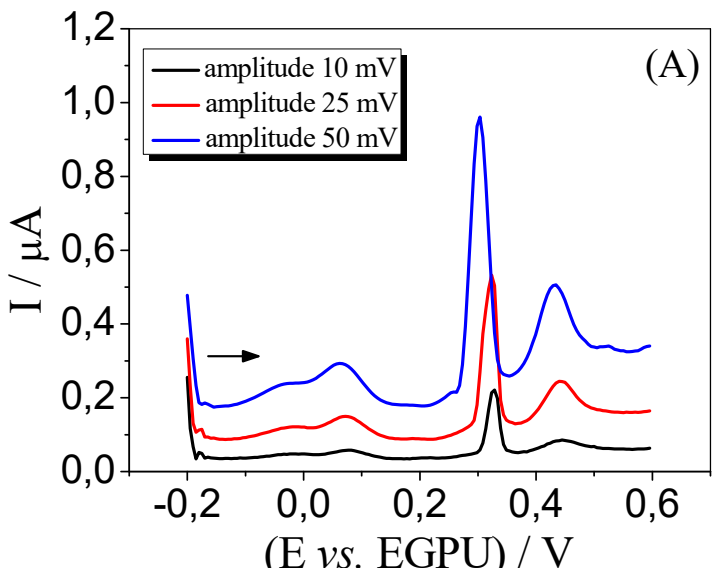

(Evs. EGPU) / V

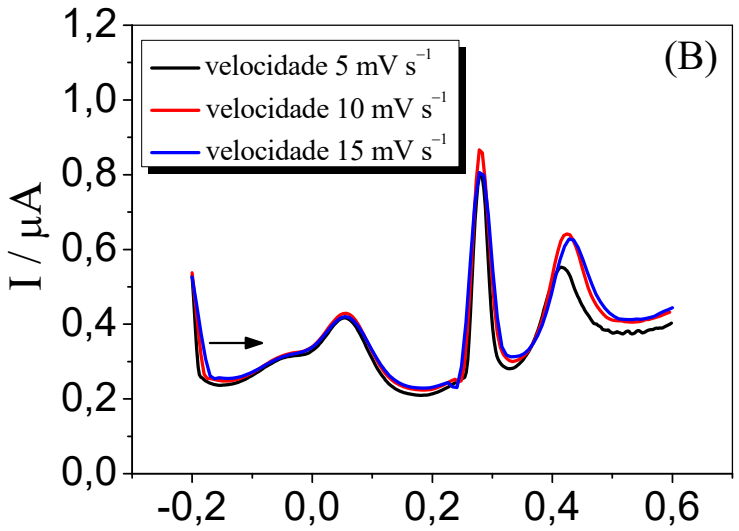

(Evs. EGPU) / V

Figura 29. Voltamogramas de DPV obtidos para bisfenol-A $15 \mu \mathrm{mol} \mathrm{L} \mathrm{L}^{-1}$ em tampão fosfato $0,10 \mathrm{~mol}$ $\mathrm{L}^{-1}$ (pH 7,4) usando PEN LAB AgNP ${ }_{2 \%}$-EGPU para diferentes valores de amplitude de pulso $(10,25$ e $50 \mathrm{mV})(\mathrm{A})$ e diferentes valores de velocidade de varredura de potenciais $\left(5,10\right.$ e $\left.15 \mathrm{mV} \mathrm{s}^{-1}\right)$ (B), com tempo de pulso de $0,5 \mathrm{~s}$ e tempo de modulação de $0,05 \mathrm{~s}$.

Com base na performance eletroquímica dos PEN LAB modificados, investigou-se a aplicação destes sensores para a determinação de bisfenol-A, considerado um disruptor endócrino. Sob condições otimizadas, voltamogramas de DPV para várias concentrações de bisfenol-A $\left(2,5\right.$ a $\left.15 \mu \mathrm{mol} \mathrm{L}^{-1}\right)$ em tampão fosfato $0,10 \mathrm{~mol} \mathrm{~L}^{-1}(\mathrm{pH} \mathrm{7,4)} \mathrm{usando} \mathrm{PEN} \mathrm{LAB}$ EGPU, PEN LAB AgNP ${ }_{2}$-EGPU, PEN LAB AgNP ${ }_{5 \%}$-EGPU e PEN LAB AgNP $10 \%$-EGPU são apresentados nas Figuras 30A-D, respectivamente. Os gráficos da variação das correntes de pico de oxidação em função das concentrações de bisfenol-A são apresentadas na Figura $30 \mathrm{E}$. 

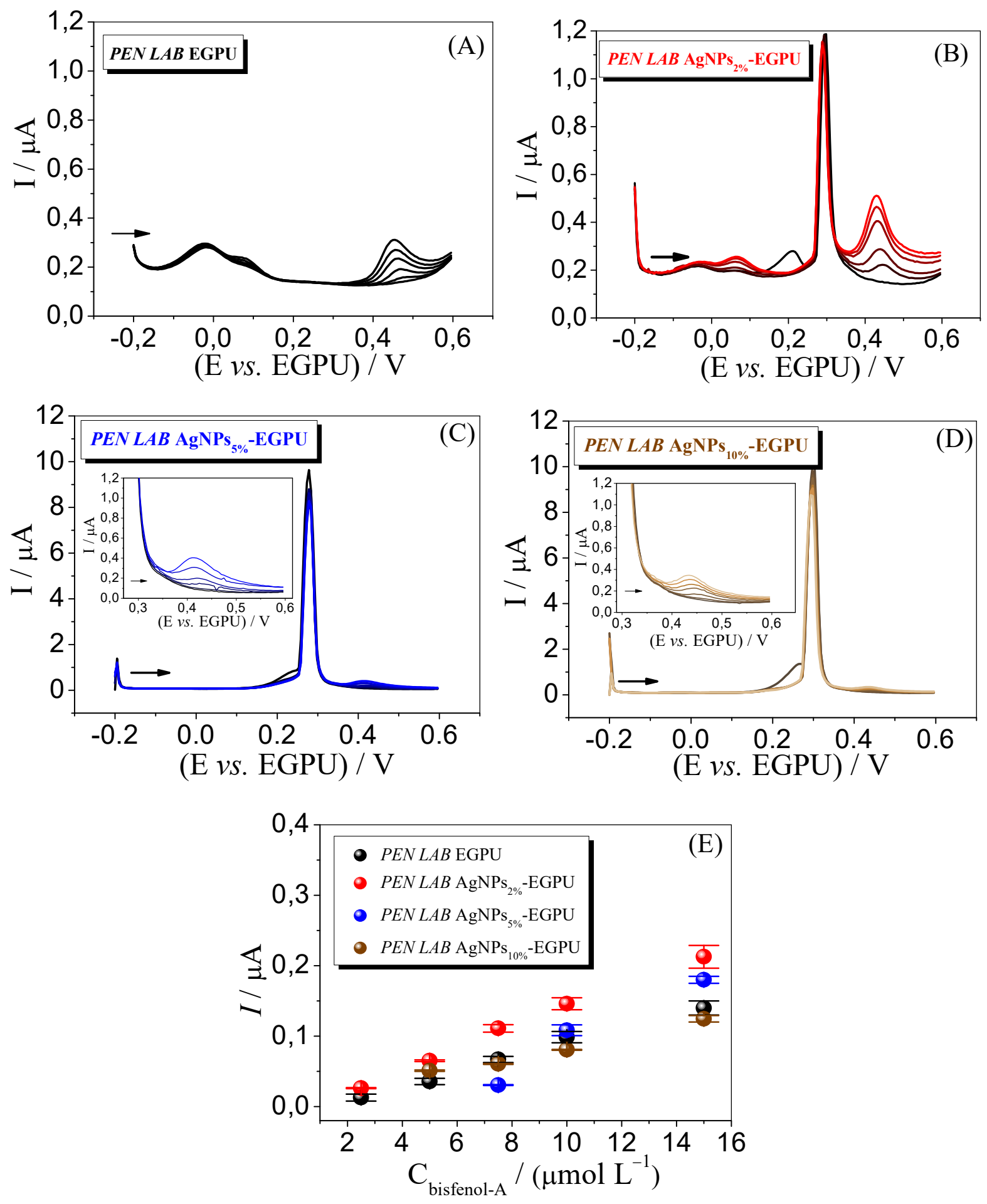

Figura 30. Voltamogramas de DPV obtidos para diferentes concentrações de bisfenol-A entre 2,5 a 15 $\mu \mathrm{mol} \mathrm{L}{ }^{-1}$ em tampão fosfato $0,10 \mathrm{~mol} \mathrm{~L}^{-1}(\mathrm{pH} 7,4)$ utilizando o PEN LAB EGPU (A), PEN $L A B$ AgNP $2 \%$-EGPU (B), PEN LAB AgNP ${ }_{5 \%}$-EGPU (C) e PEN LAB AgNP $10 \%$-EGPU (D); Parâmetros: amplitude $=50 \mathrm{mV}$, velocidade de varredura $=10 \mathrm{mV} \mathrm{s}^{-1}$, tempo de intervalo $=0,5 \mathrm{~s}$ e tempo de modulação $=0,05 \mathrm{~s}$. (E) Gráfico de $I v s . \mathrm{C}_{\text {bisfenol-A }}(\mathrm{n}=3)$. 
Com exceção do PEN LAB $\mathrm{AgNP}_{5 \%}$-EGPU, todos os demais eletrodos apresentaram uma relação linear entre o pico de corrente de oxidação e concentração de bisfenol-A, na região entre 2,5 e $15 \mu \mathrm{mol} \mathrm{L}{ }^{-1}$. A ausência de relação linear observada para o PEN LAB $\mathrm{AgNP}_{5 \%}$-EGPU, provavelmente, pode estar relacionada a um problema de homogeinização na confecção do eletrodo de trabalho e conforme a superfície do compósito foi sendo lixada, diferentes composições superficiais foram sendo obtidas, dificultando a repetibilidade da resposta para determinadas concentrações de bisfenol-A. Para facilitar a comparação dos parâmetros analíticos obtidos, estão reportadas as equações lineares, os LOD calculados, a faixa linear estudada e a sensibilidades obtidas utilizando o PEN LAB EGPU, o PEN LAB $\mathrm{AgNP}_{2 \%}$-EGPU e o PEN LAB AgNP $10 \%$-EGPU na Tabela 8.

Tabela 8. Comparação dos três $P E N L A B$ desenvolvidos para a determinação de bisfenol-A

\begin{tabular}{|c|c|c|c|}
\hline Parâmetros & PEN LAB EGPU & $\begin{array}{l}\text { PEN LAB AgNP }{ }_{2 \%-} \\
\text { EGPU }\end{array}$ & $\begin{array}{l}\text { PEN LAB AgNP } \\
\text { EGPU }\end{array}$ \\
\hline $\begin{array}{l}\text { Equação da } \\
\text { reta/ I } \mu \mathrm{A}\end{array}$ & $-0,015+0,010 \mathrm{C}_{\text {bisfenol-A }}{ }^{*}$ & $0,013+0,016 \mathrm{C}_{\text {bisfenol-A }} *$ & $-0,0080+0,0080 \mathrm{C}_{\text {bisfenol-A }}$ * \\
\hline $\begin{array}{c}\mathrm{LOD} / \\
\mu \mathrm{mol} \mathrm{L}{ }^{-1}\end{array}$ & 0,90 & 0,24 & 7,0 \\
\hline $\begin{array}{c}\text { Faixa linear/ } \\
\mu \mathrm{mol} \mathrm{L}{ }^{-1}\end{array}$ & 2,5 a 15 & 2,5 a 15 & 2,5 a 15 \\
\hline $\begin{array}{l}\text { Sensibilidade/ } \\
\mu \mathrm{A} \mu \mathrm{mol}^{-1} \mathrm{~L}\end{array}$ & 0,010 & 0,016 & 0,0080 \\
\hline
\end{tabular}

Considerando maior sensibilidade e menor LOD para a determinação de bisfenol-A, o

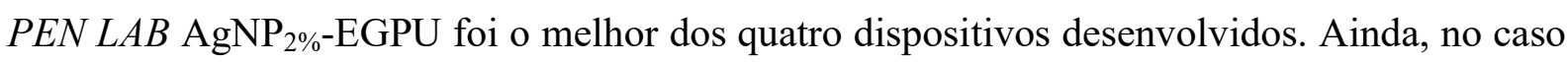

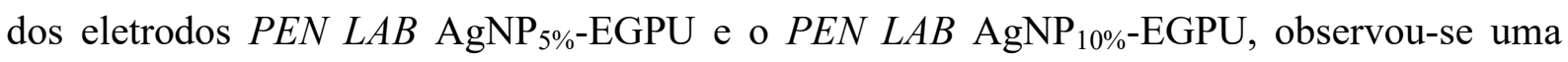
sinal elevado em $0,30 \mathrm{~V}$ (vs. EGPU) referente a oxidação da $\mathrm{Ag}^{0}$ a $\mathrm{Ag}^{+}$, o que mascarou/interferiu no pico do bisfenol-A em $0,42 \mathrm{~V}$, limitando a possibilidade de quantificar $\mathrm{o}$ analito em menores concentrações dentro da faixa de concentração escolhida. Além disso, considerando a presença dos picos em $0,30 \mathrm{~V}$ e 0,42 V (vs. EGPU) nos voltamogramas da Figura 30 e a baixa solubilidade da $\mathrm{Ag}^{+}$em meio de fosfato sugere-se o seguinte esquema representado na Figura 31 para explicar o aumento da corrente no pico de oxidação do bisfenol-A no eletrodo modificado frente ao não modificado. 


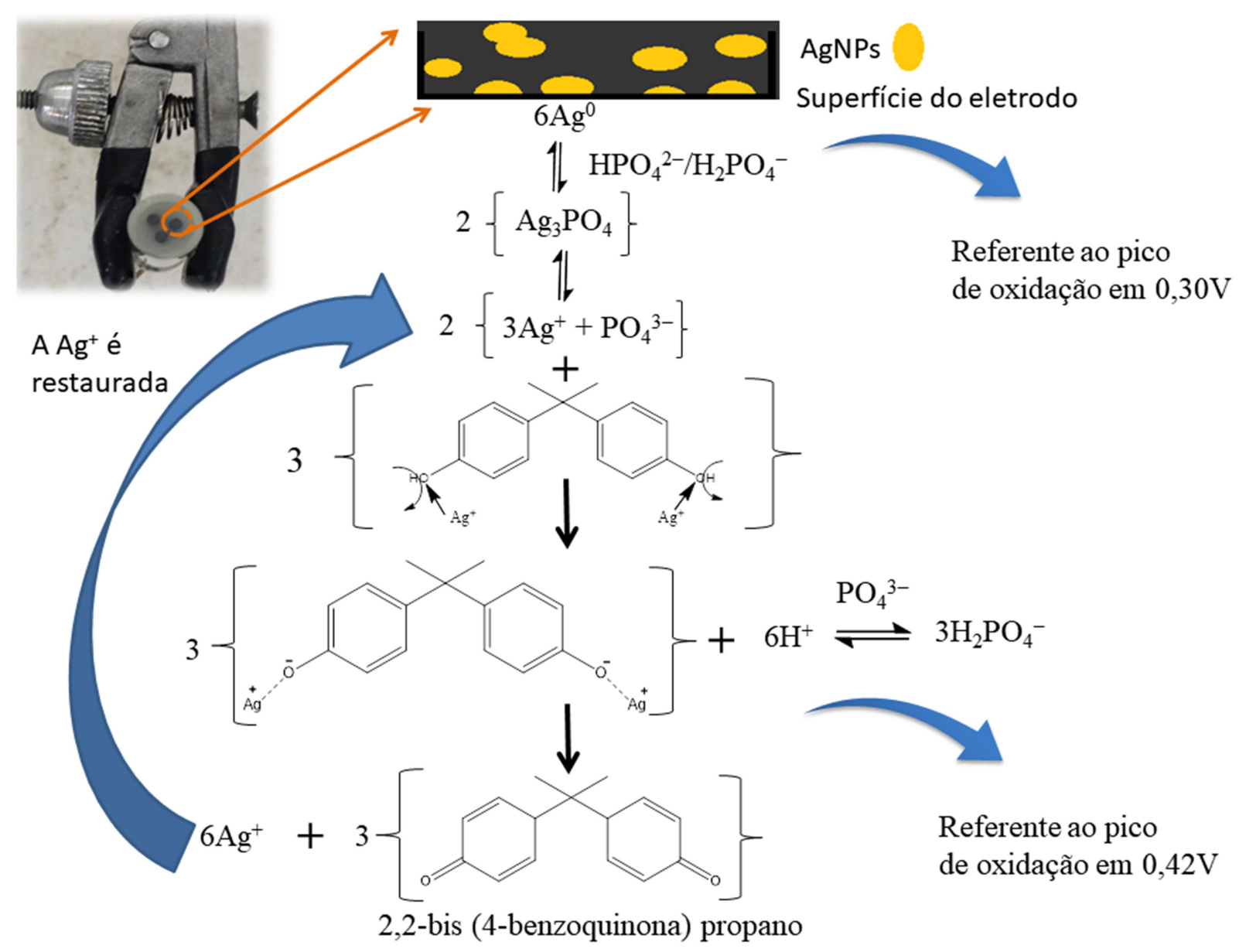

Figura 31. Esquema proposto para processo da oxidação do bisfenol-A, na presença do eletrodo contendo AgNPs.

Inicialmente, tem se a oxidação da $\mathrm{Ag}^{0}$ à $\mathrm{Ag}^{+}$, na superfície do eletrodo. Os íons $\mathrm{Ag}^{+}$ reagem, em meio tamponado, com o par $\mathrm{HPO}_{4}{ }^{2-} / \mathrm{H}_{2} \mathrm{PO}_{4}{ }^{-}$, em equilíbrio com $\mathrm{Ag}_{3} \mathrm{PO}_{4}$. Esta reação é caracterizada pelo pico de oxidação observado em torno de $0,30 \mathrm{~V}$ ( $v s$. EPGU), Figura 30. Em seguida, os íons $\mathrm{Ag}^{+}$, gerados pela reação de oxidação em equilíbrio com o sistema fosfato, interagem com bisfenol-A, servindo como sítio ativo para a acumulação do analito. Na sequência, o bisfenol-A perde os $2 \mathrm{H}^{+}$ligados aos dois oxigênios da molécula, gerando cargas negativas nesses átomos, aptos para a interação com 2 íons $\mathrm{Ag}^{+}$. Além disso, os $2 \mathrm{H}^{+}$liberados nesse processo interagem com os íons $\mathrm{PO}_{4}{ }^{3-}$ da solução eletrolítica, para produzir $\mathrm{H}_{2} \mathrm{PO}_{4}^{-}$.

A formação de um composto entre o bisfenol-A e os íons $\mathrm{Ag}^{+}$na superfície do eletrodo, provoca pré-concentração de maior quantidade de analito para a camada de difusão, onde ocorre à oxidação dessa espécie no potencial de $0,42 \mathrm{~V}$ (vs. EPGU) com perda de 2 elétrons da molécula pelo eletrodo. Como produto, obtém-se o 2,2-bis(4- 
benzoquinona)propano, como descrito por outros trabalhos encontrados na literatura, descritos a seguir.

Goulart et $a l .{ }^{46}$ propuseram a determinação voltamétrica simultânea de hidroquinona, catecol, bisfenol-A e fenol utilizando um GCE modificado com filme de CNTs e AgNPs. Em meio ácido, a oxidação de moléculas fenólicas é dificultada, uma vez que o processo envolve a perda de $\mathrm{H}^{+}$para o meio. A oxidação dessas moléculas foi facilitada pelo aumento do $\mathrm{pH}$ do meio e pode ser confirmada pelo deslocamento do pico de oxidação para valores menos positivos de potencial. Os dados aqui apresentados estão de acordo com esse modelo pois com o aumento do valor de $\mathrm{pH}$ do meio, o hidrogênio ácido é liberado, o bisfenol-A adquire uma carga negativa, e, dessa forma, ocorre interação eletrostática da molécula com as cargas positivas da superfície do eletrodo (espécies $\mathrm{Ag}^{+}$), facilitando o processo de oxidação.

Com relação à quantidade de prata presente em solução após a oxidação das AgNPs, deve-se considerar o equilíbrio de solubilidade :

$$
\mathrm{Ag}_{3} \mathrm{PO}_{4(\mathrm{~s})} \rightleftharpoons 3 \mathrm{Ag}^{+}{ }_{(\mathrm{aq})}+\mathrm{PO}_{4}{ }^{3-}{ }_{(\mathrm{aq})}
$$

$$
\text { Cujo } \mathrm{K}_{\mathrm{ps}}=\left[\mathrm{Ag}^{+}\right]^{3}\left[\mathrm{PO}_{4}^{3-}\right]=1,3 \times 10^{-20131} \quad \text { Equação } 3
$$

e os equilíbrios ácido-base do fosfato:

$$
\begin{array}{ll}
\mathrm{H}_{3} \mathrm{PO}_{4}+\mathrm{H}_{2} \mathrm{O} \rightleftharpoons \mathrm{H}_{2} \mathrm{PO}_{4}{ }^{-}+\mathrm{H}_{3} \mathrm{O}^{+} & \mathrm{p} K_{\mathrm{a} 1}=2,15 \\
\mathrm{H}_{2} \mathrm{PO}_{4}{ }^{-}+\mathrm{H}_{2} \mathrm{O} \rightleftharpoons \mathrm{HPO}_{4}{ }^{2-}+\mathrm{H}_{3} \mathrm{O}^{+} & \mathrm{p} K_{\mathrm{a} 2}=7,20 \\
\mathrm{HPO}_{4}{ }^{2-}+\mathrm{H}_{2} \mathrm{O} \rightleftharpoons \mathrm{PO}_{4}{ }^{3-}+\mathrm{H}_{3} \mathrm{O}^{+} & \mathrm{p} K_{\mathrm{a} 3}=12,3
\end{array}
$$

Para calcular a concentração de $\mathrm{Ag}^{+}$é necessário inicialmente estimar a concentração de $\mathrm{PO}_{4}{ }^{3-}$ livre, que pode ser calculada pela função $\alpha_{3}$, considerando-se o $\mathrm{pH}$ de trabalho, igual a 7,4 e a concentração total de $\mathrm{H}_{3} \mathrm{O}^{+}$igual a $4,0 \times 10^{-8} \mathrm{~mol} \mathrm{~L}^{-1}$. Assim, tem-se:

$$
\begin{gathered}
K_{a 1}=\frac{\left[\mathrm{H}_{2} \mathrm{PO}_{4}^{-}\right]\left[\mathrm{H}_{3} \mathrm{O}^{+}\right]}{\left[\mathrm{H}_{3} \mathrm{OO}_{4}\right]} \text { Equação } 4 \\
K_{a 2}=\frac{\left[\mathrm{HP}_{4}^{2-}\right]\left[\mathrm{H}_{3} \mathrm{O}^{+}\right]}{\left[\mathrm{H}_{2} \mathrm{PO}_{4}^{-}\right]} \text {Equação } 5 \\
K_{a 3}=\frac{\left[\mathrm{PO}_{4}^{3-}\right]\left[\mathrm{H}_{3} \mathrm{O}^{+}\right]}{\left[\mathrm{HPO}_{4}^{2-}\right]} \text { Equação } 6
\end{gathered}
$$


Daí,

$$
\begin{gathered}
\mathrm{C}_{0}=\left[\mathrm{H}_{3} \mathrm{PO}_{4}\right]+\left[\mathrm{H}_{2} \mathrm{PO}_{4}^{-}\right]+\left[\mathrm{HPO}_{4}^{2-}\right]+\left[\mathrm{PO}_{4}^{3-}\right] \text { Equação } 7 \\
\alpha_{3}=\frac{\left[\mathrm{PO}_{4}^{3-}\right]}{C_{0}}=\frac{K_{a 1} K_{a 2} K_{a 3}}{\left[\mathrm{H}_{3} \mathrm{O}^{+}\right]^{3}+K_{a 1}\left[\mathrm{H}_{3} \mathrm{O}^{+}\right]^{2}+K_{a 1} K_{a 2}\left[\mathrm{H}_{3} \mathrm{O}^{+}\right]+K_{a 1} K_{a 2} K_{a 3}} \text { Equação } 8 \\
\alpha_{3}=\frac{\left(7,1 \times 10^{-3}\right)\left(6,3 \times 10^{-8}\right)\left(4,8 \times 10^{-1}\right)}{\left(4,0 \times 10^{-8}\right)^{3}+\left(7,1 \times 10^{-3}\right)\left(4,0 \times 10^{-8}\right)^{2}+\left(7,1 \times 10^{-3}\right)\left(6,3 \times 10^{-8}\right)\left(4,0 \times 10^{-8}\right)+\left(7,1 \times 10^{-3}\right)\left(6,3 \times 10^{-8}\right)\left(4,0 \times 10^{-13}\right)} \\
\alpha_{3}=\frac{\left[P O_{4}^{3-}\right]}{C_{0}}=6,5 \times 10^{-6} \\
{\left[P O_{4}^{3-}\right]=\frac{6,5 \times 10^{-6}}{0,10}=6,5 \times 10^{-7} \mathrm{~mol} \mathrm{~L} L^{-1}}
\end{gathered}
$$

Substituindo esse valor da concentração de $\mathrm{PO}_{4}{ }^{3-}$ na Equação 3, tem-se a concentração de $\mathrm{Ag}^{+}$maior que $2,7 \times 10^{-5} \mathrm{~mol} \mathrm{~L}^{-1}$, a partir da qual se iniciaria a precipitação do fosfato de prata, teoricamente.

Em termos práticos é possível calcular a concentração de $\mathrm{Ag}^{+}$envolvida no processo redox em 0,30 V da Figura 30B. A concentração da prata é dada pelo número de mols da $\mathrm{Ag}^{+}$ dissolvida no volume correspondente àquele da camada de difusão. Para tanto é preciso estimar a espessura da camada de difusão $(\delta)$ :

$$
\delta=\sqrt{D \times t}
$$

Na qual $D$ é o coeficiente de difusão ${ }^{118} \mathrm{da}_{\mathrm{Ag}^{+}}$(assumido como sendo $1 \times 10^{-6} \mathrm{~cm}^{2}$ $\mathrm{s}^{-1}$ ) e $t$ é tempo decorrido durante o processo de dissolução até o final do experimento (DPV, varredura da janela de potencial de $400 \mathrm{mV}$, a uma velocidade de $10 \mathrm{mV} \mathrm{s}^{-1}$, portanto $40 \mathrm{~s}$ ). Nesse tempo a camada de difusão assume o valor de $6,3 \times 10^{-3} \mathrm{~cm}$.

Sendo a área do eletrodo igual a $0,011 \mathrm{~cm}^{2}$, o volume da camada de difusão é igual a $7,0 \times 10^{-5} \mathrm{~cm}^{3}$.

Calculado o volume da camada de difusão, o número de mol de $\mathrm{Ag}^{+}$dissolvido foi calculado pela integração do pico de oxidação em $0,30 \mathrm{~V}$ na Figura $30 \mathrm{~B}$, que resultou em uma carga total de $3,4 \times 10^{-6}$ A s e o número de mol da $\mathrm{Ag}^{+}$é dado por:

$$
\text { número de mols de } \mathrm{Ag}=\frac{3,4 \times 10^{-6} \mathrm{C}}{96487 \mathrm{C} \mathrm{mol}^{-1}}=3,5 \times 10^{-11} \mathrm{~mol}
$$


E a concentração de $\mathrm{Ag}^{+}$:

$$
C_{A g+}=\frac{3,5 \times 10^{-1} \mathrm{~mol}}{7,0 \times 10^{-8} \mathrm{~L}}=5,0 \times 10^{-4} \mathrm{~mol} \mathrm{~L}^{-1}
$$

Com isso,

$$
\left[\mathrm{Ag}^{+}\right]=5,0 \times 10^{-4} \mathrm{~mol} \mathrm{~L}-1-2,7 \times 10^{-5} \mathrm{~mol} \mathrm{~L}^{-1}=4,7 \times 10^{-4} \mathrm{~mol} \mathrm{~L}^{-1}
$$

Assim, há $\mathrm{Ag}^{+}$livre suficiente para precipitar com o fosfato, conforme resultado da Equação 3, e para reagir com o bisfenol-A. Assim, mesmo com a baixa solubilidade de $\mathrm{Ag}^{+}$ em meio de tampão fosfato, ainda sobra suficiente do cátion, disponível para reagir com o bisfenol-A.

Em seguida, avaliou-se a repetibilidade da resposta do eletrodo para o método proposto. Assim, medidas sucessivas da corrente de pico de oxidação do bisfenol-A $(9,0 \mu \mathrm{mol}$ $\mathrm{L}^{-1}$ ) foram realizadas no mesmo dia, sem a renovação de superfície entre elas. Na Figura 32A são apresentados os voltamogramas de DPV obtidos de 10 medidas consecutivas, sendo o desvio padrão relativo calculado de 4,2\%. Também foram feitas cinco medidas consecutivas para mesma concentração, em três dias diferentes, renovando-se a superfície para cada dia. Os resultados alcançados estão reportados nas Figuras 32B-D, a partir das quais foram calculadas as médias de corrente de pico de oxidação para cada dia, o desvio padrão para cada dia de 6,0; 6,2 e 5,2\%, respectivamente e o desvio padrão relativo calculado para as três médias foi de $5,4 \%$. Estes resultados confirmaram a repetibilidade da resposta do eletrodo proposto para o método de determinação do bisfenol-A, mesmo após a renovação de superfície. 

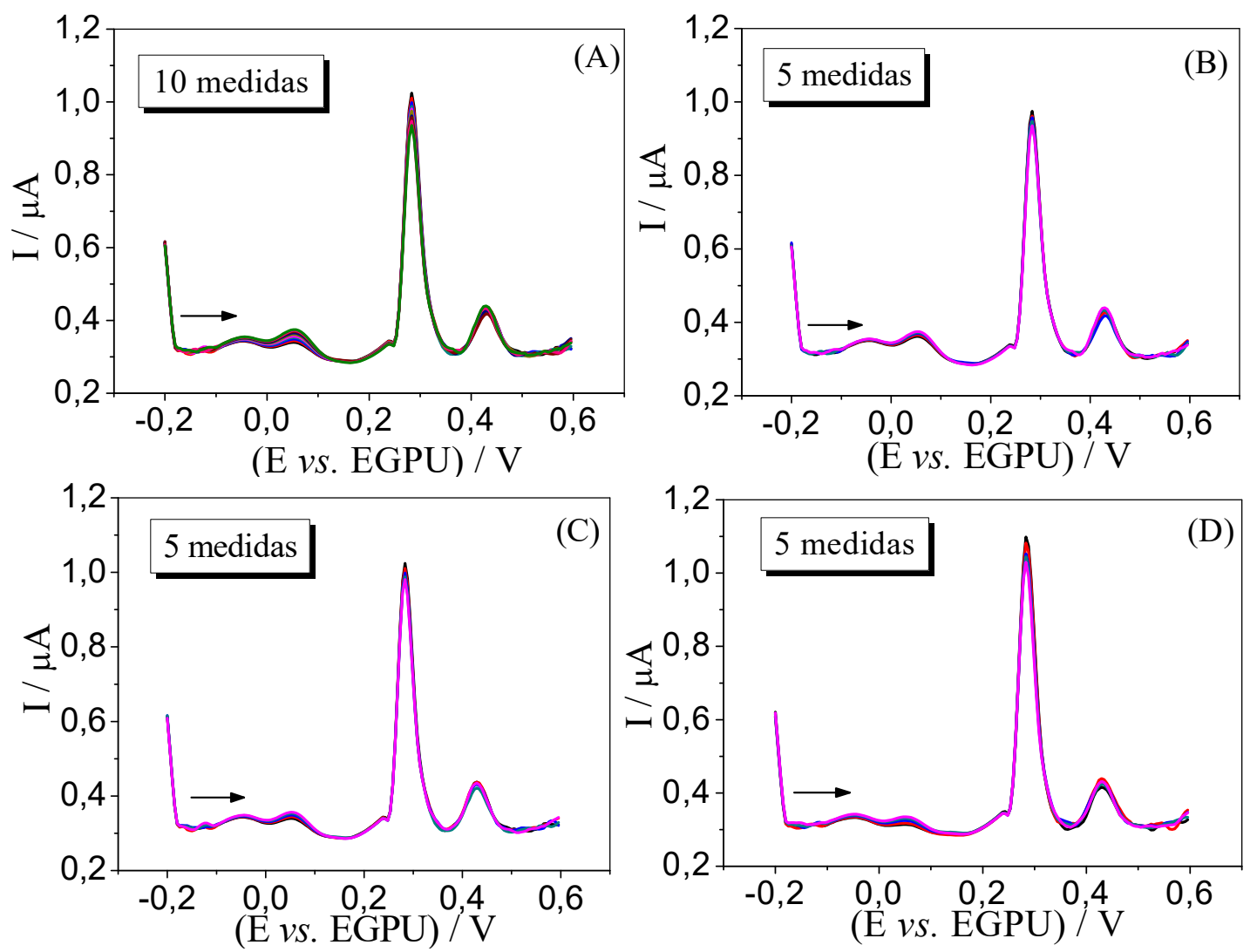

Figura 32. Voltamogramas de DPV obtidos para uma concentração de bisfenol-A $9,0 \mu \mathrm{mol} \mathrm{L^{-1 }}$ em tampão fosfato $0,10 \mathrm{~mol} \mathrm{~L}^{-1}(\mathrm{pH} 7,4)$ usando PEN LAB AgNP ${ }_{2 \%}$-EGPU para (A) para 10 medidas consecutivas no mesmo dia sem renovação de superfície entre as medidas e (BD) 5 medidas consecutivas para cada dia, com renovação de superfície entre cada dia. Parâmetros: velocidade de varredura $=10 \mathrm{mV} \mathrm{s}^{-1}$, amplitude $=50 \mathrm{mV}$, tempo de intervalo de $0,5 \mathrm{~s}$ e tempo de modulação de $0,05 \mathrm{~s}$.

Além disso, a reprodutibilidade entre eletrodos foi verificada. Para isso, foi confeccionado um novo PEN $L A B$ AgNP ${ }_{2 \%}$-EGPU e cinco medidas consecutivas da concentração $9,0 \times 10^{-6}$ mol L ${ }^{-1}$ de bisfenol-A foram realizadas, sem renovação de superfície entre as medidas, como reportado na Figura 33. O desvio padrão relativo calculado para as cinco medidas foi de $1,7 \%$. Já quando comparada a média de corrente de pico de oxidação destas cinco medidas, com as médias do estudo anterior para os três dias, foi encontrado um desvio padrão relativo de $8,5 \%$, que representa a reprodutibilidade entre os eletrodos. 


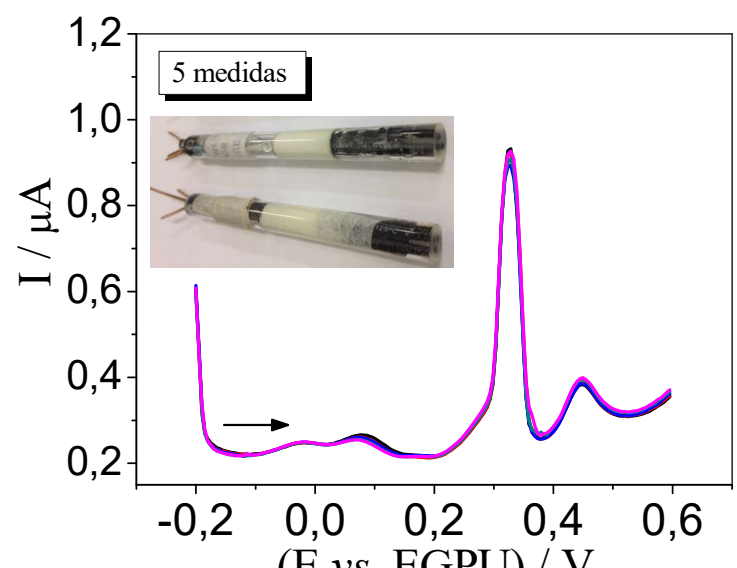

Figura 33. Voltamogramas de DPV obtidos para uma concentração de bisfenol-A $9,0 \times 10^{-6} \mathrm{~mol} \mathrm{~L}^{-1}$ em tampão fosfato $0,10 \mathrm{~mol} \mathrm{~L}^{-1}(\mathrm{pH} 7,4)$ usando PEN LAB AgNP $2 \%$-EGPU para 5 medidas consecutivas no mesmo dia. Parâmetros: velocidade de varredura $=10 \mathrm{mV} \mathrm{s}^{-1}$, amplitude $=50 \mathrm{mV}$, tempo de intervalo de $0,5 \mathrm{~s}$ e tempo de modulação de $0,05 \mathrm{~s}$.

A quantificação de bisfenol-A também foi realizada na presença de compostos de diferentes classes também, uma vez que esses poderiam ser possíveis interferentes na determinação do mesmo. Assim, furosemida (diurético), catecol (polifenol), tetraciclina (antibiótico), ibuprofeno (anti-inflamatório), e $\beta$-estradiol (hormônio), foram adicionados à solução padrão inicial, como descrito na seção experimental deste carpítulo. Os valores de corrente de pico de oxidação obtidos foram comparados àquela corrente obtida apenas para uma solução de bisfenol-A de $9,0 \mu \mathrm{mol} \mathrm{L} \mathrm{L}^{-1}$, e os valores de interferência em porcentagem estão apresentados na Tabela 9. 
Tabela 9. Possíveis interferentes na determinação de bisfenol-A

\begin{tabular}{|c|c|c|c|c|}
\hline Interferente & $\begin{array}{l}\text { Concentração } \\
\left(\mu \mathrm{mol} \mathrm{L}{ }^{-1}\right)\end{array}$ & $\begin{array}{c}I_{\text {bisfenol-A }} \\
(\mu \mathrm{A})\end{array}$ & $\begin{array}{c}I_{\text {bisfenol-A+interferente }} \\
(\mu \mathrm{A})\end{array}$ & $\begin{array}{c}\text { Interferência } \\
(\%)\end{array}$ \\
\hline furosemida & $\begin{array}{c}0,45 \\
9 \\
18\end{array}$ & 0,11 & $\begin{array}{l}0,11 \pm 0,02 \\
0,10 \pm 0,06 \\
0,10 \pm 0,03\end{array}$ & $\begin{array}{c}0 \\
-8,3 \\
-8,3\end{array}$ \\
\hline catecol & $\begin{array}{c}0,45 \\
9 \\
18\end{array}$ & 0,12 & $\begin{array}{l}0,12 \pm 0,02 \\
0,12 \pm 0,03 \\
0,11 \pm 0,02\end{array}$ & $\begin{array}{c}0 \\
0 \\
-8,3\end{array}$ \\
\hline tetraciclina & $\begin{array}{c}0,45 \\
9 \\
18\end{array}$ & 0,13 & $\begin{array}{l}0,13 \pm 0,04 \\
0,14 \pm 0,02 \\
0,15 \pm 0,04\end{array}$ & $\begin{array}{c}0 \\
+8,3 \\
+15,4\end{array}$ \\
\hline ibuprofeno & $\begin{array}{c}0,45 \\
9 \\
18\end{array}$ & 0,12 & $\begin{array}{l}0,12 \pm 0,04 \\
0,11 \pm 0,06 \\
0,10 \pm 0,03\end{array}$ & $\begin{array}{c}0 \\
-8,3 \\
-15,4\end{array}$ \\
\hline$\beta$-estradiol & $\begin{array}{c}0,45 \\
9 \\
18\end{array}$ & 0,13 & $\begin{array}{l}0,15 \pm 0,01 \\
0,19 \pm 0,02 \\
0,21 \pm 0,02\end{array}$ & $\begin{array}{c}0 \\
+46.5 \\
+61.5\end{array}$ \\
\hline
\end{tabular}

Concentração de bisfenol-A fixa em $9,0 \mu \mathrm{mol} \mathrm{L}{ }^{-1}$

Dentre os possíveis interferentes avaliados, o $\beta$-estradiol foi o que apresentou maior influência na intensidade de corrente de pico do bisfenol-A, provavelmente por se oxidar em um potencial próximo do analito ou mesmo interagir com a $\mathrm{Ag}^{+}$. Para os demais interferentes em potencial, houve interferências inferiores a $10 \%$, na razão de concentração 1:1 ( $\mathrm{mol} \mathrm{mol}^{-1}$, analito: interferente). Entretanto, quando o dobro da concentração de tetraciclina e ibuprofeno foram adicionados em relação à concentração do bisfenol-A uma interferência de aproximadamente $15 \%$ foi observada, o que pode ser aceitável para amostras ambientais.

Finalmente, o PEN LAB $\operatorname{AgNP}_{2 \%}$-EGPU proposto foi usado para quantificar bisfenolA em amostras de água de rio e de abastecimento público. Cada amostra foi fortificada com duas concentrações diferentes do analito, medidas em triplicata e os resultados, incluindo as recuperações calculadas, são apresentados na Tabela 10. Os valores experimentais e adicionados estavam de acordo com o test $t$-Student, com nível de confiança de $95 \%$. Os valores de recuperação indicam uma interferência mínima das matrizes, o que tornou o método adequado para a quantificação do bisfenol-A em amostras de água de rio e de abastecimento público. 
Tabela 10. Resultados obtidos das análises de agua de rio e de abastecimento público

\begin{tabular}{cccc}
\hline Amostras de água & Adicionado/ $\mu \mathrm{mol} \mathrm{L}^{-1}$ & Encontrado/ $\mu \mathrm{mol} \mathrm{L}^{-1}$ & Recuperado \\
\hline rio & 7,0 & $(7,2 \pm 0,3)$ & 103 \\
& 10 & $(10,5 \pm 0,8)$ & 105 \\
& & & 101 \\
abastecimento & 7,0 & $(7,1 \pm 0,2)$ & 108 \\
público & 10 & $(10,8 \pm 0,4)$ & \\
\hline
\end{tabular}
$* n=3$

$\mathrm{Na}$ literatura, alguns eletrodos compósitos de diferentes materiais também foram descritos para a determinação de bisfenol-A. As faixas lineares e os LODs são próximos aos reportados neste trabalho. No caso dos sensores reportado por Ghanam et al. ${ }^{132}$, à base de CPE, utilizando diferentes materiais de carbono com óleo mineral, denominados CPE (grafite e óleo mineral), CBPE (negro de fumo e óleo mineral) e CNTPE (CNTs e óleo mineral), os valores de LOD foram superiores ao obtido neste trabalho. Além disso, é importante ressaltar a baixa robustez mecânica e estabilidade em meios aquosos desses eletrodos, utilizando como aglutinante óleo mineral, quando comparada a PU utilizada neste trabalho.

Tabela 11. Comparação entre o trabalho presente e outros eletrodos compósitos reportados para a determinação de bisfenol-A

\begin{tabular}{|c|c|c|c|}
\hline Eletrodo compósito & $\begin{array}{c}\text { Faixa linear/ } \\
\mu \mathrm{mol} \mathrm{L}\end{array}$ & $\begin{array}{c}\text { LOD/ } \\
\mu \mathrm{mol} \mathrm{L}^{-1}\end{array}$ & Referência \\
\hline $\mathrm{CPE}^{\mathrm{a}}$ & $0,50-6,0$ & 0,36 & Ghanam et al. $^{132}$ \\
\hline $\mathrm{CBPE}^{\mathrm{b}}$ & $0,50-4,0$ & 0,80 & Ghanam et al. ${ }^{132}$ \\
\hline $\mathrm{CNTPE}^{\mathrm{c}}$ & $1,0-4,0$ & 0,70 & Ghanam et al. ${ }^{132}$ \\
\hline $\mathrm{SPE}^{\mathrm{d}}$ & $1,0-10$ & 0,051 & Brugnera et al. ${ }^{133}$ \\
\hline MWCNTs/Au/eletrodo de papel ${ }^{\mathrm{e}}$ & $0,88-88$ & 0,13 & Li et al. ${ }^{134}$ \\
\hline eletrodo de grafite esfoliado & $1,6-50$ & 0,76 & Ndlovu et al. ${ }^{135}$ \\
\hline PEN LAB AgNPs ${ }_{2 \%}$ EGPU $^{\mathrm{f}}$ & $2,5-15$ & 0,24 & Este trabalho \\
\hline
\end{tabular}

${ }^{a} \mathrm{CPE}$ : eletrodo de pasta de carbono à base de grafite e óleo mineral;

${ }^{\mathrm{b}} \mathrm{CBPE}$ : eletrodo de pasta de carbono à base de negro de fumo e óleo mineral;

${ }^{\mathrm{C}} \mathrm{CNTPE}$ : eletrodo de pasta de carbono à base de nanotubo de carbono e óleo mineral;

${ }^{\mathrm{d}} \mathrm{SPE}$ : eletrodo impresso à base de tinta comercial ;

${ }^{\mathrm{e}} \mathrm{MWCNTs} / \mathrm{Au} /$ eletrodo de papel: nanotubos de carbono de paredes múltiplas/nanopartículas de ouro/ eletrodo de papel;

${ }^{\mathrm{f}} P E N$ LAB AgNPs ${ }_{2 \%}$ EGPU: eletrodo compósito de grafite-poliuretana modificado nanopartículas de prata. 


\subsection{CONCLUSÕES PARCIAIS}

Neste trabalho, um novo dispositivo eletroquímico foi desenvolvido contendo o eletrodo de trabalho, o auxiliar e o de referência, todos baseados em compósitos GPU, no mesmo suporte do tipo caneta (denominado PEN $L A B$ ), pela primeira vez. Para o desenvolvimento do eletrodo de trabalho, três quantidades de AgNPs foram preparadas diretamente na estrutura de grafite utilizando um método simples e livre de estabilizantes poliméricos. Medidas de termogravimetria permitiram calcular a quantidade das AgNPs no compósito EGPU, denominados de $\operatorname{AgNPs}_{2 \%}$-EGPU, $\operatorname{AgNPs}_{5 \%}$-EGPU e $\operatorname{AgNPs}_{10 \%}$-EGPU, respectivamente. As AgNPs também foram caracterizadas por SEM, EDX, SEM-FEG e XRPD, que confirmam a formação das AgNPs com uma morfologia esférica e diâmetro regular. Quatro dispositivos do tipo PEN $L A B$ foram construídos, sendo a diferença dentre eles o eletrodo de trabalho (um EGPU não modificado e os outros três EGPUs modificados com diferentes quantidades de AgNPs). Suas respostas eletroquímicas foram avaliadas em solução de tampão fosfato para a determinação de bisfenol-A, sendo o $P E N \operatorname{LAB} \mathrm{AgNP}_{2 \%}$ EGPU selecionado para a quantificação de moléculas em amostras de rio e de abastecimento público, devido a sua maior sensibilidade. Utilizando a DPV, foi desenvolvido um método para determinação de bisfenol-A, o qual apresentou LOD similar ou melhor a outros eletrodos compósitos descritos na literatura. Em adição, comparado aos CPEs reportados, o sensor desenvolvido apresenta maior robustez mecânica e estabilidade em meio aquoso, devido ao caráter hidrofóbico do aglutinante PU. 


\section{CAPÍTULO 4}

Efeito da presença dos nanodiamantes em superfícies de eletrodos compósitos impressos: sondas inorgânicas e discriminação do sinal voltamétrico da dopamina e ácido úrico 


\subsection{OBJETIVOS ESPECÍFICOS}

Fabricar SPE à base de tinta de carbono comercial e modificá-los com dispersões de ND, para moldagem por gotejamento (do inglês “drop casting”).

Avaliar o desempenho eletroanalítico do sensor resultante (ND/SPE), para a determinação concomitante de DA e UA.

Investigar o porquê da condutividade e efeito eletrocatalítico desses ND para alguns analitos, segundo reportado na literatura.

Contribuir para um melhor entendimento dos efeitos eletrocatalíticos promovidos pela presença dos ND, que resultam em melhoras de sinais analíticos, para alguns analitos, quando comparado ao eletrodo sem modificação com ND. 


\subsection{MATERIAL E MÉTODOS}

\subsubsection{Reagentes}

Todos os reagentes químicos (grau analítico ou superior) foram utilizados como recebidos da Sigma-Aldrich sem purificação, o que inclui os ND. Todas as soluções foram preparadas com água purificada (resistividade $\geq 18,0 \mathrm{M} \Omega \mathrm{cm}$ ).

\subsubsection{Instrumentação}

\subsubsection{Microscopia eletrônica de transmissão}

Imagens de microscopia eletrônica de transmissão (TEM, do inglês "transmission electronic microscopy"), dos ND comerciais, foram obtidas utilizando o equipamento TECNAI G2F20, operando com um feixe primário de $200 \mathrm{kV}$ sob condições convencionais de campo claro.

\subsubsection{Microscopia eletrônica de varredura}

Imagens de SEM dos ND comerciais foram obtidas utilizando o equipamento JEOL modelo JSM-5600LV.

\subsubsection{Difração de raios $X$ de pó}

Os ND comerciais foram analisados por XRPD, usando um modelo "X'pert pó

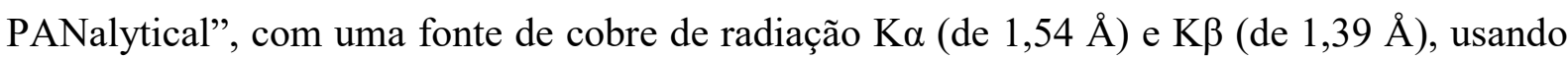
uma fina camada de níquel com uma borda de absorção de $1,49 \AA$, para absorver a radiação $\mathrm{K} \beta$.

\subsubsection{Perfilometria de luz branca}

Análises da rugosidade do eletrodo de grafite pirolítico de plano de borda (EPPG, do inglês "edge plane pyrolytic graphite"), GCE e SPE foram realizadas usando perfilometria de luz branca em um equipamento ZeGage 3D Optical Surface Profiler (Zago).

\subsubsection{Técnicas voltamétricas}

As medidas eletroquímicas foram realizadas em um potenciostato Ivium Compactstat $^{\mathrm{TM}}$ (The Netherlands). A célula eletroquímica utilizada foi um sistema convencional com compartimento único, à qual foi adicionado uma alíquota de $10,0 \mathrm{~mL}$ de 
tampão acetato $0,10 \mathrm{~mol} \mathrm{~L}^{-1}(\mathrm{pH} 5,5)$ e solução de $\mathrm{KCl} 0,10 \mathrm{~mol} \mathrm{~L}^{-1}$ para a realização das medidas eletroquímicas. Todos os experimentos foram conduzidos à temperatura de $25 \pm 1{ }^{\circ} \mathrm{C}$.

\subsubsection{Fabricação e preparo dos SPE}

Todos os SPE foram confeccionados com uma impressora DEK 248 (DEK, Weymouth, U.K.) e o processo de fabricação foi descrito detalhadamente em trabalhos prévios $^{136,137}$. Em sua fabricação: primeiro uma formulação de tinta de carbono-grafite (código do produto C2000802P2; Gwent Electronic Materials Ltd., Reino Unido), foi impressa através de tela sobre uma película flexível de poliéster (Autostat, $250 \mu \mathrm{m}$ de espessura) e, em seguida, colocada em um forno a $60{ }^{\circ} \mathrm{C}$ por 30 minutos para secagem. Para confecção do eletrodo de referência, uma pasta de $\mathrm{Ag} / \mathrm{AgCl}$ (código de produto C2030812P3; Gwent Electronic Materials Ltd., Reino Unido), foi aplicada sobre os substratos de poliéster com o auxílio de uma espátula e, novamente, os eletrodos foram levados a estufa a $60{ }^{\circ} \mathrm{C}$ durante 30 minutos. Finalmente, uma pasta dielétrica (código de produto D2070423D5; Gwent Electronic Materials Ltd., Reino Unido), foi então impressa no substrato de poliéster para cobrir as conexões. Após a cura, que se completa a $60{ }^{\circ} \mathrm{C}$ depois de 30 minutos, os SPE estão prontos para serem usados. Em cada cartela de poliéster eram impressos de uma única vez 22 eletrodos (Figura 34A). Os SPE fabricados são constituídos de um eletrodo de trabalho (WE, $\phi=3 \mathrm{~mm}$ ), um contra-eletrodo (CE) e o eletrodo de referência (RE, um pseudo referência de $\mathrm{Ag} / \mathrm{AgCl})$, como apresentado na Figura 34B.

Para a modificação do eletrodo, dispersou-se 1,0 mg de ND (adquirido da SigmaAldrich) em 1,0 mL de água ultra-pura. A solução foi homogeneizada em um banho ultrassônico durante 30 min e, em seguida, $8 \mu \mathrm{L}$ da dispersão foram gotejados na superfície do eletrodo de trabalho do SPE com o auxílio de um micropipetador. Após 2 horas a temperatura ambiente, o solvente evaporou-se completamente e o SPE modificado estava pronto para ser usado (Figura 34C). 
(A)
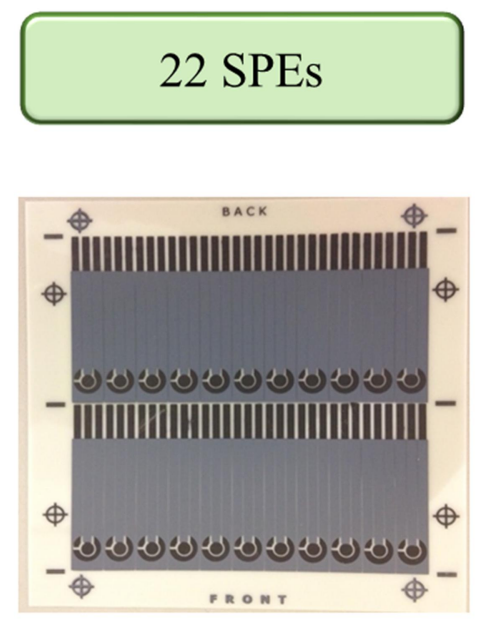

(B)
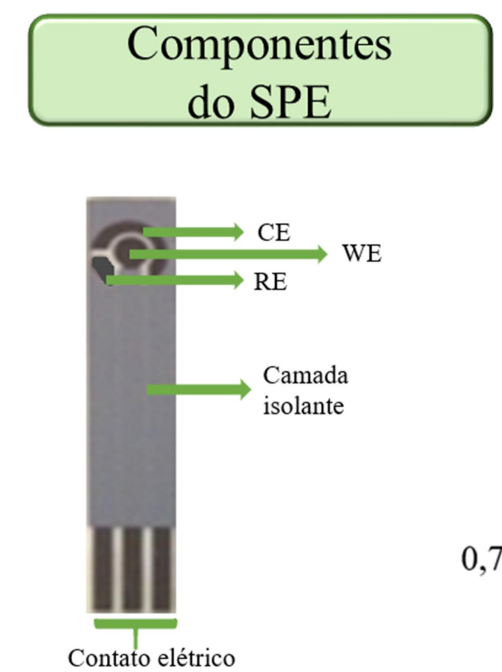

(C)

\section{Modificação do SPE}

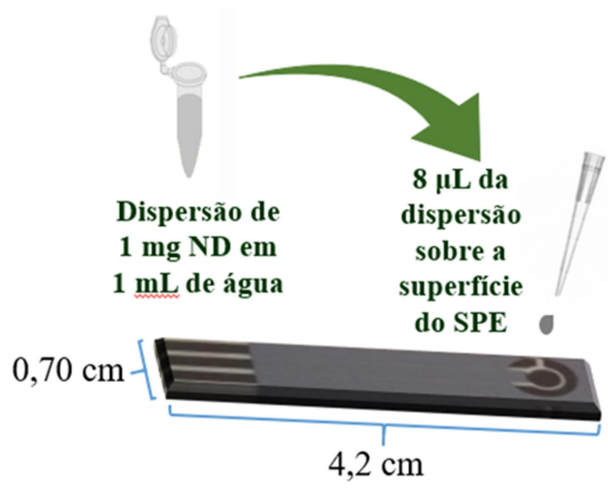

Figura 34. Esquema da fabricação dos SPEs (A); componentes do SPE (B) preparo do ND/SPE (C).

\subsubsection{Preparo dos eletrodos à base de pasta de carbono}

Para estudos de comparação do nanodiamante como material eletródico foram preparados CPE de diferentes composições de material de carbono:Nujol nas proporções 60:40\% $\left(\mathrm{m} \mathrm{m}^{-1}\right)$. Assim três eletrodos foram propostos: negro de fumo:Nujol 60:40\% $\left(\mathrm{m} \mathrm{m}^{-1}\right)$, ND:Nujol 60:40\% $\left(\mathrm{m} \mathrm{m}^{-1}\right)$ e negro de fumo:ND:Nujol 55:5:40\% $\left(\mathrm{m} \mathrm{m}^{-1}\right)$. As misturas foram homogeneizadas durante 30 minutos em um almofariz de vidro e, ao final desse período, as pastas resultantes foram inseridas em um tubo cilindro de plástico (seringa descartável com 3 mm de diâmetro). Um fio de cobre foi usado para contato elétrico externo e as superfícies dos CPE foram polidas em uma folha de papel sulfite, antes do uso.

\subsubsection{Procedimento experimental}

\subsubsection{Caracterização dos ND comerciais}

As características dos ND foram avaliadas por TEM, SEM e XRPD.

\subsubsection{Caracterização dos SPE fabricados}

A caracterização topográfica da superfície dos SPE foi realizada para investigar a rugosidade do eletrodo, usando perfilometria de luz branca. Para efeito de comparação também foram analisadas as superfícies do EPPG e GCE. 


\subsubsection{Comportamento eletroquímico da DA e UA sob o SPE e o ND/SPE}

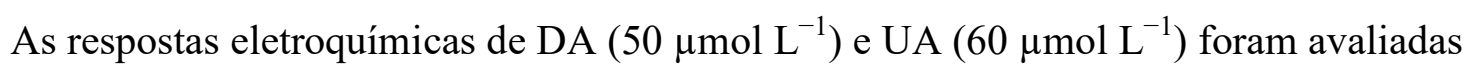
individualmente utilizando o SPE e o ND/SPE em tampão fosfato $0,10 \mathrm{~mol} \mathrm{~L}^{-1}$ (pH 7,4), a 50 $\mathrm{mV} \mathrm{s}^{-1}$, em um intervalo de varredura de potenciais entre $-0,2$ e $0,4 \mathrm{~V}$ (vs. pseudo referência de $\mathrm{Ag} / \mathrm{AgCl}$ ), empregando a voltametria cíclica, a fim de identificar os processos redox envolvidos. Em seguida, ainda utilizando a voltametria cíclica, diferentes adições de DA foram feitas à célula eletroquímica e as curvas analíticas utilizando o SPE e o ND/SPE foram obtidas. O mesmo procedimento foi realizado para UA. Valores de sensibilidade (coeficiente angular da curva) e LOD foram comparados utilizando o SPE com e sem modificação para a determinação de cada molécula.

A DPV foi escolhida para o desenvolvimento do método eletroanalítico utilizando o ND/SPE para a determinação de DA na presença de UA. Assim, inicialmente foi investigada influência da concentração hidrogeniônica do meio sob a resposta voltamétrica da DA e UA em tampão fosfato $0,10 \mathrm{~mol} \mathrm{~L}^{-1}$, com diferentes valores de $\mathrm{pH}(4,4 ; 5,5 ; 6,5 ; 7,4$ e 8,4$)$ na presença de DA $50 \mu \mathrm{mol} \mathrm{L}{ }^{-1}$ e UA $60 \mu \mathrm{mol} \mathrm{L}^{-1}$, em um intervalo de varredura de potenciais entre $-0,2$ e 0,6 V (vs. pseudo referência de $\mathrm{Ag} / \mathrm{AgCl}$ ). Os parâmetros da $\mathrm{DPV}$ foram velocidade de varredura $10 \mathrm{mV} \mathrm{s}^{-1}$, amplitude $25 \mathrm{mV}$, com tempo de intervalo de $0,5 \mathrm{~s}$ e tempo de modulação de $0,05 \mathrm{~s}$. Após a seleção do valor de $\mathrm{pH}$, foram comparadas as respostas voltamétricas das moléculas em dois eletrólitos suporte diferentes (tampão fosfato e tampão acetato) $0,10 \mathrm{~mol} \mathrm{~L}^{-1}$.

Sob condições otimizadas, foram feitas adições de DA à célula eletroquímica, estudando-se a faixa de concentração de 2 a $100 \mu \mathrm{mol} \mathrm{L}^{-1}$, em tampão acetato $0,10 \mathrm{~mol} \mathrm{~L}^{-1}$ (pH 5,5), na presença de uma concentração fixa de UA $20 \mu \mathrm{mol} \mathrm{L} \mathrm{L}^{-1}$, em um intervalo de varredura de potenciais entre 0,0 e $0,6 \mathrm{~V}$ (vs. pseudo referência de $\mathrm{Ag} / \mathrm{AgCl}$ ), usando o ND/SPE. O mesmo procedimento para UA foi realizado, estudando-se uma faixa de concentração 2,0 a 97,0 $\mu \mathrm{mol} \mathrm{L} \mathrm{L}^{-1}$, na presença de uma concentração fixa de DA 20,0 $\mu \mathrm{mol}$ $\mathrm{L}^{-1}$. A partir dos resultados obtidos, gráficos das correntes de pico de oxidação vs. concentrações de DA e UA foram construídos. Além disso, valores de LOD foram calculados como descritos anteriormente ${ }^{119}$.

\subsubsection{Avaliando e investigando o desempenho catalítico do ND/SPE}

As respostas voltamétricas de algumas sondas eletroquímicas $\left(\mathrm{Fe}(\mathrm{CN})_{6}{ }^{3-}, \mathrm{IrCl}_{6}{ }^{2-} \mathrm{e}\right.$ $\mathrm{Ru}\left(\mathrm{NH}_{3}\right)_{6}{ }^{3+}$ ) foram avaliadas em $\mathrm{KCl} 0,10 \mathrm{~mol} \mathrm{~L}^{-1}$, utilizando a voltametria cíclica, 
estudando-se uma faixa de varredura de potenciais entre 5 e $500 \mathrm{mV} \mathrm{s}^{-1}$, para entender melhor o comportamento eletroquímico do ND/SPE frente ao SPE.

Em seguida, para investigar mais detidamente a atividade eletrocatalítica e condutividade dos ND, os CPE de negro de fumo:Nujol 60:40\% $\left(\mathrm{m} \mathrm{m}^{-1}\right)$, ND:Nujol 60:40\% $\left(m \mathrm{~m}^{-1}\right.$ ) e negro de fumo:ND:Nujol 55:5:40\% $\left(\mathrm{m} \mathrm{m}^{-1}\right)$ tiveram suas performances voltamétricas avaliadas e comparadas. Para isso, medidas de voltametria cíclica foram realizadas em $\mathrm{KCl} 0,10 \mathrm{~mol} \mathrm{~L}$, na presença de $\left[\mathrm{Ru}\left(\mathrm{NH}_{3}\right)_{6}\right] \mathrm{Cl}_{3} 1,0 \mathrm{mmol} \mathrm{L}{ }^{-1} \mathrm{em}$ um intervalo de varredura de potenciais entre $-0,6$ e 0,2 V (vs. pseudo referência de $\mathrm{Ag} / \mathrm{AgCl}$ ), com v = 50 $\mathrm{mV} \mathrm{s}^{-1}$.

Por fim, adicionaram-se diferentes concentrações de ND na superfície do SPE, e avaliou-se o desempenho eletroquímico dos sensores frente às sondas eletroquímicas: $\mathrm{Fe}(\mathrm{CN})_{6}{ }^{3-}, \mathrm{IrCl}_{6}{ }^{2-}$ e $\mathrm{Ru}\left(\mathrm{NH}_{3}\right)_{6}{ }^{3+}$. Assim, foram preparadas diferentes dispersões de pó de ND em água: $0,1 \mathrm{mg} \mathrm{mL}^{-1}, 0,5 \mathrm{mg} \mathrm{mL}^{-1}, 0,8 \mathrm{mg} \mathrm{mL}^{-1}, 1,0 \mathrm{mg} \mathrm{mL}^{-1}, 1,5 \mathrm{mg} \mathrm{mL}^{-1}$ e $2,0 \mathrm{mg} \mathrm{mL}^{-1}$ e a partir dessas, $8 \mu \mathrm{L}$ foram gotejados sob a superfície dos SPE. Medidas de voltametria cíclica, $v=50 \mathrm{mV} \mathrm{s}^{-1}$, em $\mathrm{KCl} 0,10 \mathrm{~mol} \mathrm{~L}^{-1}$ na presença de $\mathrm{K}_{3}\left[\mathrm{Fe}(\mathrm{CN})_{6}\right], \mathrm{K}_{2}\left[\mathrm{IrCl}_{6}\right]$ e $\left[\mathrm{Ru}\left(\mathrm{NH}_{3}\right)_{6}\right] \mathrm{Cl}_{3} 1,0 \mathrm{mmol} \mathrm{L} \mathrm{L}^{-1}$, foram feitas utilizando os SPE modificados com diferentes concentrações de ND. 


\subsection{Resultados e discussão}

\subsubsection{Caracterização dos ND}

Os resultados aqui apresentados já foram publicados em uma revista de circulação internacional, a Microchimica Acta, por Baccarin et al., volume 186 (3), 2019, página 1-9, com o seguinte título "Nanodiamond based surface modified screen-printed electrodes for the simultaneous voltammetric determination of dopamine and uric acid".

Inicialmente, foram obtidas imagens de TEM dos ND para avaliar a morfologia dos mesmos. Nas Figuras 35A e 35B, são apresentados os resultados obtidos, nas quais se pode observar nas regiões destacados em amarelo, as partículas na forma esférica do material, com diâmetros aproximadamente de $5 \mathrm{~nm}$. Na Figura 35C é apresentada a imagem SEM dos ND na qual é possível constatar sinais distintos de aglomeração formando clusters. E na Figura 35D estão registrados picos obtidos da análise de XRPD, característicos da estrutura dos ND em $2 \theta=44^{\circ}, 75^{\circ}$ e $92^{\circ}$, correspondentes às difrações (111), (220) e (311).

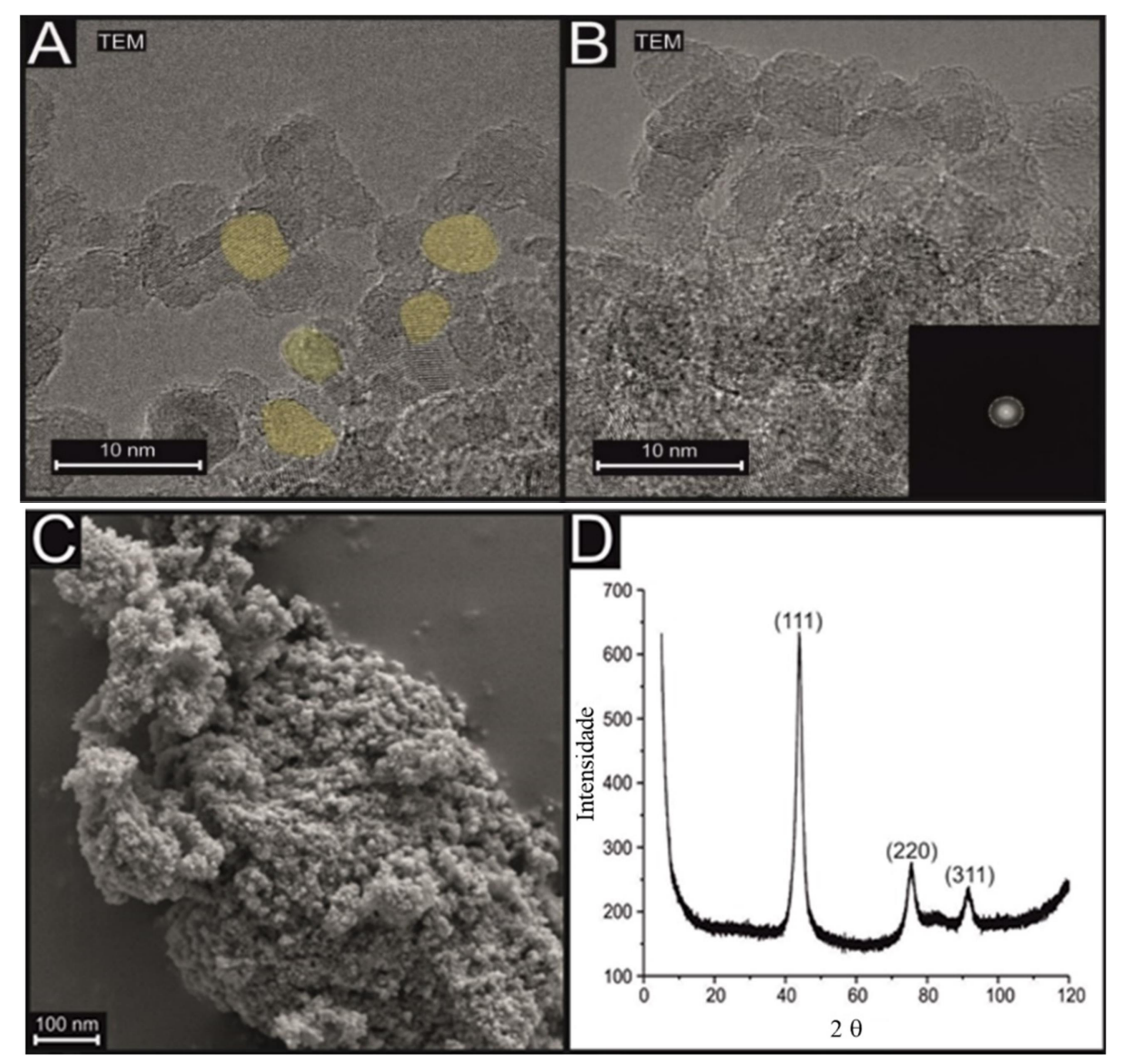

Figura 35. Imagens de TEM obtidas dos ND comerciais (A) e (B). Em amarelo estão destacados os contornos distintos das nanopartículas do ND individualmente. (C) Imagens de SEM obtidas dos ND. (D) Espectro de XRPD dos ND. 
Também foi feita uma caracterização topográfica da superfície do SPE fabricado, e para um melhor entendimento este foi comparado ao EPPG e GCE. Na Figura 36 são ilustrados os mapas de topografia superficial de perfilometria de luz branca dos três eletrodos. Observou-se que a rugosidade superficial do SPE é relativamente maior que a dos outros eletrodos, quando se compara os valores de SA (valores médios aritméticos dos valores absolutos da altura em toda a superfície) de 1539,6 nm em comparação com 19,9 nm e 12,3 nm para EPPG e GCE, receptivamente. Também é observado que os valores de SQ (valor da média de raiz quadrada das alturas sobre toda a superfície) de SPE (1904,9 nm) são maiores que os do EPPG (26,1 nm) e GCE (15,9 nm).

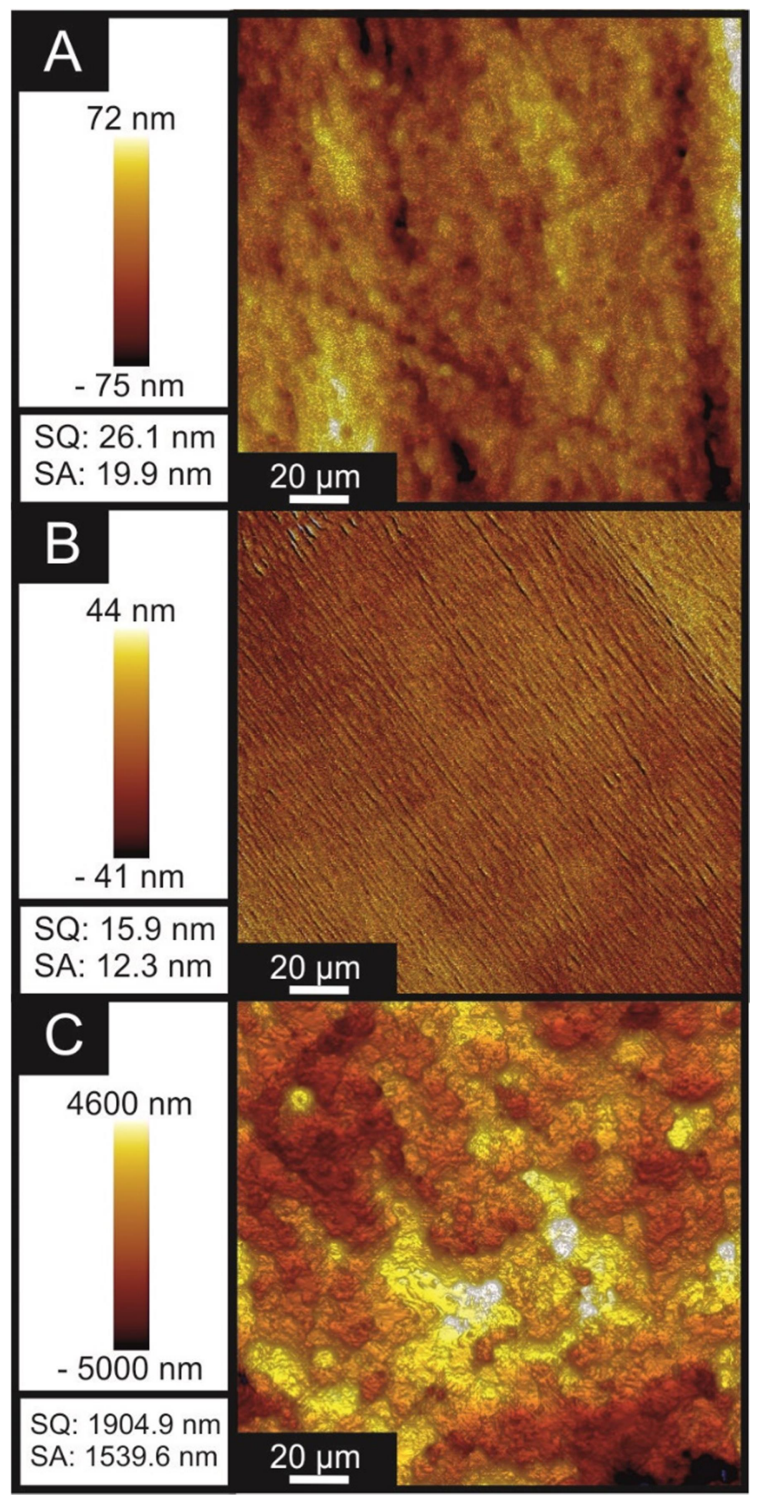

Figura 36. Mapas de topografia superficial de perfilometria de luz branca de (A) EPPG, (B) GCE e (C) SPE. 


\subsubsection{Comportamento eletroquímico da DA e UA}

A resposta eletroquímica da DA e do UA no SPE e ND/SPE foi avaliada por voltametria cíclica. Na Figura 37A são apresentados os voltamogramas cíclicos obtidos na presença de DA 50,0 $\mu \mathrm{mol} \mathrm{L}^{-1}$ e na Figura 37B na presença de UA 60,0 $\mu \mathrm{mol} \mathrm{L}{ }^{-1}$, ambos em tampão fosfato $0,10 \mathrm{~mol} \mathrm{~L}^{-1}\left(\mathrm{pH} \mathrm{7,4)}\right.$, a $50 \mathrm{mV} \mathrm{s}^{-1}$, em um intervalo de varredura de potenciais entre $-0,2$ e $0,4 \mathrm{~V}$ ( $v s$. pseudo referência de $\mathrm{Ag} / \mathrm{AgCl}$ ) para $\mathrm{DA}$ e 0,0 e 0,6 V (vs. pseudo referência de $\mathrm{Ag} / \mathrm{AgCl}$ ) para UA .

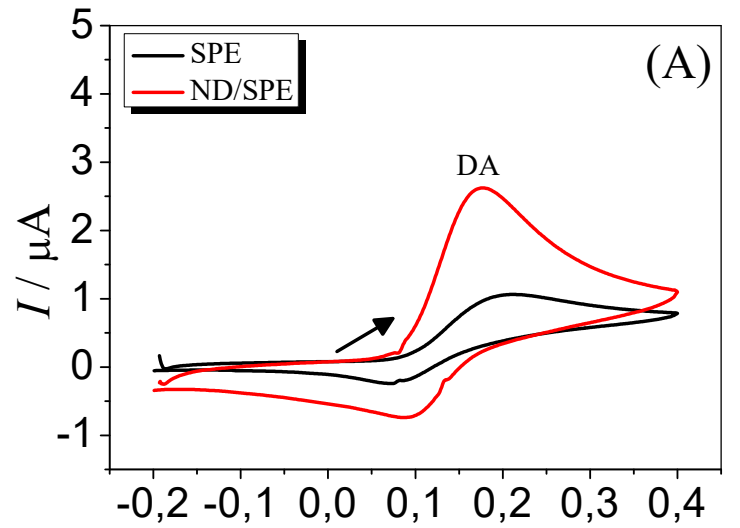

(E vs. pseudo referência de $\mathrm{Ag} / \mathrm{AgCl}$ ) / V

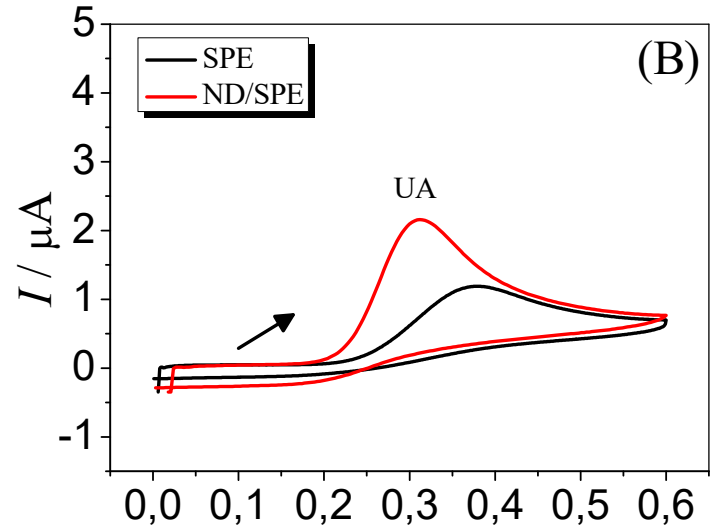

(E vs. pseudo referência de $\mathrm{Ag} / \mathrm{AgCl}$ ) / V

Figura 37. Voltamogramas cíclicos obtidos na presença de DA $50,0 \mu \mathrm{mol} \mathrm{L} \mathrm{L}^{-1}$ (A) e UA $60,0 \mu \mathrm{mol} \mathrm{L} \mathrm{L}^{-1}$ (B) em tampão fosfato $0,10 \mathrm{~mol} \mathrm{~L}^{-1}\left(\mathrm{pH} \mathrm{7,4),} \mathrm{a} 50 \mathrm{mV} \mathrm{s}^{-1}\right.$, utilizando o SPE e o ND/SPE.

A partir dos dados obtidos na Figura 37A, observou-se, um pico de oxidação para a DA por volta de $0,18 \mathrm{~V}$ e $0,20 \mathrm{~V}$ (vs. pseudo referência de $\mathrm{Ag} / \mathrm{AgCl}$ ), no sentido positivo da varredura de potenciais, utilizando o ND/SPE e o SPE, respectivamente. Ainda, no sentido inverso da varredura de potenciais, um pico de redução foi observado em $0,10 \mathrm{~V}$ e $0,080 \mathrm{~V}$ (vs. pseudo referência de $\mathrm{Ag} / \mathrm{AgCl}$ ), utilizando o ND/SPE e o SPE, respectivamente. Já na Figura 37B, foi observado um pico de oxidação para o UA em $0,31 \mathrm{~V}$ e $0,37 \mathrm{~V}$ (vs. pseudo referência de $\mathrm{Ag} / \mathrm{AgCl}$ ), utilizando o $\mathrm{ND} / \mathrm{SPE}$ e o $\mathrm{SPE}$, respectivamente. No sentido inverso de varredura não foi observado nenhum pico de redução. Quando se compara as respostas voltamétricas obtidas com os dois eletrodos para ambos os analitos, considerando os picos de oxidação se observa que a presença do ND facilita a transferência de elétrons na interface eletrodo/solução, uma vez que ocorre um aumento da corrente e um deslocamento do pico para valores mais baixos de potencial (Para a DA, o deslocamento foi de $0,02 \mathrm{~V}$ na oxidação e na redução, já para o UA o deslocamento foi de $0,06 \mathrm{~V}$ na oxidação).

Em seguida, a potencialidade eletroanalítica do eletrodo modificado foi comparada com a do não modificado em relação à detecção da DA e do UA individualmente. Assim, 
utilizando a voltametria cíclica, foram feitas diferentes adições de DA em tampão fosfato 0,10 mol L ${ }^{-1}(\mathrm{pH}=7,4)$, a $50 \mathrm{mV} \mathrm{s}^{-1}$, em um intervalo de varredura de potenciais entre $-0,2$ e 0,4 $\mathrm{V}$ (vs. pseudo referência de $\mathrm{Ag} / \mathrm{AgCl}$ ). Utilizando ambos os eletrodos, voltamogramas cíclicos foram obtidos na faixa de concentração de 50,0 a $400,0 \mu \mathrm{mol} \mathrm{L} \mathrm{L}^{-1}$, os quais são apresentados na Figura 38A e 38B. Com o SPE, obteve-se uma curva analítica correlacionando a corrente de pico anódica com a concentração de DA (gráfico inserido na Figura 38A), descrita pela seguinte equação: $I(\mathrm{~A})=2,2 \times 10^{-7}+0,0092 \mathrm{C}_{\mathrm{DA}}\left(\mathrm{mol} \mathrm{L}^{-1}\right)$, com coeficiente de correlação $(\mathrm{r})=0,998$, e LOD calculado de $12 \mu \mathrm{mol} \mathrm{L}{ }^{-1}$. Já com o ND/SPE, a curva analítica registrada (respectivo gráfico inserido na Figura 38B) foi descrita pela seguinte equação: $I(\mathrm{~A})=1,4 \times$ $10^{-6}+0,018 \mathrm{C}_{\mathrm{DA}}\left(\mathrm{mol} \mathrm{L}^{-1}\right)$, com $\mathrm{r}=0,996$ e um LOD de 9,0 $\mu \mathrm{mol} \mathrm{L} \mathrm{L}^{-1}$. Na Tabela 12 foram reportados os parâmetros analíticos (sensibilidade e LOD) obtidos a partir das respectivas curvas analíticas.

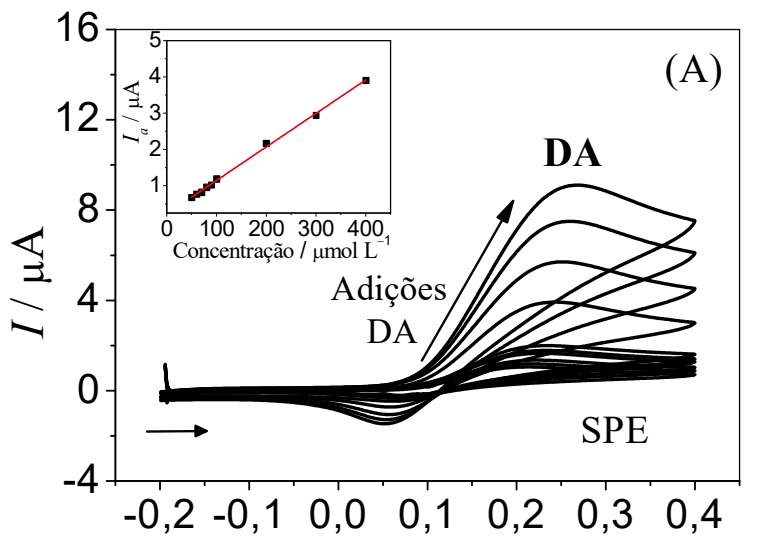

(E vs. pseudo referência de $\mathrm{Ag} / \mathrm{AgCl}$ / / V

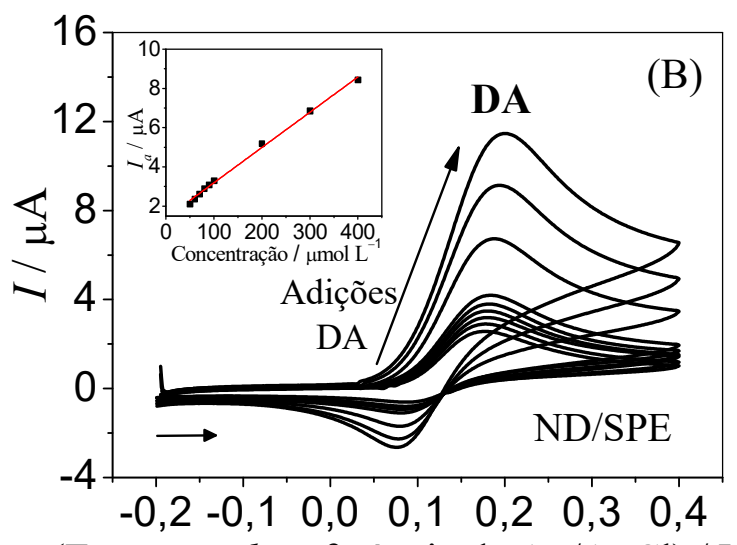

(E vs. pseudo referência de $\mathrm{Ag} / \mathrm{AgCl}) / \mathrm{V}$

Figura 38. Voltamogramas cíclicos obtidos utilizando SPE (A) e ND/SPE (B) para concentrações de DA de 50,0 a 400,0 $\mu \mathrm{mol} \mathrm{L}^{-1}$ em solução de tampão fosfato $0,10 \mathrm{~mol} \mathrm{~L}^{-1}$ (pH 7,4), velocidade de varredura: $50 \mathrm{mV} \mathrm{s}^{-1}$. Inserida as respectivas curvas analíticas, com cada medida em triplicata.

Tabela 12. Comparação entre o desempenho do SPE e do ND/SPE para a determinação de DA

\section{DA}

\begin{tabular}{ccc}
\hline Parâmetros & SPE & ND/SPE \\
\cline { 2 - 3 } & $2,2 \times 10^{-7}+0,0092 \mathrm{C}_{\mathrm{DA}}$ & $1,4 \times 10^{-6}+0,018 \mathrm{C}_{\mathrm{DA}}$ \\
Equação da reta/ $I(\mathrm{~A})$ & 12 & 9,0 \\
$\mathrm{LOD} / \mu \mathrm{mol} \mathrm{L}$ & $50 \mathrm{a} 400$ & $50 \mathrm{a} 400$ \\
Faixa linear/ $\mu \mathrm{mol} \mathrm{L}^{-1}$ & 0,0092 & 0,018 \\
Sensibilidade/ $\mu \mathrm{A} \mu \mathrm{mol}^{-1} \mathrm{~L}$ & &
\end{tabular}

O mesmo procedimento foi realizado para determinação de UA utilizando os dois eletrodos em estudo e a voltametria cíclica. Assim, diferentes adições de UA foram feitas em 
tampão fosfato $0,10 \mathrm{~mol} \mathrm{~L}^{-1}(\mathrm{pH}=7,4)$, a $50 \mathrm{mV} \mathrm{s}^{-1}$, em um intervalo de varredura de potenciais entre 0,0 e $0,6 \mathrm{~V}$ (vs. pseudo referência de $\mathrm{Ag} / \mathrm{AgCl}$ ), na faixa de concentração de 60 a $500 \mu \mathrm{mol} \mathrm{L}{ }^{-1}$ de UA (Figura 39A e 39B). Uma região linear correlacionando a corrente de pico anódica com a concentração de UA foi obtida no SPE (gráfico inserido na Figura 39A), variando de 60,0 a 200,0 $\mu \mathrm{mol} \mathrm{L} \mathrm{L}^{-1}$, descrita pela equação: $I(\mathrm{~A})=2,2 \times 10^{-7}+0,011$ $\mathrm{C}_{\mathrm{UA}}\left(\mathrm{mol} \mathrm{L}^{-1}\right), \mathrm{r}=0,998$. O LOD encontrado foi de $18,0 \mu \mathrm{mol} \mathrm{L} \mathrm{L}^{-1}$. Já com o ND/SPE, a curva analítica registrada (respectivo gráfico inserido na Figura 39B) foi descrita pela seguinte equação: $I(\mathrm{~A})=7,6 \times 10^{-7}+0,019 \mathrm{C}_{\mathrm{UA}}\left(\mathrm{mol} \mathrm{L}^{-1}\right)$, com r $=0,996$ e um LOD de 6,6 $\mu \mathrm{mol} \mathrm{L} \mathrm{L}^{-1}$. Os parâmetros de LOD e de sensibilidade obtidos utilizando o SPE e o ND/SPE para determinação de UA foram comparados e apresentados na Tabela 13.

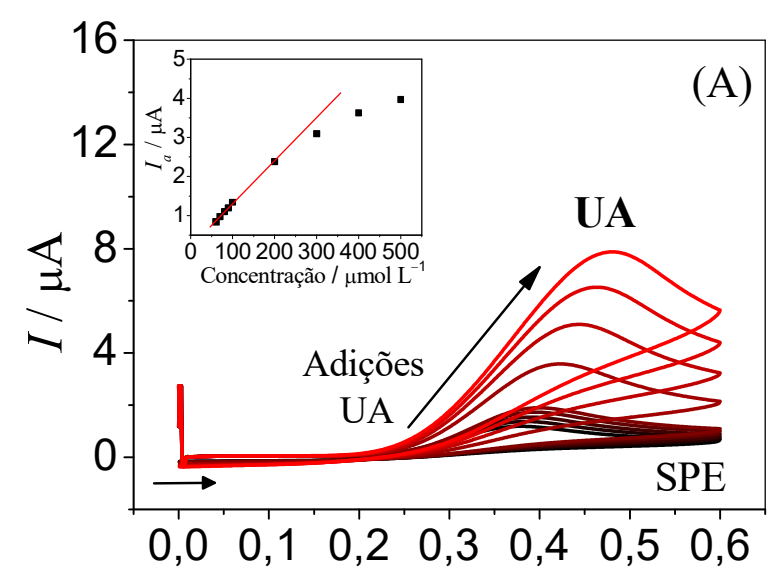

(E vs. pseudo referência de $\mathrm{Ag} / \mathrm{AgCl}$ / V

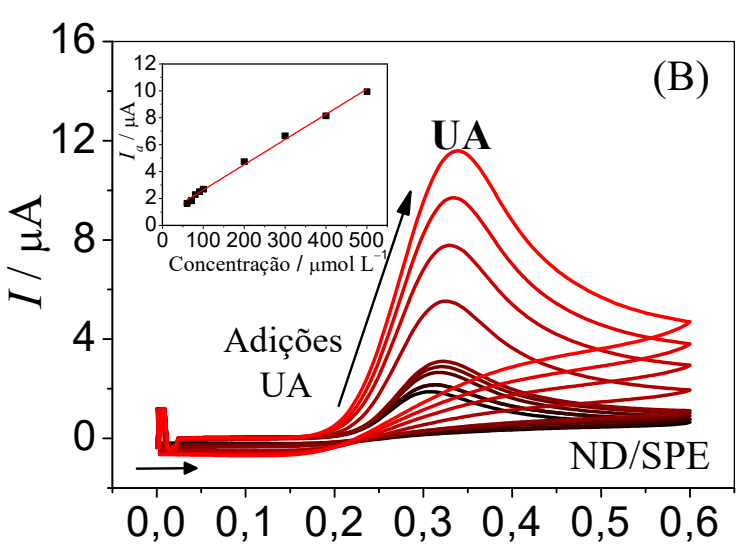

(E vs. pseudo referência de $\mathrm{Ag} / \mathrm{AgCl}$ / V

Figura 39. Voltamogramas de voltametria cíclica obtidos utilizando SPE (A) e ND/SPE (B) para concentrações de UA de 60,0 a $500,0 \mu \mathrm{mol} \mathrm{L}-1$ em solução de tampão fosfato $0,10 \mathrm{~mol} \mathrm{~L}^{-1}$ $\left(\mathrm{pH} \mathrm{7,4)}\right.$, a $50 \mathrm{mV} \mathrm{s}^{-1}$. Inserida as respectivas curvas analíticas, com cada medida em triplicata.

Tabela 13. Comparação entre o desempenho do SPE e do ND/SPE para a determinação de UA

\begin{tabular}{ccc}
\hline & \multicolumn{2}{c}{$\mathrm{UA}$} \\
\hline Parâmetros & $\mathrm{SPE}$ & $\mathrm{ND} / \mathrm{SPE}$ \\
\cline { 2 - 3 } & $2,2 \times 10^{-7}+0,011 \mathrm{C}_{\mathrm{UA}}$ & $7,6 \times 10^{-7}+0,019 \mathrm{C}_{\mathrm{UA}}$ \\
Equação da reta/ $(\mathrm{A})$ & 18 & 6,6 \\
$\mathrm{LOD} / \mu \mathrm{mol} \mathrm{L}$ & 60 a 200 & 60 a 500 \\
Faixa linear $/ \mu \mathrm{mol} \mathrm{L}^{-1}$ & 0,011 & 0,019 \\
\hline Sensibilidade $/ \mu \mathrm{A} \mu \mathrm{mol}^{-1} \mathrm{~L}$ &
\end{tabular}

A partir dos parâmetros analíticos na Tabela 12, observou-se uma sensibilidade quase duas vezes maior utilizando o ND/SPE, comparado ao SPE para a DA, além de um LOD menor que aquele encontrado com o SPE. A mesma melhora nos parâmetros analíticos foi observada para o UA, evidenciado por uma sensibilidade de 1,7 vezes do eletrodo modificado 
comparado ao não modificado e um valor de LOD 2,7 vezes menor que do SPE de acordo com a Tabela 13. Estes resultados justificam a modificação de eletrodo, bem como sua possível aplicação para a determinação destas biomoléculas e mostram que a presença dos ND melhora de forma significativa o desempenho do eletrodo, nessa determinação.

Em seguida, utilizando a DPV, foi investigada a influência da concentração hidrogeniônica do meio, na resposta analítica da DA e do UA, utilizando o ND/SPE. Na Figura 40 são apresentados os voltamogramas obtidos em tampão fosfato $0,10 \mathrm{~mol} \mathrm{~L}^{-1}$ para os diferentes valores de $\mathrm{pH}\left(4,4 ; 5,5 ; 6,5 ; 7,4\right.$ e 8,4), na presença de DA 50,0 $\mu \mathrm{mol} \mathrm{L}^{-1}$ e UA 60 $\mu \mathrm{mol} \mathrm{L} \mathrm{L}^{-1}$, em um intervalo de varredura de potenciais entre $-0,2$ e $0,6 \mathrm{~V}$ (vs. pseudo referência de $\mathrm{Ag} / \mathrm{AgCl})$. Os parâmetros da DPV foram velocidade de varredura $10 \mathrm{mV} \mathrm{s}{ }^{-1}$, amplitude $25 \mathrm{mV}$, com tempo de intervalo de $0,5 \mathrm{~s}$ e tempo de modulação de $0,05 \mathrm{~s}$. A partir dos valores de corrente de pico de oxidação $\left(I_{\mathrm{pa}}\right)$, obtidos para DA e UA, foi construído um gráfico de $I_{\mathrm{pa}} v s$. pH, apresentado na Figura 40B.

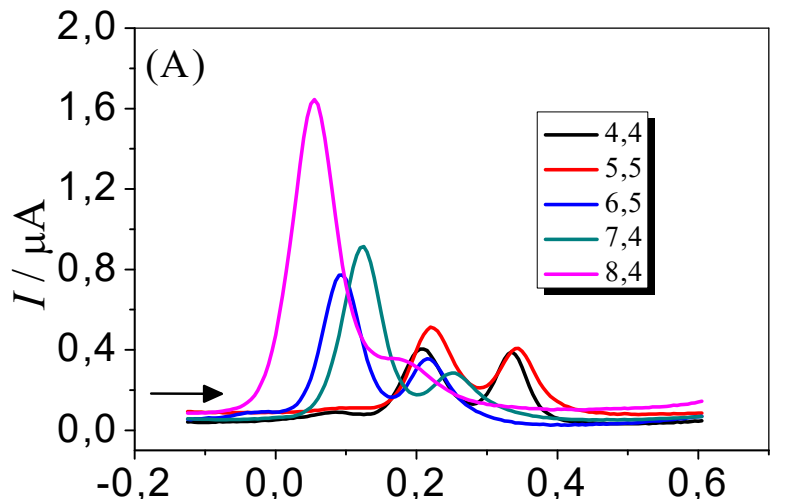

(E vs. pseudo referência de $\mathrm{Ag} / \mathrm{AgCl}$ ) / V

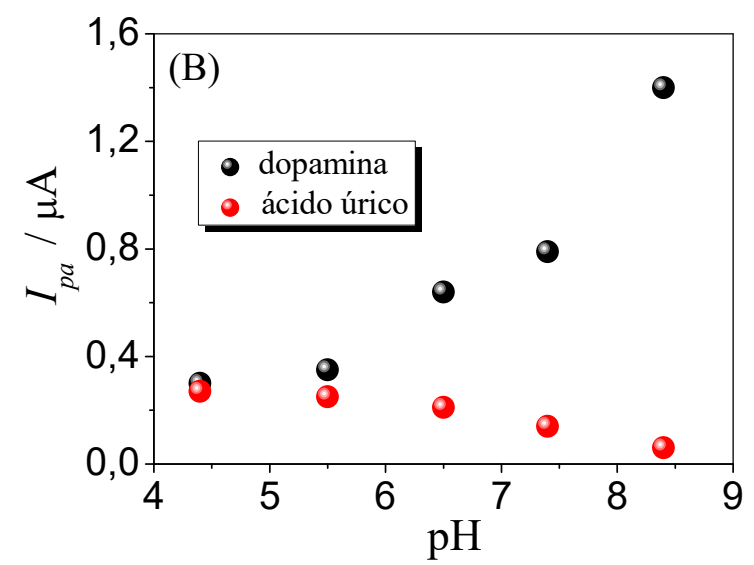

Figura 40. Voltamogramas de DPV obtidos na presença de DA $50 \mu \mathrm{mol} \mathrm{L}{ }^{-1}$ e UA $60 \mu \mathrm{mol} \mathrm{L} \mathrm{L}^{-1}$ em tampão fosfato $0,10 \mathrm{~mol} \mathrm{~L}^{-1} \mathrm{em}$ diferentes valores de $\mathrm{pH}$ : 4,4 (-), 5,5 (-), 6,5 (-), 7,4 (-) e $8,4(-)$, com velocidade de $10 \mathrm{mV} \mathrm{s}^{-1}$ e amplitude $25 \mathrm{mV}$, utilizando ND/SPE.

A partir dos resultados obtidos, observou um aumento da intensidade de corrente da DA e uma diminuição da magnitude de corrente do UA em meio mais básico, além de um aumento na dificuldade de distinguir os picos de cada analito, uma vez que começaram a sobrepor (ver voltamograma do pH 8,4, Figura 40A), perdendo resolução. Observa-se que o pH tem um efeito sobre a determinação simultânea do sinal analítico dos dois analitos.

Os valores de $\Delta E$ obtidos em pH 5,5 e 6,5 foram $122 \mathrm{mV}$ e $126 \mathrm{mV}$, respectivamente, o que não teve muita diferença significativa. Já em relação aos valores de corrente, em pH 6,5 , obteve-se $181 \%$ para DA e houve uma perda de $12 \%$ para UA comparando com os 
valores obtidos em pH 5,5. Devido a perda de sinal do UA, selecionou-se esses dois valores de $\mathrm{pH}$ para o estudo posterior, para efeito de comparação.

Em seguida, estudos de DPV também foram realizados para identificar o melhor eletrólito suporte para a determinação eletroquímica concomitante da DA e do UA, utilizando o ND/SPE. Na Figura 41 são apresentados os voltamogramas obtidos em 0,10 $\mathrm{mol} \mathrm{L}^{-1}$ de

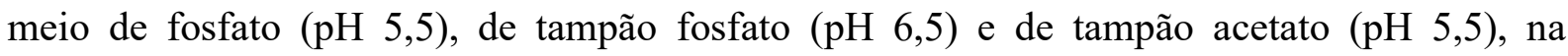
presença de DA $50 \mu \mathrm{mol} \mathrm{L}{ }^{-1}$ e UA $60 \mu \mathrm{mol} \mathrm{L}^{-1}$, em um intervalo de varredura de potenciais entre $-0,2$ e $0,6 \mathrm{~V}$ (vs. pseudo referência de $\mathrm{Ag} / \mathrm{AgCl}$ ), com velocidade de $10 \mathrm{mV} \mathrm{s}^{-1}$ e amplitude $25 \mathrm{mV}$.

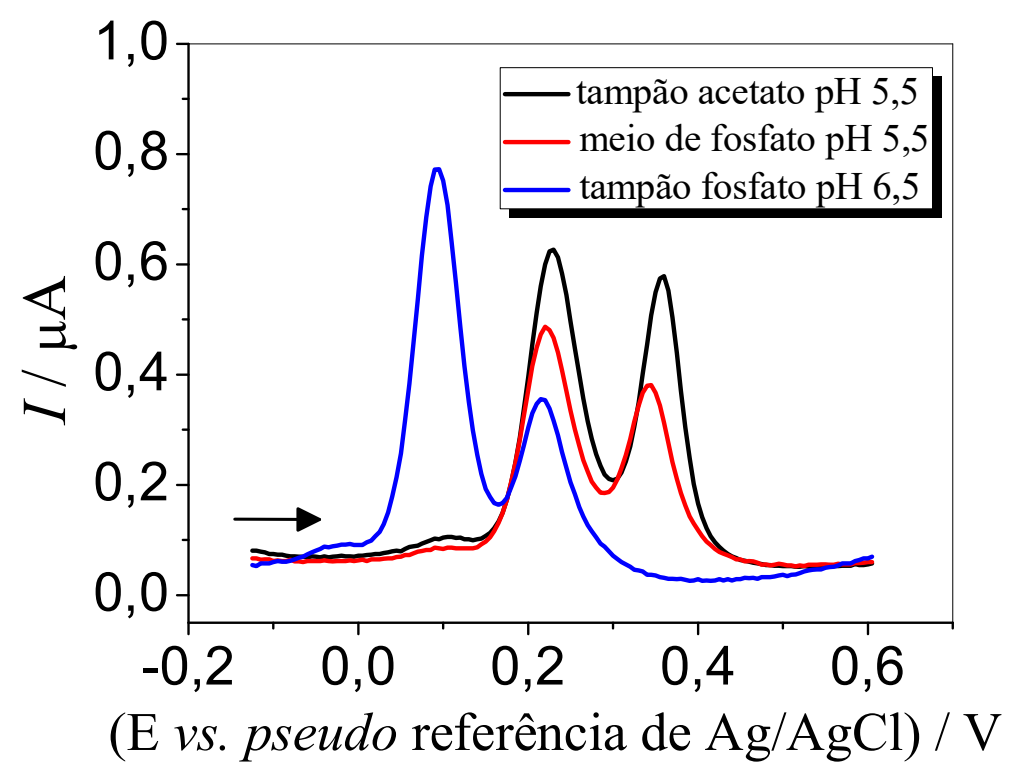

Figura 41. Voltamogramas de DPV obtidos na presença de DA $50 \mu \mathrm{mol} \mathrm{L}^{-1}$ e UA $60 \mu \mathrm{mol} \mathrm{L}{ }^{-1}$ em $0,10 \mathrm{~mol} \mathrm{~L}^{-1}$ de tampão fosfato $\mathrm{pH} 6,5$, meio de fosfato $\mathrm{pH}$ 5,5 e tampão acetato $\mathrm{pH} 5,5$ utilizando ND/SPE, com velocidade de $10 \mathrm{mV} \mathrm{s}^{-1}$ e amplitude $25 \mathrm{mV}$,

A partir dos resultados, os seguintes valores de $\Delta E$ foram obtidos $134 \mathrm{mV}, 126 \mathrm{mV}$ e $122 \mathrm{mV}$ em meio de fosfato $(\mathrm{pH} 5,5)$, de tampão fosfato $(\mathrm{pH} 6,5)$ e de tampão acetato $(\mathrm{pH}$ $5,5)$, respectivamente, o que novamente não foi uma diferença significativa. Ainda, escolheuse por não trabalhar em meio de fosfato $\mathrm{pH} 5,5$, uma vez que este, não está na região tamponante do tampão fosfato, e, portanto, não resistiria a variações de concentração de $\mathrm{H}^{+}$do meio. Dessa forma comparando-se os valores de corrente obtidos em tampão acetato $(\mathrm{pH} 5,5)$ em relação ao tampão fosfato ( $\mathrm{pH}$ 6,5), apesar de uma perda de $25 \%$ da corrente de DA em tampão acetato em relação ao fosfato, houve um ganho de corrente de $154 \%$ para UA, o que considerou se ser o eletrólito suporte mais adequado para a determinação concomintante dos analitos. 
Por fim, sob condições otimizadas, foi feita a determinação de diferentes concentrações de DA na presença de uma concentração fixa de UA em tampão acetato 0,10 mol L ${ }^{-1}$ (pH 5,5), utilizando o ND/SPE. Na Figura 42A são apresentados os voltamogramas de DPV obtidos para diferentes concentrações de DA na presença de UA $20,0 \mu \mathrm{mol} \mathrm{L} \mathrm{L}^{-1}$. Inserido na Figura 42A, está o gráfico $I_{\mathrm{a}}(\mu \mathrm{A}) v s$. Concentração de DA $\left(\mu \mathrm{mol} \mathrm{L}{ }^{-1}\right)$, no qual obteve-se uma linearidade na faixa de concentração entre 2,0 e $100,0 \mu \mathrm{mol} \mathrm{\textrm {L } ^ { - 1 }}$ para DA, representada pela Equação 9:

$$
I(\mathrm{~A})=4,1 \times 10^{-8}+0,020 \mathrm{C}_{\mathrm{DA}}\left(\mathrm{mol} \mathrm{L}^{-1}\right) \quad(\text { Equação } 9)
$$

Também se utilizou DPV para quantificar diferentes concentrações de UA na presença de DA 20,0 $\mu \mathrm{mol} \mathrm{L} \mathrm{L}^{-1}$ em tampão acetato $0,10 \mathrm{~mol} \mathrm{~L}^{-1}$ (pH 5,5), utilizando o ND/SPE e os voltamogramas obtidos são apresentados na Figura 42B. Inserida na Figura 42B está um gráfico $I_{\mathrm{a}}(\mu \mathrm{A})$ vs. Concentração de UA $\left(\mu \mathrm{mol} \mathrm{L}{ }^{-1}\right)$, na qual obteve-se uma linearidade na faixa de concentração entre 2,0 a $97,0 \mu \mathrm{mol} \mathrm{L}^{-1}$ para UA, representada pela Equação 10:

$$
I(\mathrm{~A})=8,23 \times 10^{-8}+0,030 \mathrm{C}_{\mathrm{UA}}\left(\mathrm{mol} \mathrm{L}^{-1}\right) \quad \text { (Equação 10) }
$$

A partir dessas faixas lineares obtidas para ambos os analitos, calculou-se os valores de LOD, sendo de $0,57 \mu \mathrm{mol} \mathrm{L}{ }^{-1}$ para DA e $0,89 \mu \mathrm{mol} \mathrm{L}^{-1}$ para UA.

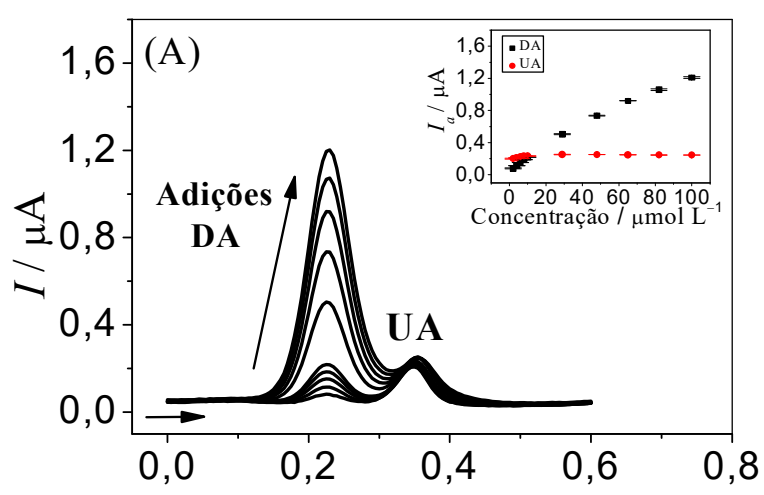

(E vs. pseudo referência de $\mathrm{Ag} / \mathrm{AgCl}$ ) / V

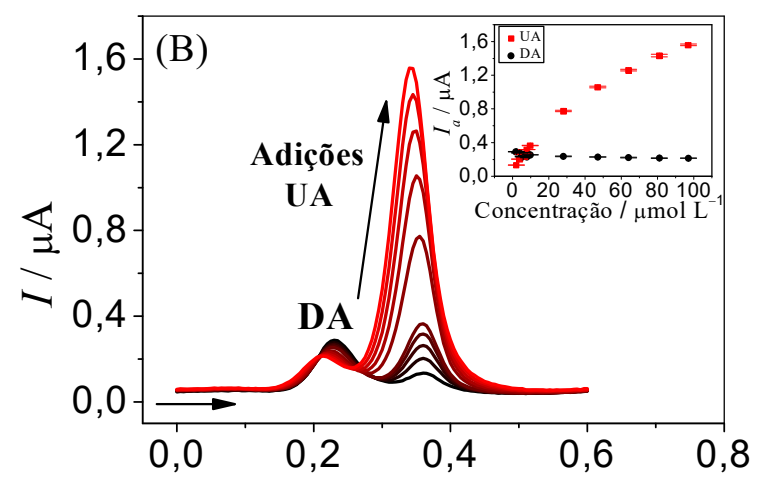

(E vs. pseudo referência de $\mathrm{Ag} / \mathrm{AgCl}$ ) / V

Figura 42. Voltamogramas de DPV obtidos utilizando ND/SPE para concentrações de: (A) DA de 2,0 a $100,0 \mu \mathrm{mol} \mathrm{L}^{-1}$ na presença de $20,0 \mu \mathrm{mol} \mathrm{L}^{-1}$ de UA e (B) UA de 2,0 a $97,0 \mu \mathrm{mol} \mathrm{L}^{-1}$ na presença de $20,0 \mu \mathrm{mol} \mathrm{L}{ }^{-1}$ de DA em solução de tampão acetato $0,10 \mathrm{~mol} \mathrm{~L}^{-1}$ (pH 5,5). Inserida as respectivas curvas analíticas, $\mathrm{n}=3$. Parâmetros de DPV: amplitude de $50 \mathrm{mV}$ e velocidade de varredura de potenciais de $10 \mathrm{mV} \mathrm{s}^{-1}$.

Para avaliar o desempenho e os resultados obtidos com o sensor proposto este foi comparado com outros eletrodos descritos na literatura para a determinação concomitante de DA e UA (ver Tabela 14). Os LOD obtidos foram similares aos de outros sensores descritos na literatura. Alguns trabalhos reportados na Tabela 14 são interessantes em sua abordagem, 
no entanto, utiliza como eletrodo suporte o GCE, o qual requer uma fase de limpeza e polimento, o que consome tempo na fabricação do sensor. Neste trabalho, no qual foi utilizado o SPE como suporte, não houve a necessidade dessa etapa, além do que, a modificação pode ser feita em batelada, o que minimiza o tempo de preparo bem como possibilita a condução de vários estudos em único dia. Em adição, tem-se a possibilidade do eletrodo ser descartável, reduzindo problemas de contaminação e apresenta custo de fabricação baixo.

Tabela 14. Comparação entre o trabalho presente e alguns sensores reportados na literatura para a determinação concomitante de DA e UA

\begin{tabular}{ccccc}
\hline \multirow{2}{*}{ Sensor } & \multicolumn{2}{c}{ Faixa linear $/ \boldsymbol{\mu}$ mol $\mathbf{L}^{-1}$} & \multicolumn{2}{c}{$\mathbf{L O D} / \boldsymbol{\mu m o l ~ \mathbf { L } ^ { - 1 }}$} \\
\cline { 2 - 5 } & $\mathbf{D A}$ & $\mathbf{U A}$ & $\mathbf{D A}$ & $\mathbf{U A}$ \\
\hline $\mathrm{In}_{3} \mathrm{C}-\mathrm{GCE}^{138}$ & $10-100$ & $10-100$ & 1,7 & 5,0 \\
$\mathrm{Au} / \mathrm{RGO} / \mathrm{GCE}^{139}$ & $6,8-41$ & $8,8-53$ & 1,4 & 1,8 \\
$\mathrm{NiO} / \mathrm{GR} / \mathrm{SPE}^{71}$ & $1,0-500$ & $125-250$ & 0,31 & - \\
$\mathrm{Pd}-\mathrm{NP} / \mathrm{CPE}^{140}$ & $0,10-151$ & $0,50-225$ & 0,030 & 0,15 \\
$\mathrm{PG} / \mathrm{GCE}^{141}$ & $5,0-710$ & $6,0-1330$ & 2,0 & 4,8 \\
$\mathrm{CILE}$ & $2,0-1500$ & $2,0-220$ & 1,0 & 1,0 \\
Este trabalho & $2,0-10$ & $2,0-10$ & 0,57 & 0,89 \\
\hline
\end{tabular}

$\mathrm{In}_{3} \mathrm{C}$-GC: Indole-3-carboxaldeído - eletrodo de carbono vítreo;

$\mathrm{Au} / \mathrm{RGO} / \mathrm{GCE}$ : nanopartículas de $\mathrm{Au} /$ óxido de grafeno reduzido / eletrodo de carbono vítreo;

$\mathrm{NiO} / \mathrm{GR} / \mathrm{SPE}$ : nanopartículas de $\mathrm{NiO} /$ nanopartículas de grafeno / eletrodo impresso;

Pd-NP/CPE: nanopartículas de paládio / eletrodo de pasta de carbono;

PG/GCE: grafeno cristalino / eletrodo de carbono vítreo;

CILE: eletrodo líquido de carbono iônico.

\subsubsection{Entendendo a melhora do desempenho eletroanalítico utilizando ND}

Os dados reportados acima, enquanto únicos no fato de ser o primeiro estudo a modificar SPE com ND, evidenciam a melhora de parâmetros analíticos (sensibilidade e LOD), frente à determinação de DA e UA comparados ao SPE sem modificação. De acordo com trabalhos reportados na literatura (Tabela 15) estes resultados já eram esperados devido ao efeito eletrocatalítico que esses materiais promovem. 
Tabela 15. Diferentes eletrodos modificados com ND para a determinação de diferentes analitos

\begin{tabular}{|c|c|c|c|c|}
\hline $\begin{array}{c}\text { Material } \\
\text { modificador }\end{array}$ & $\begin{array}{l}\text { Eletrodo } \\
\text { base }\end{array}$ & Analito & $\begin{array}{c}\mathrm{LOD} / \\
\mu \mathrm{mol} \mathrm{L}^{-1}\end{array}$ & Referência \\
\hline $\mathrm{PAA} / \mathrm{N}-\mathrm{NCD} / \mathrm{GOx}^{\mathrm{a}}$ & $\mathrm{AuE}$ & Glucose & 5,0 & Zhao et al. ${ }^{33} 2006$ \\
\hline $\mathrm{Chit} / \mathrm{UND} / \mathrm{Hb}^{\mathrm{b}}$ & GCE & $\mathrm{H}_{2} \mathrm{O}_{2}$ & 0,40 & Zhu et al..$^{35} 2007$ \\
\hline ND-NS(HRP) ${ }^{c}$ & GCE & $\mathrm{H}_{2} \mathrm{O}_{2}$ & 59 & Gopalan et al. ${ }^{143} 2013$ \\
\hline QAS-ND/Mb ${ }^{\mathrm{d}}$ & GCE & $\mathrm{H}_{2} \mathrm{O}_{2}$ & 3,5 & Xiao-Ling et al. ${ }^{144} 2014$ \\
\hline $\mathrm{LOx} / \mathrm{DNPs}^{\mathrm{e}}$ & $\mathrm{AuE}$ & Glicose & 15 & Briones et al. ${ }^{145} 2015$ \\
\hline Ni-NDs ${ }^{\mathrm{f}}$ & BDD & Glicose & 0,050 & Dai et al..$^{32} 2016$ \\
\hline ND-DHP ${ }^{g}$ & GCE & Codeína & 0,055 & Simoni et al. ${ }^{31} 2017$ \\
\hline ND & GCE & Pirazinamida & 0,22 & Simioni et al..$^{30} 2017$ \\
\hline Tyr-ND-PS ${ }^{h}$ & GCE & Catecol & 0,39 & Camargo et al. ${ }^{36} 2018$ \\
\hline ND & SPE & DA; UA & 0,$57 ; 0,89$ & Este trabalho \\
\hline
\end{tabular}

${ }^{a}$ PAA/N-NCD/GOx: poli (hidrocloreto de alilamina/ diamante não dopado nanocristalino/ glicose oxidase

${ }^{\mathrm{b}} \mathrm{Chit} / \mathrm{UND} / \mathrm{Hb}$ : quitosana/ diamante dopado nanocristalino/ hemoglobina

${ }^{\mathrm{c}} \mathrm{ND}-\mathrm{NS}$ (HRP): esponjas à base de nanodiamante com enzima peroxidase

${ }^{\mathrm{d}} \mathrm{QAS}-\mathrm{ND} / \mathrm{Mb}$ : sal de amônio quaternário - nanodiamante/ mioglobina

${ }^{\mathrm{e}} \mathrm{LOx} / \mathrm{DNPs}$ : oxidase de lactato/ nanopartículas de diamantes não dopado

${ }^{\mathrm{f}} \mathrm{Ni}-\mathrm{ND}$ : folhas de níquel - nanodiamantes

gND-DHP: diexadecil hidrogenofosfato

${ }^{\mathrm{h}}$ Tyr-ND-PS: tirosinase - nanodiamante - fecula de batata

AuE: eletrodo de ouro, BDD: diamante dopado com ouro, GCE: eletrodo de carbono vítreo

Todos estes estudos descrevem um aumento na magnitude do sinal analítico para diferentes analitos após a modificação de diferentes eletrodos base com os ND ou uma dispersão contendo os ND.

Nesse contexto, avaliou-se as respostas voltamétricas de algumas sondas amplamente utilizadas (par redox $\mathrm{Fe}(\mathrm{CN})_{6}{ }^{3-}, \mathrm{IrCl}_{6}{ }^{2-} \mathrm{e} \mathrm{Ru}\left(\mathrm{NH}_{3}\right)_{6}{ }^{2+}$ ) para entender melhor o comportamento eletroquímico do ND/SPE frente ao SPE. Para isso, experimentos de voltametria cíclica foram realizados estudando-se uma faixa de varredura de potenciais entre 5 e $500 \mathrm{mV} \mathrm{s}^{-1}$, em $\mathrm{KCl}$ 0,10 $\mathrm{mol} \mathrm{L}^{-1}$, utilizando o SPE não modificado e o modificado. Nas Figuras 43A e 43B estão registrados os voltamogramas obtidos na presença de $\mathrm{K}_{3}\left[\mathrm{Fe}(\mathrm{CN})_{6}\right] 1,0 \mathrm{mmol} \mathrm{L}{ }^{-1}$, utilizando o SPE e o ND/SPE, respectivamente. A partir desses dados, foi construído o gráfico de corrente de pico anódica $\left(I_{\mathrm{pa}}\right)$ e catódica $\left(I_{\mathrm{pc}}\right)$, em função da raiz quadrada da velocidade de varredura $\left(v^{1 / 2}\right)$ (Figura 43C), no qual observa-se que com o aumento da $v$, as $I_{\mathrm{pa}}$ e $I_{\mathrm{pc}}$ variaram 
linearmente com a $v^{1 / 2}$, tendo como coeficientes de correlação para o SPE 0,997 (para $I_{\mathrm{pa}}$ ) e 0,998 (para $I_{\mathrm{pc}}$ ) e para o ND/SPE 0,995 (para $I_{\mathrm{pa}}$ ) e 0,996 (para $I_{\mathrm{pc}}$ ). Além disso, o gráfico de $\log I_{\mathrm{pa}}$ vs. $\log v$ (Figura 43D), para ambos os eletrodos foram lineares com coeficientes angulares $(\alpha)$ de 0,54 (SPE) e 0,55 (ND/SPE), o que está próximo do valor teórico 0,5 para processos controlados apenas por difusão.

Nas Figuras 44A e 44B estão registrados os voltamogramas obtidos na presença de $\mathrm{K}_{2}\left[\mathrm{IrCl}_{6}\right] 1,0 \mathrm{mmol} \mathrm{L}^{-1}$, utilizando o SPE e o ND/SPE, respectivamente. Na Figura 44C encontra-se o gráfico $I_{\mathrm{p}} v s . v^{1 / 2}$ no qual se constatou que com o aumento da $v$, as $I_{\mathrm{pa}}$ e $I_{\mathrm{pc}}$ variaram linearmente com a $v^{1 / 2}$, tendo como coeficientes de correlação para o SPE 0,998 (para $I_{\mathrm{pa}}$ ) e 0,998 (para $I_{\mathrm{pc}}$ ) e para o ND/SPE 0,998 (para $I_{\mathrm{pa}}$ ) e 0,997 (para $I_{\mathrm{pc}}$ ). Na Figura 44D é apresentado o gráfico de $\log I_{\mathrm{pa}} v s . \log v$, no qual foi obtido linearidades para ambos os eletrodos com $\alpha$ de 0,44 (SPE) e 0,57 (ND/SPE), também próximo do valor teórico de 0,5 para processos controlados apenas por difusão.

Nas Figuras 45A e 45B estão registrados os voltamogramas obtidos na presença de $\left[\mathrm{Ru}\left(\mathrm{NH}_{3}\right)_{6}\right] \mathrm{Cl}_{3}$ 1,0 $\mathrm{mmol} \mathrm{L}^{-1}$, utilizando o SPE e o ND/SPE, respectivamente. No gráfico de $I_{\mathrm{p}} v s . v^{1 / 2}$ (Figura 45C) observa-se $I_{\mathrm{pa}}$ e $I_{\mathrm{pc}}$ variando linearmente com a $v^{1 / 2}$, e tem como coeficientes de correlação 0,997 (para $I_{\mathrm{pa}}$ ) e 0,998 (para $I_{\mathrm{pc}}$ ) utilizando o SPE e 0,998 (para $I_{\mathrm{pa}}$ ) e 0,997 (para $I_{\mathrm{pc}}$ ) utilizando o ND/SPE. No gráfico $\log I_{\mathrm{pa}} v s . \log v$ (Figura 45D), foram obtidas linearidades para ambos os eletrodos com $\alpha$ de 0,56 (SPE) e 0,64 (ND/SPE), próximo do valor teórico de 0,5 para processos controlados apenas por difusão. 

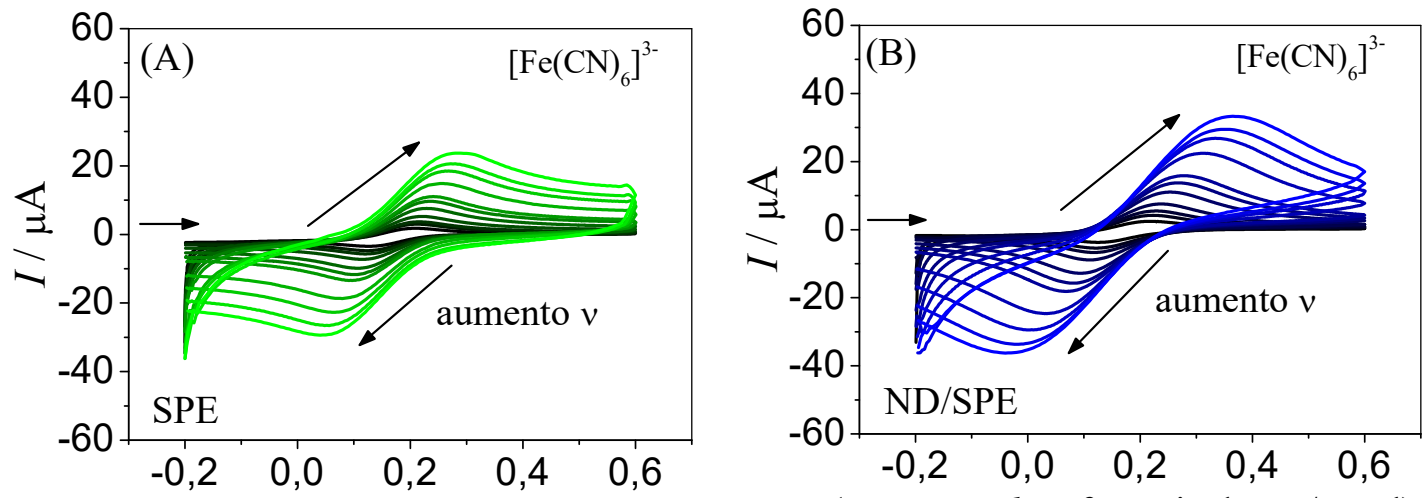

(E vs. pseudo referência de $\mathrm{Ag} / \mathrm{AgCl}$ / V

(E vs. pseudo referência de $\mathrm{Ag} / \mathrm{AgCl}$ ) / V
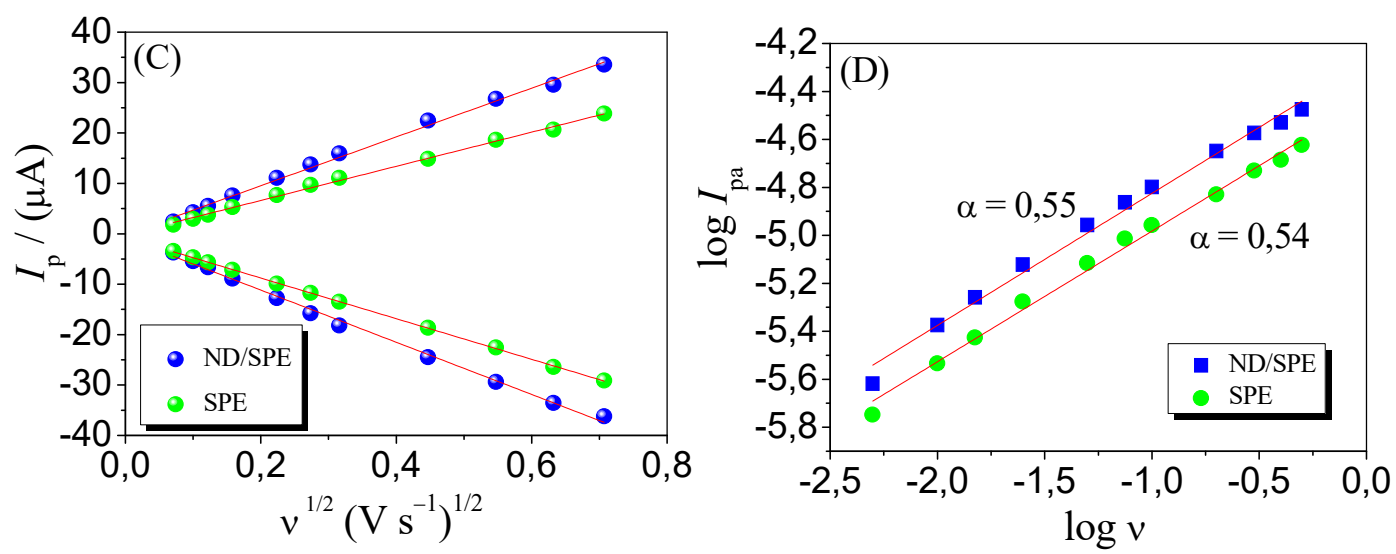

Figura 43. Voltamogramas cíclicos obtidos em diferentes velocidades de varredura potencial $(5$ e 500 $\mathrm{mV} \mathrm{s}^{-1}$ ) utilizando SPE (A) e ND/SPE (B) na presença de $\mathrm{K}_{3}\left[\mathrm{Fe}(\mathrm{CN})_{6}\right] 1,0 \mathrm{mmol} \mathrm{L}{ }^{-1} \mathrm{em}$ solução de $\mathrm{KCl} 0,10 \mathrm{~mol} \mathrm{~L}^{-1}$. (C) Gráfico de $I_{\mathrm{p}} v s$. $v^{1 / 2}$. (D) Gráfico de $\log I_{\mathrm{pa}} v s$. $\log v$. 


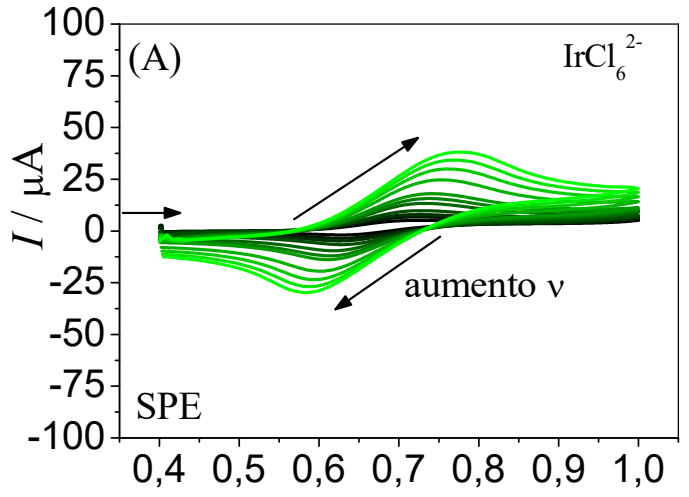

(E vs. pseudo referência de $\mathrm{Ag} / \mathrm{AgCl}) / \mathrm{V}$

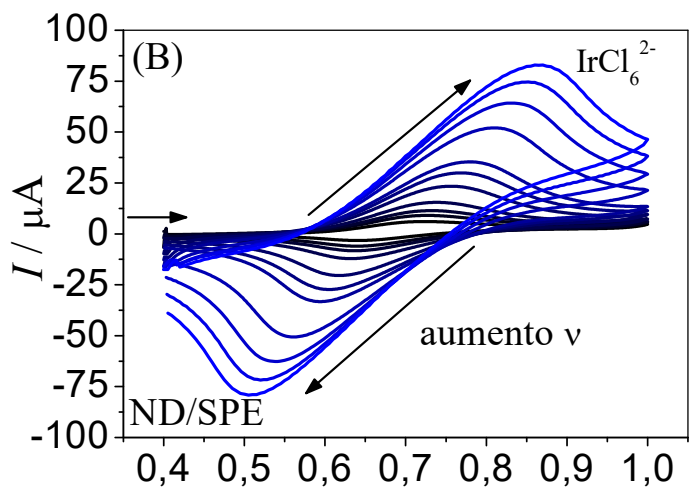

(E vs. pseudo referência de $\mathrm{Ag} / \mathrm{AgCl}) / \mathrm{V}$

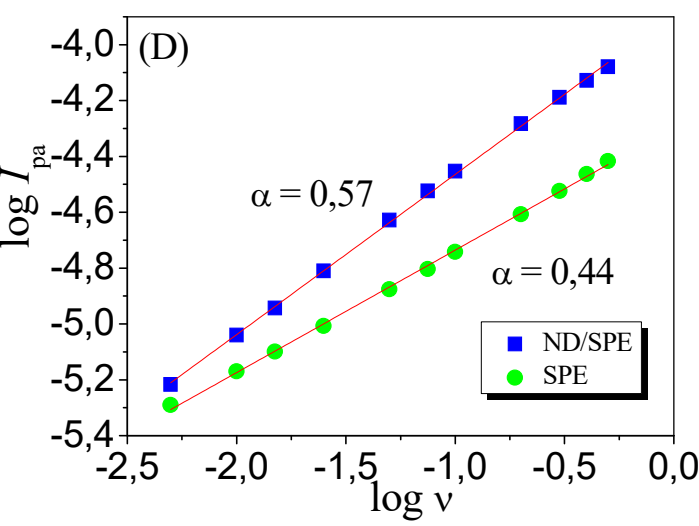

Figura 44. Voltamogramas cíclicos obtidos em diferentes velocidades de varredura potencial (5 e 500 $\mathrm{mV} \mathrm{s}^{-1}$ ) utilizando SPE (A) e ND/SPE (B) na presença de $\mathrm{K}_{2}\left[\mathrm{IrCl}_{6}\right] 1,0 \mathrm{mmol} \mathrm{L}{ }^{-1} \mathrm{em}$ solução de $\mathrm{KCl} 0,10 \mathrm{~mol} \mathrm{~L}^{-1}$. (C) Gráfico de $I_{\mathrm{p}} v s . v^{1 / 2}$. (D) Gráfico de $\log I_{\mathrm{pa}} v s . \log v$. 


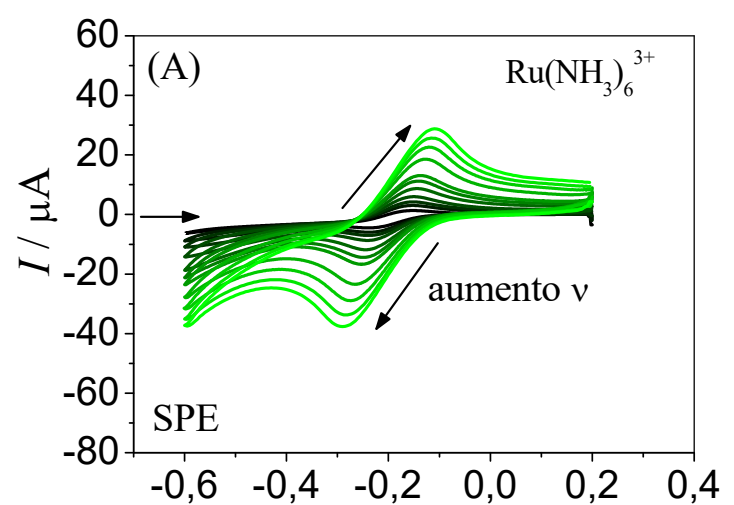

(E vs. pseudo referência de $\mathrm{Ag} / \mathrm{AgCl}$ ) / V

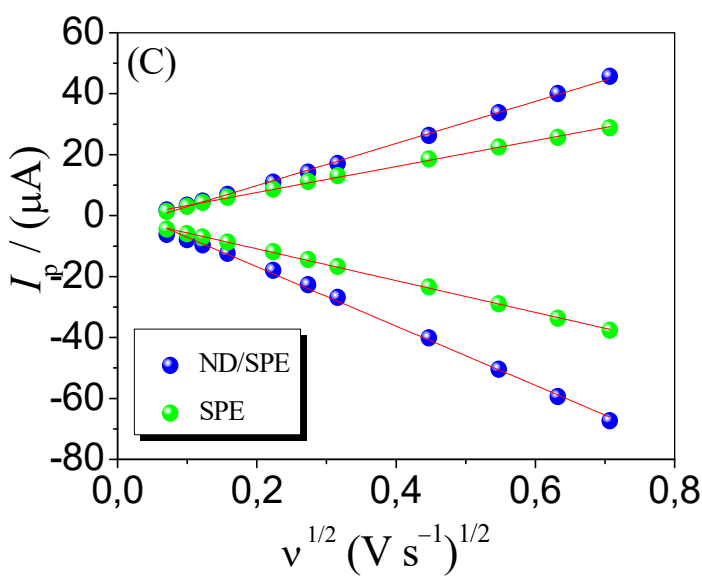

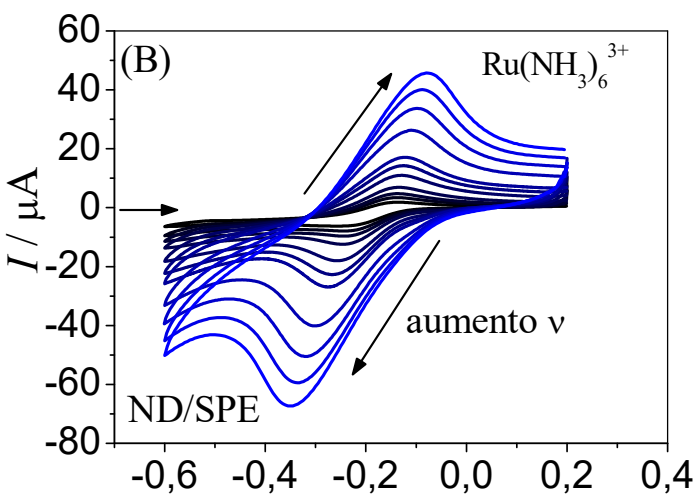

(E vs. pseudo referência de $\mathrm{Ag} / \mathrm{AgCl}) / \mathrm{V}$

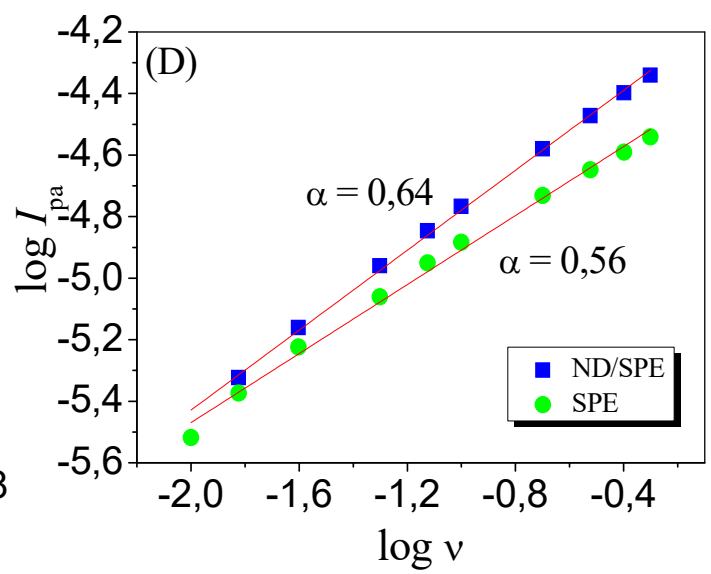

Figura 45. Voltamogramas cíclicos obtidos em diferentes velocidades de varredura potencial (5 e 500 $\mathrm{mV} \mathrm{s}^{-1}$ ) utilizando SPE (A) e ND/SPE (B) na presença de $\left[\mathrm{Ru}\left(\mathrm{NH}_{3}\right)_{6}\right] \mathrm{Cl}_{3} 1,0 \mathrm{mmol} \mathrm{L}^{-1} \mathrm{em}$ solução de $\mathrm{KCl} 0,10 \mathrm{~mol} \mathrm{~L}^{-1}$. (C) Gráfico de $I_{\mathrm{p}} v s . v^{1 / 2}$. (D) Gráfico de $\log I_{\mathrm{pa}} v s$. $\log v$.

É importante ressaltar que as espécies eletroativas estudadas acimas são classificadas como sondas redox de transferência de elétrons de esfera externa, isto é, são sensíveis principalmente a estrutura eletrônica da camada adjacente ao eletrodo. Em outras palavras a espécie carregada da sonda se aproxima da superfície do eletrodo e uma transferência de elétrons na interface heterogênea eletrodo/solução ocorre.

A partir dos resultados acima se observa que, apesar de um incremento de corrente para todas as sondas, após a modificação do SPE com ND, não houve uma facilitação da transferência de elétrons, uma vez que para as diferentes $v$ houve um aumento de $\Delta E$ (potencial anódico - potencial catódico), como apresentado na Tabela 16. Já no caso da DA e UA, além de um incremento de corrente, houve uma diminuição do potencial de oxidação quando se comparou os voltamogramas obtidos utilizando o ND/SPE comparado ao SPE, o que pode indicar uma facilidade da transferência de elétrons devido à presença dos ND.

Isso esta de acordo com o que se encontra na literatura referente a essas moléculas, consideradas como sondas de esfera interna, isto é, são sensíveis a espécies químicas na 
superfície do eletrodo (eg. grupos funcionais ou impurezas). Isto estaria de acordo com o que Holt e et $a l .{ }^{28}$ e Varley et al. ${ }^{29}$ propuseram a respeito dos ND apresentaram grupos funcionais em sua superfície e que isto poderia acarretar no efeito catalítico observado. Porém continua a dúvida a respeito do que explicaria o aumento de corrente para as moléculas que tenham um comportamento similar das esferas externas. Muitas vezes a facilidade de transferência de elétrons pode estar relacionada com um aumento de área ativa, quando se utiliza um modificador sob a superfície do eletrodo base. Entretanto, é importante relembrar, que pelos dados de perfilometria de luz branca a rugosidade do SPE é alta frente a outros eletrodos, e uma grande concentração de ND (partículas com diâmetro menor que $10 \mathrm{~nm}$, segundo os resultados de TEM) seria necessária, para recobrir a superfície do eletrodo, a ponto de aumentar a área eletroativa do mesmo. Nesse contexto, foi proposta uma visão diferente daquela apresentada na literatura sobre o que poderia estar acontecendo na superfície do eletrodo modificado com os ND, que levaria a esse aumento de corrente para diferentes analitos. 
Tabela 16. Valores de $\Delta E$ para $\mathrm{K}_{3}\left[\mathrm{Fe}(\mathrm{CN})_{6}\right], \mathrm{K}_{2}\left[\mathrm{IrCl}_{6}\right]$ e $\left[\mathrm{Ru}\left(\mathrm{NH}_{3}\right)_{6}\right] \mathrm{Cl}_{3}$ utilizando o SPE e o ND/SPE para diferentes valores de velocidade de varredura de potenciais

\begin{tabular}{|c|c|c|c|c|c|c|}
\hline \multirow{3}{*}{$\begin{array}{l}\text { Velocidade } \\
\left(\mathrm{mV} \mathrm{s}^{-1}\right)\end{array}$} & \multicolumn{6}{|c|}{$\Delta E_{\mathrm{p}}(\mathrm{mV})$} \\
\hline & \multicolumn{2}{|c|}{$\mathrm{Fe}(\mathrm{CN})_{6}{ }^{3-}$} & \multicolumn{2}{|c|}{$\mathrm{IrCl}_{6}^{2-}$} & \multicolumn{2}{|c|}{$\mathrm{Ru}\left(\mathrm{NH}_{3}\right)_{6}{ }^{3+}$} \\
\hline & SPE & ND/SPE & SPE & ND/SPE & SPE & ND/SPE \\
\hline 5 & 75 & 86 & 85 & 86 & 83 & 99 \\
\hline 10 & 78 & 100 & 88 & 90 & 84 & 99 \\
\hline 15 & 81 & 109 & 95 & 98 & 85 & 101 \\
\hline 25 & 104 & 124 & 96 & 105 & 87 & 109 \\
\hline 50 & 119 & 161 & 114 & 136 & 96 & 124 \\
\hline 75 & 131 & 185 & 123 & 162 & 108 & 138 \\
\hline 100 & 140 & 210 & 129 & 184 & 116 & 152 \\
\hline 200 & 176 & 278 & 153 & 249 & 138 & 190 \\
\hline 300 & 198 & 322 & 167 & 296 & 156 & 219 \\
\hline 400 & 218 & 357 & 183 & 331 & 168 & 244 \\
\hline 500 & 229 & 394 & 193 & 361 & 180 & 270 \\
\hline
\end{tabular}

Assim, para investigar mais a atividade eletrocatalítica e condutividade do ND, CPE foram fabricados usando quantidades variáveis de ND. Na Figura 46 são apresentados os voltamogramas cíclicos obtidos em $\mathrm{KCl} 0,10 \mathrm{~mol} \mathrm{~L}{ }^{-1}$, na presença de $\left[\mathrm{Ru}\left(\mathrm{NH}_{3}\right)_{6}\right] \mathrm{Cl}_{3} 1,0$ mmol L ${ }^{-1}$ em um intervalo de varredura de potenciais entre $-0,6$ e $0,2 \mathrm{~V}$ (vs. pseudo referência de $\mathrm{Ag} / \mathrm{AgCl})$, na $v=50 \mathrm{mV} \mathrm{s}^{-1}$, utilizando três diferentes CPE: 60:40 (\% $\left.\mathrm{m} \mathrm{m}^{-1}\right)$ negro de fumo: Nujol; 60:40 (\% $\left.\mathrm{m} \mathrm{m}^{-1}\right)$ ND:Nujol e 55:5:40 $\left(\% \mathrm{~m} \mathrm{~m}^{-1}\right)$ negro de fumo:ND:Nujol. 


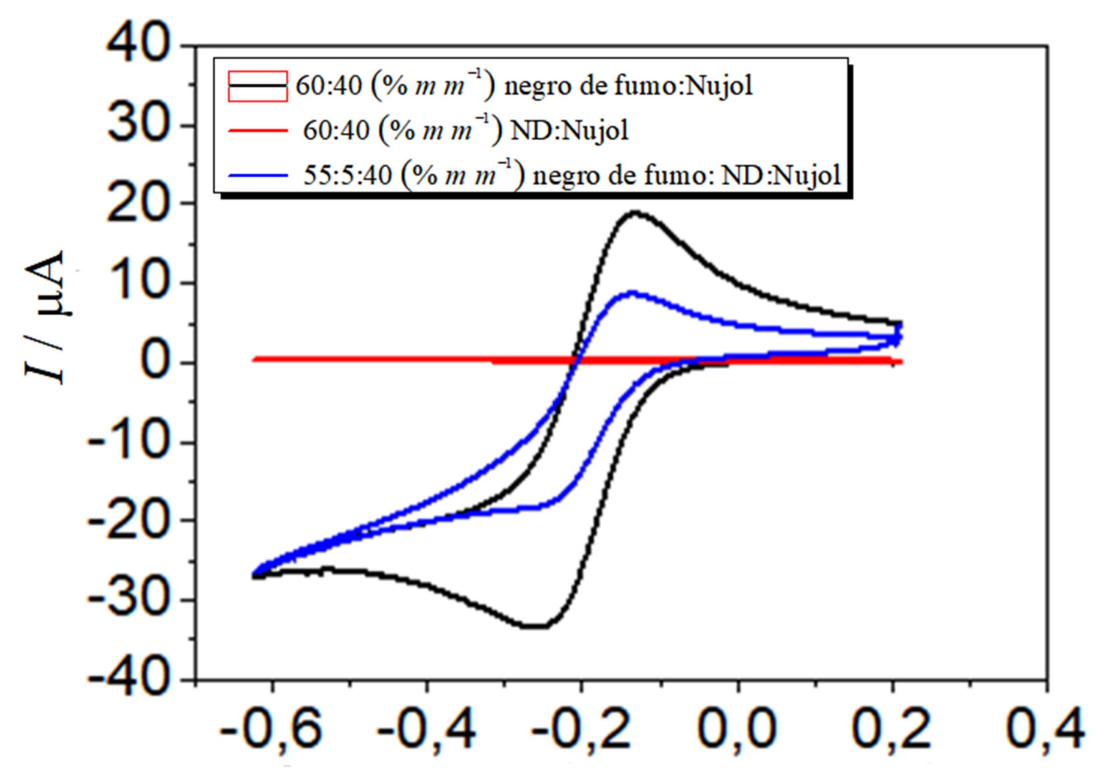

(E vs. pseudo referência de $\mathrm{Ag} / \mathrm{AgCl}$ ) / V

Figura 46. Voltamogramas cíclicos obtidos utilizando eletrodos de pasta de carbono nas seguintes proporções: negro de fumo:Nujol 60:40 $\left(\% \mathrm{~m} \mathrm{~m}^{-1}\right)$, ND:Nujol 60:40 $\left(\% \mathrm{~m} \mathrm{~m}^{-1}\right)$ e negro de

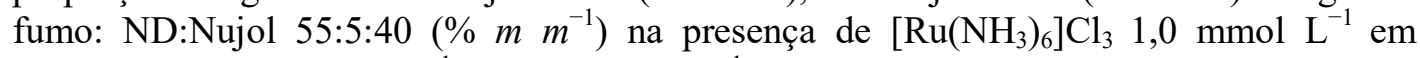
solução de $\mathrm{KCl} 0,10 \mathrm{~mol} \mathrm{~L}^{-1}$, em $v=50 \mathrm{mV} \mathrm{s}^{-1}$.

Com diferentes respostas voltamétricas na Figura 46, foi possível observar que a incorporação de uma quantidade crescente de ND no CPE resulta em uma diminuição na atividade eletroquímica/transferência de elétrons e, em última instância, resulta em perda completa da transferência de elétrons (CPE composto apenas de ND e Nujol). Estes resultados indicaram que talvez, os ND não fossem condutores e por isso um erro correlacionar o aumento de corrente para diferentes analitos devido à presença de alguns carbonos $\mathrm{sp}^{2}$ de sua superfície como reportados por alguns autores.

Também se explorou adicionar diferentes concentrações de ND sob a superfície do SPE, e avaliando o desempenho eletroquímico dos sensores frente às sondas eletroquímicas: $\mathrm{Fe}(\mathrm{CN})_{6}{ }^{3-}, \mathrm{IrCl}_{6}{ }^{2-}$ e $\mathrm{Ru}\left(\mathrm{NH}_{3}\right)_{6}{ }^{3+}$. Assim, foram preparadas diferentes dispersões de pó de ND em água: $0,1 \mathrm{mg} \mathrm{mL}^{-1}, 0,5 \mathrm{mg} \mathrm{mL}^{-1}, 0,8 \mathrm{mg} \mathrm{mL}^{-1}, 1,0 \mathrm{mg} \mathrm{mL}^{-1}, 1,5 \mathrm{mg} \mathrm{mL}^{-1}$ e $2,0 \mathrm{mg} \mathrm{mL}^{-1}$ e a partir dessas, $8 \mu \mathrm{L}$ foram gotejados sob a superfície do SPE. Na Figura 47 (A-C) estão registrados os voltamogramas obtidos em $\mathrm{KCl} 0,10 \mathrm{~mol} \mathrm{~L}^{-1}$ na presença de $\mathrm{K}_{3}\left[\mathrm{Fe}(\mathrm{CN})_{6}\right]$, $\mathrm{K}_{2}\left[\mathrm{IrCl}_{6}\right]$ e $\left[\mathrm{Ru}\left(\mathrm{NH}_{3}\right)_{6}\right] \mathrm{Cl}_{3} 1,0 \mathrm{mmol} \mathrm{L}{ }^{-1}$, respectivamente, em $v=50 \mathrm{mV} \mathrm{s}^{-1}$, utilizando o SPE modificado com diferentes concentrações de ND. Na Tabela 17 foram reportados os valores de $\Delta E, I_{\mathrm{pa}}$ e $I_{\mathrm{pc}}$ obtidos para as diferentes sondas eletroquímicas a partir dos voltamogramas obtidos. 


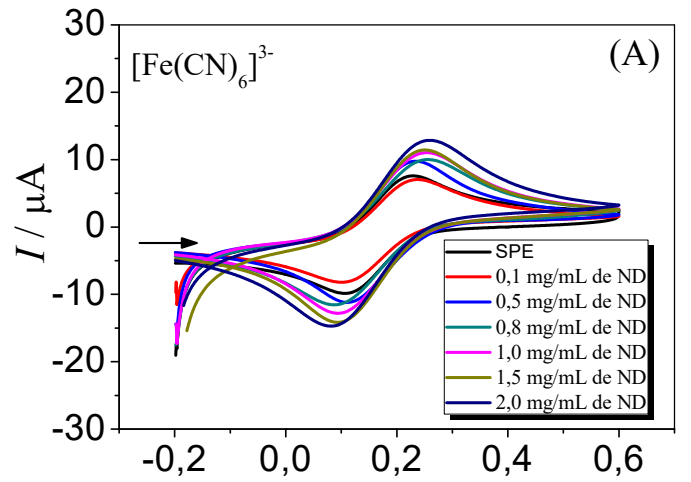

(E vs. pseudo referência de $\mathrm{Ag} / \mathrm{AgCl}$ / / V

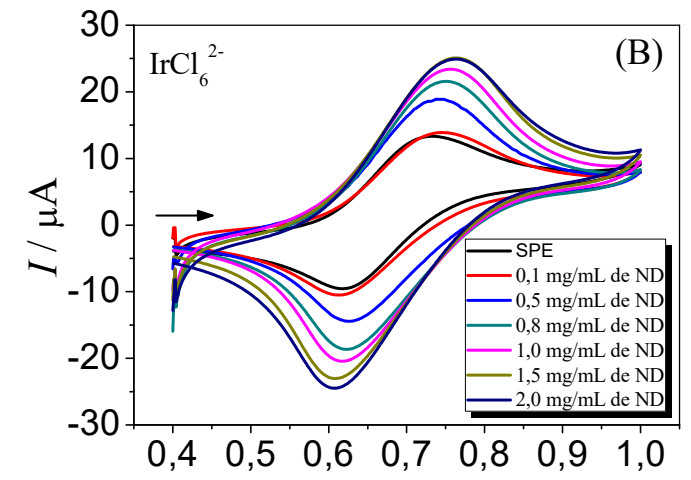

(E vs. pseudo referência de $\mathrm{Ag} / \mathrm{AgCl}$ / $/ \mathrm{V}$

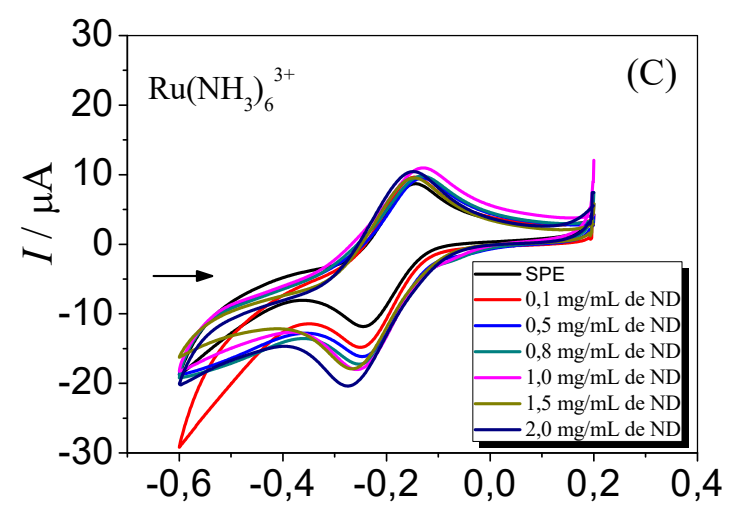

(E vs. pseudo referência de $\mathrm{Ag} / \mathrm{AgCl}$ / / V

Figura 47. Voltamogramas cíclicos obtidos na presença de $\mathrm{Fe}(\mathrm{CN})_{6}{ }^{3-}(\mathrm{A}), \mathrm{IrCl}_{6}{ }^{2-}(\mathrm{B})$ e $\mathrm{Ru}\left(\mathrm{NH}_{3}\right)_{6}{ }^{3+} 1,0$ mmol L ${ }^{-1}$ em solução de $\mathrm{KCl} 0,10 \mathrm{~mol} \mathrm{~L}^{-1}$ para as diferentes dispersões de $\mathrm{ND}$ em água: 0,$1 ; 0,5 ; 0,8 ; 1,0 ; 1,5$ e $2,0 \mathrm{mg} \mathrm{mL}^{-1}$, das quais $8 \mu \mathrm{L}$ foram gotejados sob a superfície do SPE, em $v=50 \mathrm{mV} \mathrm{s}^{-1}$.

Tabela 17. Valores de $\Delta E, I_{p a}$ e $I_{p c}$ para $\mathrm{K}_{3}\left[\mathrm{Fe}(\mathrm{CN})_{6}\right], \mathrm{K}_{2}\left[\mathrm{IrCl}_{6}\right]$ e $\left[\mathrm{Ru}\left(\mathrm{NH}_{3}\right)_{6}\right] \mathrm{Cl}_{3}$ utilizando SPE modificado com diferentes dispersões de ND em água

\begin{tabular}{cccccccccc}
\hline $\begin{array}{c}\text { Dispersão de } \\
\text { NDs em água } \\
\left(\mathrm{mg} \mathrm{mL} \mathrm{mL}^{-1}\right)\end{array}$ & \multicolumn{3}{c}{$\mathrm{Fe}(\mathrm{CN})_{6}{ }^{3-}$} & \multicolumn{3}{c}{$\mathrm{IrCl}_{6}{ }^{2-}$} & \multicolumn{3}{c}{$\mathrm{Ru}_{\mathrm{p}}$} \\
\cline { 2 - 9 }$(\mathrm{mV})$ & $\begin{array}{c}\left.I_{\mathrm{pa}}\right)_{6}{ }^{3+} \\
(\mu \mathrm{A})\end{array}$ & $\begin{array}{c}I_{\mathrm{pc}} \\
(\mu \mathrm{A})\end{array}$ & $\begin{array}{c}\Delta E_{\mathrm{p}} \\
(\mathrm{mV})\end{array}$ & $\begin{array}{c}I_{\mathrm{pa}} \\
(\mu \mathrm{A})\end{array}$ & $\begin{array}{c}I_{\mathrm{pc}} \\
(\mu \mathrm{A})\end{array}$ & $\begin{array}{c}\Delta E_{\mathrm{p}} \\
(\mathrm{mV})\end{array}$ & $\begin{array}{c}I_{\mathrm{pa}} \\
(\mu \mathrm{A})\end{array}$ & $\begin{array}{c}I_{\mathrm{pc}} \\
(\mu \mathrm{A})\end{array}$ \\
\hline 0 & 114 & 7,25 & $-6,48$ & 113 & 9,85 & $-9,85$ & 101 & 9,71 & $-7,41$ \\
0,10 & 117 & 8,21 & $-7,21$ & 115 & 10,1 & $-10,7$ & 102 & 11,8 & $-7,85$ \\
0,50 & 124 & 10,4 & $-9,31$ & 117 & 15,6 & $-14,4$ & 109 & 11,6 & $-8,67$ \\
0,80 & 158 & 10,4 & $-9,36$ & 127 & 19,0 & $-17,7$ & 112 & 12,1 & $-8,70$ \\
1,0 & 161 & 11,0 & $-10,6$ & 136 & 19,5 & $-20,3$ & 124 & 12,4 & $-10,2$ \\
1,5 & 173 & 12,0 & $-11,0$ & 155 & 20,8 & $-21,8$ & 126 & 12,5 & $-11,2$ \\
2,0 & 178 & 12,2 & $-12,3$ & 155 & 20,8 & $-22,8$ & 126 & 13,6 & $-11,7$ \\
\hline
\end{tabular}


A partir dos resultados acima se observa que, com o aumento da concentração dos ND sobre o SPE, há um incremento de corrente para todas as sondas eletroquímicas, porém não há facilitação da transferência de elétrons, uma vez que não se observa uma diminuição de $\Delta E$, mas sim um aumento de $\Delta E$ como apresentado na Tabela 17. Assim, o que poderia explicar esse aumento de corrente, essa condutividade dos ND, uma vez que esses materiais são praticamente inertes ${ }^{28}$ (constituído aproximadamente de $95 \%$ de carbonos $\mathrm{sp}^{3}$ )?

Diante do exposto, em resumo, esse aumento de corrente observado para os diferentes analitos aqui e na literatura (ver Tabela 15), não seria somente devido à eletrocatálise promovida pela presença de carbono $\mathrm{sp}^{2}$ e grupos funcionais na superfície dos ND (fatos confirmados por análises de Raman e infravermelho por transformada de Fourier ${ }^{28}$ ), mas, também, devido ao arranjo de microeletrodos que se forma na superfície do eletrodo base, que como consequência direta afeta no transporte de massa das espécies eletroativas.

A presença das partículas desse material promoveria um arranjo aleatório de sítios bloqueadores sobre toda a superfície do SPE, mas também haveria zonas limitadas ativas expostas do SPE, as quais estariam distribuídas aleatoriamente sobre a superfície do eletrodo, e se comportariam com características de microeletrodos ${ }^{146}$. Nesses sítios ativos se formariam microcamadas difusionais com tendência radial, as quais, conforme se aumenta a quantidade de ND sob o SPE, poderiam se sobrepor, levando como consequência a um incremento de corrente para diferentes analitos. Isso corrobora os resultados encontrados nas Figuras 43 a 45 , nos quais se observa que com o aumento da velocidade, a transferência de elétrons é dificultada (aumento de $\Delta E$ ), uma vez que não há tempo suficiente para as espécies ativas oxidarem e reduzirem com facilidade nesses pequenos sítios ativos.

Para maior clareza deste fenômeno, na Figura 48A-C é apresentado um esquema do que estaria acontecendo. No caso da Figura 48A, tem-se um SPE não modificado, no qual é possível observar que a resposta analítica obtida para sonda $\mathrm{Ru}\left(\mathrm{NH}_{3}\right)_{6}{ }^{3+}$, é devido a uma camada de difusão tendendo a ser planar. Na Figura 48B é observado um SPE modificado com partículas de ND, caracterizadas pelas circunferências cinza distribuídas aleatoriamente pela superfície do SPE. Pode-se observar que a resposta voltamétrica muda à medida que a quantidade de ND é aumentada. Assim, é possível imaginar três situações: (I) baixa concentração de ND gotejados sobre a superfície, como consequência tem-se camadas de difusão tendendo a serem esféricas amplamente espaçadas formadas sobre a zonas ativas expostas da superfície do SPE (sítios ativos de cor amarela); (II) aumento na concentração de ND gotejados sobre a superfície em relação ao caso I, de maneira que se tem a formação de 
camadas de difusão individuais com algumas sobrepostas, e consequentemente, observa-se aumento de corrente nos voltamogramas obtidos para a sonda $\mathrm{Ru}\left(\mathrm{NH}_{3}\right)_{6}{ }^{3+}$; (III) aumento na concentração de ND sobre a superfície até um ponto em que a sobreposição das camadas difusionais individuais resultam em uma difusão planar. Por fim, na Figura 48C se pode observar que à quantidade de ND é aumentada até um ponto em que a superfície do eletrodo é totalmente coberta/bloqueada e a transferência de elétrons não é possível, resultando na ausência de sinal voltamétrico.

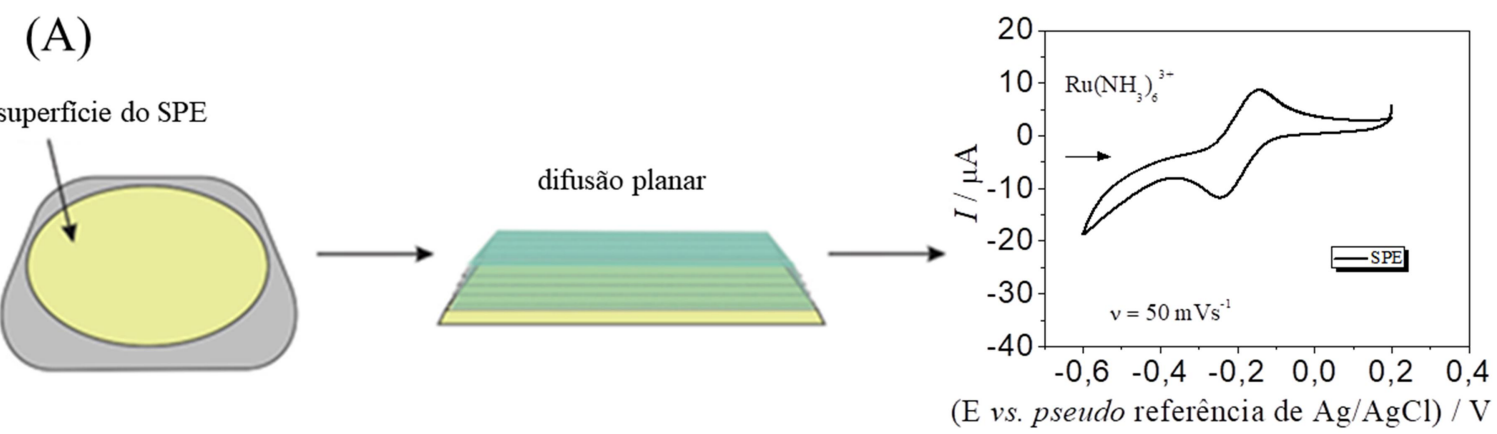

(B)

camadas de difusão individuais amplamente espaçadas

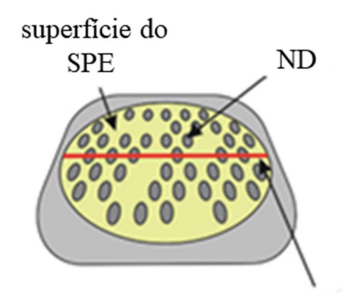

corte transversal da superficie do $\mathrm{ND} / \mathrm{SPE}$ onde os perfis de difusão A, B e C podem ser encontrados

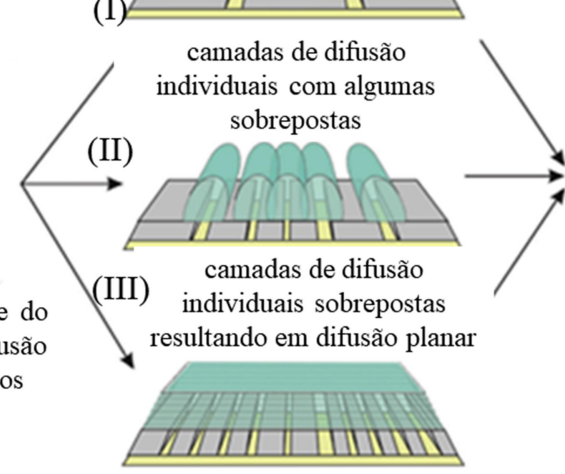

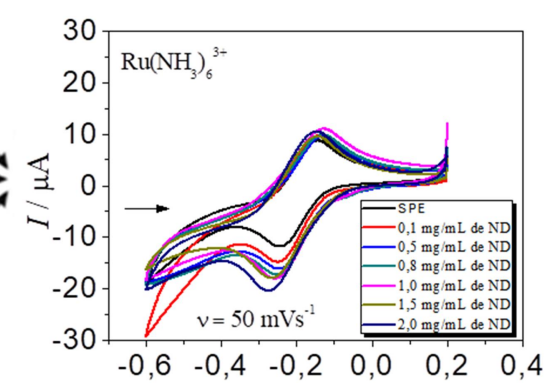

(E vs. pseudo referência de $\mathrm{Ag} / \mathrm{AgCl}$ ) / V

(C)

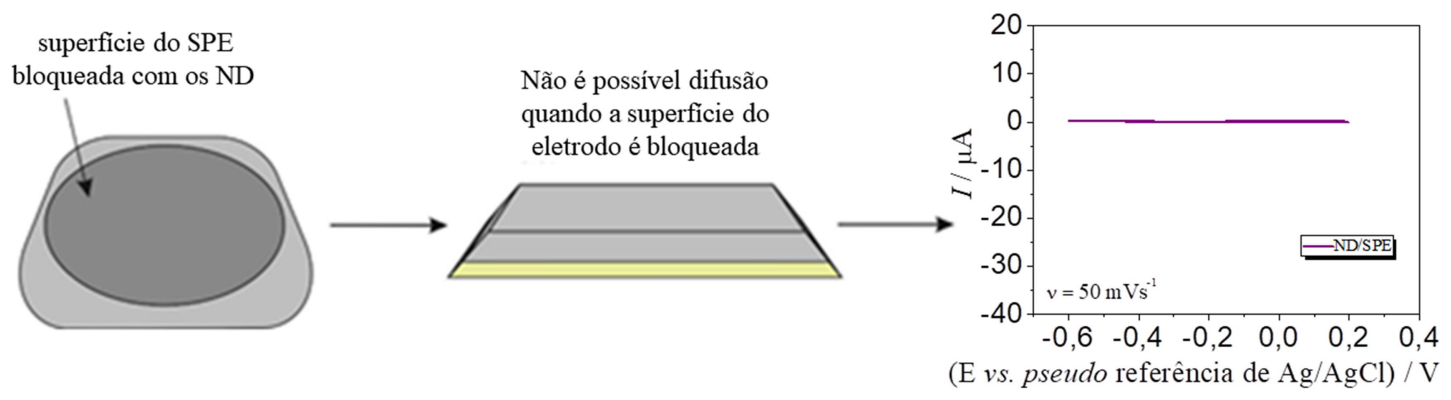

Figura 48. Voltamogramas cíclicos obtidos em $\mathrm{KCl} 0,10 \mathrm{~mol} \mathrm{~L} \mathrm{~L}^{-1}$ contendo 1 mmol L $\mathrm{L}^{-1}$ de $\left[\mathrm{Ru}\left(\mathrm{NH}_{3}\right)_{6}\right]^{3+}$ com SPE não modificado (A), com SPE modificado com $8 \mu \mathrm{L}$ da dispersão ND-água com diferentes concentrações $\left(0,1\right.$ a 2,0 $\left.\mathrm{mg} \mathrm{mL}^{-1}\right)$ (B) e SPE modificado com 8 $\mu \mathrm{L}$ da dispersão ND-água $10 \mathrm{mg} \mathrm{mL}^{-1}(\mathrm{C}), v=50 \mathrm{mV} \mathrm{s}^{-1}$. Uma visão representativa da camada difusional para cada caso do SPE não modificado, parcialmente modificado com ND, e completamente coberto com ND na superfície é apresentada. Fonte: Adaptado de Baccarin et al., $2019^{68}$. 
A ideia apresentada é baseada na teoria proposta por Compton e Banks ${ }^{146}$, na qual os autores discutiram a voltametria em superfícies heterogêneas. Os autores mostraram o efeito na resposta voltamétrica de um macroeletrodo coberto com partículas inertes de um material diferente da superfície do eletrodo base. As partículas distribuídas aleatoriamente sob o eletrodo funcionam como zonas bloqueadoras, enquanto as zonas expostas do eletrodo base seriam sítios eletroativos. Devido ao pequeno tamanho dessas regiões ativas, elas comportamse com características de microeletrodos e, consequentemente, microcamadas difusionais radiais seriam formadas nesses sítios. Como consequência, dependendo da quantidade de partículas bloqueadoras, essas zonas ativas estariam mais próximas e suas camadas difusionais individuais poderiam se sobrepor, o que teria efeito nas respostas voltamétricas. 


\subsection{CONCLUSÕES PARCIAIS}

Neste trabalho foi explorado o uso de SPE modificado com ND, pela primeira vez, como base de uma plataforma para determinação concomitante eletroquímica de DA e UA. Com a voltametria cíclica, foi observado um aumento de corrente de pico e menores potenciais de oxidação para DA e UA, usando o eletrodo proposto (ND/SPE), em relação ao SPE, além de um pico de separação de $134 \mathrm{mV}$ (vs. pseudo referência de $\mathrm{Ag} / \mathrm{AgCl}$ ) entre as moléculas, permitindo a determinação concomitante. Em adição, ao contrário do que é reportado na literatura, apresentou-se uma ideia diferente dos motivos dos efeitos eletrocatalíticos dos ND para diferentes moléculas eletroativas. Voltamogramas cíclicos obtidos com CPE e SPE modificados, com diferentes quantidades de ND, evidenciaram que um excesso dessas nanopartículas nos eletrodos leva a uma perda de sinal voltamétrico. Levando isto em consideração, após a modificação do SPE com ND, tem-se a formação de zonas inertes (partícula de ND) e zonas ativas (superfície exposta dos SPE) por toda a superfície do eletrodo. Esses sítios ativos do SPE atuariam como um arranjo de microeletrodos com uma área de difusão cumulativa maior que a do um SPE não modificado, resultando em maiores densidades de corrente para as mais diferentes espécies eletroativas. 


\section{CONSIDERAÇÕES GERAIS}

De acordo com as conclusões parciais apresentadas em cada capítulo, podem-se fazer as seguintes considerações gerais a respeito dos resultados.

Novos sensores eletroquímicos à base de eletrodos compósitos foram desenvolvidos modificados com nanoestruturas de carbono (grafeno e ND) e AgNPs para a determinação de analitos de interesse biológico e ambiental. A ênfase foi colocada na observação empírica que a presença desses modificadores na superfície dos eletrodos base, pode melhorar o desempenho analítico dos sensores, podendo proporcionar menor LOD e maior sensibilidade para os analitos estudados. Em destaque, uma nova ideia sobre a função catalítica dos ND para os diferentes analitos foi apresentada.

As vantagens como pouco tempo de preparo do eletrodo e fácil renovação de superfície foram destacadas para os eletrodos compósitos modificados no corpo frente aos convencionais, que, apenas permitem a modificação na superfície. Além disso, eletrodos compósitos à base de grafite-poliuretana, utilizam materiais de baixo custo e um aglutinante de fonte renovável, não tóxico, com cura à temperatura ambiente, eliminando a necessidade de equipamentos sofisticados. Em adição, o design desenvolvido para o PEN LAB possibilitou novos formatos de análise, sendo pela primeira vez reportada essa configuração do tipo “caneta" para eletrodos compósitos.

Já para os sensores impressos foi observada a vantagem de produção em batelada desses eletrodos, permitindo diferentes modificações de uma única vez, e como isso viabiliza menor tempo de preparo dos eletrodos. 


\section{REFERÊNCIAS BIBLIOGRÁFICAS}

1. STRADIOTTO, N.R.; YAMANAKA, H. \& ZANONI, M.V.B. Electrochemical sensors: a powerful tool in analytical chemistry. Journal of the Brazilian Chemical Society, São Paulo, v. 14, n.2, p. 159-173, 2003.

2. ZANONI, M.V.B.; BORGES, A.S.; BENEDETTI, A.V.; YAMANAKA, H.; SOTOMAYOR, M.D.P.T.; BESSEGATO, G.G.; STRADIOTTO, N.R.; ZANTA, C.L.D.P. \& ANDRADE, A.R.D. OVERVIEW OF THE ELECTROCHEMISTRY AND

ELECTROANALYTICAL CHEMISTRY IN BRAZIL. Química Nova, São Paulo, v. 40, n.6, p. 663-669, 2017.

3. BANDODKAR, A.J.; HUNG, V.W.; JIA, W.; VALDÉS-RAMÍREZ, G.; WINDMILLER, J.R.; MARTINEZ, A.G.; RAMÍREZ, J.; CHAN, G.; KERMAN, K. \& WANG, J. Tattoobased potentiometric ion-selective sensors for epidermal $\mathrm{pH}$ monitoring. Analyst,

Washington, v. 138, n.1, p. 123-128, 2013.

4. MANNOOR, M.S.; TAO, H.; CLAYTON, J.D.; SENGUPTA, A.; KAPLAN, D.L.; NAIK, R.R.; VERMA, N.; OMENETTO, F.G. \& MCALPINE, M.C. Graphene-based wireless bacteria detection on tooth enamel. Nature communications, London, v. 3, p. 763, 2012.

5. IIJIMA, S. Helical microtubules of graphitic carbon. Nature, London, v. 354, n. 6348, p. $56,1991$.

6. SANTANGELO, S.; MESSINA, G.; FAGGIO, G.; ABDUL RAHIM, S.; MILONE, C. Effect of sulphuric-nitric acid mixture composition on surface chemistry and structural evolution of liquid-phase oxidised carbon nanotubes. Journal of Raman Spectroscopy, Oxford, v. 43, n. 10, p. 1432-1442, 2012.

7. BANKS, C. E.; COMPTON, R. G. New electrodes for old: from carbon nanotubes to edge plane pyrolytic graphite. Analyst, Washington, v. 131, n. 1, p. 15-21, 2006.

8. THOSTENSON, E. T.; REN, Z.; CHOU, T.-W. Advances in the science and technology of carbon nanotubes and their composites: a review. Composites Science and Technology, Oxford, v. 61, n. 13, p. 1899-1912, 2001.

9. BRITTO, P.; SANTHANAM, K.; AJAYAN, P. Carbon nanotube electrode for oxidation of dopamine. Bioelectrochemistry and Bioenergetics, Amsterdam, v. 41, n. 1, p. 121-125, 1996.

10. TAVANA, T.; KHALILZADEH, M. A.; KARIMI-MALEH, H.; ENSAFI, A. A.; BEITOLLAHI, H.; ZAREYEE, D. Sensitive voltammetric determination of epinephrine in the presence of acetaminophen at a novel ionic liquid modified carbon nanotubes paste electrode. Journal of Molecular Liquids, Amsterdam, v. 168, p. 69-74, 2012.

11. VICENTINI, F. C.; RAVANINI, A. E.; SILVA, T. A.; JANEGITZ, B. C.; ZUCOLOTTO, V.; FATIBELLO-FILHO, O. A novel architecture based upon multi-walled carbon nanotubes and ionic liquid to improve the electroanalytical detection of ciprofibrate. Analyst, Washington, v. 139, n. 16, p. 3961-3967, 2014. 
12. NOVOSELOV, K. S.; GEIM, A. K.; MOROZOV, S. V.; JIANG, D.; ZHANG, Y.; DUBONOS, S. V.; GRIGORIEVA, I. V.; FIRSOV, A. A. Electric field effect in atomically thin carbon films. Science, Washington, v. 306, n. 5696, p. 666-669, 2004.

13. PUMERA, M.; AMBROSI, A.; BONANNI, A.; CHNG, E. L. K.; POH, H. L. Graphene for electrochemical sensing and biosensing. Trends in Analytical Chemistry, Amsterdam, v. 29, n. 9, p. 954-965, 2010.

14. FERRARI, A. C.; BONACCORSO, F.; FAL'KO, V.; NOVOSELOV, K. S.; ROCHE, S.; BØGGILD, P.; BORINI, S.; KOPPENS, F. H.; PALERMO, V.; PUGNO, N. Science and technology roadmap for graphene, related two-dimensional crystals, and hybrid systems. Nanoscale, Cambridge, v. 7, n. 11, p. 4598-4810, 2015.

15. SHANG, N. G.; PAPAKONSTANTINOU, P.; MCMULLAN, M.; CHU, M.; STAMBOULIS, A.; POTENZA, A.; DHESI, S. S.; MARCHETTO, H. Catalyst-free efficient growth, orientation and biosensing properties of multilayer graphene nanoflake films with sharp edge planes. Advanced functional materials, Weinheim, v. 18, n. 21, p. 3506-3514, 2008.

16. ALWARAPPAN, S.; ERDEM, A.; LIU, C.; LI, C.-Z. Probing the electrochemical properties of graphene nanosheets for biosensing applications. The Journal of Physical Chemistry C, Washington, v. 113, n.20, p. 8853-8857, 2009.

17. KANG, X.; WANG, J.; WU, H.; LIU, J.; AKSAY, I.A.; LIN, Y. A graphene-based electrochemical sensor for sensitive detection of paracetamol. Talanta, Amsterdam, v. 81, n. 3, p. 754-759, 2010.

18. MANI, V.; DEVADAS, B.; CHEN, S.-M. Direct electrochemistry of glucose oxidase at electrochemically reduced graphene oxide-multiwalled carbon nanotubes hybrid material modified electrode for glucose biosensor. Biosensors and Bioelectronics, Amsterdam, v. 41, p. 309-315, 2013.

19. BACCARIN, M.; SANTOS, F. A.; VICENTINI, F. C.; ZUCOLOTTO, V.; JANEGITZ, B. C.; FATIBELLO-FILHO, O. Electrochemical sensor based on reduced graphene oxide/carbon black/chitosan composite for the simultaneous determination of dopamine and paracetamol concentrations in urine samples. Journal of Electroanalytical Chemistry, Amsterdam, v. 799, p. 436-443, 2017.

20. THIRUMALRAJ, B.; PALANISAMY, S.; CHEN, S.-M.; YANG, C.-Y.;

PERIAKARUPPAN, P.; LOU, B.-S. Direct electrochemistry of glucose oxidase and sensing of glucose at a glassy carbon electrode modified with a reduced graphene oxide/fullerene-C60 composite. RSC Advances, Cambridge, v. 5, n. 95, p. 77651-77657, 2015.

21. ZHOU, N.; LI, J.; CHEN, H.; LIAO, C.; CHEN, L. A functional graphene oxide-ionic liquid composites-gold nanoparticle sensing platform for ultrasensitive electrochemical detection of $\mathrm{Hg}^{2+}$. Analyst, Washington, v. 138, n. 4, p. 1091-1097, 2013.

22. CINTI, S.; ARDUINI, F. Graphene-based screen-printed electrochemical (bio) sensors and their applications: efforts and criticisms. Biosensors and Bioelectronics, Amsterdam, v. 89, p. 107-122, 2017. 
23. WANG, Z.; LI, F.; XIA, J.; XIA, L.; ZHANG, F.; BI, S.; SHI, G.; XIA, Y.; LIU, J.; LI, Y. An ionic liquid-modified graphene based molecular imprinting electrochemical sensor for sensitive detection of bovine hemoglobin. Biosensors and Bioelectronics, Amsterdam, v. 61, p. 391-396, 2014.

24. KRUEGER, A. Diamond nanoparticles: jewels for chemistry and physics. Advanced Materials, Weinheim, v. 20, n.12, p. 2445-2449, 2008.

25. MOCHALIN, V. N.; SHENDEROVA, O.; HO, D.; GOGOTSI, Y. The properties and applications of nanodiamonds. Nature Nanotechnology, London, v. 7, n .1, p. 11-23, 2012.

26. KULAKOVA, I. Surface chemistry of nanodiamonds. Physics of the Solid State, Moscow, v. 46, n. 4, p. 636-643, 2004.

27. WILLIAMS, O. A.; ZIMMERMANN, T.; KUBOVIC, M.; DENISENKO, A.; KOHN, E.; JACKMAN, R.; GRUEN, D. Electronic properties and applications of ultrananocrystalline diamond. In: GRUEN, D. M.; SHENDEROVA, O. A.; VUL', A. Y. Synthesis, properties and applications of ultrananocrystalline diamond. Dordrecht: Springer, 2005. p. 373-382. (NATO Science Series II: Mathematics, Physics and Chemistry, v. 192)

28. HOLT, K. B.; ZIEGLER, C.; CARUANA, D. J.; ZANG, J.; MILLÁN-BARRIOS, E. J.; HU, J.; FOORD, J. S. Redox properties of undoped $5 \mathrm{~nm}$ diamond nanoparticles. Physical Chemistry Chemical Physics, Cambridge, v. 10, n. 2, p. 303-310, 2008.

29. VARLEY, T. S.; HIRANI, M.; HARRISON, G.; HOLT, K. B. Nanodiamond surface redox chemistry: influence of physicochemical properties on catalytic processes. Faraday Discussions, Cambridge, v. 172, p. 349-364, 2014.

30. SIMIONI, N. B.; SILVA, T. A.; OLIVEIRA, G. G.; FATIBELLO-FILHO, O. A nanodiamond-based electrochemical sensor for the determination of pyrazinamide antibiotic. Sensors and Actuators B: Chemical, Amsterdam, v. 250, p. 315-323, 2017.

31. SIMIONI, N. B.; OLIVEIRA, G. G.; VICENTINI, F. C.; LANZA, M. R.; JANEGITZ, B. C.; FATIBELLO-FILHO, O. Nanodiamonds stabilized in dihexadecyl phosphate film for electrochemical study and quantification of codeine in biological and pharmaceutical samples. Diamond and Related Materials, Lausanne, v. 74, p. 191-196, 2017.

32. DAI, W.; LI, M.; GAO, S.; LI, H.; LI, C.; XU, S.; WU, X.; YANG, B. Fabrication of nickel/nanodiamond/boron-doped diamond electrode for non-enzymatic glucose biosensor. Electrochimica Acta, Oxford, v. 187, p. 413-421, 2016.

33. ZHAO, W.; XU, J.-J.; QIU, Q.-Q.; CHEN, H.-Y. Nanocrystalline diamond modified gold electrode for glucose biosensing. Biosensors and Bioelectronics, Amsterdam, v. 22, n. 5, p. 649-655, 2006.

34. HUANG, L.-C.L.; CHANG, H.-C. Adsorption and immobilization of cytochrome c on nanodiamonds. Langmuir, Washington, v. 20, n. 14, p. 5879-5884, 2004. 
35. ZHU, J.-T.; SHI, C.-G.; XU, J.-J.; CHEN, H.-Y. Direct electrochemistry and electrocatalysis of hemoglobin on undoped nanocrystalline diamond modified glassy carbon electrode. Bioelectrochemistry, Amsterdam, v. 71, n. 2, p. 243-248, 2007.

36. CAMARGO, J. R.; BACCARIN, M.; RAYMUNDO-PEREIRA, P. A., CAMPOS, A.M.; OLIVEIRA, G. G.; FATIBELLO-FILHO, O.; OLIVEIRA JUNIOR, O. N.; JANEGITZ, B. C. Electrochemical biosensor made with tyrosinase immobilized in a matrix of nanodiamonds and potato starch for detecting phenolic compounds. Analytica Chimica Acta, Amsterdam, v. 30, p. 1-7, 2018.

37. CAMPBELL, F. W.; COMPTON, R. G. The use of nanoparticles in electroanalysis: an updated review. Analytical and Bioanalytical Chemistry, Heidelberg, v. 396, n. 1, p. 241$259,2010$.

38. JU-NAM, Y.; LEAD, J.R. Manufactured nanoparticles: an overview of their chemistry, interactions and potential environmental implications. Science of the Total Environment, v. 400, n.1-3, p. 396-414, 2008.

39. TURKEVICH, J.; STEVENSON, P.C.; HILLIER, J. A study of the nucleation and growth processes in the synthesis of colloidal gold. Discussions of the Faraday Society, v. 11, p. 55$75,1951$.

40. FIEVET, F.; LAGIER, J.; FIGLARZ, M. Preparing monodisperse metal powders in micrometer and submicrometer sizes by the polyol process. MRS Bulletin, New York, v. 14, n. 12 , p. 29-34, 1989.

41. CANEVARI, T. C.; RAYMUNDO-PEREIRA, P. A.; LANDERS, R.; MACHADO, S. A. Direct synthesis of Ag nanoparticles incorporated on a mesoporous hybrid material as a sensitive sensor for the simultaneous determination of dihydroxybenzenes isomers. European Journal of Inorganic Chemistry, Weinheim, v. 2013, n. 33, p. 5746-5754, 2013.

42. LUO, X.; MORRIN, A.; KILLARD, A. J.; SMYTH, M. R. Application of nanoparticles in electrochemical sensors and biosensors. Electroanalysis, Weinheim,v. 18, n. 4, p. 319-326, 206.

43. MATTIOLI, I. A.; BACCARIN, M.; CERVINI, P.; CAVALHEIRO, E. T. Electrochemical investigation of a graphite-polyurethane composite electrode modified with electrodeposited gold nanoparticles in the voltammetric determination of tryptophan. Journal of Electroanalytical Chemistry, Amsterdam, v. 835, p. 212-219, 2019.

44. RAYMUNDO-PEREIRA, P. A.; CAMPOS, A. M.; PRADO, T. M.; FURINI, L. N.; BOAS, N. V.; CALEGARO, M. L.; MACHADO, S. A. Synergy between Printex nanocarbons and silver nanoparticles for sensitive estimation of antioxidant activity. Analytica Chimica Acta, Amsterdam, v. 926, p. 88-98, 2016.

45. SANTOS, A. M.; WONG, A.; FATIBELLO-FILHO, O. Simultaneous determination of salbutamol and propranolol in biological fluid samples using an electrochemical sensor based on functionalized-graphene, ionic liquid and silver nanoparticles. Journal of Electroanalytical Chemistry, Amsterdam, v. 824, p. 1-8, 2018. 
46. GOULART, L. A.; GONÇALVES, R.; CORREA, A. A.; PEREIRA, E. C.; MASCARO, L. H. Synergic effect of silver nanoparticles and carbon nanotubes on the simultaneous voltammetric determination of hydroquinone, catechol, bisphenol A and phenol.

Microchimica Acta, Wien, v. 185, n. 1, p. 12, 2018.

47. KALAMBATE, P. K.; RAWOOL, C. R.; KARNA, S. P.; SRIVASTAVA, A. K. Highly sensitive and selective determination of methylergometrine maleate using carbon nanofibers/silver nanoparticles composite modified carbon paste electrode. Materials Science and Engineering C: Materials for Biological Applications, Amsterdam, v. 69, p. 453-461, 2016.

48. FEKRY, A. M. A new simple electrochemical moxifloxacin hydrochloride sensor built on carbon paste modified with silver nanoparticles. Biosensors and Bioelectronics, Amsterdam, v. 87, p. 1065-1070, 2017.

49. TALLMAN, D. E.; PETERSEN, S. L. Composite electrodes for electroanalysis: principles and applications. Electroanalysis, Weinheim, v. 2, n. 7, p. 499-510, 1990.

50. WANG, J.; GOLDEN, T.; VARUGHESE, K.; EL-RAYES, I. Polishable and robust modified graphite epoxy electrodes. Analytical Chemistry, Washington, v. 61, n. 5, p. 508$512,1989$.

51. DOMÉNECH, A.; ALARCÓN, J. Determination of hydrogen peroxide using glassy carbon and graphite/polyester composite electrodes modified by vanadium-doped zirconias. Analytica Chimica Acta, Amsterdam, v. 452, n. 1, p. 11-22, 2002.

52. LEE, H.; KIM, J.; PARK, J.; JOE, Y.; LEE, T. Performance of polypyrrole-impregnated composite electrode for unitized regenerative fuel cell. Journal of Power Sources, Amsterdam, v. 131, n. 1-2, p. 188-193, 2004.

53. BUORO, R.M.; BACIL, R.P.; DA SILVA, R.P.; DA SILVA, L.C.; LIMA, A.W.; COSENTINO, I.C. \& SERRANO, S.H. "Lignin-AuNp modified carbon paste electrodesPreparation, characterization, and applications". Electrochimica Acta, Oxford, v. 96, p. 191198, 2013.

54. SALIMI, A.; MAMKHEZRI, H.; HALLAJ, R. Simultaneous determination of ascorbic acid, uric acid and neurotransmitters with a carbon ceramic electrode prepared by sol-gel technique. Talanta, Amsterdam, v. 70, n.4, p. 823-832, 2006.

55. CERVINI, P.; CAVALHEIRO, E. T. Vegetable oil-derived polyurethane composites with graphite as electrode materials for electroanalysis. In: THOMAS, S.; DATTA, J.; HAPONIUK, J. T.; REGHUNADHAN, A., (eds.). Polyurethane polymers: composites and nanocomposites. Amsterdam: Elsevier, 2017. p. 427-455.

56 BAYER, W. The ICI polyurethane book. New York: John Wiley, 1987. p. 432. 
57. OHBUCHI, Y.; MAEDA, Y.; KAWASAKI, M.; SATO, S.; AKIMOTO, M., Thermoplastic polyurethane resin from p-phenylene diisocyanate, a poly (hexamethylene carbonate) polyol, and a short chain polyol. US 5066762. Depósito: 19 Nov. 1991. Disponível em: http://patft.uspto.gov/netacgi/nphParser? $\mathrm{d}=\mathrm{PALL} \& \mathrm{p}=1 \& \mathrm{u}=\% 2 \mathrm{Fnetahtml} \% 2 \mathrm{FPTO} \% 2 \mathrm{Fsrchnum} . \mathrm{htm} \& \mathrm{r}=1 \& \mathrm{f}=\mathrm{G} \& \mathrm{l}=50 \& \mathrm{~s} 1=50$ 66762.PN.\&OS=PN/5066762\&RS=PN/5066762. Acesso em 13 ago. 2019.

58. MENDES, R.; CLARO-NETO, S.; CAVALHEIRO, E. Evaluation of a new rigid carboncastor oil polyurethane composite as an electrode material. Talanta, Amsterdam, v. 57, n. 5, p. 909-917, 2002.

59. MENDES, R. K.; CERVINI, P.; CAVALHEIRO, E. T. G. The use of a graphite-castor oil polyurethane composite electrode for the determination of hydroquinone in photographic developers. Talanta, Amsterdam, v. 68, n. 3, p. 708-712, 2006.

60. CERVINI, P.; CAVALHEIRO, E. T. G. Determination of paracetamol at a graphitepolyurethane composite electrode as an amperometric flow detector. Journal of the Brazilian Chemical Society, São Paulo, v. 19, n. 5, p. 836-841, 2008.

61. CALIXTO, C. M.; CERVINI, P.; CAVALHEIRO, E. T. Determination of tetracycline in environmental water samples at a graphite-polyurethane composite electrode. Journal of the Brazilian Chemical Society, São Paulo, v. 23, n. 5, p. 938-943, 2012.

62. CERVINI, P.; CAVALHEIRO, E. T. G. Evaluation of the analytical potentialities of a composite electrode modified with molecularly imprinted polymers. Analytical Letters, New York, v. 42, n. 13, p. 1940-1957, 2009.

63. DOS SANTOS, S. X.; CAVALHEIRO, E. T. G. Determination of hydroquinone with a carbon nanotube/polyurethane resin composite electrode. Analytical Letters, New York,v. 49, n. 10, p. 1513-1525, 2016.

64. WONG, A.; SANTOS, A. M.; BACCARIN, M.; CAVALHEIRO, E. T. G.; FATIBELLOFILHO, O. Simultaneous determination of environmental contaminants using a graphite oxide-polyurethane composite electrode modified with cyclodextrin. Materials Science and Engineering C: Materials for Biological Applications, Amsterdam, v. 99, p. 1415-1423, 2019.

65. ANGNES, L.; NASCIMENTO, V. Eletrodos fabricados por silk-screen. Química Nova, São Paulo, v. 21, p. 5, 1998.

66. KADARA, R. O.; JENKINSON, N.; BANKS, C. E. Characterisation of commercially available electrochemical sensing platforms. Sensors and Actuators B: Chemical, Amsterdam, v. 138, n. 2, p. 556-562, 2009.

67. SACILOTO, T. R.; CERVINI, P.; CAVALHEIRO, E. T. Simultaneous voltammetric determination of $\mathrm{Zn}$ (II), $\mathrm{Pb}$ (II), $\mathrm{Cu}$ (II), and $\mathrm{Hg}$ (II) in ethanol fuel using an organofunctionalized modified graphite-polyurethane composite disposable screen-printed device. Electroanalysis, Weinheim, v. 26, n. 12, p. 2664-2676, 2014. 
68. BACCARIN, M.; ROWLEY-NEALE, S. J.; CAVALHEIRO, E. T.; SMITH, G. C.; BANKS, C. E. Nanodiamond based surface modified screen-printed electrodes for the simultaneous voltammetric determination of dopamine and uric acid. Microchimica Acta, Wien, v. 186, n.3, p. 200, 2019.

69. LIANA, D. D.; RAGUSE, B.; GOODING, J. J.; CHOW, E. Recent advances in paperbased sensors. Sensors, Basel, v. 12, n. 9, p. 11505-11526, 2012.

70. DE ARAUJO ANDREOTTI, I. A.; ORZARI, L. O.; CAMARGO, J. R.; FARIA, R. C.; MARCOLINO JUNIOR, L.H.; BERGAMINI, M. F.; GATTI, A.; JANEGITZ, B. C.

Disposable and flexible electrochemical sensor made by recyclable material and low cost conductive ink. Journal of Electroanalytical Chemistry, v. 840, p. 109-116, 2019.

71. JAHANI, S.; BEITOLLAHI, H. Selective detection of dopamine in the presence of uric acid using nio nanoparticles decorated on graphene nanosheets modified screen-printed electrodes. Electroanalysis, Weinheim, v. 28, n. 9, p. 2022-2028, 2016.

72. LI, D.-W.; LI, Y.-T.; SONG, W.; LONG, Y.-T. Simultaneous determination of dihydroxybenzene isomers using disposable screen-printed electrode modified by multiwalled carbon nanotubes and gold nanoparticles. Analytical Methods, Cambridge, v. 2, n. 7, p. 837$843,2010$.

73. TOMEI, M.R.; ARDUINI, F.; NEAGU, D.; MOSCONE, D. Carbon black-based disposable sensor for an on-site detection of free chlorine in swimming pool water. Talanta, Amsterdam, v. 189, p. 262-267, 2018.

74. WORLD HEALTH ORGANIZATION. Geneva: WHO, 2017. Disponível em: https://apps.who.int/iris/bitstream/handle/10665/254610/who-msd-mer-2017.2-eng.pdf. Acesso em: 13 ago. 2019.

75. PRESKORN, S.H.; STANGA, C.Y.; FEIGHNER, J.P.; ROSS, R. ( eds.). Antidepressants: past, present and future. Berlin: Springer, 2012. E-book.

76. SKANDALI, N.; ROWE, J. B.; VOON, V.; DEAKIN, J. B.; CARDINAL, R. N.; CORMACK, F.; PASSAMONTI, L.; BEVAN-JONES, W. R.; REGENTHAL, R.; CHAMBERLAIN, S. R. Dissociable effects of acute SSRI (escitalopram) on executive, learning and emotional functions in healthy humans. Neuropsychopharmacology, London, v. 43, n.13, p. $2645,2018$.

77. NEVADO, J. J. B.; CABANILLAS, C. G.; LLERENA, M. J. V.; ROBLEDO, V. R. Enantiomeric determination, validation and robustness studies of racemic citalopram in pharmaceutical formulations by capillary electrophoresis. Journal of Chromatography A, London, v. 1072, n. 2, p. 249-257, 2005.

78. SÁNCHEZ, C. R-citalopram attenuates anxiolytic effects of escitalopram in a rat ultrasonic vocalisation model. European Journal of Pharmacology, Amsterdam, v. 464, n. 2-3, p. 155-158, 2003. 
79. DWORKIN, R. H.; BACKONJA, M.; ROWBOTHAM, M. C.; ALLEN, R. R.; ARGOFF, C. R.; BENNETT, G. J.; BUSHNELL, M. C.; FARRAR, J. T.; GALER, B. S.;

HAYTHORNTHWAITE, J. A. Advances in neuropathic pain: diagnosis, mechanisms, and treatment recommendations. Archives of Neurology, Chicago, v. 60, n. 11, p. 1524-1534, 2003.

80. JUNG, A. C.; STAIGER, T.; SULLIVAN, M. The efficacy of selective serotonin reuptake inhibitors for the management of chronic pain. Journal of General Internal Medicine, New York, v. 12, n. 6, p. 384-389, 1997.

81. FRISON, G.; FAVRETTO, D.; VOGLIARDI, S.; TERRANOVA, C.; FERRARA, S. D. Quantification of citalopram or escitalopram and their demethylated metabolites in neonatal hair samples by liquid chromatography-tandem mass spectrometry. Therapeutic Drug Monitoring, Philadelphia, v. 30, n. 4, p. 467-473, 2008.

82. DHAVALE, N.; GANDHI, S.; SABNIS, S.; BOTHARA, K. Simultaneous HPTLC determination of escitalopram oxalate and clonazepam in combined tablets.

Chromatographia, Heidelberg, v. 67, n. 5-6, p. 487-490, 2008.

83. GANDHI, S. V.; DHAVALE, N. D.; JADHAV, V. Y.; SABNIS, S. S.

Spectrophotometric and reversed-phase high-performance liquid chromatographic methods for simultaneous determination of escitalopram oxalate and clonazepam in combined tablet dosage form. Journal of AOAC International, Rockville, v. 91, n. 1, p. 33-38, 2008.

84. KAKDE, R. B.; SATONE, D. D.; GADAPAYALE, K. K.; KAKDE, M. G. Stabilityindicating RP-HPLC method for the simultaneous determination of escitalopram oxalate and clonazepam. Journal of Chromatographic Science, Oxford, v. 51, n. 6, p. 490-495, 2012.

85. AL-TAMIMI, S. A.; ALY, F. A.; AL-OTAIBI, O. M. Kinetic spectrophotometric determination of escitalopram oxalate in bulk and pharmaceutical formations using alkaline potassium permanganate. Journal of the Indian Chemical Society, Jodhpur, v. 90, n. 3, p. 309-317, 2013.

86. AL-TAMIMI, S. A.; ALY, F. A.; AL-OTAIBI, O. M. Spectrophotometric determination of escitalopram oxalate in bulk and pharmaceutical formulations using 7, 7, 8, 8Tetracyanoquinodimethane. Asian Journal of Chemistry, Ghaziabad, v. 24, n. 12, p. 5515$5518,2012$.

87. KAKDE, R.; SATONE, D. Spectrophotometric method for simultaneous estimation of escitalopram oxalate and clonazepam in tablet dosage form. Indian Journal of Pharmaceutical Sciences, Munbai, v. 71, n. 6, p. 702, 2009.

88. DENG, X.; DE WOLF, J.; VERVOORT, R.; PAMPERIN, D.; ADAMS, E.; SCHEPDAEL, A. V. Development and validation of a capillary electrophoresis method for the determination of escitalopram and sensitive quantification of its enantiomeric impurity in formulations. Electrophoresis, Weinheim, v. 33, n. 11, p. 1648-1651, 2012.

89. ALARFAJ, N. A.; ALY, F .A.; AL-QAHTANY, A. A. Flow-injection chemiluminescence and electrogenerated chemiluminescence determination of escitalopram oxalate in tablet form. Luminescence, Oxford, v. 28, n. 1, p. 84-92, 2013. 
90. AL-AMRI, F. M.; ALARFAJ, N. A.; ALY, F. A. Development of new sensors for determination of escitalopram oxalate in dosage forms and biological fluids. International Journal of Electrochemical Science, Belgrade, v. 8, p. 10044-10058, 2013.

91. JAIN, R.; SHARMA, S. Bismuth (III) oxide/glassy carbon sensor for sensing of antidepressant drug escitalopram in micellar media. Colloids and Surfaces A:

Physicochemical and Engineering Aspects, Amsterdam, v. 436, p. 178-184, 2013.

92. ATTIA, A. K.; MOHAMED, M. A.; FEKRY, A. M. Electroanalytical determination of escitalopram oxalate using nickel nanoparticles modified carbon paste sensor. Acta Chimica Slovenica, Ljubljana, v. 64, n. 2, p. 415-421, 2017.

93. GHOLIVAND, M.-B.; AKBARI, A. A novel voltammetric sensor for citalopram based on multiwall carbon nanotube/(poly (p-aminobenzene sulfonic acid)/ $\beta$-cyclodextrin). Materials Science and Engineering C: Materials for Biological Applications, v. 62, p. 480-488, 2016.

94. GHAEDI, H.; AFKHAMI, A.; MADRAKIAN, T.; SOLTANI-FELEHGARI, F. Construction of novel sensitive electrochemical sensor for electro-oxidation and determination of citalopram based on zinc oxide nanoparticles and multi-walled carbon nanotubes. Materials Science and Engineering C: Materials for Biological Applications, v. 59, p. 847-854, 2016.

95. NICHKOVA, M.; WYNVEEN, P.M.; MARC, D. T.; HUISMAN, H.; KELLERMANN, G. H. Validation of an ELISA for urinary dopamine: applications in monitoring treatment of dopamine-related disorders. Journal of Neurochemistry, Hoboken, v. 125, n. 5, p. 724-735, 2013.

96. SILVA, L. I.; FERREIRA, F. D.; FREITAS, A. C.; ROCHA-SANTOS, T. A.; DUARTE, A. Optical fiber biosensor coupled to chromatographic separation for screening of dopamine, norepinephrine and epinephrine in human urine and plasma. Talanta, Amsterdam, v. 80, n. 2, p. 853-857, 2009.

97. SAJID, M.; NAZAL, M. K.; MANSHA, M.; ALSHARAA, A.; JILLANI, S. M. S.;

BASHEER, C. Chemically modified electrodes for electrochemical detection of dopamine in the presence of uric acid and ascorbic acid: a review. TrAC Trends in Analytical Chemistry, Oxford, v. 76, p. 15-29, 2016.

98. DAI LAM, T.; TRAM, P. T. N.; BINH, N. H.; VIET, P. H. Electrochemically selective determination of dopamine in the presence of ascorbic and uric acids on the surface of the modified Nafion/SWCNTs/poly (3-methylthiophene) glassy carbon electrodes. Colloids and Surfaces B: Biointerfaces, Amsterdam, v. 88, n. 2, p. 764-770, 2011.

99. HAN, D.; HAN, T.; SHAN, C.; IVASKA, A.; NIU, L. Simultaneous determination of ascorbic acid, dopamine and uric acid with chitosan-graphene modified electrode. Electroanalysis, Weinheim, v. 22, n. 17-18, p. 2001-2008, 2010.

100. HUANG, J.; LIU, Y.; HOU, H.; YOU, T. Simultaneous electrochemical determination of dopamine, uric acid and ascorbic acid using palladium nanoparticle-loaded carbon nanofibers modified electrode. Biosensors and Bioelectronics, Amsterdam, v. 24, n. 4, p. 632-637, 2008. 
101. JIA, D.; DAI, J.; YUAN, H.; LEI, L.; XIAO, D. Selective detection of dopamine in the presence of uric acid using a gold nanoparticles-poly (luminol) hybrid film and multi-walled carbon nanotubes with incorporated $\beta$-cyclodextrin modified glassy carbon electrode.

Talanta, Amsterdam, v. 85, n. 5, p. 2344-2351, 2011.

102. STAPLES, C. A.; DOME, P. B.; KLECKA, G. M.; OBLOCK, S. T.; HARRIS, L. R. A review of the environmental fate, effects, and exposures of bisphenol A. Chemosphere, Oxford, v. 36, n. 10, p. 2149-2173, 1998.

103. LANG, I. A.; GALLOWAY, T. S.; SCARLETT, A.; HENLEY, W. E.; DEPLEDGE, M.; WALLACE, R. B.; MELZER, D. Association of urinary bisphenol A concentration with medical disorders and laboratory abnormalities in adults. Jama, Chicago, v. 300, n. 11, p. 1303-1310, 2008.

104. ELSBY, R.; MAGGS, J. L.; ASHBY, J.; PARK, B. K. Comparison of the modulatory effects of human and rat liver microsomal metabolism on the estrogenicity of bisphenol A: implications for extrapolation to humans. Journal of Pharmacology and Experimental Therapeutics, Bethesda, v. 297, n. 1, p. 103-113, 2001.

105. MORIYAMA, K.; TAGAMI, T.; AKAMIZU, T.; USUI, T.; SAIJO, M.; KANAMOTO, N.; HATAYA, Y.; SHIMATSU, A.; KUZUYA, H.; NAKAO, K. Thyroid hormone action is disrupted by bisphenol A as an antagonist. The Journal of Clinical Endocrinology \& Metabolism, Chevy Chase, v. 87, n. 11, p. 5185-5190, 2002.

106. FLINT, S.; MARKLE, T.; THOMPSON, S.; WALLACE, E. Bisphenol A exposure, effects, and policy: a wildlife perspective. Journal of Environmental Management, Oxford, v. 104, p. 19-34, 2012.

107. ROPERO, A.; ALONSO-MAGDALENA, P.; GARCIA-GARCIA, E.; RIPOLL, C.; FUENTES, E.; NADAL, A. Bisphenol-A disruption of the endocrine pancreas and blood glucose homeostasis. International Journal of Andrology, Oxford, v. 31, n. 2, p. 194-200, 2008.

108. NEWBOLD, R. R.; PADILLA-BANKS, E.; JEFFERSON, W. N.; HEINDEL, J. J. Effects of endocrine disruptors on obesity. International journal of andrology, Oxford, $v$. 31, n.2, p. 201-208, 2008.

109. FROMME, H.; KÜCHLER, T.; OTTO, T.; PILZ, K.; MÜLLER, J.; WENZEL, A. Occurrence of phthalates and bisphenol $\mathrm{A}$ and $\mathrm{F}$ in the environment. Water Research, Oxford, v. 36, n. 6, p. 1429-1438, 2002.

110. NIU, X.; YANG, W.; WANG, G.; REN, J.; GUO, H.; GAO, J. A novel electrochemical sensor of bisphenol A based on stacked graphene nanofibers/gold nanoparticles composite modified glassy carbon electrode. Electrochimica Acta, Oxford, v. 98, p. 167-175, 2013.

111. ZHENG, Z.; DU, Y.; WANG, Z.; FENG, Q.; WANG, C. Pt/graphene-CNTs nanocomposite based electrochemical sensors for the determination of endocrine disruptor bisphenol A in thermal printing papers. Analyst, Washington, v. 138, n. 2, p. 693-701, 2013. 
112. YIN, H.; CUI, L.; CHEN, Q.; SHI, W.; AI, S.; ZHU, L.; LU, L. Amperometric determination of bisphenol A in milk using PAMAM-Fe3O4 modified glassy carbon electrode. Food Chemistry, Oxford, v. 125, n. 3, p. 1097-1103, 2011.

113. TAN, F.; CONG, L.; LI, X.; ZHAO, Q.; ZHAO, H.; QUAN, X.; CHEN, J. An electrochemical sensor based on molecularly imprinted polypyrrole/graphene quantum dots composite for detection of bisphenol A in water samples. Sensors and Actuators B: Chemical, Lausanne, v. 233, p. 599-606, 2016.

114. HE, J.-B.; CHEN, C.-L.; LIU, J.-H. Study of multi-wall carbon nanotubes self-assembled electrode and its application to the determination of carbon monoxide. Sensors and Actuators B: Chemical, Lausanne, v. 99, n. 1, p. 1-5, 2004.

115. LAUBE, N.; MOHR, B.; HESSE, A. Laser-probe-based investigation of the evolution of particle size distributions of calcium oxalate particles formed in artificial urines. Journal of Crystal Growth, Amsterdam, v. 233, n. 1-2, p. 367-374, 2001.

116. OPALKO, F. J.; ADAIR, J.; KHAN, S. Heterogeneous nucleation of calcium oxalate trihydrate in artificial urine by constant composition. Journal of Crystal Growth, Amsterdam, v. 181, n. 4, p. 410-417, 1997.

117. OSER, B. L.; HAWK, P. B. Hawk's physiological chemistry. 14. ed. New York: McGraw-Hill, 1965. 1472 p.

118. BARD, A. J.; FAULKNER, L. R.; LEDDY, J.; ZOSKI, C. G. Electrochemical methods: fundamentals and applications. New York: Wiley, 1980.

119. MILLER, J. N. Basic statistical methods for analytical chemistry. Part 2. Calibration and regression methods. A review. Analyst, Washington, v. 116, n. 1, p. 3-14, 1991.

120. DATSYUK, V.; KALYVA, M.; PAPAGELIS, K.; PARTHENIOS, J.; TASIS, D.; SIOKOU, A.; KALLITSIS, I.; GALIOTIS, C. Chemical oxidation of multiwalled carbon nanotubes. Carbon, Oxford, v. 46, n. 6, p. 833-840, 2008.

121. BANKS, C. E.; DAVIES, T. J.; WILDGOOSE, G. G.; COMPTON, R. G. Electrocatalysis at graphite and carbon nanotube modified electrodes: edge-plane sites and tube ends are the reactive sites. Chemical Communications, Cambridge, n. 7, p. 829-841, 2005 .

122. GOSSER, D. K. Cyclic voltammetry: simulation and analysis of reaction mechanisms. New York: VCH, 1993. 156 p.

123. NOUWS, H. P.; DELERUE-MATOS, C.; BARROS, A. A.; MAESEN, E.; MOREIRA, S. C.; NEVES, M. M. Static and hydrodynamic monitoring of citalopram based on its electrooxidation behavior at a glassy-carbon surface. Analytical Letters, New York, v. 41, n. 12, p. 2171-2185, 2008.

124. SVENSSON, H. T. Uses of escitalopram. US2007259952. Depósito: 8 Nov. 2007. Disponível em: https://pubchem.ncbi.nlm.nih.gov/compound/escitalopram\#section=stabilityshelf-life. Acesso em 13 ago. 2019. 
125. SKRABALAK, S. E.; WILEY, B. J.; KIM, M.; FORMO, E. V.; XIA, Y. On the polyol synthesis of silver nanostructures: glycolaldehyde as a reducing agent. Nano Letters, Washington, v. 8, n. 7, p. 2077-2081, 2008.

126. WENDLANDT, W. W. Thermal analysis. 3. ed. New York: John Willey, 1986. 814 p. (Chemical analysis: a series of monographs on analytical chemistry and its applications)

127. CALIXTO, C. M. F.; MENDES, R. K.; OLIVEIRA, A. C. D.; RAMOS, L. A.; CERVINI, P.; CAVALHEIRO, E. T. G. Development of graphite-polymer composites as electrode materials. Materials Research, São Carlos, v. 10, n. 2, p. 109-114, 2007.

128. LI, J.; KUANG, D.; FENG, Y.; ZHANG, F.; XU, Z.; LIU, M.; WANG, D. Green synthesis of silver nanoparticles-graphene oxide nanocomposite and its application in electrochemical sensing oftryptophan. Biosensors and Bioelectronics, Amsterdam, v. 42, p. 198-206, 2013.

129. WONG, A.; SILVA, T. A.; FATIBELLO-FILHO, O. Graphite oxide and gold nanoparticles as alternative materials in the design of a highly sensitive electrochemical sensor for the simultaneous determination of biological species. Electroanalysis, Weinheim, v. 29, n.11, p. 2491-2497, 2017.

130. CINCOTTO, F. H.; CANEVARI, T. C.; CAMPOS, A. M.; LANDERS, R.; MACHADO, S. A. Simultaneous determination of epinephrine and dopamine by electrochemical reduction on the hybrid material $\mathrm{SiO}$ 2/graphene oxide decorated with $\mathrm{Ag}$ nanoparticles. Analyst, Washington, v. 139, n. 18, p. 4634-4640, 2014.

131. SKOOG, D.A.; WEST, D.M.; HOLLER, F.J. Fundamentos de química analítica. 4. ed. Barcelona: Reverté 1997.

132. GHANAM, A.; LAHCEN, A. A.; AMINE, A. Electroanalytical determination of Bisphenol A: Investigation of electrode surface fouling using various carbon materials. Journal of Electroanalytical Chemistry, Amsterdam, v. 789, p. 58-66, 2017.

133. BRUGNERA, M. F.; TRINDADE, M. A. G.; ZANONI, M. V. B. Detection of bisphenol A on a screen-printed carbon electrode in CTAB micellar medium. Analytical Letters, New York, v. 43, n. 18, p. 2823-2836, 2010.

134. LI, H.; WANG, W.; LV, Q.; XI, G.; BAI, H.; ZHANG, Q. Disposable paper-based electrochemical sensor based on stacked gold nanoparticles supported carbon nanotubes for the determination of bisphenol A. Electrochemistry Communications, Philadelphia v. 68, p. 104-107, 2016.

135. NDLOVU, T.; AROTIBA, O. A.; SAMPATH, S.; KRAUSE, R. W.; MAMBA, B. B. An exfoliated graphite-based bisphenol A electrochemical sensor. Sensors, Basel, v. 12, n. 9, p. 11601-11611, 2012.

136. CUMBA, L. R.; SMITH, J. P.; BROWNSON, D. A.; INIESTA, J.; METTERS, J. P.; DO CARMO, D. R.; BANKS, C. E. Electroanalytical detection of pindolol: comparison of unmodified and reduced graphene oxide modified screen-printed graphite electrodes. Analyst, Washington, v. 140, n. 5, p. 1543-1550, 2015. 
137. METTERS, J. P.; KADARA, R. O.; BANKS, C. E. New directions in screen printed electroanalytical sensors: an overview of recent developments. Analyst, Washington, v. 136, n. 6, p. 1067-1076, 2011.

138. LIN, L.; CHEN, J.; YAO, H.; CHEN, Y.; ZHENG, Y.; LIN, X. Simultaneous determination of dopamine, ascorbic acid and uric acid at poly (Evans Blue) modified glassy carbon electrode. Bioelectrochemistry, Amsterdam, v. 73, n. 1, p. 11-17, 2008.

139. WANG, C.; DU, J.; WANG, H.; ZOU, C. E.; JIANG, F.; YANG, P.; DU, Y. A facile electrochemical sensor based on reduced graphene oxide and Au nanoplates modified glassy carbon electrode for simultaneous detection of ascorbic acid, dopamine and uric acid. Sensors and Actuators B: Chemical, Amsterdam, v. 204, p. 302-309, 2014.

140. RAFATI, A. A.; AFRAZ, A.; HAJIAN, A.; ASSARI, P. Simultaneous determination of ascorbic acid, dopamine, and uric acid using a carbon paste electrode modified with multiwalled carbon nanotubes, ionic liquid, and palladium nanoparticles. Microchimica Acta, Wien, v. 181, n. 15-16, p. 1999-2008, 2014.

141. QI, S.; ZHAO, B.; TANG, H.; JIANG, X. Determination of ascorbic acid, dopamine, and uric acid by a novel electrochemical sensor based on pristine graphene. Electrochimica Acta, Oxford, v. 161, p. 395-402, 2015.

142. SAFAVI, A.; MALEKI, N.; MORADLOU, O.; TAJABADI, F. Simultaneous determination of dopamine, ascorbic acid, and uric acid using carbon ionic liquid electrode. Analytical Biochemistry, Philadelphia, v. 359, n. 2, p. 224-229, 2006.

143. GOPALAN, A. I.; KOMATHI, S.; ANAND, G. S.; LEE, K.-P. Nanodiamond based sponges with entrapped enzyme: a novel electrochemical probe for hydrogen peroxide.

Biosensors and Bioelectronics, Amsterdam, v. 46, p. 136-141, 2013.

144. XIAO-LING, M.; CHENG-JUN, D.; ZHANG, P.; WEI, G.; HONG-XIA, L.

Electrochemical characterizations of quaternarized nanodiamond-myoglobin modified electrode. Chinese Journal of Analytical Chemistry, Changchun, New York, v. 42, n. 9, p. 1332-1337, 2014.

145. BRIONES, M.; CASERO, E.; PETIT-DOMÍNGUEZ, M.; RUIZ, M.; PARRAALFAMBRA, A.; PARIENTE, F.; LORENZO, E.; VAZQUEZ, L. Diamond nanoparticles based biosensors for efficient glucose and lactate determination. Biosensors and Bioelectronics, Amsterdam, v. 68, p. 521-528, 2015.

146. COMPTON, R.G.; BANKS, C.E. Understanding voltammetry. Singapore: World Scientific, 2011. 


\section{APÊNDICE I}

\section{Artigos Publicados}

BACCARIN, M.; CERVINI, P.; CAVALHEIRO, E. T. G. Comparative performances of a bare graphite-polyurethane composite electrode unmodified and modified with graphene and carbon nanotubes in the electrochemical determination of escitalopram. Talanta, v. 178, p. 1024-1032, 2018.

MATTIOLI, I.A.; BACCARIN, M.; CERVINI, P.; CAVALHEIRO, E. T. G. Electrochemical investigation of a graphite-polyurethane composite electrode modified with electrodeposited gold nanoparticles in the voltammetric determination of tryptophan. Journal of Electroanalytical Chemistry, v. 835, p. 212-219, 2019.

WONG. A.; SANTOS, A. M.; BACCARIN, M.; CAVALHEIRO, E. T. G.; FATIBELlOFILHO, O. Simultaneous determination of environmental contaminants using a graphite oxide-polyurethane composite electrode modified with cyclodextrin. Materials Science \& Engineering. C, v.99, p. 1415-1423, 2019.

BACCARIN, M.; ROWLEY-NEALE, S. J.; CAVALHEIRO, E. T. G.; SMITH, G. C.; BANKS, C. E. Nanodiamonds based surface modified screen-printed electrodes for the simultaneous voltammetric determination of dopamine and uric acid. Microchimica Acta, v. 186, p. 200-209, 2019.

\section{Trabalhos apresentados em congressos, simpósios e eventos}

Desenvolvimento de eletrodo compósito à base de grafite-poliuretana modificado com nanopartículas de ouro na determinação voltamétrica de triptofano, 25 SIICUSP - Simpósio Internacional de Iniciação Científica e Tecnológica da Universidade de São Paulo, São Carlos, SP, 2017.

Estudo comparativo do desempenho dos eletrodos GPU, GPU-GR e GPU-CNTs na determinação de escitalopram em amostras biológicas sintéticas, XXI SIBEE- Simpósio Brasileiro de Eletroquímica e Eletroanalítica, Natal, RN, 2017.

Utilização da ferramenta computacional Origin ${ }^{\circledR}$ na disciplina de Análise Instrumental III, Workshop P.A.E, São Carlos, SP, 2017.

Avaliação da potencialidade do eletrodo compósito de óxido de grafite-poliuretana modificado com $\beta$-ciclodextrina na discriminação simultânea de sinais voltamétricos, XXIII Sibae - Congreso de la Sociedad Iberoamericana de Electroquímica, Cusco, Peru, 2017. 
Determinação da N-Nitrosodifenilamina em amostras de urina sintética com eletrodo compósito à base de grafite-poliuretana, XXII SIBEE - Simpósio Brasileiro de Eletroquímica e Eletroanalítica, Ribeirão Preto, SP, 2019.

Design and fabrication of a Pen Lab based on graphite-polyurethane composite and silver nanoparticles for detecting bisphenol-A in water samples, XXII SIBEE - Simpósio Brasileiro de Eletroquímica e Eletroanalítica, Ribeirão Preto, SP, 2019.

Desenvolvimento e aplicação de um eletrodo compósito de grafite-poliuretana modificado com nanopartículas de ouro para a determinação voltamétrica de triptofano, XXII SIBEE Simpósio Brasileiro de Eletroquímica e Eletroanalítica, Ribeirão Preto, SP, 2019.

\section{Estágio no exterior}

A doutoranda realizou um estágio de três meses (agosto de 2017 a outubro de 2017) no Grupo de pesquisas do Professor Craig Banks na Universidade Metropolitana de Manchester - Inglaterra, com auxílio do Programa Santander Universidades.

\section{Atividades de docência}

Estágio do Programa de Aperfeiçoamento de Ensino (PAE) junto a disciplina Análise Instrumental III (SQM 0421) para os alunos de química com carga horária de 6h semanais na Universidade de São Paulo, São Carlos, SP, Brasil, de 02/2017 - 06/2017.

\section{Participação em bancas e comissões julgadoras}

Participou como avaliadora do $24^{\circ}$ SIICUSP - Simpósio Internacional de Iniciação Científica e Tecnológica da Universidade de São Paulo, na Universidade de São Paulo. São Carlos, SP, 2016.

Participou na banca de Trabalho de Conclusão de Curso (TCC) de Maíra da Costa Ferreira com a monografia intitulada: "Amido: propriedades e usos industriais", na Universidade Federal de São Carlos. São Carlos, SP, 2017.

Participou como avaliadora do $26^{\circ}$ SIICUSP - Simpósio Internacional de Iniciação Científica e Tecnológica da Universidade de São Paulo, na Universidade de São Paulo. São Carlos, SP, 2018.

Participou na banca de Trabalho de Conclusão de Curso (TCC) de Maíra da Costa Ferreira com a monografia intitulada: "Desenvolvimento de dispositivo microfluídico baseado em papel para a determinação de analitos de interesse ambiental em amostras de água utilizando suporte impresso em 3D”, na Universidade Federal de São Carlos. Araras, SP, 2018. 


\section{APÊNDICE II}

Os resultados apresentados nesta tese que já foram publicados em artigo científico foram feitas com autorização das editora como segue a licença abaixo.

$26 / 06 / 2019$

Rightslink® by Copyright Clearance Center

Copyright

Clearance

Center

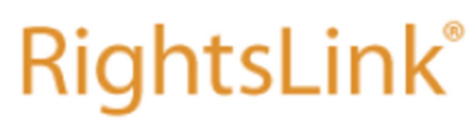

Title: $\quad$ Nanodiamond based surface

modified screen-printed

SPRINGER NATURE

electrodes for the simultaneous voltammetric determination of dopamine and uric acid

Author: Marina Baccarin, Samuel J.

Rowley-Neale, Éder T. G.

Cavalheiro et al

Publication: Microchimica Acta

Publisher: Springer Nature

Date: Jan 1, 2019

Copyright (c) 2019, The Author(s)

\section{Creative Commons}

This is an open access article distributed under the terms of the Creative Commons CC BY license, which permits unrestricted use, distribution, and reproduction in any medium, provided the original work is properly cited.

You are not required to obtain permission to reuse this article.

To request permission for a type of use not listed, please contact Springer Nature 